
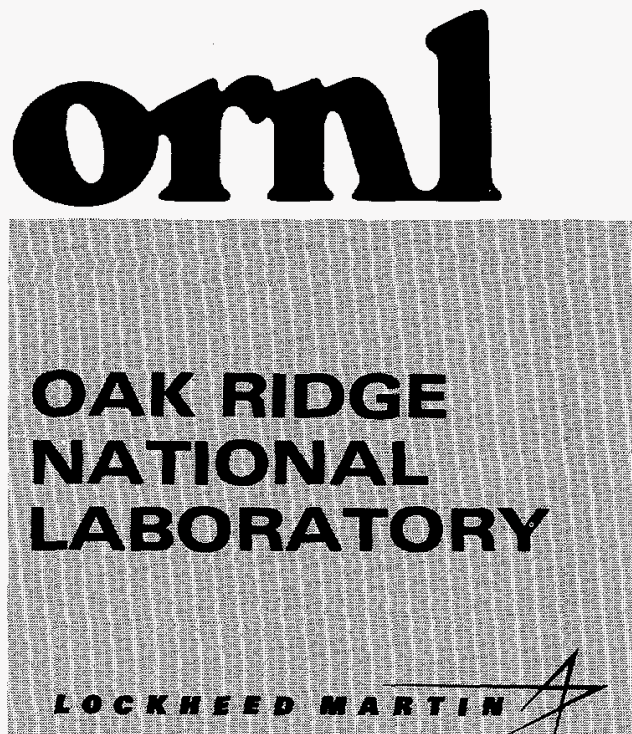

\title{
Comparative Testing of Slurry Monitors
}

\author{
T. D. Hylton \\ M. S. Anderson \\ D. C. Van Essen \\ C. K. Bayne
}

\section{RECEIVEC MAY 261999 Q.8.TI}

\section{MASTER}

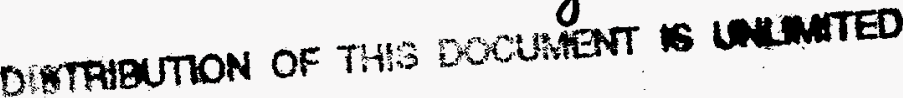


This report has ben reproduced directly from the best available copy.

Available to DOE and DOE contriactors from the Office of Scientific and Technical Informetion, P.O. Box 62, Oak. Ridge, TN 37831; prices available trom (615) 576-8401. FTS 626-8401.

Available to the public from the National Tectnical Information Service, U.S. Department of Commerce, 5285 P'ort Royal Rd., Springfield, VA 22161.

This report was prepared as an account of work sponsored by an agency of the United States Government. Neither the United States Government nor any agency thereof, nor any of their employees, makes any warranty, express or implied, or assumes any legal liability or responsibility for the sccuracy, completeness, or usefulness of any information, apparatus, product, or process disclosed, or represents that its use would not infringe privately owned rights. Reference herein to any specifi; commercial product, process, or service by trade name, trademark, manufaclurer, or otherwise, does not necessarily constitute or imply its endorsement, revommendation, or favoring by the United States Government or any agency thereof. The views and opinions of authors expressed herein do not necessurily state or reflect those of the United States Government or any agency therext. 


\section{DISCLAIMER}

Portions of this document may be illegible in electronic image products. Images are produced from the best available original document. 


\title{
COMPARATIVE TESTING OF SLURRY MONITORS
}

\author{
T. D. Hylton \\ M. S. Anderson* \\ D. C. Van Essen ${ }^{\dagger}$ \\ C. K. Bayne
}

"Ames Laboratory, Ames, Iowa.
${ }^{\dagger}$ Advanced Integrated Management Services, Inc., Oak Ridge, Tennessee.
${ }^{\ddagger}$ ORNL, Computer Science and Mathematics Division, Oak Ridge, Tennessee.

Date Published: May 1998

\author{
Prepared by \\ OAK RIDGE NATIONAL LABORATORY \\ Oak Ridge, Tennessee 37831-6285 \\ managed by \\ LOCKHEED MARTIN ENERGY RESEARCH CORP. \\ for the \\ U.S. DEPARTMENT OF ENERGY \\ under contract DE-AC05-96OR22464
}





\section{TABLE OF CONTENTS}

LIST OF FIGURES $\ldots \ldots \ldots \ldots \ldots \ldots \ldots \ldots \ldots \ldots \ldots \ldots \ldots \ldots \ldots \ldots \ldots \ldots \ldots$ vii

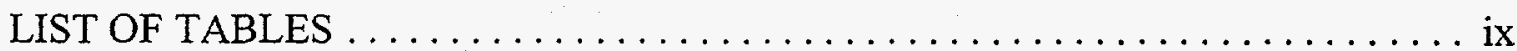

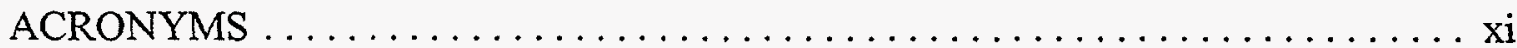

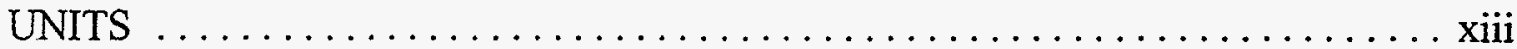

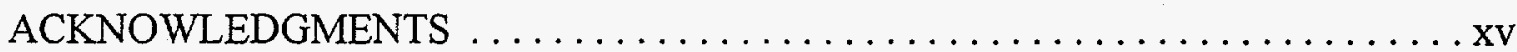

EXECUTIVE SUMMARY $\ldots \ldots \ldots \ldots \ldots \ldots \ldots \ldots \ldots \ldots \ldots \ldots \ldots \ldots \ldots \ldots \ldots \ldots$

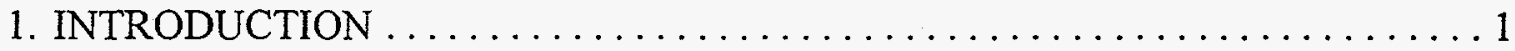

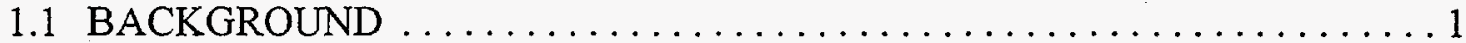

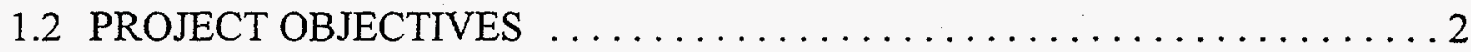

1.3 SURROGATE SLURRY DEVELOPMENT $\ldots \ldots \ldots \ldots \ldots \ldots \ldots \ldots$

2. TEST FACILITY AND INSTRUMENTATION DESCRIPTION $\ldots \ldots \ldots \ldots \ldots 5$

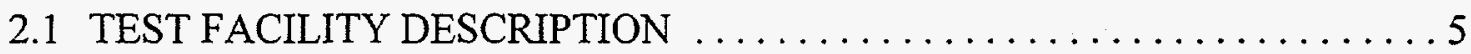

2.2 INSTRUMENTATION DESCRIPTION $\ldots \ldots \ldots \ldots \ldots \ldots \ldots \ldots \ldots$

2.2 .1 PNNL Densitometer . . . . . . . . . . . . . . . . . . . 11

2.2.2 Sandia In-Tank and Pipeline Quartz Resonating Instruments . . . . . 16

2.2.3 Argonne Ultrasonic Flow Instrument $\ldots \ldots \ldots \ldots \ldots \ldots \ldots \ldots \ldots \ldots$

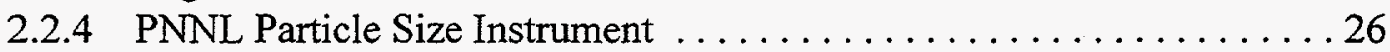

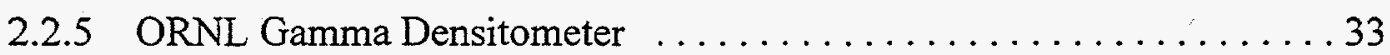

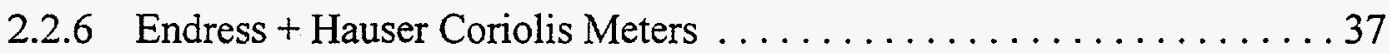

2.2 .7 BTG SMS-3000 ............................... 41

2.2 .8 Inverted U-Loop . . . . . . . . . . . . . . . . . . . . 43

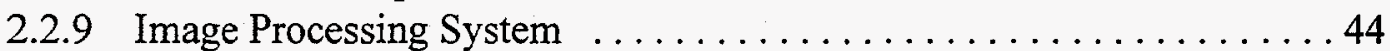

2.3 REFERENCE SAMPLING DEVICES $\ldots \ldots \ldots \ldots \ldots \ldots \ldots \ldots \ldots \ldots$

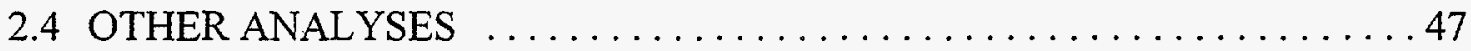

3. INSTRUMENTATION TESTING $\ldots \ldots \ldots \ldots \ldots \ldots \ldots \ldots \ldots \ldots \ldots \ldots$

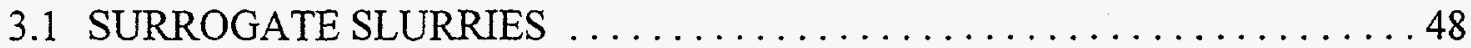

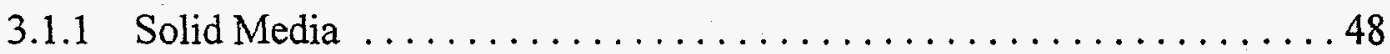

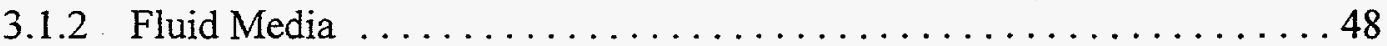

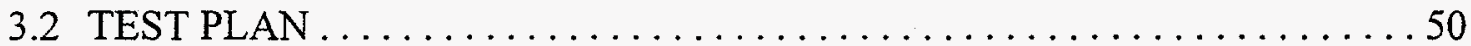

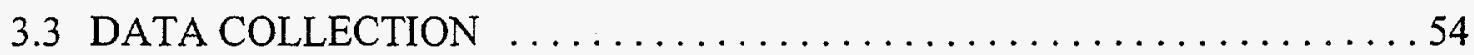

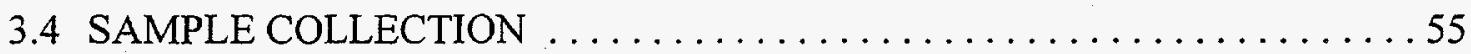

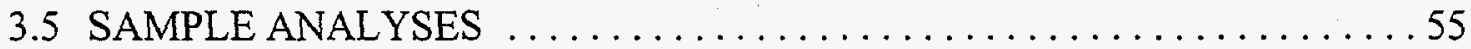

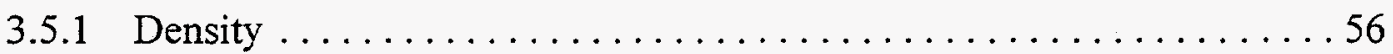

3.5.2 Suspended Solids Concentration $\ldots \ldots \ldots \ldots \ldots \ldots \ldots \ldots \ldots \ldots$

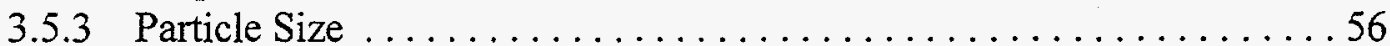

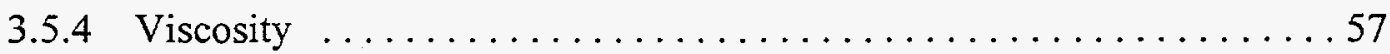




\section{TABLE OF CONTENTS (cont.)}

3.6 NSTRUMENT PERFORMANCE NOTES ...........................

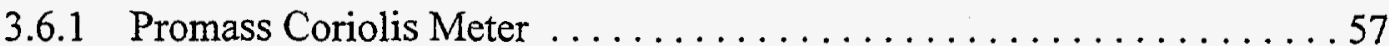

3.6.2 PNNL Pipeline and In-Tank Densitometers . . . . . . . . . . . . 58

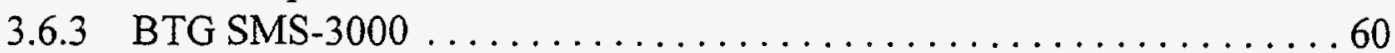

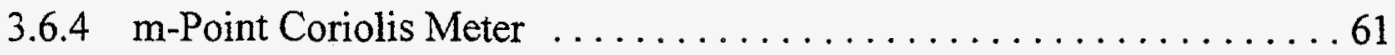

3.6.5 ORNL Gamma Densitometer ...................... 61

3.6.6 Sandia Pipeline Density-Viscosity Meter $\ldots \ldots \ldots \ldots \ldots \ldots \ldots \ldots 6$

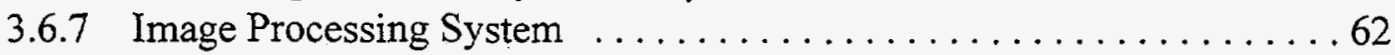

3.6.8 Argonne's Ultrasonic Flow Instrument . . . . . . . . . . . . . . 63

3.6 .9 U-Loop Density . . . . . . . . . . . . . . . . . . . . . . 63

3.6.10 Sandia In-Tank Density-Viscosity Instrument . . . . . . . . . . 64

3.6.11 PNNL In-Tank Particle Size Instrument . . . . . . . . . . 64

4. PARAMETERS USED IN DATA EVALUATION $\ldots \ldots \ldots \ldots \ldots \ldots \ldots \ldots \ldots$

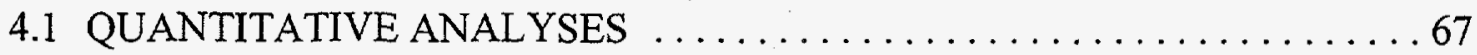

4.2 QUALITATIVE ANALYSES . . . . . . . . . . . . . . . 68

5. TECHNOLOGY PERFORMANCE AND EVALUATION . . . . . . . . . . . . 69

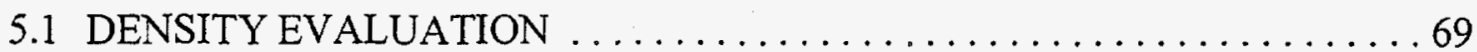

5.1 .1 Reference Density Measurements . . . . . . . . . . . . 70

5.1.2 Completeness of the Experimental Design . . . . . . . . . . . 70

5.1.3 Average Density Bias and Precision of Density Measurements . . . . . 71

5.1.4 Density Bias for Slurry Flow-Rate Experiments . . . . . . . . . . 73

5.1.5 Precision of Density Measurements for Slurry

Flow-Rate Experiments . . . . . . . . . . . . . . . . . . . . . . . 77

5.1.6 Density Bias for the Experiments with Different Air Flows . . . . . . . 80

5.1.7 Precision for the Experiments with Different Air Flows . . . . . . . . 83

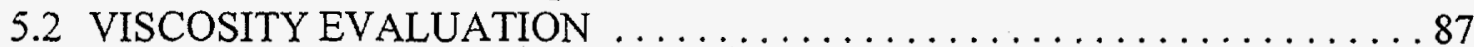

5.3 PARTICLE-SIZE EVALUATION $\ldots \ldots \ldots \ldots \ldots \ldots \ldots \ldots \ldots \ldots \ldots$

5.4 SUSPENDED SOLIDS CONCENTRATION EVALUATION . . . . . . . . . 89

5.4.1 Recommendations for Suspended Solids Monitor . . . . . . . . . . . . . . 94

5.4.2 Suspended Solids Concentration from Density Measurement . . . . . . . . 94

5.5 PUMP CURRENT AND POWER VS SOLIDS CONCENTRATION . . . . . 99

5.5.1 Current and Power Measurements . . . . . . . . . . . . . . . . . 99

5.5 .2 Flow Rate Effects . . . . . . . . . . . . . . . . . . . . . . . 101

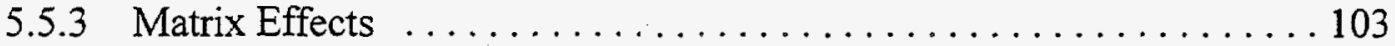

5.5 .4 Temperature Effects ... . . . . . . . . . . . . . . . . 105

5.5 .5 Matrix Composition Effects . . . . . . . . . . . . . . 106

5.5.6 Summary of Current and Power Variation $\ldots \ldots \ldots \ldots \ldots \ldots 11$ 


\section{TABLE OF CONTENTS (cont.)}

$\underline{\text { Page }}$

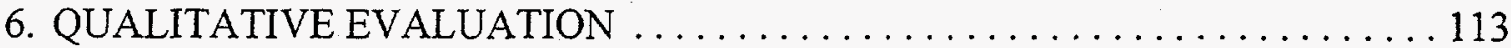

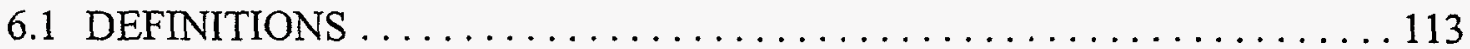

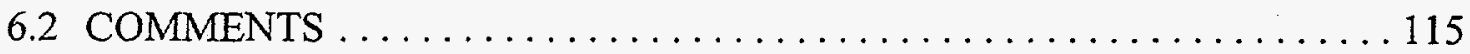

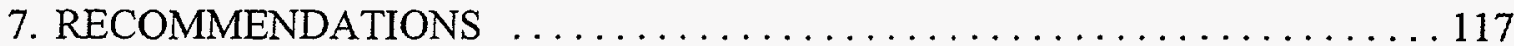

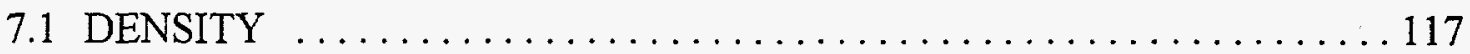

7.2 SUSPENDED SOLIDS CONCENTRATION $\ldots \ldots \ldots \ldots \ldots \ldots \ldots \ldots$

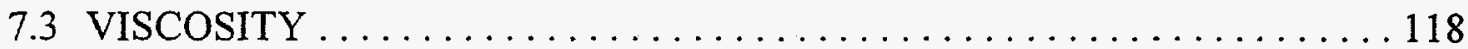

7.4 PARTICLE SIZE DISTRIBUTION $\ldots \ldots \ldots \ldots \ldots \ldots \ldots \ldots \ldots \ldots \ldots \ldots$

7.5 PUMP CURRENT AND POWER . . . . . . . . . . . . . . . . . . 119

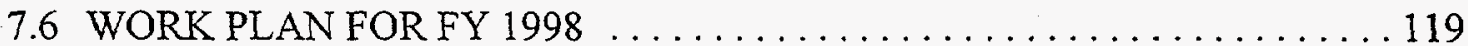

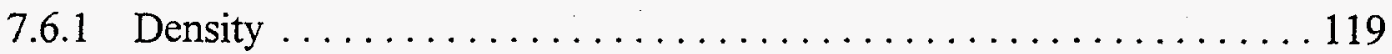

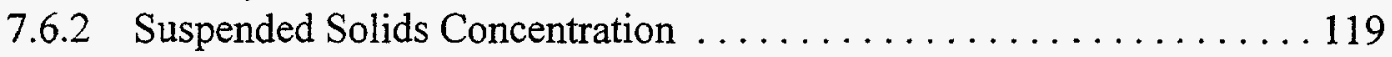

7.6 .3 Viscosity . . . . . . . . . . . . . . . . . . . . . . 120

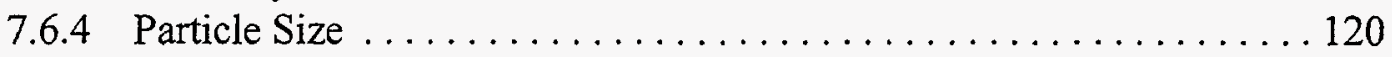

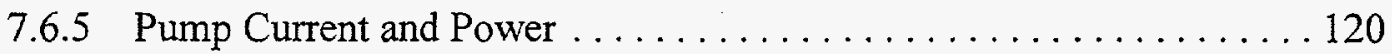

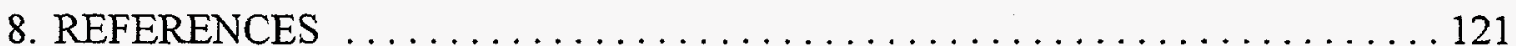

Appendix A. VISCOSITY REPORT FROM PNNL $\ldots \ldots \ldots \ldots \ldots \ldots \ldots \ldots$ A-1

Appendix B. DENSITY DATA ........................

Appendix C. RESPONSE FROM ARGONNE NATIONAL LABORATORY:

ULTRASONIC FLOW INSTRUMENT $\ldots \ldots \ldots \ldots \ldots \ldots \ldots \ldots$ C-1

Appendix D. RESPONSE FROM PACIFIC NORTHWEST NATIONAL

LABORATORY: ULTRASONIC REFLECTION

COEFFICIENT DENSITOMETER . . . . . . . . . . . D-1

Appendix E. RESPONSE FROM SANDIA NATIONAL LABORATORY:

QUARTZ RESONATOR INSTRUMENT . . . . . . . . . . . . E-1

Appendix F. RESPONSE FROM ENDRESS + HAUSER:

PROMASS CORIOLIS METER (DENSITY) . . . . . . . . . F-1

Appendix G: RESPONSE FROM ZELLWEGER ANALYTICS:

BTG SMS-3000 SUSPENDED SOLIDS MONITOR

G-1 



\section{LIST OF FIGURES}

Number

Title

2.1 Photograph of the test loop that was used to evaluate the slurry

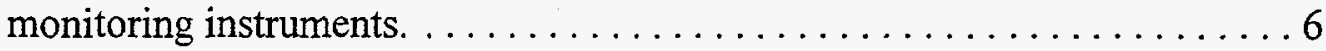

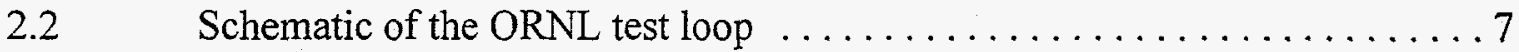

2.3 Schematic illustrating the pipeline instrumentation test section $\ldots \ldots \ldots 12$

2.4 Reflection coefficient sensor configuration .................. 13

2.5 Density sensor spool piece, 12 -in.-long, schedule 40 pipe $\ldots \ldots \ldots \ldots 15$

2.6 Cross-sectional view of a thickness shear mode resonator with upper surface contacted by a mass layer and a liquid $\ldots \ldots \ldots \ldots \ldots \ldots \ldots \ldots \ldots$

2.7 The shift in resonator frequency as a function of increasing

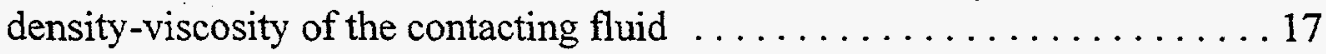

2.8 Schematic of the lever oscillator designed to operate the quartz resonator in liquid media .......................... 19

$2.9 \quad$ Experimental configuration and setup for viscometer $\ldots \ldots \ldots \ldots \ldots 25$

$2.10 \quad$ Attenuation of a $10 \mathrm{vol} \%$ suspension of $6-\mu \mathrm{m}$-diam particles $\ldots \ldots \ldots 28$

2.11 Attenuation spectrum for $20 \%$ kaolin by weight in a $50 \%$ sugar water solution, density $=1.354 \mathrm{~g} / \mathrm{mL} \ldots \ldots \ldots \ldots \ldots \ldots \ldots \ldots \ldots \ldots \ldots \ldots \ldots \ldots$

2.12 Attenuation spectrum for $7.5 \%$ kaolin by weight and $2.5 \%$ sand by weight in a $50 \%$ sugar water solution, density $=1.348 \mathrm{~g} / \mathrm{mL} \ldots \ldots \ldots \ldots . \ldots 31$

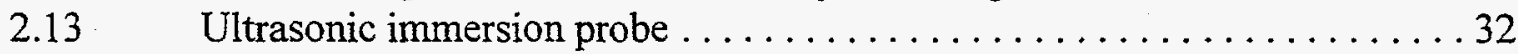

2.14 Illustration of the gamma-ray densitometer designed and implemented

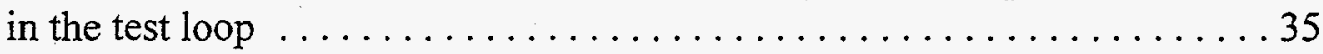

2.15 Coriolis forces in the measuring pipes ..................... 38

2.16 Phase shift of pipe vibration with mass flow $\ldots \ldots \ldots \ldots \ldots \ldots \ldots 40$

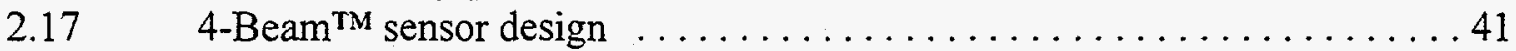

2.18 Schematic representing setup for inverted U-loop $\ldots \ldots \ldots \ldots \ldots \ldots 43$

2.19 Illustration of ISOLOK sampling device $\ldots \ldots \ldots \ldots \ldots \ldots \ldots \ldots$

3.1 Typical particle size distribution of kaolin clay used in slurries . . . . . . . 49

3.2 Typical particle size distribution of sand used in slurries . . . . . . . . .49

3.3 Typical particle size distribution of gravel used in slurries . . . . . . . . 49

5.1 Average of density bias measurements and the standard deviations (SD) of density bias measurements over all experimental conditions . ....... 72

5.2 Range of calculated standard deviations (SD) for density measurements over all experimental conditions except the initial and the final water runs. Center line indicates median $\mathrm{SD}$ value $\ldots \ldots \ldots \ldots \ldots \ldots \ldots 73$

5.3 Box plots of the density biases measured by different density instruments for all combinations of the factors examined in the slurry flow-rate experiments ............................ 75

5.4 Box plot of standard deviations (SD) of density readings from the slurry

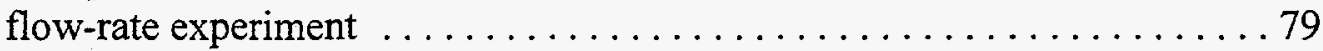




\section{LIST OF FIGIJRES (cont.)}

Number

Title

Page

5.5 Average density biases vs air flow for ANL (solid circle), MPOINT (open circle), ORNL (solid triangle), PNNL_P (open triangle), PROMASS (solid square), and ULOOP (open square) ........... 83

5.6 Box plots of standard deviations (SD) of density measurements by different density instruments for all combinations of the factors examined in the air flow-rate experiments ................. 87

5.7 Viscosity bias for different instruments and matrixes: $\mathrm{ANL}=$ Argonne National Laboratory instrument; $\mathrm{PF}=\mathrm{SNL}$ pipeline frequency; $\mathrm{PV}=\mathrm{SNL}$ pipeline voltage; $\mathrm{TF}=\$ \mathrm{SNL}$ tank frequency; $\mathrm{TV}=\mathrm{SNL}$ tank voltage $\mathrm{KW}=$ kaolin/water; $\mathrm{KS}=$ kaolin/sugar $\ldots \ldots \ldots \ldots \ldots . \ldots 88$

5.8 Relationship between suspended solids concentration and density for a slurry (solid particle density $=2.65 \mathrm{~g} / \mathrm{mL}$ ) $\ldots \ldots \ldots \ldots \ldots . \ldots 96$

5.9 Example illustrating the relative accuracy of using a density instrument to determine the suspended solids concentration $\ldots \ldots \ldots \ldots \ldots \ldots 96$

5.10 Example illustrating the potential difference between the suspended solids concentration calculated from a density measurement vs

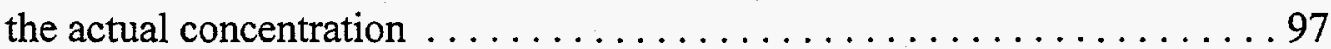

5.11 Relative standard deviation of suspended solids concentration for density RSDs of $0.2 \%$ and $1.0 \% \ldots \ldots \ldots \ldots \ldots \ldots \ldots$

5.12 Box plots of the current measured on pumps EM-300 and EM-400 . . . 100

5.13 Box plots of the power measured on pumps EM-300 and EM-400 . . . 100

5.14 Current as a function of slurry flow rate for EM-300 (solid circles) and EM-400 (open circles) . . . . . . . . . . . . . . . . . 102

5.15 Power as a function of slurry flow rate for EM-300 (solid circles, solid line) and EM-400 (open circles, dashed line) . .......... 102

5.16 Example of power vs solids concentration for EM-400 pumping $\mathrm{kaolin} / \mathrm{sand} /$ gravel mixture at $5 \mathrm{ft} / \mathrm{s}$ at $30^{\circ} \mathrm{C} \ldots \ldots \ldots \ldots \ldots \ldots . \ldots 109$

5.17 Example of power vs density for EM-400 for pumping a kaolin/sand/gravel mixture at $5 \mathrm{ft} / \mathrm{s}$ at a temperature of $30^{\circ} \mathrm{C} . \ldots \ldots \ldots \ldots \ldots \ldots \ldots \ldots \ldots$ 


\section{LIST OF TABLES}

Number

1.1

2.2

2.3

2.4

2.5

2.6

2.7

2.8

3.1

3.2

5.1

5.2

5.3

5.4

5.5

5.6

5.7

5.8

5.9

5.10

5.11

5.12

Title

Page

Ranges of acceptable slurry properties for the ORNL and Hanford pipeline transfer systems $\ldots \ldots \ldots \ldots \ldots \ldots \ldots \ldots \ldots \ldots$

Characteristics of test loop equipment $\ldots \ldots \ldots \ldots \ldots \ldots$

Monitoring instrumentation installed in the test loop $\ldots \ldots \ldots \ldots . . .8$

List of slurry monitoring instruments included in the evaluation . . . . 10

Density probe data compared with independent measurements . . . . 15

Estimated costs for Sandia National Laboratories' Density-Viscosity

Slurry Monitoring System (assuming production-like fabrication) . . . . 21

Estimated life expectancy and replacement rates for Sandia National

Laboratories' Density-Viscosity slurry monitoring system . . . . . . 22

Cost estimate for the ANL ultrasonic flow instrument $\ldots \ldots \ldots \ldots 26$

Comparison of sensor calculated and independently measured

mean diameter and solid fraction . . . . . . . . . . . . . . . 30

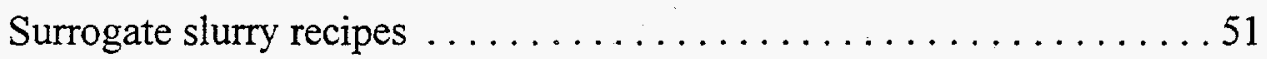

Combinations of factor levels for testing the slurry monitoring

instruments . . . . . . . . . . . . . . . . . . . . . . 52

Percentage of experimental runs completed by the density

instruments . . . . . . . . . . . . . . . . . . 71

Average density biases $(\mathrm{g} / \mathrm{mL})$ for slurry flow-rate experiment . . . . . 74

Significant sources of variation at the $5 \%$ significance level for

the slurry flow-rate experiment $\ldots \ldots \ldots \ldots \ldots \ldots \ldots \ldots 77$

Standard deviations $(\mathrm{g} / \mathrm{mL})$ averaged over flow rates for the

slurry flow-rate experiment . . . . . . . . . . . . . 78

Significant sources of variation for density precision at the $5 \%$

significance level for the slurry flow-rate experiment . . . . . . . . . 79

Completed runs in the air flow-rate experiment $\ldots \ldots \ldots \ldots . \ldots 80$

Significant sources of variation at the $5 \%$ significance level

for the air effects experiment

Significant sources of variation in the standard deviations of the

density readings at the $5 \%$ significance level for the air flow-rate

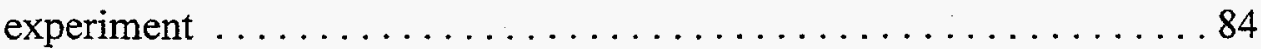

Standard deviations $(\mathrm{g} / \mathrm{mL})$ for air flow-rate experiment $\ldots \ldots \ldots . .85$

Total suspended solids concentration for slurry flow-rate

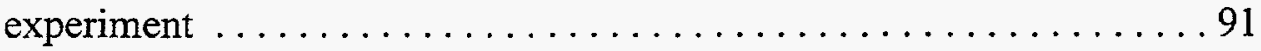

Total suspended solids concentration for air flow-rate experiment . . . 993

Intercepts and slopes for the matrix effect models fitted to

current data 


\section{LIST OF TAELES (cont.)}

Number

Title

Page

5.13 Intercepts and slopes for the matrix effect models fitted to

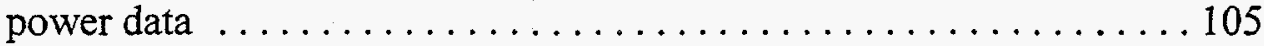

5.14 Summary of experimental factors affecting current and power

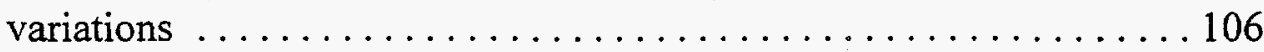

5.15 Intercepts and slopes for the response model with a term for concentration of suspended solids $\ldots \ldots \ldots \ldots \ldots \ldots \ldots \ldots \ldots . \ldots 108$

5.16 Intercepts and slopes for the response model with the

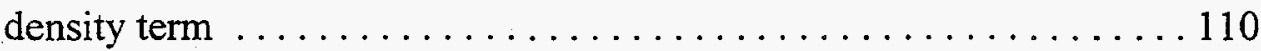

5.17 Summary of variation statistics for the response model that

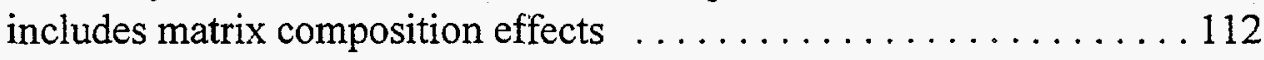

6.1 Qualitative evaluation of the instruments 


\section{ACRONYMS}

$\begin{array}{ll}\text { ANL } & \text { Argonne National Laboratory } \\ \text { ANOVA } & \text { analysis of variance } \\ \text { ASTM } & \text { American Society for Testing and Materials } \\ \text { BVEST } & \text { Bethel Valley Evaporator Service Tanks } \\ \text { CMST-CP } & \text { Characterization, Monitoring, and Sensor Technology } \\ & \text { Crosscutting Program } \\ \text { CTPSM } & \text { Comparative Testing of Pipeline Slurry Monitors } \\ \text { DOE } & \text { U.S. Department of Energy } \\ \text { GAAT } & \text { Gunite and Associated Tanks } \\ \text { HTI } & \text { Hanford Tanks Initiative } \\ \text { INEEL } & \text { Idaho National Engineering and Environmental Laboratory } \\ \text { MVST } & \text { Melton Valley Storage Tanks } \\ \text { NHC } & \text { Numatec Hanford Company } \\ \text { NIST } & \text { National Institute of Standards and Technology } \\ \text { ORNL } & \text { Oak Ridge National Laboratory } \\ \text { OST } & \text { Office of Science and Technology } \\ \text { PNNL } & \text { Pacific Northwest National Laboratory } \\ \text { SAIC } & \text { Scientific Applications International Corporation } \\ \text { SNL } & \text { Sandia National Laboratories } \\ \text { TFA } & \text { Tanks Focus Area } \\ \text { TSS } & \text { total suspended solids }\end{array}$





\section{UNITS}

$\begin{array}{ll}\text { A } & \text { amp } \\ \mathrm{cfm} & \text { cubic foot per minute } \\ \mathrm{cm} & \text { centimeter } \\ \mathrm{cP} & \text { centipoise } \\ \mathrm{ft} / \mathrm{s} & \text { foot per second } \\ \mathrm{g} & \text { gram } \\ \mathrm{gal} & \text { gallon } \\ \mathrm{gpm} & \text { gallon per minute } \\ \mathrm{h} & \text { hour } \\ \mathrm{in} . & \text { inch } \\ \mathrm{kg} & \text { kilogram } \\ \mathrm{krad} & \text { kilorad } \\ \mathrm{kWh} & \text { kilowatt-hour } \\ \mathrm{m} & \text { meter } \\ \mathrm{MHz} & \text { megahertz } \\ \mathrm{min} & \text { minute } \\ \mathrm{mL} & \text { milliliter } \\ \mathrm{mm} & \text { millimeter } \\ \mathrm{Pa} & \text { pascal } \\ \mathrm{ppm} & \text { parts per million } \\ \mathrm{psig} & \text { pounds per square inch, gauge } \\ \mathrm{s} & \text { second } \\ \mathrm{wt} \% & \text { weight percent } \\ { }^{\circ} \mathrm{C} & \text { degree Celsius } \\ { }^{\circ} \mathrm{F} & \text { degree Fahrenheit } \\ \mu \mathrm{m} & \\ & \text { micrometer } \\ \mathrm{m} & \end{array}$





\section{ACKNOWLEDGMENTS}

This project was sponsored by the U.S. Department of Energy through the joint cooperation of the Characterization, Monitoring, and Sensor Technology Crosscutting Program and the Tanks Focus Area of the Office of Science and Technology, Office of Environmental Management, through Technical Task Plan OR-17C231, CCADS 3TFR.

The success of this project can be attributed to the cooperation from many individuals and organizations. The authors would like to express their appreciation to the following individuals and organizations for their contributions.

\section{Instrument Developers and Instrument Manufacturer Representatives}

Judith Bamberger (Pacific Northwest National Laboratory)

Richard Cernosek (Sandia National Laboratories)

Jeff Chapman (Oak Ridge National Laboratory)

Hual-Te Chien (Argonne National Laboratory)

Michael J. Geis (Endress + Hauser)

Margaret Greenwood (Pacific Northwest National Laboratory)

Robert Hill (Endress + Hauser)

Art Rumpf (Ktech, representative of Sandia National Laboratories)

Shuh-Haw Sheen (Argonne National Laboratory)

Lance Weems (Oak Ridge National Laboratory)

\section{Program Committee}

Eric Daymo (Pacific Northwest National Laboratory)

William Haas* (Ames Laboratory)

Marshall Johnson (Oak Ridge National Laboratory)

Tom May (Numatec Hanford Company)

Phong Nguyen (Science Applications International Corporation)

Tom Thomas ${ }^{\dagger}$ (Idaho National Engineering and Environmental Laboratory)

\section{Others}

Carey Chambers (Analytical Services Organization, Y-12)

Mike Hurst (Instrumentation and Controls Division - ORNL)

Lynette Jagoda (Pacific Northwest National Laboratory)

Martha Stewart (Chemical Technology Division - ORNL)

\footnotetext{
"Representative of Characterization, Monitoring, and Sensor Technology Crosscutting Program.

${ }^{\dagger}$ Representative of Tanks Focus Area.
} 



\section{EXECUTIVE SUMMARY}

The U.S. Department of Energy has millions of gallons of radioactive liquid and sludge wastes that must be retrieved from underground storage tanks, transferred to treatment facilities, and processed to a final waste form. To remove the wastes from the current storage tanks, the sludge wastes will typically be mobilized and mixed with the liquid wastes to create a slurry. The slurry will then be transferred by pipeline to the desired destination. Since the slurries are radioactive, it is critically important that they are transferred safely and successfully.

To reduce the risk of plugging a pipeline, the transport properties (e.g., density, suspended solids concentration, viscosity, particle size range) of the slurry should be determined to be within acceptable limits prior to transferring radioactive slurries and monitored and controlled within specified limits while the transfer is in progress. The baseline method for determining the transport properties of slurries is sampling and analysis. This method, which is very time consuming, radiation exposure intensive, and costly, does not provide real-time information. On-line instrumentation that measures the transport properties of slurries and provides data in real time is a highly desirable option. The on-line information provides immediate feedback to controllers or operators who can respond quickly to prevent conditions that could lead to pipeline plugging.

The goal of this project was to test the performance of some newly developed instruments, along with several commercially available instruments, for monitoring slurry transport properties. This project was sponsored by the U.S. Department of Energy through the joint cooperation of the Characterization, Monitoring, and Sensor Technology Crosscutting Program (CMST-CP) and the Tanks Focus Area (TFA) of the Office of Science and Technology, Office of Environmental Management.

Nine pipeline and three in-tank instruments were evaluated under conditions similar to a field environment for measurement of percent suspended solids, density, viscosity, and particle size. In addition to these instruments, the pump current and power were monitored to determine if these parameters could be used to monitor the transport conditions. The surrogate slurries that were used had transport properties similar to those expected to be encountered with the actual radioactive wastes. The evaluation was performed with slurries ranging from $\sim 10$ to $30 \mathrm{wt} \%$ suspended solids at nominal temperatures of 25 and $50^{\circ} \mathrm{C}$. There were also some tests performed that evaluated the performance of the instruments when air was intentionally introduced into the slurry. The results obtained from the various instruments were compared with data obtained from laboratory analyses and evaluated statistically. The results are summarized in the paragraphs that follow. 


\section{Density}

Seven instruments were evaluated for their ability to measure the densities of the slurries. The statistical analysis indicated that the instruments that showed the least bias (i.e., highest accuracy) and the least variance for slurries without induced air were the Endress + Hauser Promass Coriolis meter, the Endress + Hauser m-Point Coriolis meter, the ORNL gamma densitometer, and the Argonne National Laboratory ultrasonic flow instrument. When air was introduced into the slurries, this group remained as the best performers, with the exception of the m-Point Coriolis meter.

Suspended solids concentration

Three instruments were evaluated for measuring the concentrations of suspended solids of the slurries. The BTG SMS-3000 with a RDP-10/5 sensor probe performed well when the concentration of suspended solids was $\sim 10 \mathrm{wt} \%$ but was saturated at suspended solids concentrations above $15 \mathrm{wt} \%$. The instrument worked well at $25^{\circ} \mathrm{C}$ but not at $50^{\circ} \mathrm{C}$. The BTG system is an optical system, and the response of the instrument is highly dependent on the properties of the slurries to be evaluated (e.g., color, particle size, particle shape). The other two suspended solids concentration monitors were newly developed instruments, and the results obtained with them did not compare well with the laboratory measurements. These instruments need more development work.

Viscosity

Three instruments were evaluated for measuring the viscosities of the slurries. Two of these instruments, which were based on quartz crystal resonation technology, were developed by Sandia National Laboratories; however, one was installed in the pipeline, and one was installed in the tank. The other viscosity instrument, which was based on the technology of ultrasonic impedances and scattering, was developed by Argonne National Laboratory; it was installed in the pipeline. While none of these instruments reported the true absolute viscosity of the slurry, it may be possible to use the quartz resonator instrument as a qualitative indicator of viscosity. Since this instrument is pressure sensitive, it is probably better suited for use ir. an in-tank application (nonpressurized).

Particle size

Only one instrument was evaluated for monitoring particle size, and it was mounted in the tank. This instrument, which was developed by Pacific Northwest National Laboratory, was based on the methodology of ultrasonic attenuation. The testing of the instrument was done with slurries that contained nominal particle size distributions ranging from 1 to $100 \mu \mathrm{m}, 1$ to $1000 \mu \mathrm{m}$, and 1 to $4000 \mu \mathrm{m}$. The instrument responded with the same mean particle size for each test that was performed. The instrument 
developer evaluated the data and indicated that the instrument was responding as if air was entrained in the slurry. This instrument needs more development work.

Pump current and power

The pump current and power were evaluated with respect to density, suspended solids concentration, and viscosity. The results indicated that the changes in current and power were not sensitive enough to detect changes in transport properties quickly enough.

The work plan for FY 1998 is to install selected instruments in a radioactive slurry application and to evaluate their performance. Based on the results of this testing, the following recommendations are submitted with regard to which instruments should be considered for testing in the next phase of this project (i.e., radioactive slurries) in FY 1998.

Density

The Endress + Hauser Promass Coriolis meter provided the best results and should be evaluated in the next phase. The Argonne ultrasonic flow instrument measured density quite well. This instrument is more compact than the Promass meter and may work in applications where the Promass would not. The ORNL gamma densitometer also performed well and should be considered for further development. This instrument is compact and has the advantage that it attaches to a pipe and does not directly contact the slurry.

\section{Concentration}

Of the suspended solids monitoring instruments evaluated, the BTG SMS-3000 system performed the best and should be considered for additional evaluation. However, there is some uncertainty about whether the manufacturer has a probe that will work satisfactorily in the desired concentration range ( 0 to $30 \mathrm{wt} \%)$ and whether it will work properly in radioactive slurries. The temperature and pressure of the application must also be considered.

Viscosity

If the Argonne instrument is selected for further evaluation (e.g., as a density instrument), then it is reasonable that the Argonne instrument could also be evaluated as an on-line viscosity sensor in a radioactive application; however, more development is needed on this function. 
Particle size

Unless the air interference problem can be resolved, the results of this study cannot recommend deployment of the particle size probe in the next phase of this project. 


\section{INTRODUCTION}

\subsection{BACKGROUND}

The U.S. Department of Energy (DOE) has millions of gallons of radioactive liquid and sludge wastes that must be retrieved from underground storage tanks, transferred to treatment facilities, and processed to a final waste form. The wastes will be removed from the current storage tanks by mobilizing the sludge wastes and mixing them with the liquid wastes to create slurries. Each slurry would then be transferred by pipeline to the desired destination.

Since the wastes are radioactive, it is critically important that the slurries are transferred safely and successfully. If the transport properties of a given slurry increase beyond the design limits of the transfer pumps, a pipeline plug can occur. The consequences of plugging a pipeline with radioactive waste are unacceptable from safety, cost, and schedule perspectives. If conventional methods (e.g., water flushing) for removing pipeline plugs are not successful, either the pipeline must be abandoned and replaced or the plug must be located and sections of the pipeline must be excised and replaced. Either option would require some radiation exposure to workers, and the costs and schedule delays could become untenable under these conditions. If the pipeline plug is removed by conventional means, delays in the schedule and additional costs to the project will still be incurred. For example, flushing a plugged line creates additional cost due to the effort required to process the excess water.

The problem with pumping slurries without on-line monitoring instrumentation can be illustrated by a situation at the Hanford Site, which has six cross-site slurry pipelines-approximately 6 miles long. Five of these six pipelines have been plugged, and all conventional means for unplugging them have been unsuccessful. Thus, those five pipelines have been abandoned, and the remaining pipeline is reserved for liquid-only transfers. A new cross-site pipeline is currently being designed and built at Hanford for slurry transfers. ${ }^{1}$ 
To reduce the risk of plugging a pipeline, the transport properties (e.g., density, suspended solids concentration, viscosity, particle size range) of the slurry should be determined to be within acceptable limits prior to transfer. These properties should also be manitored and controlled within specified limits while the slurry transfer is in progress.

The baseline method for determining the transport properties of slurries is sampling and analysis. This method is very time consuming, exposure intensive, costly, and does not provide real-time information. On-line instrumentation that measures the transport properties of slurries and provides data in real time is a highly desirable option. The on-line information provides immediate feedback to controllers or operators who can respond quickly to prevent conditions that could lead to pipeline plugging.

The DOE issued a call for proposals for cleveloping on-line instrumentation to measure the transport properties of slurries. At that time, it was believed that either commercial instrumentation was not available or that the existing commercial instrumentation would not work properly in the needed applications. In response to the call for proposals, several researchers submitted proposals and were funded to develop slurry monitoring instruments. These newly developed DOE instruments are currently in the prototype stage. Before the instruments were installed in a radioactive application, the DOE wanted to evaluate them under nonradioactive conditions to determine if they were accurate, reliable, and dependable.

The goal of this project was to test the performance of the newly developed DOE instruments along with several commercially available instruments. The baseline method for comparison utilized the results from grab-sample analyses.

\subsection{PROJECT OBJECTIVES}

The objective of this project was to perform an extensive performance evaluation of several commercially available slurry monitoring instruments and several new prototype instruments that are being developed for the IDOE. These on-line monitoring instruments were tested under conditions similar to a field environment for measurement of the 
following slurry properties: percent suspended solids, density, viscosity, and particle size. The instruments that successfully completed this cold-test program were to be evaluated for inclusion in a test where radioactive suspended solids will be transported. The two measures of quantitative performance for slurry monitoring instruments are bias and variance. These two measures are defined as

- bias: the difference between the average of measurement readings by a slurry monitoring instrument and the accepted reference value;

- variance: a measure of dispersion of replicate measurement readings by a slurry monitoring instrument.

The instruments were also evaluated from a qualitative perspective. The qualitative factors that were assessed include portability, ruggedness, ease of operation, maintenance and training requirements, clarity of output, any special requirements (e.g., recalibration for slurry matrix change, etc.), and expected performance if used to monitor transport of radioactive slurries.

Personnel at the Oak Ridge National Laboratory (ORNL) and the Hanford Site dealing with the transfer of slurries were requested to provide specifications regarding the allowable bias and variance for the parameters being measured by the instruments. Both sites indicated that there are no current requirements for the instruments; therefore, the instruments cannot be evaluated in terms of whether they meet the user site requirements.

\subsection{SURROGATE SLURRY DEVELOPMENT}

The DOE sites that have indicated a need for slurry monitoring instruments are ORNL and Hanford; however, other DOE sites (e.g., Savannah River) are also expected to have applications. Personnel at ORNL and Hanford with the need for slurry monitors were requested to provide information regarding the transport properties that were expected to be encountered and/or limiting system conditions (e.g., pipe diameter, pressure drop). This information, which is shown in Table 1.1, formed the basis for developing formulations for the surrogate slurries and the test conditions. 
Table 1.1. Ranges of acceptable slurry properties for the ORNL and Hanford pipeline transfer systems

\begin{tabular}{|c|c|c|c|c|c|}
\hline \multirow[b]{2}{*}{ Parameter } & \multirow[b]{2}{*}{ Units } & \multicolumn{2}{|c|}{$\mathrm{ORNL}^{a}$} & \multicolumn{2}{|c|}{ Hanford ${ }^{b}$} \\
\hline & & Range & Nominal & Range & Nominal \\
\hline Flow rate & gpm & $5-75$ & 60 & $250-400$ & 350 \\
\hline Temperature & ${ }^{\circ} \mathrm{F}$ & $40-120$ & 70 & $40-120$ & 75 \\
\hline Operating pressure & psig & $30-100^{c}$ & $50^{\circ}$ & $140-310$ & 165 \\
\hline MVST alternate pressure & psig & $<300^{c}$ & $260^{c}$ & NA & NA \\
\hline Pipe diameter & in. & $1.5-2.0$ & 2.0 & 4.0 & 4.0 \\
\hline Viscosity & $\mathrm{cP}$ & $1.0-40.0$ & 5.0 & $4-100$ & 15 \\
\hline Specific gravity & & $1.0-1.25$ & 1.1 & $1-1.2$ & 1.15 \\
\hline Particle size & $\mu \mathrm{m}$ & $1-200$ & $<100$ & $d$ & $d$ \\
\hline Suspended solidis & wt $\%$ & $0-35$ & 10 & $0-30$ & 10 \\
\hline $\mathrm{pH}$ & & $7.5-11$ & 9.5 & $8-11$ & 9 \\
\hline
\end{tabular}

${ }^{a}$ Data provided by M. A. Johnson, ORNL.

${ }^{b}$ Data provided by E. A. Daymo, PNNL, and T. H. May, NHC.

'Operating pressure of the interconnecting pipeline from Bethel Valley to Melton Valley is approximately 250 psig, with a maximum operating pressure less than 300 psi (based on double-wall pipe pressurized annulus system). Transfers within the Gunite Tank area and from the Gunite Tanks to the Bethel Valley Evaporator Storage Tanks (BVEST) will operate at approximately 50 psig. The current baseline is to transfer slurry from the Gunite Tanks to the BVEST, with an alternate scenario of direct transfer from the Gunite Tanks to Melton Valley.

${ }^{\prime}$ Project W-058 functional design criteria indicate the following particle size distribution (percentages shown are volume percent of settled solids):
$95 \%$ of solids
$<5 \%$ of solids
$<50 \mu \mathrm{m}$
$<1 \%$ of solids
50 to $500 \mu \mathrm{m}$
500 to $4000 \mu \mathrm{m}$ 


\section{TEST FACILITY AND INSTRUMENTATION DESCRIPTION}

\subsection{TEST FACILITY DESCRIPTION}

The evaluation of the slurry monitoring instruments was conducted using a test loop located in Building 2528 at the Oak Ridge National Laboratory (ORNL). A photograph of the test loop is shown in Fig. 2.1; a schematic is shown in Fig. 2.2. The test loop, which was locally engineered and fabricated, consisted of pumps, slurry tanks, mixer, and piping and was compactly assembled in an area that is roughly $20 \mathrm{ft}$ long by $10 \mathrm{ft}$ wide by $12 \mathrm{ft}$ high (except U-loop). A heat exchanger was located in an auxiliary loop. The total flow path contained approximately $240 \mathrm{ft}$ of 2 -in.-diam, schedule 40 welded and flanged stainless steel pipe.

Since the solid particles may have a tendency to settle, the instruments were installed in vertical pipe sections to ensure a more homogenous flow. Also, the testing was conducted in such a manner that the slurry flowed upward through each instrument to allow the slurry velocity to counteract changes in suspended solids concentration caused by gravitational settling.

The test loop was designed to provide variability in slurry flow rate, temperature, and induced air flow to the instruments being tested. The characteristics of the test loop equipment are given in Table 2.1. Some instrumentation was installed in the test loop to monitor its operation and to provide comparison values for the various slurry property measurements during the test runs. These instruments, which measured flow rate, pressure, temperature, pump power, and pump current, are listed in Table 2.2. Prior to beginning the test program, the flow transmitters, pressure transmitter, differential pressure transmitters, and thermocouples were calibrated with National Institute of Standards and Technology (NIST)-traceable sources.

The test loop controls and the data acquisition computer system was located in a control room approximately $50 \mathrm{ft}$ from the test loop. All data were collected electronically. 


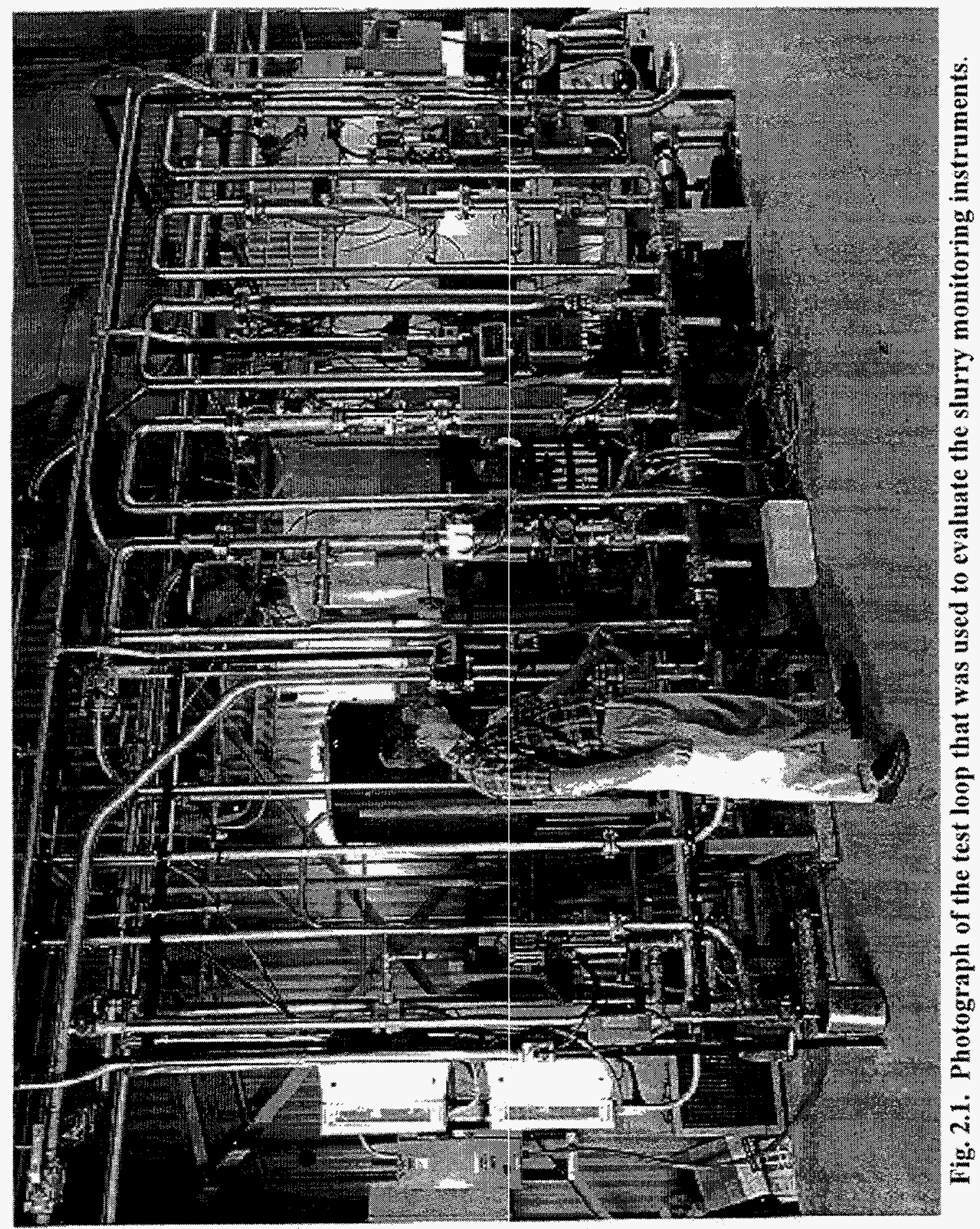




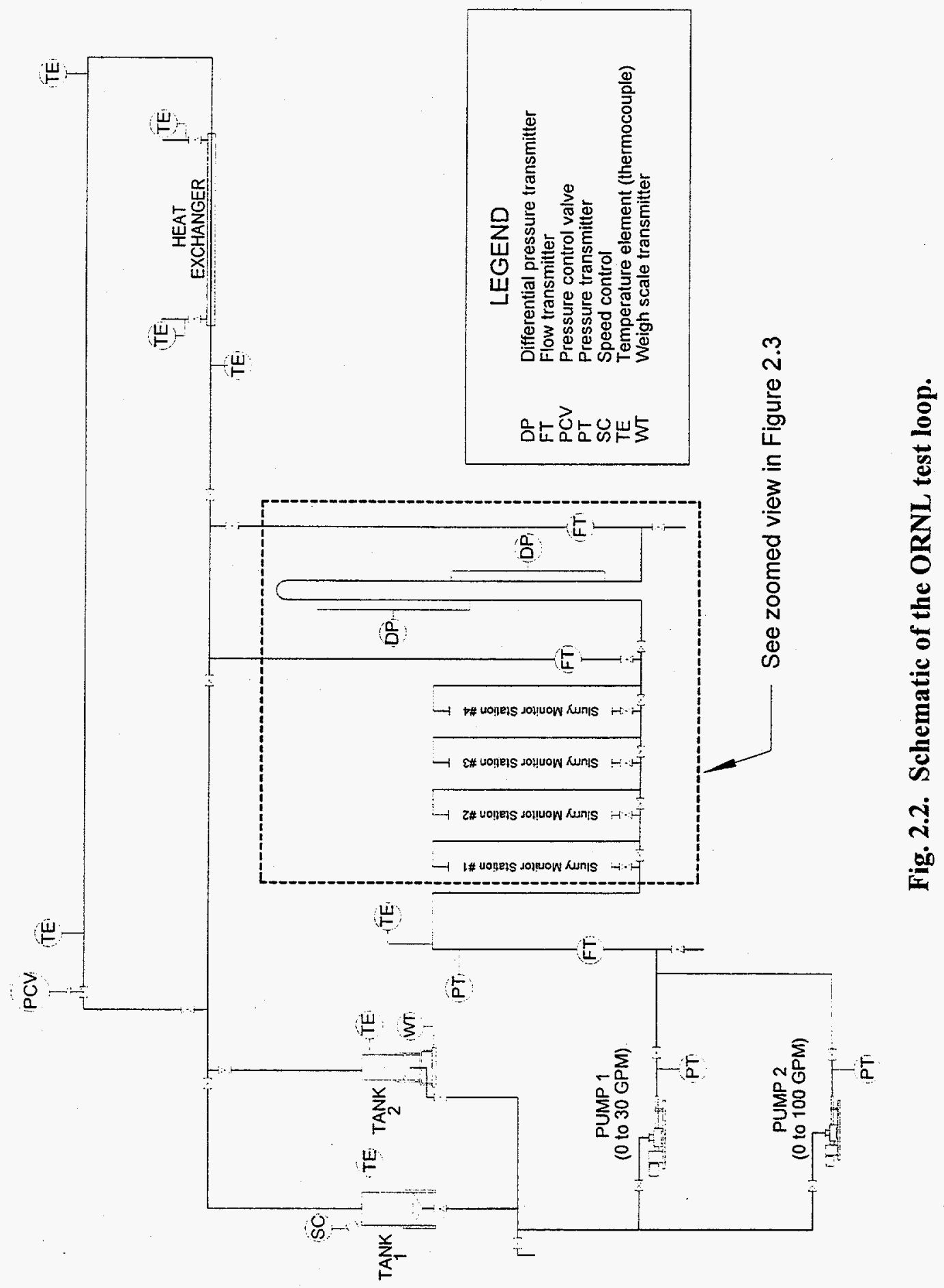


Table 2.1. Characteristics of test loop equipment

\begin{tabular}{|c|c|}
\hline Item & Description $^{a}$ \\
\hline Test loop & $\begin{array}{l}\text { Approximately } 240 \mathrm{ft} \text { long (flow path); includes } \sim 110 \mathrm{ft} \text { of } \\
\text { horizontal } 2 \text {-in. pipe, } \sim 80 \mathrm{ft} \text { of vertical } 2 \text {-in. pipe and } \sim 50 \mathrm{ft} \text { of } \\
\text { vertical } 1 \text {-in. pipe (inverted U-loop); all pipe was schedule } 40 \\
\text { stainless steel }\end{array}$ \\
\hline Number of test legs & Four vertical upward flow test legs plus the inverted U-loop \\
\hline Pump 1 & $\begin{array}{l}\text { Moyno }{ }^{\otimes} \text { progressive cavity pump (Frame/Type } 2 \mathrm{~L} 8 \mathrm{SSB} \text {, Trim } \\
\text { AAA), nominal flow capacity } 0 \text { to } 30 \mathrm{gpm}\end{array}$ \\
\hline Pump 2 & $\begin{array}{l}\text { Moyno }{ }^{\otimes} \text { progressive cavity pump (Frame/Type } 2 \text { F036G1 SSB, } \\
\text { Trim AAA), nominal flow capacity } 0 \text { to } 100 \mathrm{gpm}\end{array}$ \\
\hline Tank 1 & Nalgene ${ }^{\bowtie}, 100$-gal, high-density polyethylene, conical bottom \\
\hline Tank 2 & Stainless steel, 50-gal, conical bottom (fabricated in-house) \\
\hline Mixer & Lightnin ${ }^{\otimes}$ Model XJ.174AM \\
\hline Heat exchanger & $\begin{array}{l}\text { Fabricated in-house; } 2 \text {-in. pipe (tube) in } 3 \text {-in. pipe (shell), } \\
\text { steam heated, process water with chiller for cooling }\end{array}$ \\
\hline Samplers (on-line) & $\begin{array}{l}\text { Bristol Equipment Company Isolok }{ }^{\circledR} \text { Sampler, } \\
\text { Model SAA-19-09-44 }\end{array}$ \\
\hline
\end{tabular}

${ }^{a}$ Manufacturer, model, and characteristics.

Table 2.2. Monitoring instrumentation installed in the test loop

\begin{tabular}{ll}
\hline \multicolumn{1}{c}{${\text { Item }(\text { label })^{a}}^{-}$} & \multicolumn{1}{c}{ Description $^{b}$} \\
\hline Flow meters (FT) & $\begin{array}{l}\text { EMCO MAGFLO Mag3000 } \\
\text { Endress + Hauser Variomag }\end{array}$ \\
Pressure sensors (PT) & $\begin{array}{l}\text { Red Valve }{ }^{\circledR} \text { Series 40 } \\
\text { Honeywell ST3000 }\end{array}$ \\
Pump controllers & Allen-Bradley 1336 Plus \\
Pressure control valve (PCV) & Red Valve Series 5200 (pinch) \\
Temperature (TE) & Type K thermocouples \\
Pump current and power & Allen Bradley 1336 Plus (pump controller) \\
\hline
\end{tabular}

${ }^{a}$ Label is shown in test loop schematic in Fig. 2.2.

${ }^{b}$ Manufacturer, model, and characteristics. 


\subsection{INSTRUMENTATION DESCRIPTION}

The evaluation included 12 instruments, 9 of which were installed in or on the pipeline and 3 installed in the feed tank. Nine of the instruments are considered prototypes, while the other three are commercially available. Table 2.3 lists the instruments that were tested, the operational technique of the instrument, the location of installation (pipeline or in-tank), the organization that developed or manufactured the instrument, and a technical contact. Some of the instruments that were evaluated contained commercially available parts that were merged at ORNL to form a slurry monitoring instrument (e.g, inverted U-loop, image processing system).

The commercially available instruments included two Coriolis meters manufactured by Endress + Hauser. The original plan was to perform the evaluation with the m-Point Coriolis meter, which had been procured by ORNL approximately 2 years prior to this project. Endress + Hauser was contacted and informed about the test program that was to be conducted. Endress + Hauser representatives were then sent to ORNL to view how the instrument would be installed in the test loop. They approved the testing setup; however, they decided that they preferred the testing to be performed with their latest model of Coriolis meter, which was called the Promass. Endress + Hauser loaned a Promass instrument to ORNL for this evaluation. Since the m-Point was already on hand, it was also included in the testing.

The BTG SMS-3000 solids monitoring instrument had been procured by ORNL in 1993. When BTG was informed about the test evaluation, it was learned that the product line had been sold to Zellweger Analytics. On being contacted about the test program, the regional sales manager for Zellweger indicated that the SMS-3000 model is no longer manufactured but has been superseded by an updated version that works on the same principle. The regional sales manager expressed some concern about the reliability of the instrument in a radioactive application. He indicated it had been tried previously and that the plastic window through which light shines into the slurry tends to degrade (e.g., flake). The sales manager declined to visit ORNL to look at our test facility or to loan an updated version of the instrument for the evaluation. ${ }^{2}$ 
Table 2.3. List of slurry monitoring instruments included in the evaluation

\begin{tabular}{|c|c|c|c|c|}
\hline Instrument & Technique & Mounted & Organization & Technical contact \\
\hline Particle size probe & $\begin{array}{l}\text { Ultrasonic signal } \\
\text { attenuation }\end{array}$ & In-tank & $\begin{array}{l}\text { Pacific Northwest } \\
\text { National Laboratory }\end{array}$ & Judith Bamberger \\
\hline Density probe & $\begin{array}{l}\text { Ultrasonic reflection } \\
\text { coefficient }\end{array}$ & $\begin{array}{l}\text { Pipeline, } \\
\text { in-tank }\end{array}$ & $\begin{array}{l}\text { Pacific Northwest } \\
\text { National Laboratory }\end{array}$ & Judith Bamberger \\
\hline $\begin{array}{l}\text { Viscosity-density } \\
\text { product }\end{array}$ & $\begin{array}{l}\text { Quartz crystal } \\
\text { resonation }\end{array}$ & $\begin{array}{l}\text { Pipeline, } \\
\text { in-tank }\end{array}$ & $\begin{array}{l}\text { Sandia National } \\
\text { Laboratories }\end{array}$ & Richard Cernosek \\
\hline Density probe & Gamma-ray attenuation & Pipeline & $\begin{array}{l}\text { Oak Ridge National } \\
\text { Laboratory }\end{array}$ & Jeff Chapman \\
\hline $\begin{array}{l}\text { Density, viscosity, and } \\
\text { volume percent solids }\end{array}$ & $\begin{array}{l}\text { Ultrasonic impedances } \\
\text { and scattering }\end{array}$ & Pipeline & $\begin{array}{l}\text { Argonne National } \\
\text { Laboratory }\end{array}$ & Shuh-Haw Sheen \\
\hline Percent solids & $\begin{array}{l}\text { Image processing } \\
\text { system }\end{array}$ & Pipeline & $\begin{array}{l}\text { Items purchased } \\
\text { separately and merged } \\
\text { to form a system }\end{array}$ & None \\
\hline Density (U-loop) & Pressure drop & Pipeline & Fabricated in-house & None \\
\hline Density meter & Coriolis effect & Pipeline & $\begin{array}{l}\text { Endress }+ \text { Hauser } \\
\text { (Promass) }\end{array}$ & Mark Boise \\
\hline Density meter & Coriolis effect & Pipeline & $\begin{array}{l}\text { Endress + Hauser } \\
\text { (m-Point) }\end{array}$ & Mark Boise \\
\hline Percent solids & Backscattering of light & Pipeline & $\begin{array}{l}\text { BTG } \\
\text { (SMS-3000 System) }\end{array}$ & $\begin{array}{l}\text { Bobby Hill, } \\
\text { Jim Edwards } \\
\text { (Zellweger Analytics) }\end{array}$ \\
\hline
\end{tabular}


The test loop has four vertical legs to permit the installation of test instrumentation. Most of the pipeline instrumentation was installed in the test loop as spool pieces. To ensure that all the instruments were tested under the same conditions, the slurry passed through each of the four vertical legs in series. Testing the instruments in series also reduced the number of samples that had to be analyzed.

The slurry monitoring instruments were installed as illustrated in Fig. 2.3. The location of each instrument in the test loop was assigned so that the operation of any upstream instrument did not interfere with the other instruments (e.g., signals from an ultrasonic instrument would not interfere with another ultrasonic instrument downstream). The locations of the instruments in the test loop were approved by the instrument developers prior to installation of the instruments.

The instrument developers were asked to provide the technical descriptions of their instrumentation for this report. Details of the commercial instruments were taken from the respective operation manuals. The information that was obtained is shown, essentially verbatim, in the subsections that follow. Where applicable, the source of the information is identified at the beginning of the section for a particular instrument. Any references cited by a developer or manufacturer are provided at the end of the subsection rather than at the end of this report.

The instrument developers and instrument manufacturers were also requested to provide capital cost estimates for their instruments as well as an estimate for the expected lifetime of the instrument. These data are included along with the technical descriptions of the various instruments.

\subsubsection{PNNL Densitometer}

\section{Source: J. A. Bamberger, Pacific Northwest National Laboratory}

This project is developing an in situ technique to measure fluid (liquid and slurry) density in vessels and in pipelines. The sensor can be used to measure density with real time measurement update. The method is based on the reflection coefficient of the ultrasonic signal as it passes through a wedge and impacts the slurry to provide data to 


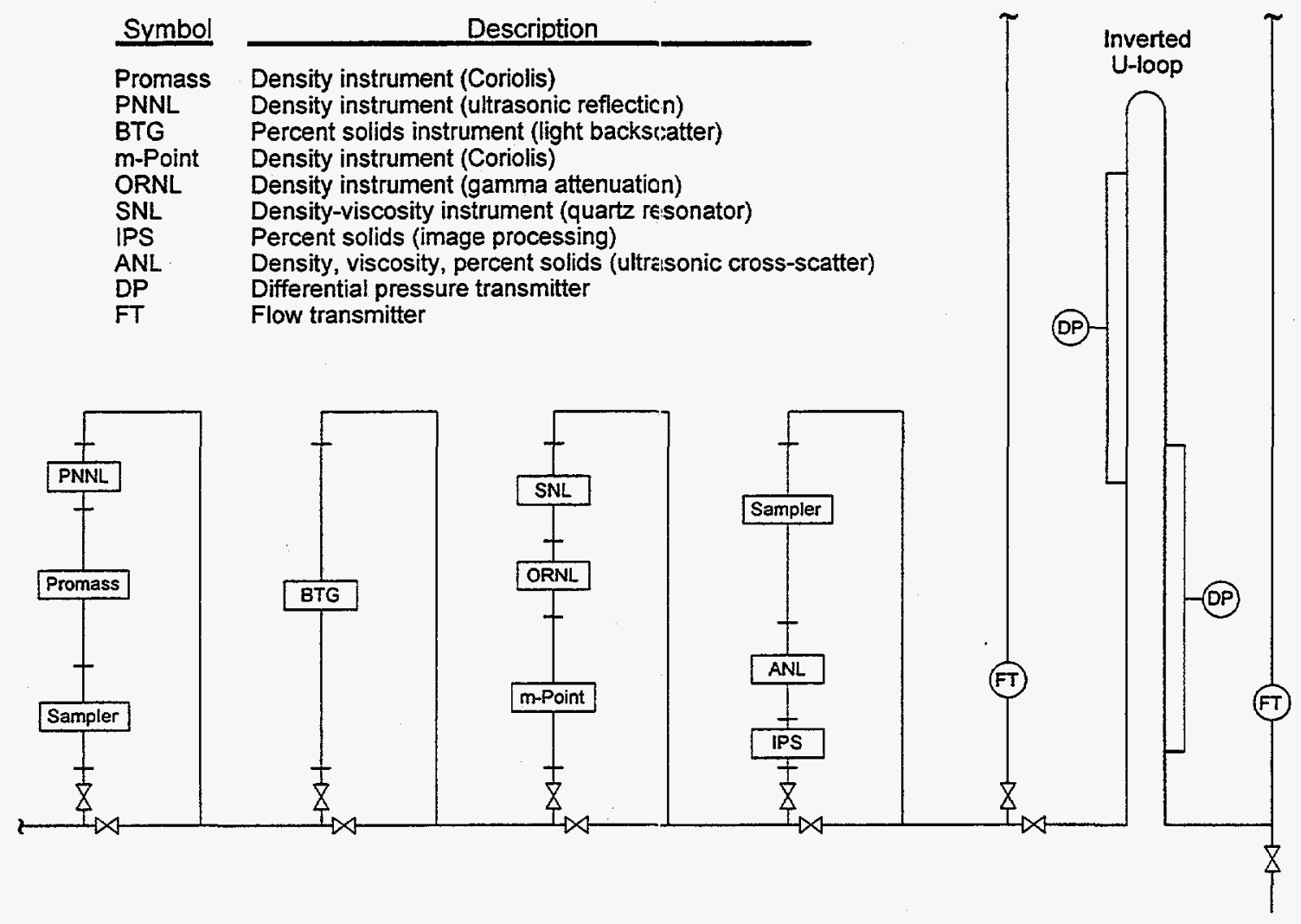

Fig. 2.3. Schematic illustrating the pipeline instrumentation test section. 
calculate slurry density. The bottom surface of the wedge must contact the fluid whose density is to be measured. Alternatively, the sensor can be submerged in the fluid if this is advantageous. Sensor operation is described in Fig. 2.4.

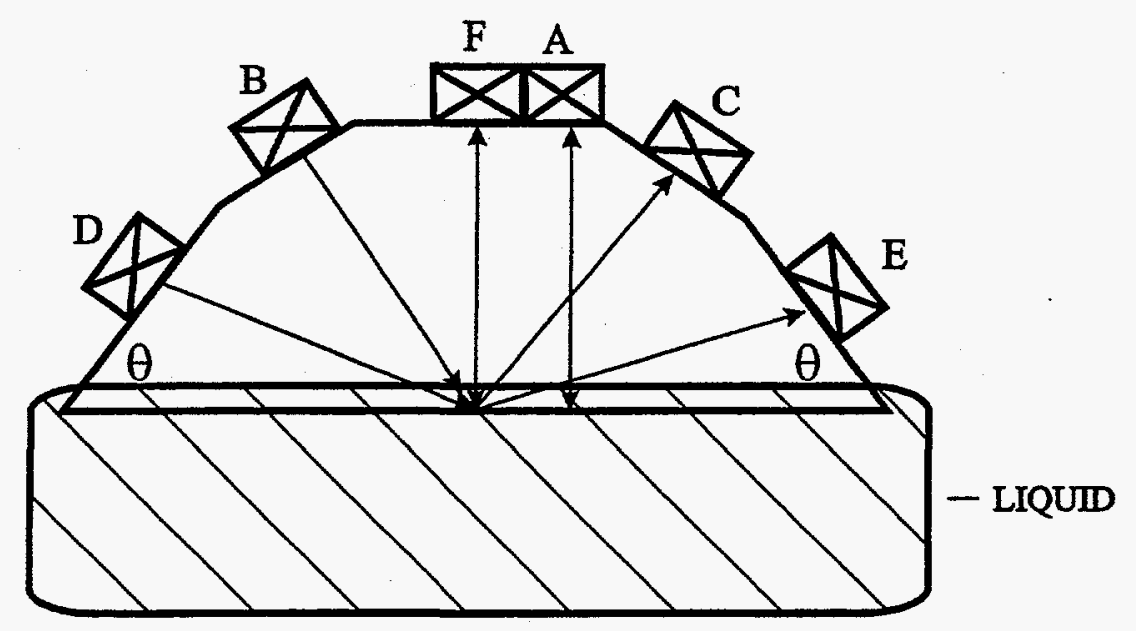

Fig. 2.4. Reflection coefficient sensor configuration.

The transducers operate at an ultrasonic frequency of $2.25 \mathrm{MHz}$. Ultrasound emitted from transducer $F$ travels through the wedge material and strikes the wedge-fluid interface; part of the signal is reflected and travels back to transducer $\mathrm{F}$, producing a voltage signal or echo; part of the signal is transmitted into the liquid. Similarly, when the ultrasound from transducer B (or D) strikes the wedge-liquid interface, (1) some is reflected to transducer $\mathrm{C}$ (or $\mathrm{E}$ ), producing a voltage signal; (2) some of the longitudinal wave mode converts to a shear wave; and (3) some is transmitted into the liquid. Transducer $\mathrm{A}$ is a shear wave transducer and is used to measure the speed of the shear wave in the wedge material. The signals of interest are those reflected back to $\mathrm{F}$ and received by $\mathrm{C}$ and $\mathrm{E}$. The reflection coefficients are obtained by comparing the voltages on the transducer when the bottom surface is in contact with a liquid to a reference measurement made in water or air.

The reflection coefficients depend on (1) the density of the wedge, (2) the speed of the longitudinal wave in the wedge, (3) the speed of the shear wave in the wedge, (4) the angle at which the ultrasound beam strikes the surface, (5) the speed of the longitudinal 
wave in the liquid, and (6) the density of the slurry or liquid. Only the last two of these quantities are unknown. By measuring two reflection coefficients from transducers $F$ and $\mathrm{D}$, one has two equations with two unknowns; therefore, the density of the liquid and the speed of sound in the liquid can be determined.

Experiments to verify this technique were performed using solutions of sugar in water, 2-propanol, paraffin oil, trichloroethane, and slurries consisting of silicon dioxide particles $(0.0015$ in. diam, $38 \mu \mathrm{m})$ in water. These data are summarized in Table 2.4. Density measurement uncertainties were less than $1.2 \%$. For slurries, the ultrasonic wavelength is many times the diameter of the particles; individual particles cannot be resolved, and the ultrasonic senses an average density. An ultrasonic wave, traveling in water with a frequency of $2.25 \mathrm{MHz}$, has a wavelength of $0.66 \mathrm{~mm}$.

\subsubsection{Advantage/Disadvantage}

This sensor provides a simple in situ method to measure slurry or liquid density in real time. Real-time, in situ density data of liquids and slurries inside waste storage tanks and in pipelines can be used to characterize wastes prior to and during mixing and transfer operations to provide process monitoring and control. Multiple sensors arranged over a range of elevations in the tank or placed around the circumference of a pipeline can provide stratification or settling information.

The pipe spool piece that houses the sensor is shown in Fig. 2.5. The sensor is flush with the pipe wall and does not protrude into the flow path. The spool piece (1) is compact (contained in a 12-in.-long pipe spool piece), (2) can operate next to pumps (the ultrasonic signal is not degraded by noise or vibration), (3) requires fully mixed turbulent flow (the expected condition at the retrieval line inlet), and (4) can detect onset of settling (by placing sensors at several angles around the horizontal pipe). The probe material is inherently radiation hardened.

There are several advantages to this reflection-coefficient method. One novel feature of this method is that it can measure the densities of very attenuative slurries. Secondly, the voltage on the transducers can be low (on the order of $30 \mathrm{~V}$ ) because the signals travel only a short distance; this is important for safety considerations. Thirdly, no previous laboratory calibration measurements are needed because the density is determined directly.

A disadvantage is that the sensor may not provide adequate data if particles are not distributed homogeneously across the pipe. 
Table 2.4. Density probe data compared with independent measurements

\begin{tabular}{lccc}
\hline \multirow{2}{*}{ Fluid } & \multicolumn{2}{c}{ Density $\left(\mathrm{kg} / \mathrm{m}^{3}\right)$} & $\begin{array}{c}\text { Percent } \\
\text { difference }\end{array}$ \\
\cline { 2 - 3 } & Probe & Independent & 0.6 \\
Sugar water 1A & 1010 & 1016 & 0.7 \\
Sugar water 2A & 1028 & 1035 & 0.7 \\
Sugar water 3A & 1045 & 1052 & 0.0 \\
Sugar water 4A & 1069 & 1069 & 0.4 \\
Sugar water 5A & 1095 & 1099 & 0.8 \\
Carbopol & 1005 & 997 & 0.1 \\
Detergent & 1051 & 1052 & \\
& Model II Probe $(42$ deg angle) & \\
Water & 998 & & 0.4 \\
Sugar water 40 & 1185 & 1180 & 0.2 \\
Sugar water 50 & 1222 & 1220 & 1.2 \\
Sugar water 60 & 1295 & 1280 & \\
\hline
\end{tabular}

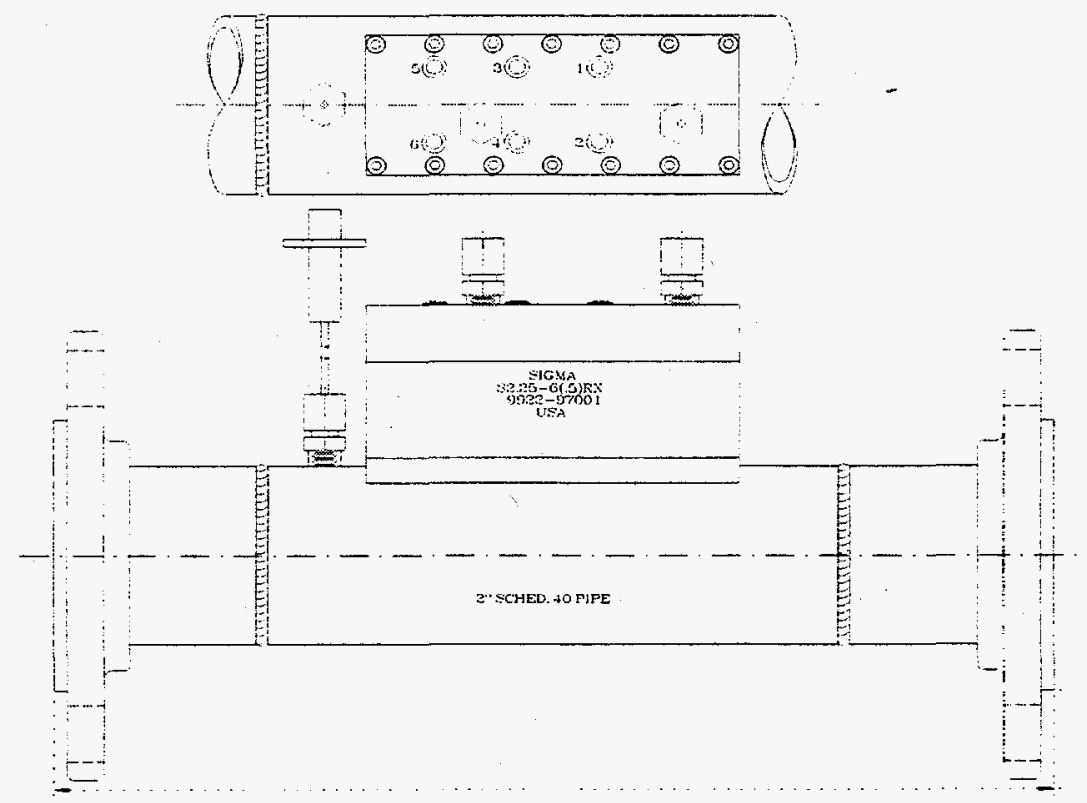

Fig. 2.5. Density sensor spool piece, 12-in.-long, schedule 40 pipe. 


\subsubsection{Capital Cost Estimate and Life Expectancy for the Density Probe}

The density probe includes the sensor and its spool piece and computer and electronics associated with sensor operation. The probe includes the wedge that contacts the slurry with the transducers mounted on the opposite end and the pipeline or immersion configuration for the spool piece. The computer control system includes the rugged computer with integral pulser-receiver-multiplexer-digitizer card.

The spool piece configured for pipeline or immersion application is projected to have a life expectancy of 3 to 5 years. The computer-based electronics is projected to have a life expectancy of 10 years or more.

The spool piece and probe are projected to have an off-the-shelf cost of $\$ 4 \mathrm{~K}$. The computer-based controller is projected to have an off-the-shelf cost of $\$ 14 \mathrm{~K}$.

\subsubsection{Sandia In-Tank and Pipeline Quartz Resonating Instruments}

\section{Source: R. W. Cernosek, Sandia National Laboratories}

\subsubsection{Technology Description}

The basic quartz resonator sensor consists of a thin wafer of AT-cut quartz with metal (typically gold) electrodes deposited on opposing faces of the crystal. Application of an RF voltage to the electrodes imparts a strain in the piezoelectric quartz, exciting the thickness shear mode (TSM) of vibration (see Fig. 2.6). When operated in fluid, the oscillating crystal surface interacts mechanically with the fluid: the in-plane motion launches a critically damped shear wave as shown in Fig. 2.6. The resulting shifts in crystal resonant frequency and resonance damping are both proportional to $(\rho \eta)^{1 / 2}$, where $\rho$ and $\eta$ are the fluid density and viscosity [1]. Figure 2.7 shows the measured sensor frequency shift versus $(\rho \eta)^{1 / 2}$. In many applications, the magnitude of variations in the fluid density is significantly smaller than changes in the viscosity, allowing this technique to be used as a direct indicator of viscosity. 


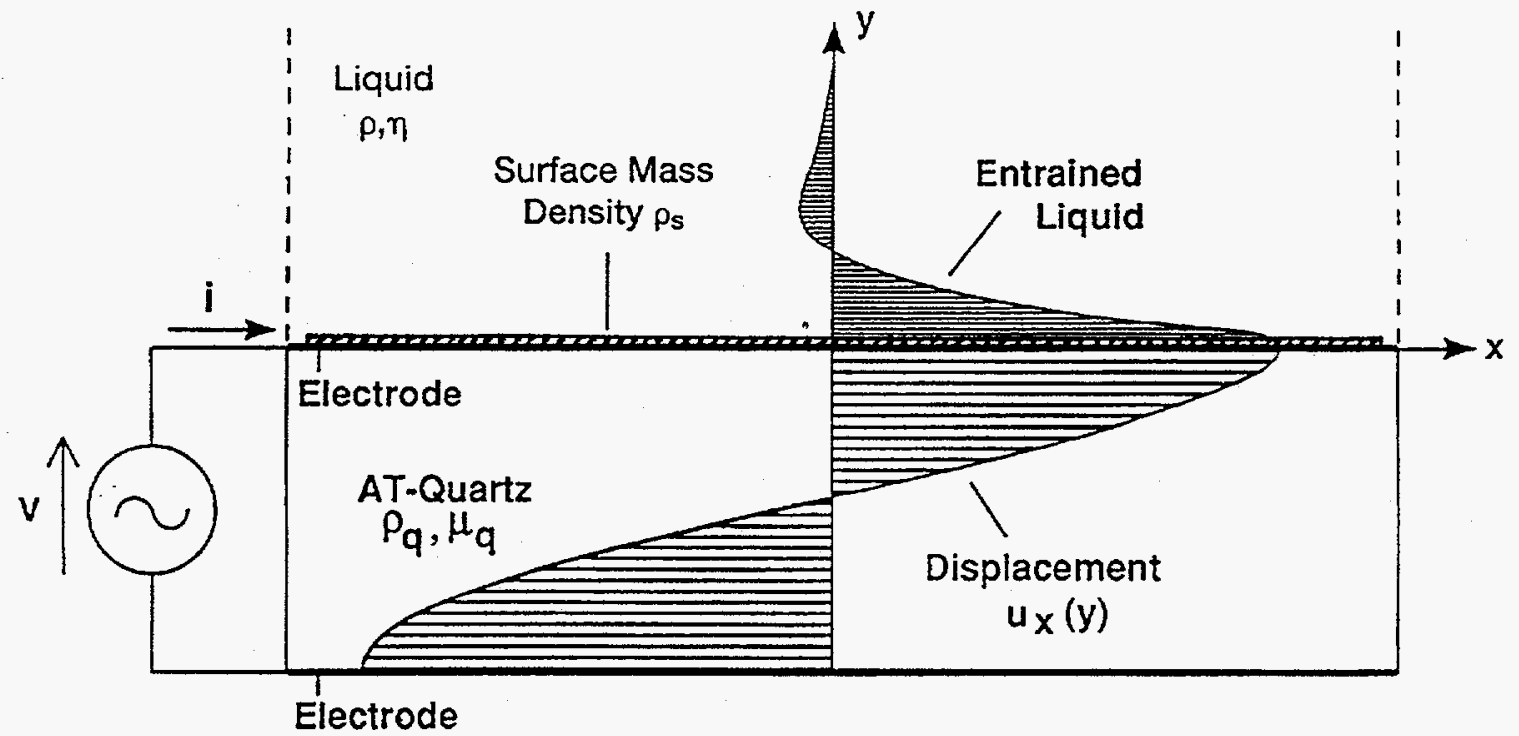

Fig. 2.6. Cross-sectional view of a thickness shear mode resonator with upper surface contacted by a mass layer and a liquid.

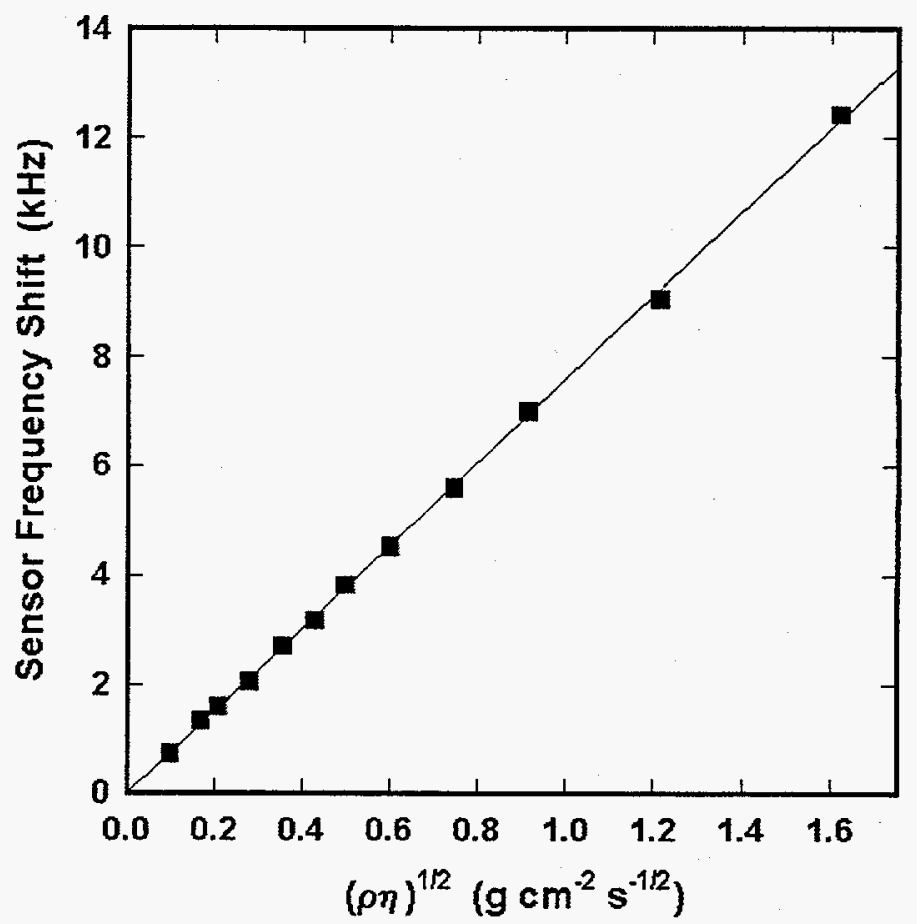

Fig. 2.7. The shift in resonator frequency as a function of increasing density-viscosity of the contacting fluid. For reference, the first point is the response for water. 
Mass layers or rigid particles in contact with the quartz surface decrease the crystal resonant frequency linearly in proportion to the accumulated mass [2]. (This "weighing" ability gives rise to the often-used terminology "quartz crystal microbalance" or QCM.) Because ideal mass layers dissipate no energy, no resonance damping is exhibited in the crystal response. This distinguishes mass loading from liquid loading and, using a Sandia-patented technique, allows for simultaneous measurement of both interactions [1,3]. In the case of fine solid particulates (average diameter $\leq 1 \mu \mathrm{m}$ ) suspended in a liquid, the resonator will respond to the average fluid viscosity and density integrated over the acoustic wave penetration depth - approximately $1.5 \mu \mathrm{m}$ for a fluid with $\rho=1.5 \mathrm{~g} / \mathrm{mL}$ and $\eta=50 \mathrm{cP}$ in contact with a $5-\mathrm{MHz}$ resonator. If the particles precipitate onto the quartz surface, the increased mass reduces the crystal response frequency. However, solid particulates of size much larger than the acoustic penetration depth or in high volume concentrations ( $230 \%)$ in slurries inhibit the resonator from correctly interrogating the average fluid properties. Resultant measurements lead to effective viscosity values lower than those for the homogenous fluid. In general, the quartz resonator can be used as a phase-change monitor or to extract some quantitative information about mixed-prase systems.

In the quartz resonator measurement techniques, changes in crystal resonant characteristics (frequency and damping) can be determined from the electrical admittance - conducted current divided by the driving voltage. This measurement requires scanning the frequencies near resonance using a network analyzer or similar instrument. A simpler, less expensive alternative uses an oscillator circuit to operate the sensor near its resonant frequency. To accommodate the increased crystal damping produced by viscous fluids, a special "lever" oscillator circuit, Fig. 2.8, was designed and patented [4]. The oscillator circuit is unique in that it maintains the resonator impedance phase near zero, provides an automatic level control over a wide viscosity dynamic range, and has a voltage output signal that is directly proportional to $(\rho \eta)^{1 / 2}$. 


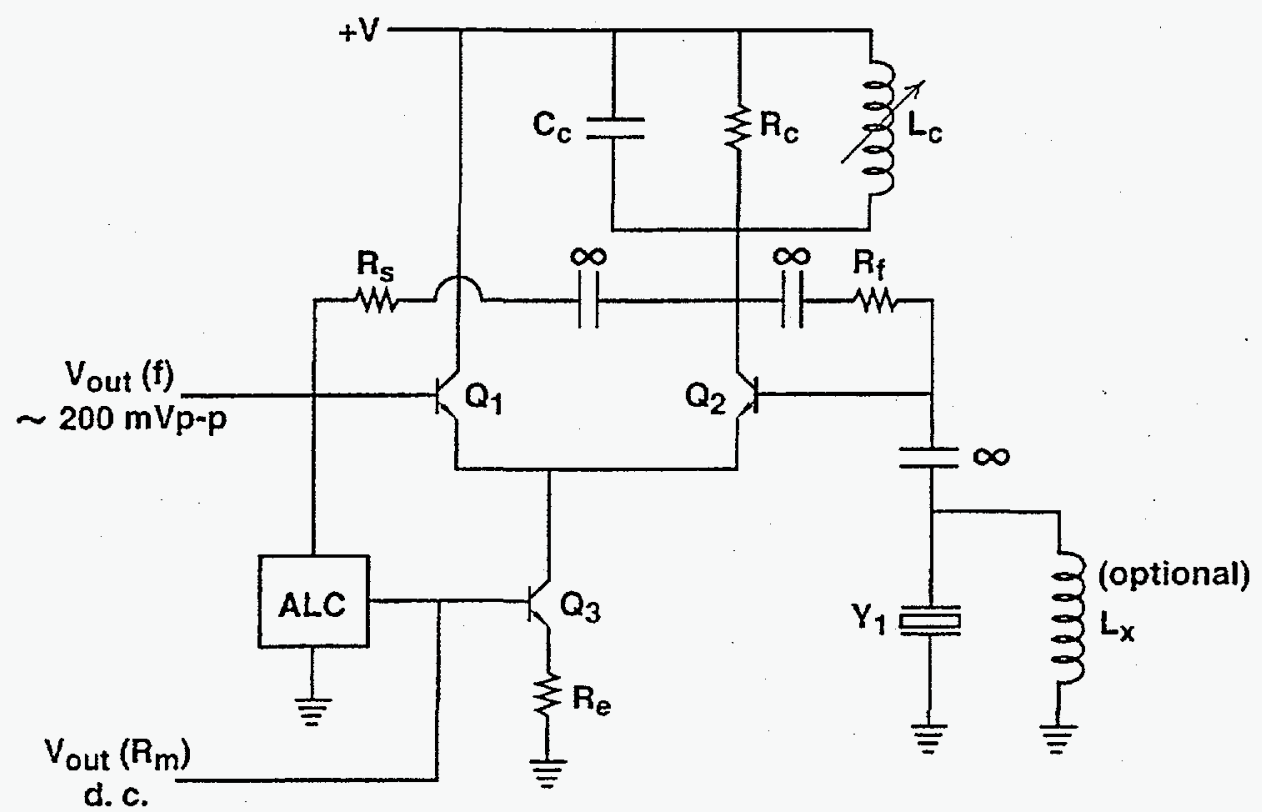

Fig. 2.8. Schematic of the lever oscillator designed to operate the quartz resonator in liquid media.

\subsubsection{Prototype Test System}

The prototype unit consists of two stainless steel sensor probe heads, each containing a single smooth-surface 5-MHz quartz resonator, a "lever" oscillator circuit, a thermistor temperature probe embedded in the metal housing, and a Sandia-developed RADFET monitor [5]. Approximately 20 to $25 \mathrm{ft}$ of shielded cable connects the two probes to the interface module containing power supplies, RADFET and temperature probe support electronics, and the data acquisition board - a microprocessor-controlled unit with two $10-\mathrm{MHz}$ frequency counters, eight channels of 16-bit A/D voltage measurement, and an RS-232 serial communications port. A notebook computer interacting with the interface module via the serial port completes the prototype assembly. Control, data acquisition (sensor frequency, sensor damping voltage, temperature, and RADFET voltage drop), information storage, and real-time graphical display are accomplished using an HPVEE software code. The sensor system is calibrated in the laboratory using viscosity/density 
standards, and individual calibration coefficients are generated for each sensor probe. No additional on-site calibration is required.

During operation, all sensor parameters are acquired, stored and displayed in real time at predesignated intervals ( $30 \mathrm{~s}$ to $2 \mathrm{~min}$ are typical). Quartz resonator frequency shift, oscillator damping voltage, and computed density-viscosity for each of the two sensors are plotted in strip-chart fashion. All other parameters are simply updated in separate panels on the computer display.

The stainless steel probe housings protect the remote sensors from the harsh, chemical environment. Thus, the sensor "probe" constitutes a fully submersible, in situ or in-line monitor. Housings are 2 in. in diameter (dictated primarily by the 1 -in.-diam quartz crystals) and 1.5 in. in height. Probes can be constructed in several different configurations; the two implementations in this prototype assembly are (1) mounting the structure in the perpendicular branch of a 2-in. pipe tee until the resonator surface is approximately flush with the straight-through slurry flow, and (2) attaching a stainless steel wand directly to the housing so the senscr head can be submersed in the slurry tank.

The interface electronics module remains external to the liquid environment. The remote electronic systems can drive long cable lengths, allowing for separations greater than $20 \mathrm{ft}$ if necessary. The operating temperature range for the lever oscillator board and other components in the sensor probes exceeds $100^{\circ} \mathrm{C}$, sufficient for all projected tank environments. Components in the sensor probes also have been gamma-irradiation tested; they will survive doses greater than $200 \mathrm{krad}$.

\subsubsection{Estimated Costs for Sandia National Laboratories' Density-Viscosity Slurry Monitoring System (assuming production-like fabrication)}

The cost of the quartz resonator probes and associated equipment is listed in Table 2.5. Information about life expectancy the replacement rates of the instrument is shown in Table 2.6. 
Table 2.5. Estimated costs for Sandia National Laboratories' Density-Viscosity Slurry Monitoring System (assuming production-like fabrication)

\begin{tabular}{|c|c|c|c|}
\hline Quantity & Component description & $\begin{array}{l}\text { Unit cost } \\
\qquad(\$)\end{array}$ & $\begin{array}{l}\text { Extended cost } \\
\qquad(\$)\end{array}$ \\
\hline \multirow[t]{3}{*}{2} & $\begin{array}{l}\text { Standard configuration sensor probe heads with } \\
\text { quartz resonator, lever oscillator circuit, temperature } \\
\text { sensor, RADFET sensor, and misc. electronics in } \\
\text { stainless steel housing with connecting shielded } \\
\text { cable }\end{array}$ & 200 & 400 \\
\hline & $\begin{array}{l}\text { Add: probe head configured as minimum in-line } \\
\text { flow sensor }\end{array}$ & 100 & 100 \\
\hline & $\begin{array}{l}\text { Option: probe head configured inside special in-line } \\
\text { fixture or spool piece (add cost instead of above } \\
\text { item) }\end{array}$ & 1500 & \\
\hline 1 & $\begin{array}{l}\text { Interface electronic module (IEM), wall plug } \\
\text { compatible, RS } 232 \text { interface }\end{array}$ & 250 & 250 \\
\hline 1 & $\begin{array}{l}\text { Operations and control software; HPVee executable } \\
\text { code running under Windows } 95\end{array}$ & 200 & 200 \\
\hline \multirow[t]{7}{*}{2} & $\begin{array}{l}\text { Temperature and fluid calibration services, required } \\
\text { for each individual probe }\end{array}$ & 100 & 200 \\
\hline & $\begin{array}{l}\text { Total for standard configuration components with } \\
\text { two calibrated sensor probes: one for submersion in } \\
\text { tank, one for in-line operation; IEM; and software, } \\
\text { with no computer (minimum possible configuration) }\end{array}$ & & 1150 \\
\hline & $\begin{array}{l}\text { Total for premium configuration components with } \\
\text { two calibrated sensor probes: one for submersion in } \\
\text { tank, one for in-line operation with special fixture; } \\
\text { IEM; and software, no computer }\end{array}$ & & 2550 \\
\hline & $\begin{array}{l}\text { Total for configuration with one calibrated tank } \\
\text { sensor probe; IEM; and software, no computer }\end{array}$ & & 750 \\
\hline & $\begin{array}{l}\text { Total for minimum configuration with one } \\
\text { calibrated in-line sensor probe; IEM; and software, } \\
\text { no computer }\end{array}$ & & 850 \\
\hline & $\begin{array}{l}\text { Total for premium configuration with one calibrated } \\
\text { in-line sensor probe in special fixture; IEM; and } \\
\text { software, no computer }\end{array}$ & & 2250 \\
\hline & $\begin{array}{l}\text { Note: Estimated costs for modifying IEM and } \\
\text { software to accommodate additional sensor probes } \\
\text { without changing remaining configuration }\end{array}$ & $100 /$ probe & \\
\hline 1 & $\begin{array}{l}\text { Notebook (laptop) computer, minimally configured } \\
\text { to run software, store data, and display plots }\end{array}$ & 1000 & 1000 \\
\hline
\end{tabular}


Table 2.5 (cont.)

\begin{tabular}{|c|c|c|c|}
\hline Quantity & Component description & $\begin{array}{l}\text { Unit cost } \\
\text { (\$) }\end{array}$ & $\begin{array}{l}\text { Extended cost } \\
\qquad(\$)\end{array}$ \\
\hline & Option: PCMCIA network card for notebook & 400 & \\
\hline & $\begin{array}{l}\text { Option: Notebook computer with features as used in } \\
\text { field trials (Pentium processor, color monitor, etc.) }\end{array}$ & 3000 & \\
\hline & $\begin{array}{l}\text { Best estimate of minimally configured system with } \\
\text { two calibrated probes (one tank, one in-line) plus } \\
\text { computer }\end{array}$ & & 2150 \\
\hline & $\begin{array}{l}\text { Maximum costs for system with two probes, one a } \\
\text { special in-line sensor configuration, and a notebook } \\
\text { computer, with network card, as used in the field trials }\end{array}$ & & 5950 \\
\hline & $\begin{array}{l}\text { Best estimate of minimally configured system with } \\
\text { one calibrated tank probe plus computer }\end{array}$ & & 1750 \\
\hline & $\begin{array}{l}\text { Best estimate of minimally configured system with } \\
\text { one calibrated in-line probe plus compurer }\end{array}$ & & 1850 \\
\hline & $\begin{array}{l}\text { Premium configured system with one calibrated tank } \\
\text { probe, enhanced computer with network card }\end{array}$ & & 4150 \\
\hline & $\begin{array}{l}\text { Premium configured system with one calibrated in- } \\
\text { line probe in special fixture, enhanced computer with } \\
\text { network card }\end{array}$ & & 5650 \\
\hline
\end{tabular}

Table 2.6. Estimated life expectancy and replacement rates for Sandia National Laboratories' Density-Viscosity slurry monitoring system

\begin{tabular}{|c|c|}
\hline Component & Life expectancy \\
\hline \multicolumn{2}{|l|}{ Nonradiation environment } \\
\hline Sensor probes & $\begin{array}{l}\text { Approx. } 12 \text { to } 18 \text { months, until surface wear } \\
\text { changes sensor calibration }\end{array}$ \\
\hline Interface electronic module & Minimum 5 years \\
\hline Computer & $\begin{array}{l}\text { Approx. } 3 \text { years, based on need to upgrade } \\
\text { components or software to remain compatible } \\
\text { with industry support }\end{array}$ \\
\hline \multicolumn{2}{|c|}{ Radiation environment (based on $100 \mathrm{rad} / \mathrm{h}$ ) } \\
\hline Sensor probes & Approx. $2000 \mathrm{~h}$ following continuous exposure \\
\hline
\end{tabular}




\section{References for Section 2.2.2}

[1] S. J. Martin, V. E. Granstaff, and G. C. Frye, "Characterization of a Quartz Crystal Microbalance with Simultaneous Mass and Liquid Loading," Anal. Chem. 63, pp. 2272-2281 (1991).

[2] G. Sauerbrey, "Verwendung von Schwingquarzen zur Wägung dünner Schichten and zur Mikrowägung," Z. Phys. 155, pp. 206-222 (1959).

[3] V. E. Granstaff and S. J. Martin, "Method for Simultaneous Measurement of Mass Loading and Fluid Property Changes Using a Quartz Crystal Microbalance," U.S. Patent \# 5,210,215 (1993).

[4] K. O. Wessendorf, "The Lever Oscillator for Use in High Resistance Resonator Applications," Proc. IEEE Intl. Frequency Control Symp., pp. 711-717 (1993). K. O. Wessendorf, "Oscillator Circuit for High-Loss Quartz Resonator Sensors," U.S. Patent \# 5,416,448 (1995).

[5] J. R. Schwank, S. B. Roeske, D. E. Beutler, D. J. Moreno, and M. R. Shaneyfelt, "A Dose Rate Independent pMOS Dosimeter for Space Applications," Trans. Nuclear Science (1996).

\subsubsection{Argonne Ultrasonic Flow Instrument}

Sources: S. H. Sheen, H. T. Chien, and A. C. Raptis, "Ultrasonic Methods for Measuring Liquid Viscosity and Volume Percent of Solids." Additional input by direct communication from $S$. H. Sheen.

\subsubsection{Technology Description}

Argonne National Laboratory's (ANL) ultrasonic viscometer is a nonintrusive in-line device that measures both fluid density and viscosity. The principle of the viscometer is based on acoustic- and shear-impedance measurements, a technique first applied by Moore and McSkimin [1] to measure dynamic shear properties of solvents and polystyrene solutions. Incident ultrasonic shear $(1-10 \mathrm{MHz})$ and longitudinal waves $(1 \mathrm{MHz})$ are launched to two wedge surfaces that are in contact with the fluid, and their reflections are measured. The reflection coefficients, along with sound speed in the fluid, are used to calculate fluid density and viscosity. Oblique incidence was commonly used because of better sensitivity, but mode-converted waves often occur in wedges that are 
not of perfect crystal structure and lack well-polished surfaces. For practical applications, we use the normal-incidence arrangement.

The basic design, as shown in Fig. 2.9, consists of two transducer wedges mounted on a pipe opposite one another and flush with the inner surface of the pipe. The wedge uses an offset surface to provide the reference reflection that is compared with the reflection from the sensing surface to give the reflection coefficient measurement. In effect, the offset surface provides a continuous reference signal for self-calibration. Two types of transducer, shear (SH) and longitudinal, are used; both operate under the pulseecho mode. Three major reflections are detected for longitudinal-wave operation, corresponding to reflections from the offset surface, the sensing surface that is in contact with the fluid, and the pipe wall on the opposite side. The amplitude ratio of the first two reflections produces a measure of reflection crefficient, while the time-of-flight between the second and the third reflections deduces the phase velocity of the longitudinal wave in the fluid. Thus, longitudinal-wave operation gives a direct measure of fluid density. Shear-wave operation detects only two reflections because most fluids do not support shear waves. The amplitude ratio of the two reflections calculates the reflection coefficient from which the density-viscosity product is deduced.

The longitudinal-wave reflectance method is used to measure fluid density. Note that variation in phase velocity of the standard liquids does not correlate with their density change; thus, phase velocity alone cannot be used to predict liquid density. However, by combining phase velocity and acoustic impedance measurements, we can obtain an accurate measurement of liquid density.

The ANL instrument is also facilitated with capability of measuring solid concentration. The principle of measuring solid concentration is based on correlations between solid concentration and sound velocity, attenuation, and scattering amplitude. Phenomenological models have shown that solund velocity varies with solid concentration but the correlation depends on acoustic properties of the suspended solids. Sound attenuation measurement has been used for predicting solid concentration of a solid 


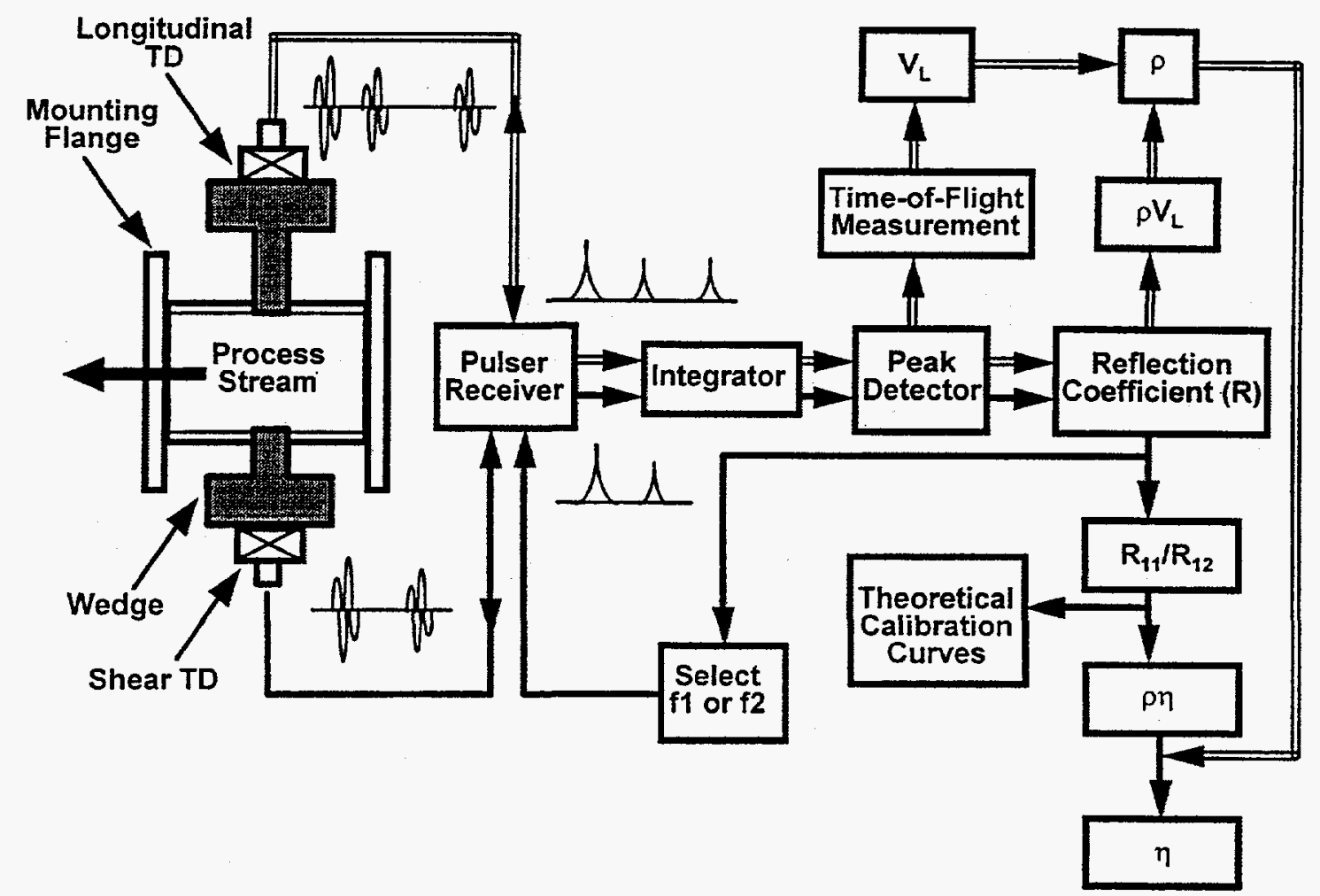

Fig. 2.9. Experimental configuration and setup for viscometer.

suspended flow. Linear relationship can be obtained for dilute solid/liquid flows. For high solid concentrations, backscattering measurement may be applied. The ANL spool piece has the design that provides the three measurements. An additional longitudinal transducer is included in the spool piece design on the opposite side of the pipe to the shear-wave transducer. This transducer allows one to measure scattering amplitudes from which solid concentration is estimated.

\subsubsection{ANL Ultrasonic Flow Instrument Cost Estimate}

The cost of the ANL ultrasonic flow instrument and associated equipment is listed in Table 2.7. ANL estimates that the instrument will have a life expectancy $>10$ years 
(without changing the wedge) as long as the transducer wedge surface remains intact (minimal erosion damage).

Table 2.7. Cost estimate for the A.NL ultrasonic flow instrument

\begin{tabular}{lcccc}
\hline \multicolumn{1}{c}{ Component } & Manufacturer & $\begin{array}{c}\text { Unit cost } \\
(\$)\end{array}$ & $\begin{array}{c}\text { Number of } \\
\text { units }\end{array}$ & $\begin{array}{c}\text { Extended cost } \\
(\$)\end{array}$ \\
\hline $\begin{array}{l}\text { 5-MHz Shear-wave } \\
\text { transducer }\end{array}$ & Panametrics & 532 & 1 & 532 \\
$\begin{array}{l}\text { 1-MHz Longitudinal } \\
\text { transducer }\end{array}$ & Panametrics & 259 & 2 & 518 \\
$\begin{array}{l}\text { Control electronics } \\
\text { Fabrication of sensor }\end{array}$ & ANL & 400 & 1 & 400 \\
$\begin{array}{l}\text { assembly } \\
\text { PC Computer/monitor }\end{array}$ & ANL & 400 & 1 & 400 \\
Data acquisition board & National & 1,500 & 1 & 1,500 \\
& Instrument & 510 & 1 & 510 \\
Total & & & & $\mathbf{3 , 8 6 0}$ \\
\hline
\end{tabular}

\section{Reference for Section 2.2 .3}

[1] R. S. Moore and H. J. McSkimin, "Dynamic Shear Properties of Solvents and Polystyrene Solutions from 20 to $300 \mathrm{MHz}$," Physical Acoustics, Vol. VI, pp. 167-242, 1970.

\subsubsection{PNNL Particle Size Instrument}

\section{Source: J. A. Bamberger, Pacific Northwest National Laboratory}

\subsubsection{Theory of Instrument Operation}

The sensor uses acoustic attenuation spectra taken over a range of frequencies to infer mean particle size, a measure of the width of the particle size distribution as well as concentration. These parameters have a unique solution. 
The attenuation of ultrasound in a suspension is influenced by numerous interactions between ultrasound and the physical and rheological properties of the slurry. For slurries consisting of solids in a liquid such as fine sand in water, there are three principal regimes that define these characteristics:

- viscous regime (thick boundary layers)

- inertial regime (thin boundary layers)

- Rayleigh scattering regime (dilation and contraction of particles).

In the viscous regime the relative motion between the particles and the fluid is governed by Stokes drag. This corresponds to the situation where the viscous boundary layer thickness is larger than the particle radius. The inertial regime sets in as the frequency is increased such that the viscous boundary layer becomes thinner than the particle radius. In this regime, losses occur in the thin boundary layer surrounding the particles. Elsewhere the fluid behaves in an inviscid manner. At sufficiently high frequencies, Rayleigh scattering sets in. It causes energy from the coherent incident sound to be scattered by the random distribution of particles, thereby attenuating the coherent wave. The scattered wave is caused by the difference in acoustic impedance between the liquid and the solid, and, in the long wavelength limit, it is spherical.

For a fixed particle size, the transition between each of these regimes occurs at a frequency that is defined by the particle size and the mechanical properties of the solid and the fluid. Figure 2.10 shows a typical plot of the attenuation in a $10 \%$ suspension of $6-\mu \mathrm{m}$ silica particles in water. This plot reveals the three regimes of attenuation. The viscous regime exhibits a quadratic scaling with frequency; the inertial regime scales with $1 / 2$ power of frequency, while the Rayleigh scattering regime scales with $f^{4}$. Each regime exhibits a constant slope on this log-log plot. The first transition from the viscous to the inertial regime is gradual, and occurs over 2 decades or more, while Rayleigh scattering sets in over a narrower range in frequency. 


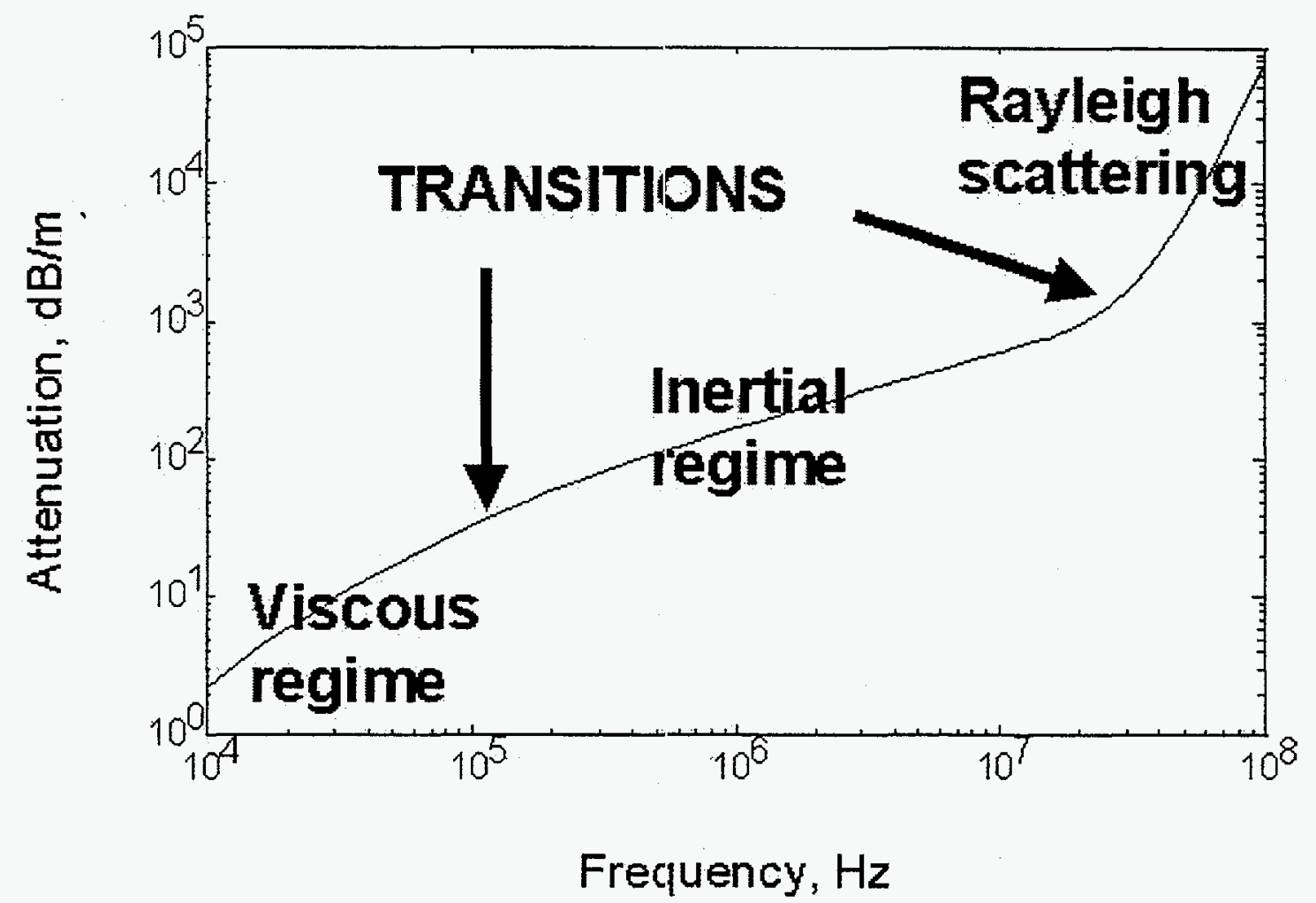

Fig. 2.10. Attenuation of a $10 \mathrm{vol} \%$ suspension of 6 - $\mu \mathrm{m}$-diam particles.

The frequency, or range of frequencies, over which transition occurs is strongly dependent upon particle size. For larger particles, the transitions will tend to occur at lower frequencies, and conversely at higher frequencies for smaller particles. The present instrument and approach make use of this dependence to determine particle size information. To this end, not only is it necessary to have a good understanding of the dependence of attenuation on frequency for each of the regimes, but also to understand the nature of the transitions, where all information about particle size is found.

\subsubsection{Advantage/Disadvantage}

The sensor configured as an immersion probe or a pipeline probe has several advantages as discussed below. 
On-line, in situ: This method does not sample the medium to make the measurement; it is made in situ. This avoid time delays and particle segregation within a sample as well as segregation due to the choice of the sampling location.

Noninvasive: In its ultimate configuration this method is noninvasive. In a pipeline application, the instrument does not need to come in contact with the slurry; the ultrasonic sensors can be encased in the spool piece. This ensures instrument longevity as it does not have to be subjected to the erosive and adverse environment of a flowing slurry. It also provides no disruption to the flow. In the ORNL test, the sensor was submerged in the mixing tank.

Continuously updated: The measurement is made continuously and provides a continuous update to the operator or the process automated controller. The instrument is ideally suited to process control applications that require continuous process data. Ability to recognize large particles: This method accommodates both small particles below $1 \mu \mathrm{m}$ and large particles up to more than $1 \mathrm{~mm}$. The instrument is particularly well suited to recognize large particles. Large particles cause early transition into the Rayleigh scattering regime, and the instrument will easily recognize this transition.

Attenuation data were obtained for three particle types: Potters, Minusil, and kaolin clay. Each of these particle types requires distinct calibration constants. The transition between regimes is based on the particle size and width of the size distribution. One transition regime may be dominant, based on the character and slope of the attenuation curve. The tests with Minusil emphasize the inertial regime; those with Potters show the transition to Rayleigh scattering. These size distributions can be represented by a log-normal size distribution.

Comparisons between the sensor calculated and independently measured mean diameters and solids fraction for the Potters and Minusil particles are compiled in Table 2.8. The agreement between the ultrasonic probe measurements and the independently measured values for both the Potters and the Minusil is very good. 
Table 2.8. Comparison of sensor calculated and independently measured mean diameter and solid fraction

\begin{tabular}{lccrccc}
\hline & \multicolumn{2}{c}{ Solid fraction $(\%)$} & & \multicolumn{2}{c}{ Mean diameter $(\mu \mathrm{m})$} \\
\cline { 2 - 3 } \cline { 5 - 6 } & \multicolumn{2}{c}{ Actual } & Calculated & & Actual & \multicolumn{2}{c}{ Calculated } \\
\hline \multirow{2}{*}{ Potters } & 10 & 11.5 & & 19.95 & 20.0 \\
Minusil & 5.5 & 5.0 & & 5.67 & 4.95 \\
\hline
\end{tabular}

${ }^{a}$ Volume average.

The attenuation spectra for the kaolin and kaolin/sand mixtures show similar trends (see Figs. 2.11 and 2.12), indicating the ability to determine mean particle size and concentration based on calibration constant selection.

Robust approach: The instrument and the algorithm were designed to be robust and to meet the needs of the processing environment. The algorithm has built-in redundancies. For example, it uses two regime transitions rather than one for particle sizing. It minimizes the amount of needed information by assuming a reasonable shape for the size distribution. In this manner, the instrument determines mean particle size, width of the distribution and solids fraction simultaneously and with high confidence.

Robust concentration measurement: The concentration measurement is not dependent on the size distribution. Thus, the concentration of any slurry of known material properties can be monitored with no prior knowledge of size distribution.

Mechanical simplicity: The working end of the instrument consists of ultrasonic transducers. These are inherently simple with no moving parts and can withstand the harshest of environments. These also lend thernselves to radiation hardening.

The ultrasonic transducer pairs have center frequencies of $0.5,1.0,2.25,5.0,7.5$, and $10 \mathrm{MHz}$. The sensor, configured as an immersion probe, is shown in Fig. 2.13. A pipeline spool-piece configuration has also been envisioned. In the immersion configuration, the $0.5-$ through $5.0-\mathrm{MHz}$ transducer pairs are separated by $10.2 \mathrm{~cm}$ and the $7.5-\mathrm{MHz}$ and $10-\mathrm{MHz}$ transducer pairs are separated by $5.1 \mathrm{~cm}$. A toneburst 


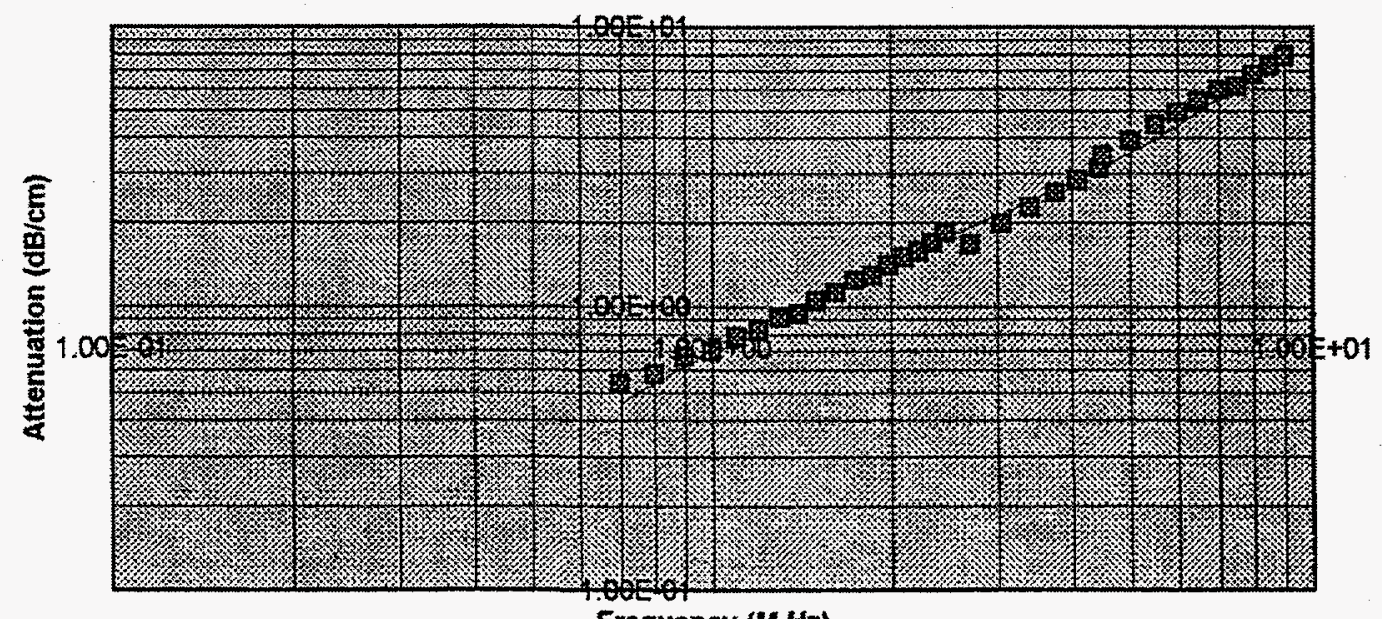

Frequency ( $\mathrm{M} \mathrm{Hz}$ )

Fig. 2.11. Attenuation spectrum for $\mathbf{2 0 \%}$ kaolin by weight in a $\mathbf{5 0} \%$ sugar water solution, density $=1.354 \mathrm{~g} / \mathrm{mL}$.

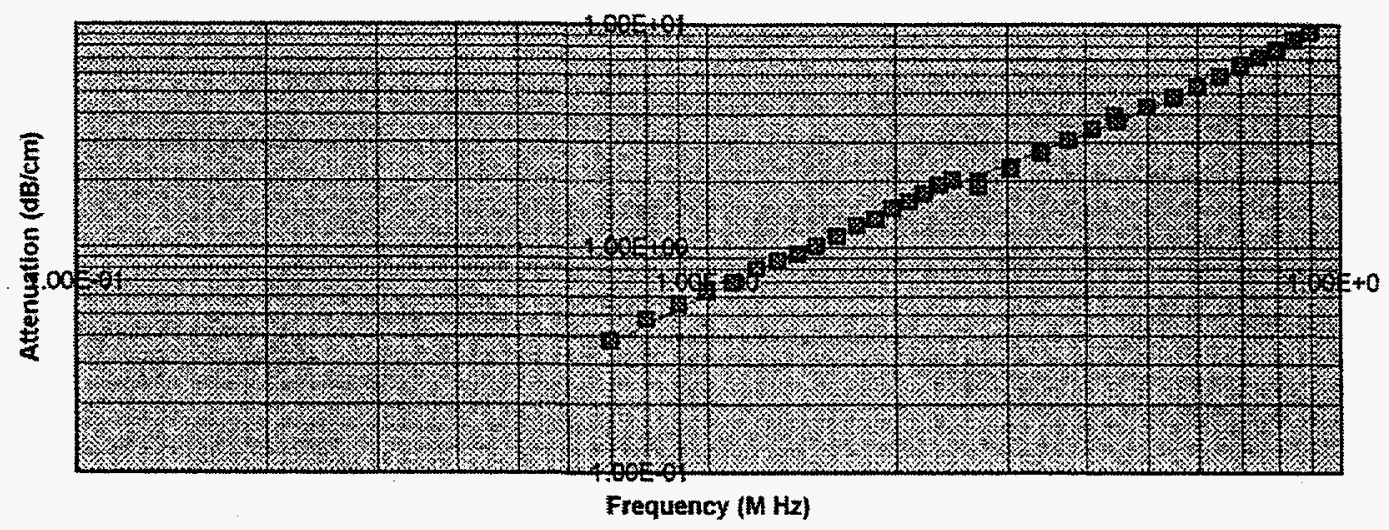

Fig. 2.12. Attenuation spectrum for $7.5 \%$ kaolin by weight and $2.5 \%$ sand by weight in a $50 \%$ sugar water solution, density $=1.348 \mathrm{~g} / \mathrm{mL}$. 


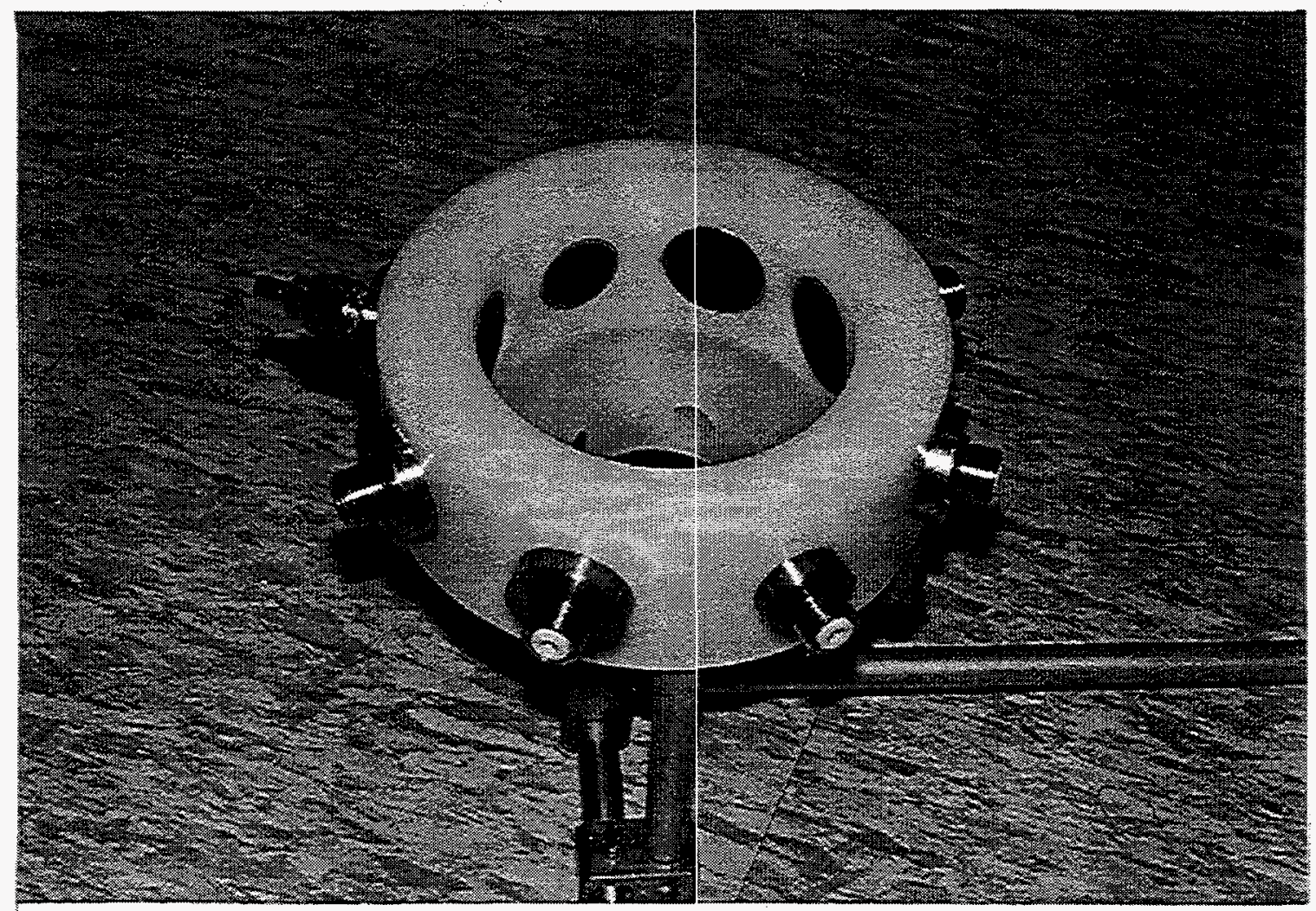

Fig. 2.13. Ultrasonic immersion probe.

generator supplies the signal to the "send" transducer. The attenuated signal from the "receive" transducer is digitized. The signal from the digitizer is analyzed on a personal computer using Pacific Northwest National Laboratory custom-designed software to control data acquisition, calculation of the attenuation, and particle-size analysis.

Disadvantages: The presence of bubbles and nonhomogeneous solids suspension will affect instrument performance.

\subsubsection{Capital Cost Estimate and Life Expectancy for the Particle-Size Probe}

The particle-size probe includes the transducer array in its spool piece and the computer and electronics associated with sensor operation. The probe includes the six 
transmitter receiver pairs of transducers mounted in either a pipeline or immersion configuration for the spool piece. The computer control system includes the rugged computer with integral toneburst, multiplexer, and digitizer functions.

The spool piece configured for pipeline or immersion application is projected to have a life expectance of 2 to 4 years. The computer-based electronics is projected to have a life expectancy of 10 years or more.

The transducer array and spool piece are expected to have an off-the-shelf cost of $\$ 6 \mathrm{~K}$. The computer-based controller is projected to have an off-the-shelf cost of $\$ 18 \mathrm{~K}$.

\subsubsection{ORNL Gamma Densitometer}

Source: J. A. Chapman and L. D. Weems, "Real-Time Slurry Density Measurements by Gamma-Ray Densitometry," Oak Ridge National Laboratory

\subsubsection{Principle}

Gamma-ray densitometry is the measurement of material density by determining the degree to which that material attenuates electromagnetic radiation (photons) of a known and controlled energy. Four important points characterize this measurement technique:

1. Element and compound specific: Photon interaction probabilities, upon which the measurement is based, are dependent on atomic number. Gamma-ray energy can be selected to optimize system response for specific conditions.

2. Bulk density and composition measurement: This information is possible, provided the calibration envelope has been sufficiently extended to mimic the real "unknown" case.

3. Nondestructive and nonintrusive instrumentation: There are no physical penetrations into the vessel, pipe, or material of interest; all instrumentation is completely external.

4. Time dependent changes in density: These changes can be resolved well within a 1-minute transient and can be optimized for specific conditions. 
Neglecting time and energy-dependent effects for the time being, gamma-ray densitometry is based on the exponential absorption relationship of nonparticle, ionizing radiation (Beer's Law):

where

$$
I=I_{0} e^{-\mu \rho x},
$$

$I=$ transmitted intensity of 'uncollided,' energy-specific photon radiation, through both the vessel and material of interest (photons $\mathrm{s}^{-1}$ ),

$I_{0}=$ initial intensity of 'uncollided,' energy-specific photon radiation, through the vessel only (photons $\mathrm{s}^{-1}$ ),

$\mu=$ mass attenuation coefficient of material for energy-specific photon $\left(\mathrm{cm}^{2} \mathrm{~g}^{-1}\right)$,

$\rho=$ mass density of material $\left(\mathrm{g} \mathrm{mL}^{-1}\right)$,

$\mathrm{x}=$ thickness of material $(\mathrm{cm})$.

The degree to which material attenuates electromagnetic radiation of a specific energy is based on the ratio of uncollided flux for the case when the material of interest is present and when it is absent:

$$
\mathrm{T}=\frac{\mathrm{I}}{\mathrm{I}_{0}}=\mathrm{e}^{-\mu \rho \mathrm{x}},
$$

where

$\mathrm{T}=$ material transmission fraction.

From the material transmission measurement, a linear, empirical relationship between the density of the material and the measured material transmission can be established. This relationship allows a direct, real-time material density measurement. There are a wide variety of photon detectors that will enable the energy-dependent effects to be treated explicitly. A number of algorithms may be applied to the raw data to optimize the instrument transient response time. 


\subsubsection{Design}

The gamma-ray densitometer, which was used for the evaluation, used a $2-\mu \mathrm{Ci}{ }^{137} \mathrm{Cs}$ emission source and a $\mathrm{Nal}$ detector with associated electronics to isolate and accommodate energy-dependent effects. As illustrated in Fig. 2.14, the test pipe was juxtaposed between the emission source and the detector. A lead collimator assembly was designed and fabricated to optimize instrument response in the uncollided gammaray energy region at $662 \mathrm{keV}$.

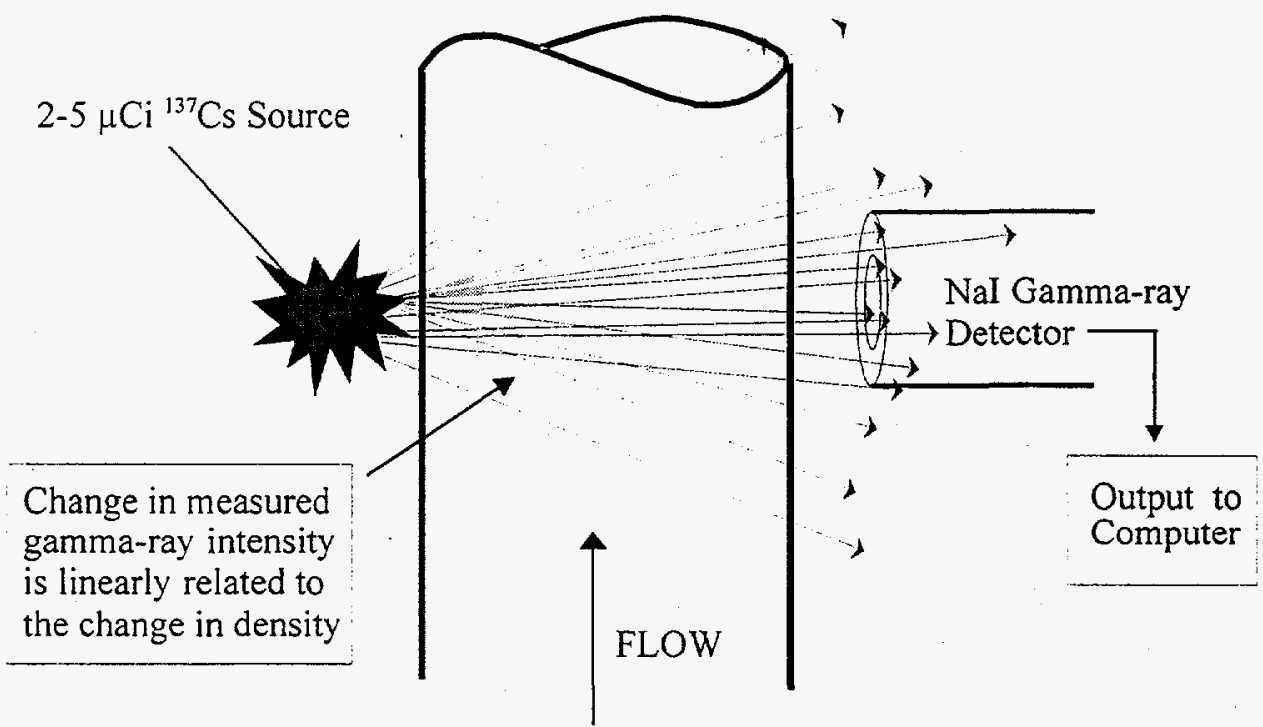

Fig. 2.14. Illustration of the gamma-ray densitometer designed and implemented in the test loop.

\subsubsection{Data Handling}

The output of the detector was fed to a shaping amplifier and then to an analog-todigital converter for digitization of the pulse train for viewing on an APTEC multichannel analyzer. A background-corrected region of interest was established for the integration of detected events for $\mathrm{I}_{0}$ (the gamma-ray intensity for the pipe alone) and for I (the gammaray intensity when both the pipe and material are present). 


\subsubsection{Features}

The gamma-ray densitometer is a viable solution to measuring material density. The major features are that

(1) it connects to the exterior of a pipe;

(2) there is no interference with pipe integrity;

(3) there are no sensors in contact with the slurry;

(4) it can detect changes in density easily within minutes but can be optimized to be much more time responsive;

(5) it is easily sensitive to $10 \%$ changes in density (at 2 sigma);

(6) it is reliable and robust gamma-ray spectrometry measurement;

(7) it is simple to set up and easy to run; maintenance is minimum, and all control features can be completely automatec; and

(8) in materials that are inherently radioactive, the system can be adjusted to measure the amount of radioactive material present at the same time the density is measured; this feature, of course, takes additional development and the construction of a multidetector array.

\subsubsection{Complications, Limitations, and Future Development Opportunities}

Gamma-ray densitometers require the use of radioactive material that emits electromagnetic radiation. For most DOE installations where this device would actually be implemented, this is not an issue. However, in the case of the test loop, significant restrictions were imposed by limiting the amount of radioactive material to an exempt quantity. This limitation increased statistical variation, increased the nominal acquisition interval, and excluded us from trying more exotic emission sources that would enable us to explore more advanced processing using multienergy spectrometry.

The test-loop protocol did not explore the vulnerabilities of gamma-ray densitometry. For example, the tests were not performed under extreme environmental conditions, they did not involve the presence of radioactive material in the slurry material itself, and they were not designed to evaluate instrument response time following transients. Depending on the specific application, there are solutions to these complications which we have at least thought about: gamma-gamma coincidence 
counting, neutron-gamma coincidence counting, various gamma-ray energy-dependent schemes using different detectors, and construction of a multidetector array for subtraction of background from signal. Additionally, there are a number of numerical - schemes widely used in the electronics industry to optimize the instrument response time to transients. The reason for participating in the 'cold' test loop was to not only

demonstrate the effectiveness of gamma-ray densitometry, from a simple straightforward sense, but also to conceptually think about advanced research and development activities that would enable their use in much more difficult environments, such as those that exist on the Hanford reservation.

\subsubsection{Capital Cost and Life Expectancy}

As implemented, the capital cost of the gamma densitometer was about $\$ 10 \mathrm{~K}$. This included the detector, collimator, radioactive source, detector electronics, data acquisition card, and personal computer. The system is expected to operate for 10 years and require approximately $\$ 1 \mathrm{~K}$ per year for maintenance.

It should be emphasized that the costs as indicated above are for the densitometer as implemented for the testing with nonradioactive slurries. Depending on the complexity, the capital cost is expected not to increase more than $\$ 20$ to $\$ 30 \mathrm{~K}$ when the instrument is adapted for use with radioactive slurries.

\subsubsection{Endress + Hauser Coriolis Meters}

The Promass 63 (henceforth referred to as the Promass) and m-Point Coriolis meters are manufactured by Endress + Hauser. These meters work on the same principle (described below). Some key differences between the Promass and the $\mathrm{m}$-Point include (1) the Promass unit has a driver on each tube, whereas the m-Point has a driver on one tube; and (2) the Promass uses a magnetic pickup sensor to detect the vibrations in the tube; whereas the m-Point uses an optical sensor. According to a manufacturer representative, the driver on each tube allows the Promass to work with a higher volume of air in the flow stream. ${ }^{3}$ 


\subsubsection{Technology Description}

\section{Source: Promass 63 and m-Point Operating Manuals}

The measuring principle is based on the controlled generation of Coriolis forces. These forces are always present when both translational (straight-line) and angular (rotational) movement occur simultaneously (see Fig. 2.15):

where

$$
\overrightarrow{\mathrm{F}}_{\mathrm{C}}=2 \cdot \Delta \mathrm{m}(\vec{\omega} \times \overrightarrow{\mathrm{v}}),
$$

$\vec{F}_{\mathrm{C}}=$ Coriolis force,

$\Delta \mathrm{m}=$ mass of moving body,

$\vec{\omega}=$ angular velocity,

$\vec{v}=$ radial velocity in a rotating or oscillating system.

The amplitude of the Coriolis force depends on the moving mass, its velocity in the system, and therefore its mass flow.
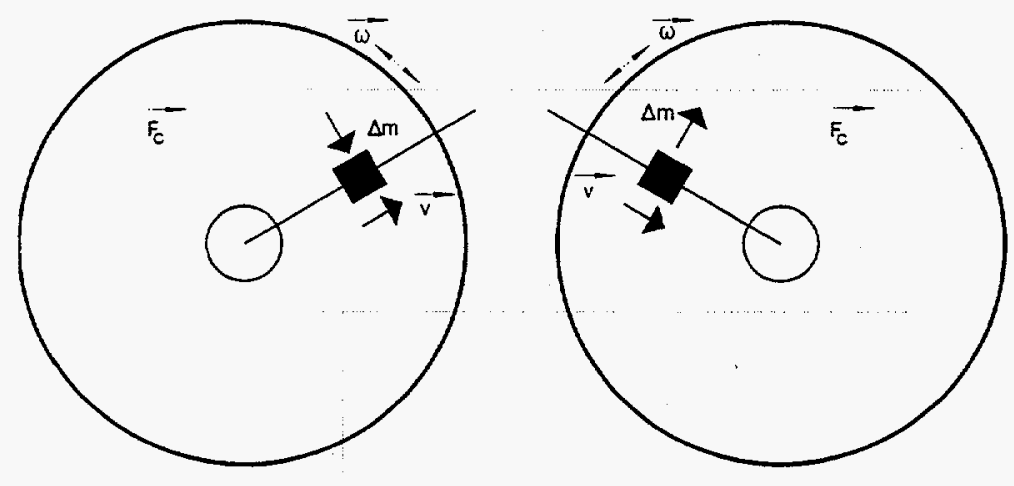

Schematic diagram of a me asuring pipe

Fig. 2.15. Coriolis forces in the measuring pipes.

The Promass and $\mathrm{m}$-Point Coriolis meters use an oscillation instead of a constant angular velocity, and two parallel measuring pipes, with liquid flowing through them, are 
made to oscillate in antiphase so that they act like a tuning fork. The measuring principle is illustrated in Fig. 2.16.

\subsubsection{Density Measurement}

The measuring pipes are always made to oscillate at their resonant frequency. This excitation frequency adjusts automatically as soon as the mass, and therefore the density, of the oscillating system changes (measuring pipes and medium). The resonant frequency is thus a function of the density of the medium and enables the microprocessor to produce a density signal.

\subsubsection{Temperature Measurement}

The temperature of the measuring pipes is determined and used to compensate for temperature effects. The signal produced is a function of the product temperature and can be used for external purposes.

\subsubsection{Estimated Cost and Life Expectancy}

The price of the Promass 63F Coriolis meter evaluated in the test was $\$ 9,460$ and includes the Coriolis meter with stainless steel tubes and a remote transmitter with $33 \mathrm{ft}$ of cable. The price also includes a special five-point calibration performed by the factory prior to shipping the unit to ORNL. If a standard flow and density calibration are desired, the purchase price could be reduced by $\$ 1,875$. The life expectancy of the meter will be dependent on the abrasiveness of the slurry, but it is estimated to be 3 to 5 years. 


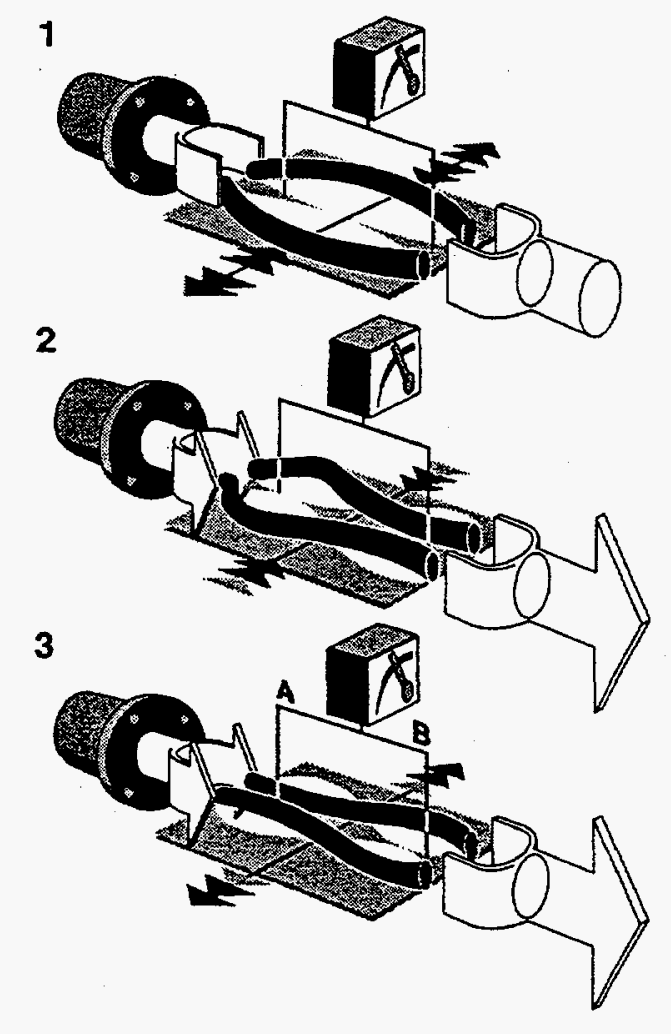

The Coriolis forces produced at the measuring pipes cause a phase shift in the pipe oscillation as illustrated at left:

a. When there is zero flow (i.e., with the fluid standing still), both pipes oscillate in phase (1).

b. When there is mass flow, the pipe oscillation is decelerated at the inlet (2) and accelerated at the outlet (3).

As the mass flow rate increases, the phase difference also increases $(A-B)$. The oscillations of the measuring pipes are determined using sensors at the inlet and outlet. The operating principle is independent of temperature, pressure, viscosity, or flow profile.

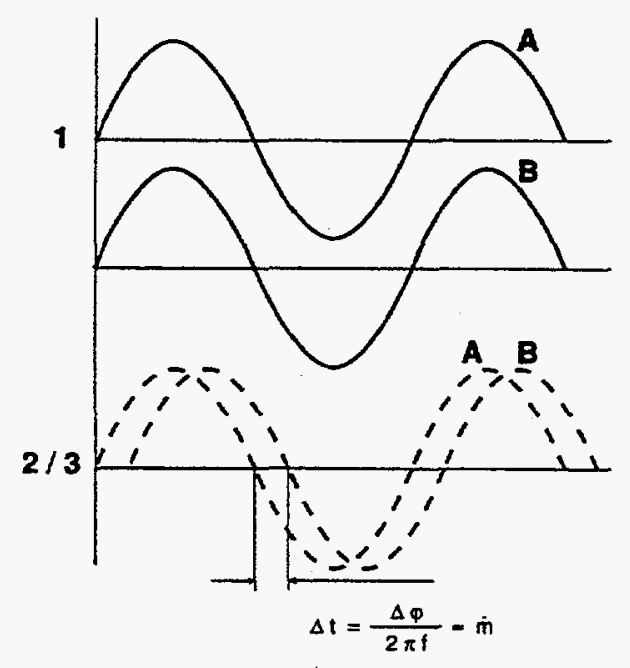

Fig. 2.16. Phase shift of pipe vibration with mass flow. 


\subsubsection{BTG SMS-3000}

\subsubsection{Technical Description}

\section{Source: SMS-3000 Solids Monitoring System Operations Manual (M240.20/1a-e)}

The BTG SMS-3000 Solids Monitoring System consists of the SMS-3000 electronics unit and up to four suspended solids sensors. The sensors are powered by and communicate with the SMS-3000 electronics unit through connecting cables. In an application, the sensors are immersed in the process to be measured, or inserted through a ball valve assembly into the process. Sensors provide the SMS-3000 electronics unit with raw "probe signal" value used in suspended solids measurement.

BTG 4-Beam ${ }^{\mathrm{Tm}}$ sensors are typically used to measure low to medium concentrations of dark suspended solids. All 4-Beam ${ }^{\mathrm{m}}$ sensors use the same measuring principle and share the same basic design. The design incorporates the use of two light-emitting diodes (LEDs) and two photodetectors mounted in the sensor body. The SMS-3000 turns the LEDs on and off alternately and measures the amount of light received by the photodetectors as illustrated in Fig. 2.17. The detector signals are processed and linearized to produce a signal value proportional to the suspended solids concentration in the process. Power and communication are provided by the SMS-3000 electronic unit through connecting cables.

1 Light emitting diodes

2 Photodetectors

3 Process medium

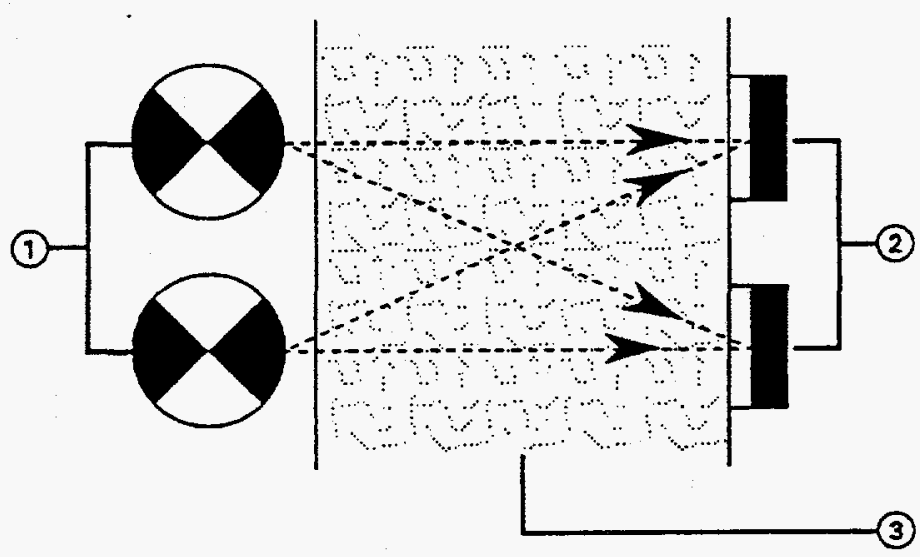

Fig. 2.17. 4-Beam ${ }^{\text {TM }}$ sensor design. 
The measuring range of a sensor type varies greatly, depending on the particle size and infrared absorption characteristics of the solids in the suspension. In municipal wastewater applications, such as activated sludge, 4-Beam ${ }^{\mathrm{Tm}}$ sensors typically measure below $1.5 \%$ solids by weight. For very light-colored materials, the maximum value of the range can be much higher. For example, an $\mathrm{RD}-10 / 5$ sensor may have a maximum range of $1.5 \%$ in municipal activated sludge but, in a lighter-colored medium (such as silica), it can measure concentrations as high as $90 \%$ solids by weight.

A variety of sensors are available. The kind of sensor you need depends on the following factors:

- the range of solids to be measured;

- certain process conditions, such as temperature, corrosiveness, and sanitary requirements; and

- whether measurement will be conducted in a pipeline, or in an open tank, vessel, or channel.

\subsubsection{Estimated Capital Cost and Life Expectancy}

As previously discussed, BTG sold the production rights of the SMS-3000 system to Zellweger Analytics, Inc. The following list gives the total cost of the BTG SMS-3000 system when purchased in 1993.

$\begin{array}{lr}\text { Monitoring system } & \$ 10,000 \\ \text { Probe (RDP-10/5) } & 840 \\ \text { Ball valve assembly } & 1,500 \\ \text { Cable } & 430 \\ \text { Cable Adapter } & 150 \\ \text { Installation support } & 1.000 \\ \text { Total } & \$ 13,920\end{array}$

The probe would be the main item that would need occasional replacement. The replacement frequency would be dependent or. the abrasiveness of the slurry with regard to the window and the effect that radiation has on the materials in the probe. 


\subsubsection{Inverted U-Loop}

\subsubsection{Technology Description}

To obtain a derivation of the theory of this technique, the reader is referred to a journal article prepared by Clift and Clift. ${ }^{4}$

In this method, the user begins with a piping system as illustrated in Fig. 2.18. On one side of the pipe, the fluid (or slurry) flows upward, and on the other side it flows downward. The pressure drop $(\Delta \mathrm{P})$ is measured across a known length $(z)$ of pipe on each side of the U-loop. By measuring the two pressure drops and summing them together, the net effect is that the head losses due to friction are negated.

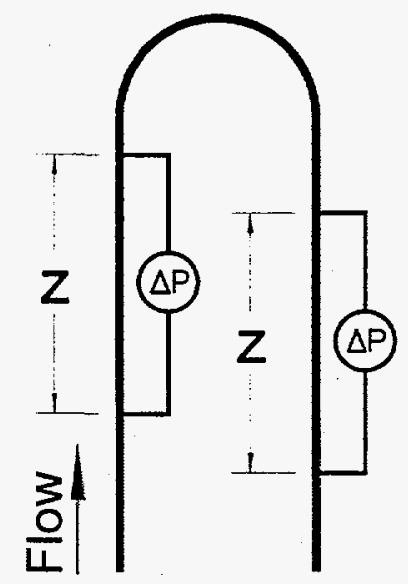

Fig. 2.18. Schematic representing setup for inverted U-loop.

Assuming that the density of the fluid is equivalent in each leg, the density of the fluid may be calculated from the following equation:

$$
\rho=\frac{\left(\Delta \mathrm{P}_{\mathrm{up}}\right)+\left(\Delta \mathrm{P}_{\mathrm{down}}\right)}{2 \mathrm{~g} z},
$$


where

$$
\begin{aligned}
& \rho=\text { density }\left(\mathrm{kg} / \mathrm{m}^{3}\right) \\
& \Delta \mathrm{P}=\text { pressure drop }(\mathrm{Pa}) \\
& \mathrm{g}=\text { acceleration of gravity }=9.81 \mathrm{~m} / \mathrm{s}^{2} \\
& \mathrm{z}=\text { distance between pressure measurement points }(\mathrm{m})
\end{aligned}
$$

The concentration of suspended solids, by volume, can be similarly calculated from the same measurements by the following equation (also assuming that the concentration of suspended solids in the upflow leg is equivalent to the concentration of suspended solids in the downflow leg:

$$
C_{v}=\left[\frac{\left(\Delta P_{\text {up }}\right)+\left(\Delta P_{\text {down }}\right)}{g z}-2 \rho_{L}\right] \times \frac{1}{2}\left(\frac{1}{\rho_{s}-\rho_{L}}\right) \text {, }
$$

where

$\mathrm{C}_{\mathrm{v}}=$ concentration of suspended solids by volume,

$\rho_{\mathrm{L}}=$ density of liquid phase $\left(\mathrm{kg} / \mathrm{m}^{3}\right)$,

$\rho_{\mathrm{S}}=$ density of solid phase $\left(\mathrm{kg} / \mathrm{m}^{3}\right)$.

\subsubsection{Estimated Cost and Life Expectancy}

The estimated cost of the inverted U-loop can be itemized as follows:

Fabrication of U-loop

$\$ 1,000$

Differential pressure transmitters (2@\$1000 each)

Total

$\$ 3,000$

It is estimated that the U-loop system would be expected to have a life of 3 to 5 years.

\subsubsection{Image Processing System}

\subsubsection{Technology Description}

This system, collectively referred to as an image processing system, uses a highspeed digital camera (Kodak Megaplus Model XHF camera) in combination with 
software to collect photographs (Coreco F64 Pro) and to analyze the photographs (ImagePro Plus).

The methodology for this system in our test program was to take a digital photograph of the slurry as it passed through a sight glass that was installed in the test loop. The photograph would be downloaded into a software package, and the software package would count the number of particles seen in the photograph. The concentration of suspended solids would be proportional to the number of particles. It may also be possible to obtain particle-size information with this method. The use of this system would require a calibration with the actual slurries that are to be analyzed.

\subsubsection{Estimated Cost and Life Expectancy}

The purchase cost of the image processing system is not known. The life of the system is dependent on the effect that the radiation has on the camera.

\subsection{REFERENCE SAMPLING DEVICES}

Bristol Equipment Company ISOLOK ${ }^{\circledast}$ sampling devices (Model SAA-19-09-44) were procured and installed on the test loop to obtain representative grab samples from the pipeline. These devices obtained samples as illustrated in Fig. 2.19 and in the following manner. When a sample was needed, the operator initiated a switch that caused a probe to extend into the pipeline. The probe contained an annulus that filled with the slurry in the pipeline. The probe was retracted, and the sample drained from the annulus into a collection jar. The probe stayed in the retracted position except during sample collection. Each extension and retraction of the probe retrieved an aliquot of approximately $8 \mathrm{~mL}$. A full sample ( $\geq 200 \mathrm{~mL}$ ) was obtained by repeatedly extending and retracting the probe.

The illustration in Fig. 2.19, which is based on a drawing in the manufacturer's brochure (Bulletin 593-R1), is representative of using the sampling device in a 5-in. pipe; therefore, the probe in the drawing does not extend across the pipe. The pipe in the 
ORNL test loop was $2 \mathrm{in}$. in diam, which allowed the probe to extend nearly across the diameter of the pipe.

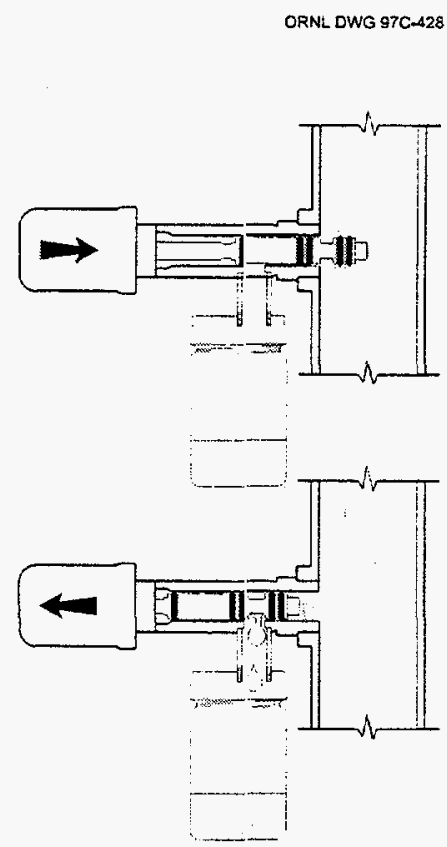

Fig. 2.19. Illustration of ISOLOK sampling device.

Two of the ISOLOK sampling devices were installed on the test loop. One of these devices was located on the upflow leg at the teginning of the slurry monitoring instrumentation section, and the other one was located at the end of the section (see Fig. 2.3). Samples were collected from both locations to determine if any changes in composition occurred in the instrumentation section.

In addition to pipeline sampling, some grab samples were collected from the feed tank with a device manufactured at ORNL. This device consisted of a stainless steel beaker attached to the end of a shaft. The beaker was sealed with a rubber stopper and then lowered to the desired depth in the tank. The rubber stopper was removed to allow the beaker to fill with slurry. The beaker was reclosed with the stopper and then removed from the tank, and the sample was transferred to a sample collection jar. 
The grab samples were collected by ORNL staff and sent to laboratories for viscosity, density, percent suspended solids, and particle size distribution analyses. The viscosity samples were analyzed by the Pacific Northwest National Laboratory. The analyses for density, total suspended solids concentration, and particle size distribution were performed by the Analytical Services Organization at ORNL.

\subsection{OTHER ANALYSES}

The Hanford Tank Initiative project requested that ORNL determine whether the pump current or power could be correlated to the viscosity or solids concentration of the slurries. The pump current and power data were provided by the variable-speed controllers for the pumps. These data were collected simultaneously with the data for the other slurry monitoring instruments. 


\section{INSTRUMENTATION TESTING}

\subsection{SURROGATE SLURRIES}

\subsubsection{Solid Media}

As previously discussed, surrogate slurries were used to evaluate the slurry monitoring instrumentation because the actual waste is radioactive. The suspended particles in the surrogate slurries were kaolin clay (Feldspar EPK Kaolin), sand (Quikrete Play Sand), and chert gravel (Rogers Group). These materials were selected because (1) their particle sizes and densities matched well with the properties identified by the ORNL and Hanford users (see Table 1.1), and (2) the materials are relatively nonhazardous and could be more easily disposed of than materials that more closely resemble the actual waste by chemical composition.

A sample of kaolin clay was analyzed by a Coulter laser-scattering instrument. The results of the analysis, shown in Fig. 3.1, indicated that the particle size distribution ranged up to approximately $90 \mu \mathrm{m}$ and that the mean nominal diameter was approximately $20 \mu \mathrm{m}$ (by volume).

A particle size analysis was performed on a sample of sand with standard sieves. The results from that analysis indicated that $\sim 75 \mathrm{wt} \%$ of the particles were between 250 and $500 \mu \mathrm{m}$ and that $>95 \mathrm{wt} \%$ of the particles were between 125 and $500 \mu \mathrm{m}$. These results are shown in Fig. 3.2.

Chert gravel is finely crushed gravel. To obtain the desired particle size range, a sample of the gravel was obtained and sieved such that the particle size was $>1000$ and $<4000 \mu \mathrm{m}$. The results of a particle size distribution of the gravel is shown in Fig. 3.3.

\subsubsection{Fluid Media}

Laboratory testing with slurries of kaolin clay and water indicated that the viscosities of the mixtures may not approach the viscosities expected by the user sites. Sucrose (Dixie Crystals Pure Sugar, Extra Fine Granules) was dissolved in the water to obtain a slurry with a higher viscosity and also a higher density. 


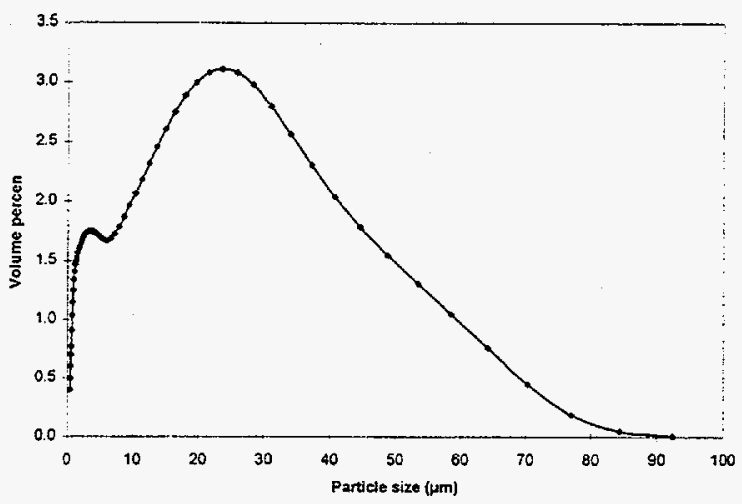

Fig. 3.1. Typical particle size distribution of kaolin clay used in slurries.

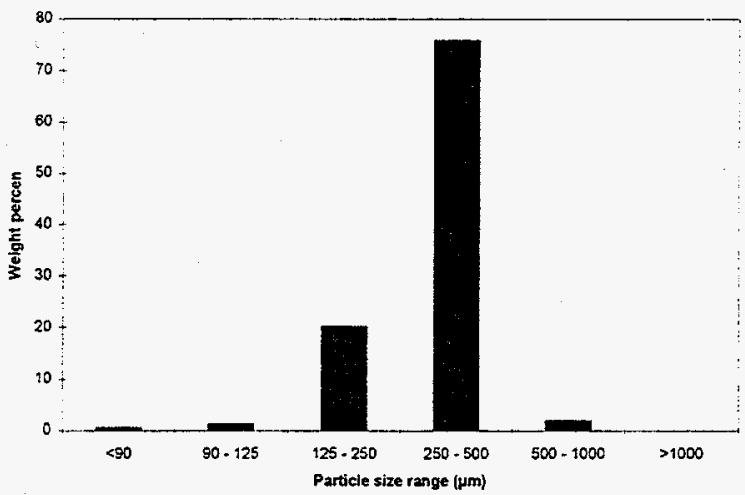

Fig. 3.2. Typical particle size distribution of sand used in slurries.

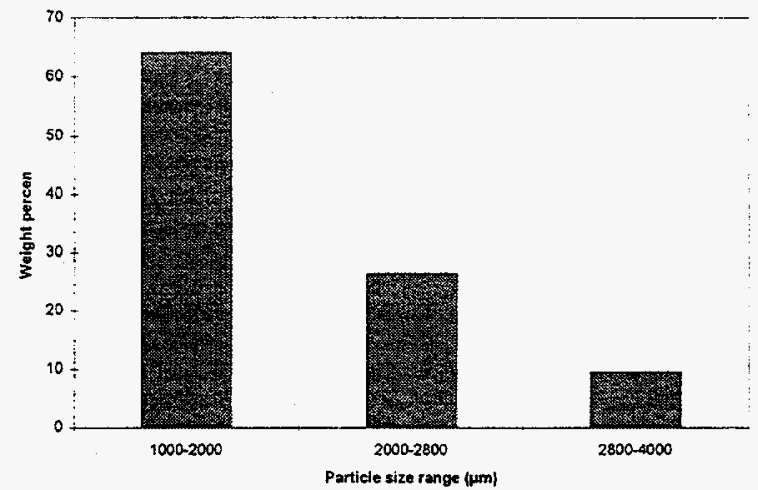

Fig. 3.3. Typical particle size distribution of gravel used in slurries. 
Tests were performed with two fluid media. A set of tests was performed with a slurry of kaolin clay and water. Following the completion of that set of tests, sucrose was added to the mixture such that the fluid medium was $50 \mathrm{wt} \%$ sucrose. Sodium hypochlorite (chlorine bleach) was added to the mixture to adjust the chlorine concentration to approximately $10 \mathrm{ppm}$ to control biological activity. The viscosity of the $50 \mathrm{wt} \%$ sucrose is significantly higher than that of water, so the suspended solids (particularly the kaolin clay particles) settle more slowly in the sucrose medium than in the water. By testing with both fluid media, a broader range of data was obtained.

\subsection{TEST PLAN}

Five quantitative factors (slurry matrix, slurry temperature, suspended solids concentration, induced air flow, and slurry flow rate) were varied during the test program. Other quantitative factors were monitored and/or held constant.

The compositions of the slurry matrices used to evaluate the monitors are shown in Table 3.1. These compositions were chosen to simulate the nominal, high, and low values for density, viscosity, and particle sizes for ORNL and Hanford slurries. The high and low concentration levels provide ranges of slurry properties that bracket the nominal slurry values to test the measurement capabilities and ruggedness of the slurry monitoring instruments.

The test conditions are listed in Table 3.2. Each slurry matrix was evaluated at three concentrations of suspended solids. The ratio of solid constituents was held constant for each concentration of the matrix. The slurries were evaluated at eight flow rates and two temperatures. The DOE site users (ORNL and Hanford) have indicated that their slurries may contain entrained air, so instrument sensitivity to air content was tested by bubbling air into the slurry (slurry velocity $\approx 5 \mathrm{ft} / \mathrm{s}$ ) through the system at 0.33 and 0.66 cubic feet per minute $(\mathrm{cfm})$ and comparing instrument responses to those obtained with no air present. The induced air flow rates correspond to approximately 5 and $10 \mathrm{vol} \%$ of the slurry flow. 
Table 3.1. Surrogate slurry recipes ${ }^{a}$

\begin{tabular}{cccccccc}
\hline & $\begin{array}{c}\mathrm{TSS}^{b} \\
(\mathrm{wt} \%)\end{array}$ & $\begin{array}{c}\text { Ratio, } \\
\mathrm{K}: \mathrm{S}: \mathrm{G}^{c}\end{array}$ & $\begin{array}{c}\text { Sugar } \\
(\mathrm{wt} \%)\end{array}$ & $\begin{array}{c}\text { Water } \\
(\mathrm{wt} \%)\end{array}$ & $\begin{array}{c}\text { Kaolin } \\
(\mathrm{wt} \%)\end{array}$ & $\begin{array}{c}\text { Sand } \\
(\mathrm{wt} \%)\end{array}$ & $\begin{array}{c}\text { Gravel } \\
(\mathrm{wt} \%)\end{array}$ \\
\hline
\end{tabular}

Set 1: Water

$\begin{array}{cccccccc}\text { W1 } & 0 & \mathrm{n} / \mathrm{a} & 0 & 100 & 0 & 0 & 0 \\ & & & \text { Set 2: } & \text { Sucrose (sugar water) } & & & \\ \text { S1 } & 0 & \mathrm{n} / \mathrm{a} & 40 & 60 & 0 & 0 & 0 \\ \text { S2 } & 0 & \mathrm{n} / \mathrm{a} & 50 & 50 & 0 & 0 & 0 \\ \text { S3 } & 0 & \mathrm{n} / \mathrm{a} & 60 & 40 & 0 & 0 & 0\end{array}$

Set 3: Kaolin clay in water

$\begin{array}{llllllll}\text { KI } & 10 & 1: 0: 0 & 0 & 90 & 10 & 0 & 0 \\ \text { K2 } & 20 & 1: 0: 0 & 0 & 80 & 20 & 0 & 0 \\ \text { K3 } & 30 & 1: 0: 0 & 0 & 70 & 30 & 0 & 0\end{array}$

Set 4: Kaolin clay in $50 \mathrm{wt} \%$ sucrose

$\begin{array}{llllllll}\text { SK1 } & 10 & 1: 0: 0 & 45 & 45 & 10 & 0 & 0 \\ \text { SK2 } & 20 & 1: 0: 0 & 40 & 40 & 20 & 0 & 0 \\ \text { SK3 } & 30 & 1: 0: 0 & 35 & 35 & 30 & 0 & 0\end{array}$

Set 5: Kaolin clay and sand in $50 \mathrm{wt} \%$ sucrose

$\begin{array}{llllllll}\text { SKS1 } & 10 & 3: 1: 0 & 45 & 45 & 7.5 & 2.5 & 0 \\ \text { SKS2 } & 20 & 3: 1: 0 & 40 & 40 & 15.0 & 5.0 & 0 \\ \text { SKS3 } & 30 & 3: 1: 0 & 35 & 35 & 22.5 & 7.5 & 0\end{array}$

Set 6: Kaolin clay, sand, and gravel in $\mathbf{5 0} \mathrm{wt} \%$ sucrose

$\begin{array}{llllllll}\text { SKSG1 } & 10 & 74: 25: 1 & 45 & 45 & 7.4 & 2.5 & 0.1 \\ \text { SKSG2 } & 20 & 74: 25: 1 & 40 & 40 & 14.8 & 5.0 & 0.2 \\ \text { SKSG3 } & 30 & 74: 25: 1 & 35 & 35 & 22.2 & 7.5 & 0.3\end{array}$

Set 7: Water

$\begin{array}{cccccccc}\mathrm{W} 2 & 0 & \mathrm{n} / \mathrm{a} & 0 & 100 & 0 & 0 & 0 \\ { }^{\circ} \text { Chlorine bleach was added to the slurries containing sugar water to control biological growth. The }\end{array}$ concentration of chlorine in the slurries was approximately $10 \mathrm{ppm}$.

${ }^{b} \mathrm{TSS}=$ total suspended solids.

${ }^{c}$ Weight ratios for the solid constituents; $K=$ kaolin, $S=$ sand, $G=$ gravel, $n / a=$ not applicable. 
Table 3.2. Combinations of factor levels for testing the slurry monitoring instruments

\begin{tabular}{|c|c|c|c|c|}
\hline Matrix & $\begin{array}{l}\text { Slurry } \\
\text { temp. } \\
\left({ }^{\circ} \mathrm{C}\right) \\
\end{array}$ & Slurry recipe $\mathrm{ID}^{a}$ & $\begin{array}{c}\text { Induced } \\
\text { air flow } \\
(\mathrm{cfm})\end{array}$ & $\begin{array}{l}\text { Slurry velocity }{ }^{b} \\
(\mathrm{ft} / \mathrm{s})\end{array}$ \\
\hline Water & 25 & W1, W2 & Off & $1,3,5,7,9$ \\
\hline Sucrose & 25 & $\mathrm{~S} 1, \mathrm{~S} 2, \mathrm{~S} 3$ & Off & $1,3,5,7,9, \mathrm{~L} 1, \mathrm{~L} 2, \mathrm{~L} 3$ \\
\hline Sucrose & 50 & $\mathrm{~S} 1, \mathrm{~S} 2, \mathrm{~S} 3$ & Off & $1,3,5,7,9, \mathrm{~L} 1, \mathrm{~L} 2, \mathrm{~L} 3$ \\
\hline Water/kaolin clay & 25 & $\mathrm{~K} 1, \mathrm{~K} 2, \mathrm{~K} 3$ & Off & $1,3,5,7,9, \mathrm{~L} 1, \mathrm{~L}, 2, \mathrm{~L} 3$ \\
\hline Water/kaolin clay & 25 & $\mathrm{~K} 1, \mathrm{~K} 2, \mathrm{~K} 3$ & $0.33,0.66$ & 5 \\
\hline Sucrose/kaolin clay & 25 & SK1, SK2, SK3 & Off & $1,3,5,7,9, \mathrm{~L} 1, \mathrm{~L} 2, \mathrm{~L} 3$ \\
\hline Sucrose/kaolin clay & 50 & SK1, SK2, SK3 & Off & $1,3,5,7,9, \mathrm{~L} 1, \mathrm{~L} 2, \mathrm{~L} 3$ \\
\hline Sucrose/kaolin clay & 25 & SK1, SK2, SK3 & $0.33,0.66$ & 5 \\
\hline Sucrose/kaolin clay & 50 & SK1, SK2, SK3 & $0.33,0.66$ & 5 \\
\hline Sucrose/kaolin/sand & 25 & SKS1, SKS2, SKS3 & Off & $1,3,5,7,9, \mathrm{~L} 1, \mathrm{~L} 2, \mathrm{~L} 3$ \\
\hline Sucrose/kaolin/sand & 50 & SKSI, SKS2, SKS3 & Off & $1,3,5,7,9, \mathrm{~L} 1, \mathrm{~L} 2, \mathrm{~L} 3$ \\
\hline Sucrose/kaolin/sand & 25 & SKS1, SKS2, SKS3 & $0.33,0.66$ & 5 \\
\hline Sucrose/kaolin/sand & 50 & SKS1, SKS2, SKS3 & $0.33,0.66$ & 5 \\
\hline Sucrose/kaolin/sand/gravel & 25 & SKSG1, SKSG2, SKSG3 & Off & $5,7,9$ \\
\hline Sucrose/kaolin/sand/gravel & 50 & SKSG1, SKSG2, SKSG3 & Off & $5,7,9$ \\
\hline Sucrose/kaolin/sand/gravel & 25 & SKSG 1, SKSG2, SKSG3 & $0.33,0.66$ & 5 \\
\hline Sucrose/kaolin/sand/gravel & 50 & SKSG1, SKSG2, SKSG3 & $0.33,0.66$ & 5 \\
\hline
\end{tabular}

${ }^{a}$ See Table 3.1.

" $\mathrm{L} 1, \mathrm{~L} 2$, and $\mathrm{L} 3$ are symbolic designations for laminar flow rates that were dependent on the Reynolds number for the particular slurry. 
The test design was both a crossed (or factorial) and a hierarchical (or nested) classified design. ${ }^{5,6}$ Slurry temperature, slurry flow, and induced air flow represent the same factor levels for each slurry matrix and matrix concentration. The nested factor levels of matrix concentration depend on the slurry matrix type. Table 3.2 shows the combinations of different factor levels. The water matrix is used for a series of five runs to check both the test loop and the functionality of the slurry monitoring instruments and to compare the conditions at the beginning of the evaluation with those at the end of the evaluation.

Prior to beginning the tests, the instrument developers visited ORNL and viewed the installation of their instruments in the test loop and trained ORNL personnel to operate and to collect data with their instruments and associated equipment. The instrument developers were requested to provide calibrated instruments to ORNL. It was planned that the testing with water would be a calibration verification of the instruments, and that the testing with sugar water (sucrose) would begin the evaluation procedure. However, it became apparent that as the testing proceeded, the instrument developers also needed the sucrose water runs to fine-tune the calibrations. Some of the instrument developers made calibration changes during the sucrose runs.

While the test program was being developed, the instrument developers were given the following information regarding instrument malfunctions. If an instrument malfunction occurred during a test, the operator would examine the unit for any obvious problem and fix it if possible (e.g., reconnect a communications cable, etc.). If the problem was not obvious, the operator would notify the instrument developer. The developer could then try to resolve the problem by discussing the problem with the operator and providing instructions by telephone. If the problem was successfully repaired, the instrument would continue to be included in the test program. If the problem could not be resolved and the instrument developer elected to repair the instrument, the developer was given the option of (1) visiting ORNL to examine and repair the instrument or (2) having ORNL personnel remove the instrument from the test loop and ship it back to the developer for repair. The instrument developers were also 
notified that because of the tight schedule for the program, the testing would proceed and their instrument would miss the portion of the test program conducted during the repair period. After the instrument had been repaired, the instrument developer could request that it be included in the remainder of the testing; however, missed slurries were not repeated.

\subsection{DATA COLLECTION}

Each of the instrument developers supplied a computer to operate their respective instrument(s) and to collect and report the data. A local area network was set up so that each computer could write the data into a single database; however, one computer could not be networked because of software incompatibility. Another computer arrived late, and the effort required to try to add it to the network at that point was not considered worthwhile. In addition to writing the data to the server computer, each instrument developer recorded the data on their respective computers for backup purposes. The computer clocks were synchronized at the beginning of each day when data collection was performed.

In order to prevent the solids from settling in the test loop, one of the recirculation pumps was run continuously after suspended solids had been added to the system. The agitator mixer was also run continuously. To minimize the unwanted induction of air into the slurry, the agitator stirring speed was adjusted to provide vigorous mixing - but without creating a vortex.

A typical data run was performed as follows. The slurry flow rate was adjusted to the desired flow, and the system pressure was adjusted to $\sim 50$ psig with a pressure control valve. The system was then allowed to equilibrate for $5 \mathrm{~min}$. If a flow rate or pressure adjustment was necessary, the 5-min equilibration period was restarted. Data collection began at the completion of the equilibration period. Data were taken for $15 \mathrm{~min}$ at intervals of $30 \mathrm{~s}$ except in the case of the PNNL particle size instrument, which provided data points at $60-\mathrm{s}$ intervals. At the completion of the data collection period, samples were collected and the flow rate and pressure were adjusted for the next run. 
The inverted U-loop was constructed from 1-in. pipe in order to acquire a measurable pressure drop and still keep the pipe inside the building. In order to test the U-loop at conditions similar to those encountered by the rest of the slurry monitoring instruments, the flow rate through the U-loop was adjusted so that the slurry velocity in the U-loop matched the slurry velocity in the 2 -in. piping. When data were collected at the laminar flow rates, the flow rate in the U-loop was adjusted so that the Reynolds number for the U-loop matched the Reynolds number for the 2-in. piping.

The surrogate slurries were prepared using the recipes in Table 3.1. After the ingredients had been combined, the slurries were agitated and recirculated for at least $16 \mathrm{~h}$ to allow the rheological properties of the slurry to stabilize.

ORNL staff operated the test loop and collected all the data, with one exception. PNNL supplied a student for approximately 6 weeks to help with the setup, calibration, and testing of their instruments.

\subsection{SAMPLE COLLECTION}

Samples were collected with the ISOLOK sampling equipment described in Sect. 2.3. When obtaining a sample, the operator cycled the plunger two to three times to condition the sampling device. After being conditioned, a new sample jar was installed on the sampler and a sample was collected. After the desired volume had been obtained, the sample jar was removed, closed, and labeled. The sampler included a built-in feature to flush the annulus section. After the sample was removed from the device, another jar was placed on the sampler and the annulus section of the probe was flushed with water to remove trapped sample residue.

\subsection{SAMPLE ANALYSES}

Samples that were to be analyzed for density, suspended solids concentration, and particle size analysis were delivered to the Analytical Services Organization at ORNL. Samples that were to be analyzed for viscosity were transferred to PNNL. When 
possible, standard methods of analysis were used. A brief description of the analytical methods is provided below.

\subsubsection{Density}

The analytical method used for density was adapted from the standard procedure of the American Society for Testing and Materials (ASTM) procedure D70-82 for measuring the specific gravity and density of Semi-Solid Bituminous Materials. ${ }^{7}$ In this procedure, the density of the slurry is determined by weighing an aliquot into a specially designed vial (a pycnometer) that has a known volume. Modifications to the procedure included the following: (1) the materials evaluated were not semi-solid bituminous, (2) the samples were not heated except to adjust the temperature of the sample to 25 or $50^{\circ} \mathrm{C}$ to match the temperature at which it was collected, and (3) the temperature was adjusted by a constant-temperature water bath.

\subsubsection{Suspended Solids Concentration}

The method of analysis for the suspended. solids content was adapted from a standard method for determining the suspended solids content in water and wastewater (Standard Method 2540D). ${ }^{8}$ With this method, the suspended solids concentration was determined by weighing an aliquot of slurry sample and then filtering the sample to separate the liquid from the suspended solids. The filtrate was flushed with water to remove any dissolved solids (i.e., sugar), dried, and reweighed. The weight of the dried solids was then compared with the weight of the sample aliquot to determine the concentration of suspended solids.

\subsubsection{Particle Size}

Since the particle size of the solids in the slurries ranged from approximately 1 to $4000 \mu \mathrm{m}$, a combination method of analysis was needed. A Microtrac instrument, which is based on a laser light-scattering method, was used to detect and measure particles 
$\leq 125 \mu \mathrm{m}$. Particles sizes that were $>125 \mu \mathrm{m}$ were determined by wet sieving the slurry samples.

Standard sieves were used to perform the particle size analyses. The sieve trays were dried and weighed; then the samples were poured on the top sieve and flushed with water to break up any clumps and remove the dissolved solids. The sieves were shaken and then dried in an oven. After being dried, the trays were reweighed to determine the amount of solids retained on each tray. The solids that passed through the $125-\mu \mathrm{m}$ tray were analyzed with the Microtrac laser light-scattering instrument.

\subsubsection{Viscosity}

Viscosity analyses of the slurry samples were performed at PNNL under the direction of Lynette Jagoda. A report prepared by Jagoda describing the methods used to perform the analyses and the results that were obtained is included in Appendix A.

\subsection{INSTRUMENT PERFORMANCE NOTES}

This section provides some information about the operational performance of the various instruments during the test program. Several of the instruments that were evaluated were prototypes. By definition, a prototype may have some glitches that are not identified until it is subjected to field-type conditions. Since these prototypes had not been exposed to such conditions, it was not unusual that some of them developed maintenance problems during the test program. Those issues, by themselves, should not necessarily be used to determine whether an instrument should be considered for further testing.

\subsubsection{Promass Coriolis Meter}

The Endress + Hauser Promass Coriolis meter completed all the runs. 


\subsubsection{PNNL Pipeline and In-Tank Densitometers}

PNNL submitted two densitometer probes, a pipeline probe and an in-tank probe, to ORNL for testing. These instruments were prototypes developed for the CMST-CP. As delivered, they were set up to collect data with fluids at $25^{\circ} \mathrm{C}$. The calibration points for $50^{\circ} \mathrm{C}$ operation were to be obtained during the calibration runs. Further development is needed for these instruments to make them capable of compensating for the slurry temperature. As delivered, these instruments required manual adjustment of the instrument gain between runs when the slurry composition was changed. With further development, this function could be automated. The instrument developer reported that time constraints prevented this update prior to probe delivery to ORNL. PNNL sent a student employee to ORNL for approximately 6 weeks to help with the setup and calibration of their instruments and to set up the parameters to ensure proper data collection. The student had worked with the instruments at PNNL and was very familiar with their setup.

The instrument developer encountered many problems in trying to calibrate their instruments at $\mathrm{ORNL}$; however, the instrumert developer reported that the instruments had performed very well in the laboratory at PNNL. The developer indicated that the laboratory at PNNL had the advantage of a more constant operating temperature, which produced a more stable calibration. The instruments contained thermocouples that recorded the temperature of the slurry, the temperature near the base of the wedge, and the temperature near the top of the wedge. The developer reported that when the instruments were being calibrated at ORNL, the nominal temperature was $25^{\circ} \mathrm{C}$ and the temperature of the base and the top of the wedge fluctuated several degrees. PNNL personnel concluded that finer steps in the voltage-vs-temperature measurements would yield a greater accuracy.

The pipeline instrument was removed from the test loop and returned to the instrument developer for repair on two occasions. The first problem occurred during the shakedown testing with water in the system when the density output was observed to be changing erratically. Upon inspection of the instrument, water was found to be dripping 
from some of the communication connections, which indicated that the sealant around the wedge had failed. In accordance with instructions from the developer, the instrument was removed from the test loop and returned to PNNL. PNNL, which had subcontracted the fabrication of the instrument, then sent the instrument to the subcontractor for repair. After the subcontractor had repaired the leak by using a different type of sealant, the instrument was returned to ORNL and reinstalled in the test loop. No other leaks were experienced with the instrument after this repair. Because the pipeline instrument had been removed for repair, it missed the water calibration runs performed at $50^{\circ} \mathrm{C}$. Therefore, tests at $50^{\circ} \mathrm{C}$ were completed using the $25^{\circ} \mathrm{C}$ calibration constants. Following completion of the tests, the pipeline probe was returned to PNNL, where their personnel performed temperature calibrations over the range from 23 to $50^{\circ} \mathrm{C}$, renormalized the slurry data collected at $50^{\circ} \mathrm{C}$, and then provided the revised data to ORNL for inclusion in the statistical analysis.

The second problem with the pipeline instrument occurred while recirculating kaolin and water slurry. The PNNL summer student reported that the instrument was behaving as if one of the ultrasonic transducers had become detached from the wedge. After the student had performed some troubleshooting and discussed the situation with the instrument developer, ORNL staff were requested to remove the instrument from the test loop and to send it to PNNL for repair. Following the repair procedure and subsequent return to ORNL, it was reinstalled in the test loop for the remainder of the test program.

The in-tank instrument completed only a few tests before it was removed from the ORNL test program. The ambient conditions included high humidity, particularly when the testing was conducted at $50^{\circ} \mathrm{C}$; however, this would be representative of an actual application. The problem that affected the in-tank probe was identified when the probe was removed from the tank. The wedge housing, which was submersed in the slurry, was suspended in the tank via a long tube. Electrical wiring for the thermocouples and transducers were enclosed in the tube, which had a connector box on top. The thermocouple connectors were such that air could enter the tube. When the temperature changed from $50^{\circ} \mathrm{C}$ to $25^{\circ} \mathrm{C}$, water vapor condensed on the inside walls of the tube, then 
flowed down the tube and into the base of the probe. When the water contacted the transducers, the signal characteristics were changed and the instrument did not report valid results. This problem could be easily resolved by simply waterproofing the probe to prevent moist air from entering the tube.

\subsubsection{BTG SMS-3000}

This instrument was used with the accessory equipment that ORNL had on hand. It was thought that the detector probe (RDP-10/5) that was used would be sufficient to measure the concentration of suspended solids up to approximately $30 \mathrm{wt} \%$. However, during calibration, it was learned that the upper limit for this particular probe with kaolin clay slurries was 12 to $15 \mathrm{wt} \%$. The probe was left in position for all the tests, but it was known ahead of time that the data obtained would only be useful for the nominal $10 \mathrm{wt} \%$ slurries.

The detector probe was installed in a 4-in. pipe according to the manufacturer's instructions. It should be noted that the slurry velocities cited in this report are in reference to a 2 -in. pipe. The slurry velocity through the 4 -in. pipe section is lower because of the larger cross-sectional area of the pipe. The velocity through the 4-in. section can be determined by dividing the velocity through the 2 -in. pipe by 4 .

If this system were to be used in a specific application, the manufacturer would need to be consulted to help determine the proper type of probe. The probe would also have to be calibrated with the actual waste slurries since the response can be affected by properties such as color, type of solids, size of solids, and other reflection factors. It should be noted that if the slurry properties (e.g., color, particle size) change significantly, then the probe would need to be recalibrated.

Since the SMS-3000 electronics accepts simultaneous input from four probes, it is conceivable that multiple probes could be installed to cover a wide range of concentration percentages. As mentioned in Section 2.2.7, this system is no longer manufactured by BTG. The new manufacturer (Zellweger Analytics) has discontinued manufacturing the SMS-3000 but has replaced it with a new version that works on the same principle; 
however, the new version will only accept one probe input. The issues of measurable range and radiation resistance of suspended solids would need to be addressed by the manufacturer.

\subsection{4 m-Point Coriolis Meter}

The m-Point Coriolis meter, which was manufactured by Endress + Hauser, is the predecessor of the Promass. The density output from the m-Point meter was typically within $\pm 0.003 \mathrm{~g} / \mathrm{mL}$ of the density value from the Promass instrument except when air was induced into the slurry. The response of the m-Point instrument to the presence of air in the slurries was to go into a default error mode. The m-Point instrument was programmed to respond with the maximum set-point range when a default error occurred. Since it reported the same value during the induced-air testing, the variance was zero. Therefore, care must be exercised when reviewing the results.

\subsubsection{ORNL Gamma Densitometer}

This instrument, which was a prototype developed for the Waste Management and Remedial Action Division at ORNL, collected data from all the test runs except one in which a computer lockup error occurred.

\subsubsection{Sandia Pipeline Density-Viscosity Meter}

This instrument was a prototype developed for the CMST-CP. The output from the instrument was the product of the density and viscosity. During the development of the test program, the instrument developer was concerned about the pipeline pressure at which the tests were being conducted. The test pressure was limited to $\sim 50 \mathrm{psig}$, which was the nominal pressure limit provided for the ORNL Gunite and Associated Tanks application. When the system pressure was adjusted, the output of the instrument was observed to change, depending on the system pressure; however, this was not observed in our results since system pressure was not a variable. 
The pipeline instrument failed shortly after sand has been added to the slurry mixture. At the time, it was not known whether the instrument failed because of the presence of the sand (e.g., abrasion) or for some other reason. The instrument developer was informed of the problem, but he declined to remove and/or repair the instrument, citing the repair cost vs the limited number of test conditions remaining.

On completion of the testing, the instrument was removed from the test loop. A representative of SNL inspected the instrument and noted that the sensor had shifted approximately $0.25-0.5 \mathrm{in}$. backward from its original position. There was a crack in the quartz crystal, which had allowed moisture access to the electronics. It is reasonable to believe that system pressure caused the sensor to slide backward. Although the data collection was conducted at $50 \mathrm{psig}$, the system pressure reached approximately $100 \mathrm{psig}$ for very short periods of duration. When the system pressure was greater than $50 \mathrm{psig}$, it was typically caused by operator interactions (e.g., the flow rate being increased faster than the response of the pressure control valve). The test system was designed to automatically shut down the recirculation pum.ps if the system pressure was $>100$ psig. The failure of the instrument occurred approximately $6 \mathrm{~h}$ after testing was completed for that day, so it cannot be ascertained whether the crystal cracked due to overpressurization or to fatigue. The instrument developer believes that the failure mechanism was crystal fatigue due to repetitive overpressures ( $>50 \mathrm{psig})$.

Shortly after failure of the pipeline instrurnent, the communication link between the computer and the interface electronics was interrupted, stopping the computer. This was a problem only because it affected the software program diagnostics and would not allow data collection with the in-tank probe. The situation was corrected by disconnecting the pipeline probe cable from the interface electronic module and restarting the computer program.

\subsubsection{Image Processing System}

The image processing system was evaluated with a $10 \mathrm{wt} \%$ kaolin clay slurry prior to beginning the test program. The particles were not distinguishable in the photograph 
(which was no surprise to ORNL personnel). The lowest concentration of interest in this study was $10 \mathrm{wt} \%$, so no further testing was conducted with the system.

It should be noted that although the image processing system was not usable with the slurries at the concentrations of interest for this application, it may be worthwhile in applications that have dilute concentrations of suspended solids (e.g., $<1 \mathrm{wt} \%$ ).

\subsubsection{Argonne's Ultrasonic Flow Instrument}

This instrument, which was a prototype developed for the CMST-CP, was designed to determine density, viscosity, and percent suspended solids data for slurries.

The instrument was observed to be affected by electromagnetic noise that appeared to be generated from the motor speed controllers in the test loop. Several attempts were made by the instrument developers and ORNL personnel to resolve the noise problem (e.g., by shielding the communication wiring and by using an uninterruptible power supply for the ANL instrument); however, it could not be completely eliminated. This problem is one that may be encountered in a user application; and if development is continued, should be resolved.

No other operational problems were encountered with the instrument itself; however, some difficulties were experienced with the computer equipment. On one occasion, the developer had to replace an $\mathrm{A} / \mathrm{D}$ circuit board. On another occasion, the hard drive failed and the computer was shipped back to Argonne for repair. After Argonne had replaced the hard drive and returned the computer to ORNL, the instrument was restored to operational status in the test program.

\subsubsection{U-Loop Density}

The inverted U-loop device, which was fabricated at ORNL, was initially equipped with remote sealed-diaphragm differential-pressure transmitters. It was observed that the ambient temperature of the test area was affecting the output data from the system. Therefore, a decision was made to convert to a different differential-pressure measurement system. The new system used four pressure transmitters (instead of two. 
differential pressure transmitters). The differential pressure was determined by the difference in the two pressure transmitters on each leg of the U-loop. In hindsight, changing to this configuration may have been a mistake. After sand had been added to the slurry, the pressure sensor ports plugged. Flush ports were part of the design, but the plugs could not be removed by flushing. As a result, the U-loop data are probably only valid for the testing done before the addition of sand to the slurries. Since this pipeline configuration had previously been used in ancther slurry application with particles up to $500 \mu \mathrm{m}$ and the remote sealed-diaphragm differential-pressure transmitter, it is possible that it may not have plugged or that the plug could have been removed by flushing if the transmitters had not been changed.

A major disadvantage of the U-loop is the large size of the unit. Our particular unit, which was approximately $20 \mathrm{ft}$ tall, may prove difficult (and costly) to shield personnel from radiation exposure. One alternative to the shielding dilemma would be to install the U-loop inside an existing tank, but this design would also present problems with accessing the differential-pressure transmitters for calibration, maintenance, or other activities.

\subsubsection{Sandia In-Tank Density-Viscosity Instrument}

This instrument, which was one of the prototypes developed for the CMST-CP, is similar to the unit described in Section 3.5.6, except that it was installed in the feed tank; therefore, it was not sensitive to the system pressure. There were no operational problems with the in-tank instrument; however, it would probably be wise for either the users or the instrument developer to include the ability to occasionally flush the sensor with water to remove solids that build up on the unit.

\subsubsection{PNNL In-Tank Particle Size Instrument}

This instrument, a prototype instrument developed for the TFA, was delivered to ORNL by PNNL with instructions that it was 1.0 be tested only at $25^{\circ} \mathrm{C}$ and that the maximum time for submersing the transducers was $8 \mathrm{~h}$. PNNL personnel indicated that 
the receipt of funding for development of this test probe was delayed from October 1996 until February 1997; therefore, the probe was integrated for the ORNL demonstration using existing transducers. According to PNNL staff, the manufacturer of the transducers guaranteed that they could be used for operations up to $122^{\circ} \mathrm{F}\left(50^{\circ} \mathrm{C}\right)$; however, PNNL personnel observed that the protective faces of the transducers started to delaminate when operated in the laboratory at temperatures above ambient conditions. Therefore, PNNL requested ORNL to operate the probe during the tests performed only at $25^{\circ} \mathrm{C}$. PNNL personnel indicate that alternate transducers have since been identified that permit continuous immersion and operation at $50^{\circ} \mathrm{C}$; however, timing and funding did not permit such a change to be implemented during this demonstration.

This instrument required some detailed knowledge about the computer software program in order for it to be used. Further development effort is needed to make the software more automated.

The instrument developer evaluated the data that were obtained with the instrument and remarked that the highly attenuative signal indicated that air had been entrained in the slurry. The PNNL principal investigator reported that a similar phenomenon was observed in the laboratory at PNNL during slurry manufacture. PNNL personnel indicated that air entrapment occurred when dry kaolin was poured into the fluid, and a lengthy period was required for these small "clumps" of particulate and air to break down and the air to migrate out of the slurry. After PNNL's slurry was initially mixed in their laboratory, the ultrasonic probe produced a highly attenuated signal. PNNL personnel report that after mixing for the lengthy period of time (on the order of $24 \mathrm{~h}$ ), the entrained air had dissipated and the size distribution of the slurry could be measured.

PNNL personnel theorize that the slurries used at ORNL also contained small bubbles of entrained air attached to the kaolin clay particles. The kaolin clay used to make up the test slurries was added in 50-lb increments and worked into the slurry. At least $16 \mathrm{~h}$ was allowed for the slurry conditions to stabilize between the time that the slurry was prepared and the time that data collection began. The slurry was continuously mixed by an in-tank agitator and by recirculation through the test loop. Although it is 
possible that the entrapped air in the slurry was from the addition of the kaolin to the slurry, there were occasions during which the slurry was mixed for more than $24 \mathrm{~h}$ and the particle size probe still behaved in the same manner.

After the test program had been completed, the instrument developer requested ORNL personnel to put the particle size probe into a batch of slurry that had been quiescent for several days. Although the slurry was previously used in the test program, it was not a representative mixture because some of the particles had settled. The purpose of this test was to determine if the probe behaved the same way after air had a chance to dissipate out of the mixture. According to the instrument developer, the probe responded properly (i.e., the ultrasonic signal was not completely attenuated). The instrument developer inferred from this test that entrained air bubbles were probably the cause of the problem during the testing. PNNL personnel have indicated that the entrained air associated with wetting and mixing of the dry kaolin clay is not indicative of the entrained air that will be found during waste mixing and transport at ORNL and Hanford. 


\section{PARAMETERS USED IN DATA EVALUATION}

The data that were collected from the instruments and from the grab samples were used to quantitatively evaluate the instruments. The instruments were also evaluated from a qualitative perspective.

\subsection{QUANTITATIVE ANALYSES}

The responses from the slurry monitoring instruments were measured over a fixed time period for each factor-level combination. They were compared with reference values obtained from grab samples taken before and after the instrument test section. Two performance statistics, the bias and variance, were calculated for the responses during each fixed time period. The bias statistic was calculated as the average difference between the individual responses during a time interval and the reference value, as defined by

$$
\text { Bias }=\sum_{k=1}^{K} \frac{\left(R_{k}-R_{r e f}\right)}{K} \text {, }
$$

where

$$
\begin{aligned}
& \mathrm{R}_{\mathrm{k}}=\text { measured value by the instrument, } \\
& \mathrm{R}_{\mathrm{tef}}=\text { measured value determined by laboratory analysis, } \\
& \mathrm{K}=\text { number of measurements, } \\
& \mathrm{k} \quad=\text { index. }
\end{aligned}
$$

The variance statistic was calculated as the sum of the squared difference between a response and its average, divided by the number of responses minus one (i.e., the standard deviation squared):

$$
\text { Variance }=\frac{\sum_{k=1}^{K}\left(R_{k}-\bar{R}\right)^{2}}{K-1} \text {, }
$$


where

$$
\overline{\mathrm{R}}=\frac{1}{\mathrm{~K}} \sum_{\mathrm{l}}^{\mathrm{K}} \mathrm{R}_{\mathrm{k}} .
$$

The bias equation can be rewritten as

$$
\text { Bias }=\bar{R}-R_{\text {ref }} \text {. }
$$

The data from each of the slurry monitoring instruments were used to test statistical hypotheses on the effects of test factors on the two performance statistics, where $\mathrm{H}_{0}$ is the null hypothesis:

$\mathrm{H}_{0}$ : expected bias is equal to zero for all test factors

$\mathrm{H}_{0}$ : test factors do not affect the expected variance

These hypotheses about the effects of test factors were evaluated using the analysis of variance (ANOVA) method.

\subsection{QUALITATIVE ANALYSES}

The qualitative factors that were assessed included the following: portability, ruggedness, ease of operation, maintenance and training requirements, clarity of output, any special requirements (e.g., recalibration for slurry matrix change, etc.), and expected performance if used to monitor transport of radioactive slurries. 


\section{TECHNOLOGY PERFORMANCE AND EVALUATION}

This section presents the results obtained from testing the various slurry monitoring instruments. The results are presented in terms of the slurry parameter that was measured by the instrument (density, viscosity, particle size, and suspended solids concentration). The instrument developers and manufacturers were provided a draft copy of this report for review and comment. They were requested to provide written responses to the results and comments that were presented in the report and informed that their responses would be included in this report. No format was given, except that they limit their response to ten pages. The responses that were received from the developers and manufacturer are included in Appendixes $\mathrm{C}$ through $\mathrm{G}$.

Box plots are used throughout this section to present the data. The boxes in the plots represent the middle $50 \%$ of the data. The 10th and 90 th percentile of the data are represented by upper and lower caps on the box whiskers. Bias values outside these caps are displayed as circles and represent the largest and smallest values.

\subsection{DENSITY EVALUATION}

Seven instruments measured density during the pipeline waste monitor technology demonstration:

$$
\begin{aligned}
& \text { ANL }=\text { Argonne National Laboratory ultrasonic flow instrument, } \\
& \text { MPOINT }=\mathrm{m} \text {-Point Coriolis instrument, } \\
& \text { ORNL = Oak Ridge National Laboratory gamma-ray attenuation instrument, } \\
& \text { PNNL_P }=\text { Pacific Northwest National Laboratory in-pipe ultrasonic reflection } \\
& \text { PNNL_T }=\text { Pacific Northwest National Laboratory in-tank ultrasonic reflection } \\
& \text { PROMASS }=\text { Promass Coriolis instrument, and } \\
& \text { ULOOP }=\text { U-Loop density determination instrument. }
\end{aligned}
$$

The density measurements from these instruments were compared with the results obtained from grab samples that were analyzed in a laboratory. A density bias for each measurement was calculated using the difference between the average density 
measurement over the experimental run time and the reference laboratory density value for that experimental run:

Density Bias $=$ Average Density Measurement - Reference Laboratory Value.

Standard deviations of the average density biases can be calculated over different levels of the experimental factors.

The precision of a density measurement for an experimental run is represented by the standard deviation of the density measurements over run time. These standard deviations are calculated from the replicate density measurements (e.g., about 30 replicates) for each experiment.

\subsubsection{Reference Density Measurements}

Reference density values are given in Appendix B. Density values are not available for every experimental run because of cost restrictions. Predicted density values are estimated from a linear regression fitted to measured density values vs flow rate for each combination of matrix type, weight percent, and temperature.

\subsubsection{Completeness of the Experimental Design}

Technical problems, primarily caused by the inability to operate at high flow rates and still keep the system pressure from exceeding $50 \mathrm{psig}$, prevented us from running the complete experimental design. The planned experiment included 263 experimental runs. The actual number completed was 208 , which is $79.1 \%$ of those originally planned. In addition, a final set of three experimental runs was completed with a water matrix at flow rates of 1,3 , and $5 \mathrm{ft} / \mathrm{s}$ to compare with an initial set of five experimental runs with flow rates of $1,3,5,7$, and $9 \mathrm{ft} / \mathrm{s}$. The final set of water runs could not be completed at 7 and $9 \mathrm{ft} / \mathrm{s}$ because of excessive vibration of the test loop (a steam line was ruptured because of the vibration). This vibration was probably caused by damage inflicted to the pump rotor 
and or stator by the slurries. Table 5.1 shows the number of runs completed with the different density instruments relative to the total number of experiments performed.

Table 5.1. Percentage of experimental runs completed by the density instruments

\begin{tabular}{|c|c|c|c|c|c|c|c|}
\hline \multirow{2}{*}{ Experiments run } & \multicolumn{7}{|c|}{ Instrument } \\
\hline & ANL & MPOINT & ORNL & PNNL_P & PNNL_T & PROMASS & ULOOP \\
\hline $\begin{array}{l}\text { Total } \\
(211)\end{array}$ & 77.3 & 100 & 99.5 & 65.9 & 9.4 & 100 & 77.7 \\
\hline $\begin{array}{l}\text { Initial and final water runs } \\
\text { (8) }\end{array}$ & 75.0 & 100 & 100 & 50.0 & 37.5 & 100 & 62.5 \\
\hline $\begin{array}{l}\text { Excluding water runs } \\
\text { (203) }\end{array}$ & 77.3 & 100 & 99.5 & 66.5 & 8.4 & 100 & 78.3 \\
\hline $\begin{array}{l}\text { Excluding water runs } \\
\text { air flow }=0 \mathrm{cfm} \\
(168)\end{array}$ & 77.4 & 100 & 99.4 & 63.1 & 10.1 & 100 & 81.5 \\
\hline $\begin{array}{l}\text { Excluding water runs } \\
\text { matrix flow }=5 \mathrm{ft} / \mathrm{s} \\
\text { air flow }=0,0.33,0.66 \mathrm{cfm} \\
(57)\end{array}$ & 77.2 & 100 & 100 & 82.4 & 0.0 & $100^{\circ}$ & 63.2 \\
\hline
\end{tabular}

\subsubsection{Average Density Bias and Precision of Density Measurements}

Figure 5.1 shows a histogram of the averages of the density bias measurements and the standard deviations of these measurements over all experimental conditions. Different designs were utilized to determine which experimental factors had the greatest influence on the variation of the density biases. Ideally, the density bias should be zero for each instrument.

Figure 5.2 shows the range of standard deviations for density readings calculated for each run. These standard deviations include all experimental conditions except those for the initial and the final water runs. The values show the stability of the density readings from the instruments during an approximate measurement period of 15 min. Most of the density readings were very stable with the exception of the ULOOP, which may have been unknowingly plugged. 

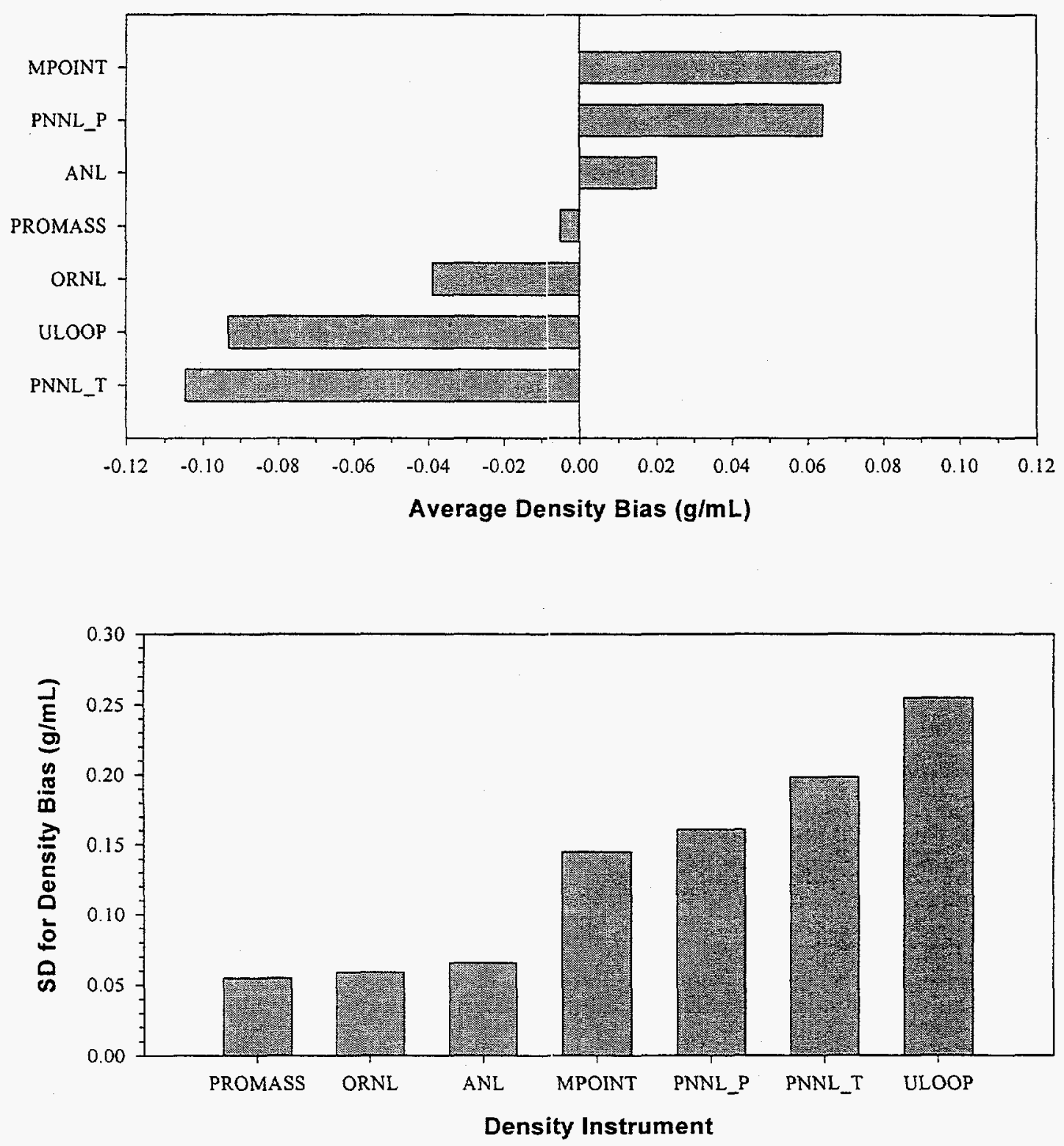

Fig. 5.1. Averages of density bias measurements and the standard deviations (SD ) of density bias measurements over all experimental conditions. 


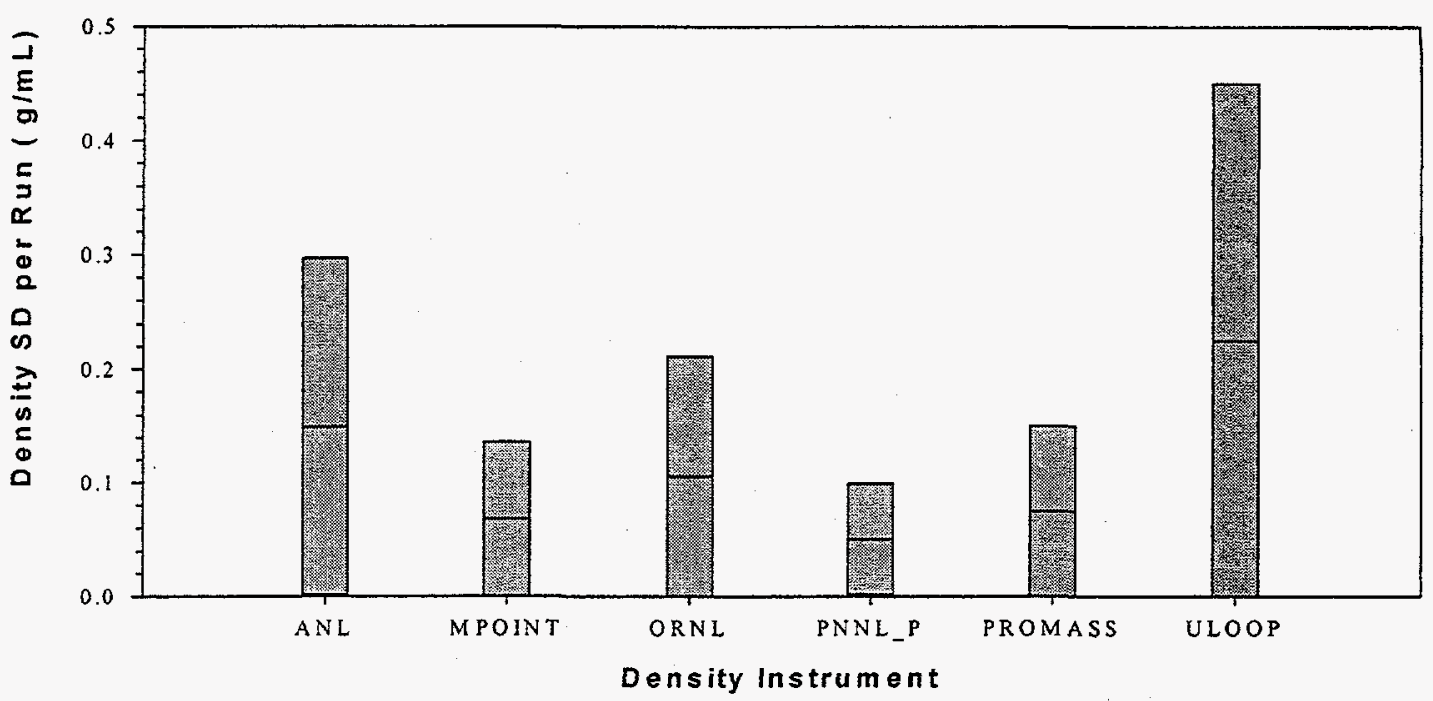

Fig. 5.2. Range of calculated standard deviations (SD) for density measurements over all experimental conditions except the initial and the final water runs. Center line indicates median SD value.

\subsubsection{Density Bias for Slurry Flow-Rate Experiments}

Experiments were performed to examine the effects of slurry flow rate. In these experiments the induced air flow rate was fixed at $0 \mathrm{cfm}$ and the initial and final water runs were not included. Slurry flow rates ranged from 0.2 to $9 \mathrm{ft} / \mathrm{s}$ for sugar, $\mathrm{kaolin} /$ water, and kaolin/sugar matrices and ranged from 0.3 to $7 \mathrm{ft} / \mathrm{s}$ for kaolin/sand and kaolin/sand/gravel matrices. Table 5.2 shows the averages of density bias values that were summarized over all flow rates for the temperature, matrix type, and weight percent factors. Figure 5.3 shows box plots of the density bias measurements over all combinations of the experimental factors (i.e., temperature, matrix type, weight percent, flow rate). As shown in Fig. 5.3, the PROMASS instrument exhibited the smallest variation of density bias and the ULOOP showed the largest variation of density bias values. 


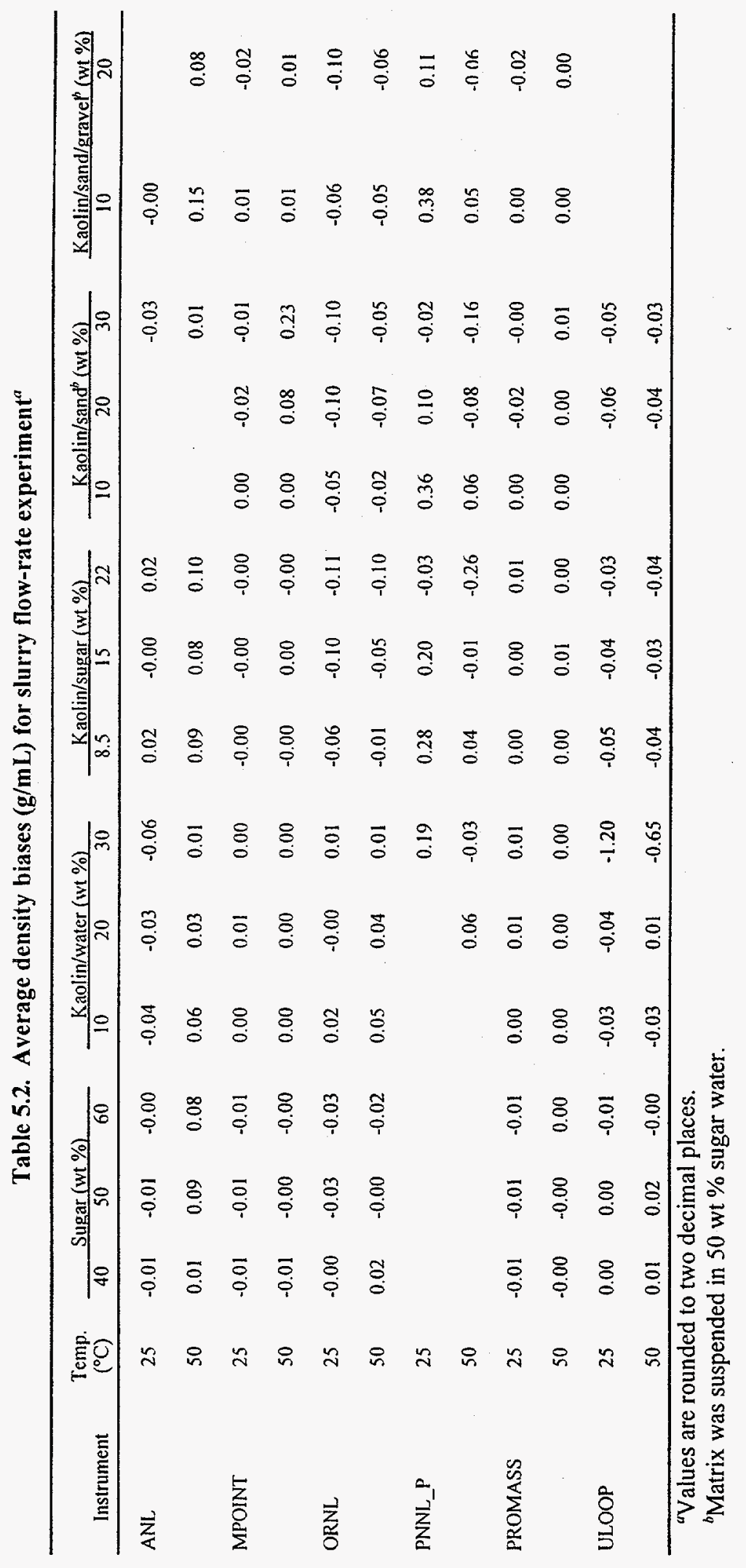




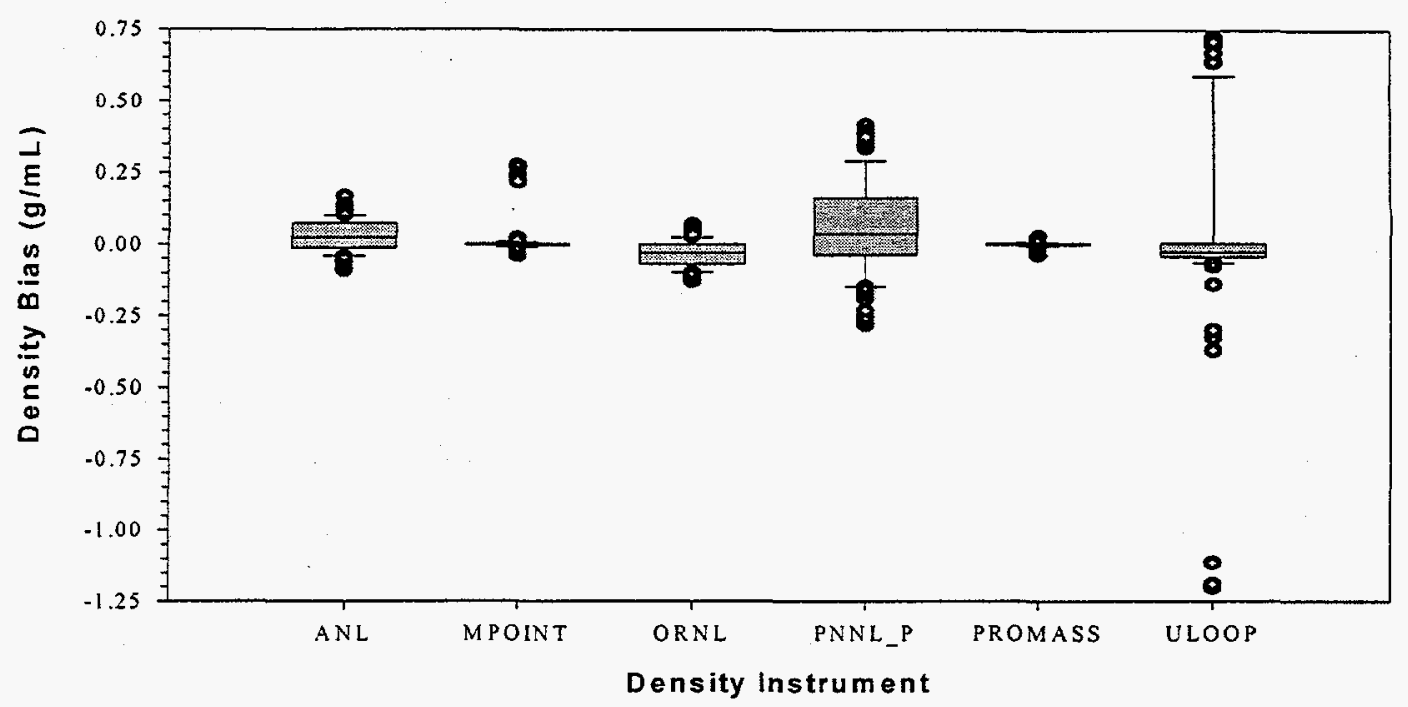

Fig 5.3. Box plots of the density biases measured by different density instruments for all combinations of the factors examined in the slurry flow-rate experiments.

The effects of the different experimental factors on density bias were analyzed by the ANOVA method. An ANOVA model is used to represent the sources of variation for density bias, which are then compared with the experimental error to test for effects at the $5 \%$ significance level.

The ANOVA model to represent density bias variation was

Density Bias $=$ Mean + Temp + Matrix + Wt_Pct (matrix $)+(\beta \times$ Flow $)+$ Error, where

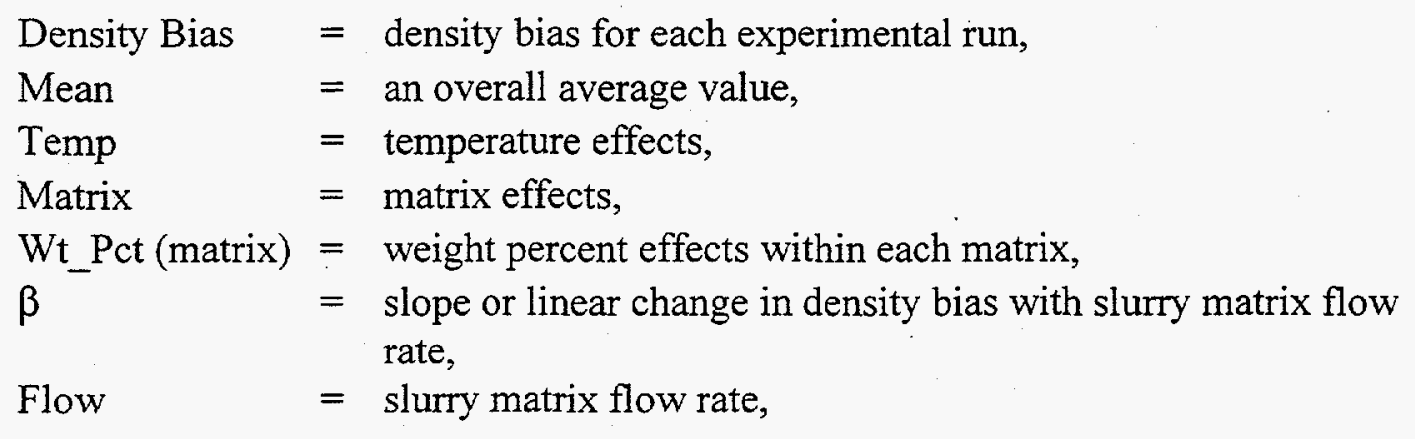


Error $\quad=$ experimental error or the variation of the density biases not explained by other sources of variation. (The experimental error is assumed to be distributed as an independent normal random variable with zero expected value and constant variance.)

Table 5.3 shows the results of the ANOVA model calculation by identifying the significant sources of variation for the density bias measurements. Significant differences among averages of density biases over the experimental factor levels are relative to the standard deviation of the experimental error and the number of observations used for the averages. Large standard deviations of the experimental error indicate that additional experimental factors (not necessarily known) influence the density measurements or that the density measurements have large variation.s. Small standard deviations indicate that even small effects in the sources of variation can be detected as significant.

Table 5.3 also shows the maximum change among different levels of each experimental factor. These changes are calculated as the difference between the largest and smallest average density biases for the different levels of each factor.

Standard deviations of the experimental error listed in Table 5.3 indicate that the ANOVA model identifies most of the sources of variation for all the density instruments except the ULOOP.

Temperature was a statistically significant factor for all density bias measurements except for the ULOOP. This factor had its greatest effect on the ANL and the PNNL_P density instruments. ANL had a difference of average density biases between the two temperature levels $\left(25^{\circ} \mathrm{C}\right.$ and $\left.50^{\circ} \mathrm{C}\right)$ of $0.08 \mathrm{~g} / \mathrm{mL}$, while PNNL_P had a difference of $0.21 \mathrm{~g} / \mathrm{mL}$.

Matrix type was also a statistically significant factor for all density instruments. ANL density measurements were affected to the greatest extent by the kaolin/sand/gravel matrix. MPOINT, ORNL, and PNNL_P density measurements were affected most by the kaolin/sand matrix, and PROMASS and ULOOP by the kaolin/water matrix. The matrix effect depends on the weight percent factor. The maximum matrix effect may occur at either the low or the high weight percent level. Slurry flow rate did not significantly affect the average density bias readings from any of the six instruments. 
Table 5.3. Significant sources of variation at the $5 \%$ significance level for the slurry flow-rate experiment $t^{a, b}$

\begin{tabular}{ccccccc}
\hline \multirow{2}{*}{$\begin{array}{c}\text { Sources of } \\
\text { variation in } \\
\text { density bias }\end{array}$} & ANL & MPOINT & ORNL & PNNL_P & PROMASS & ULOOP \\
\cline { 2 - 7 } Temperature & $\mathrm{S}(0.08)$ & $\mathrm{S}(0.03)$ & $\mathrm{S}(0.03)$ & $\mathrm{S}(0.21)$ & $\mathrm{S}(0.004)$ & $\mathrm{NS}(0.02)$ \\
Matrix & $\mathrm{S}(0.08)$ & $\mathrm{S}(0.06)$ & $\mathrm{S}(0.09)$ & $\mathrm{S}(0.08)$ & $\mathrm{S}(0.01)$ & $\mathrm{S}(0.71)$ \\
Wt_Pct (matrix) & $\mathrm{S}(0.07)$ & $\mathrm{S}(0.12)$ & $\mathrm{S}(0.07)$ & $\mathrm{S}(0.32)$ & $\mathrm{S}(0.01)$ & $\mathrm{S}(0.91)$ \\
$\beta$ & $\mathrm{NS}(6.6 \mathrm{E}-5)$ & $\mathrm{NS}(1.7 \mathrm{E}-3)$ & $\mathrm{NS}(-7.6 \mathrm{E}-5)$ & $\mathrm{NS}(-2.2 \mathrm{E}-3)$ & $\mathrm{NS}(1.1 \mathrm{E}-4)$ & $\mathrm{NS}(5.6 \mathrm{E}-4)$ \\
$\begin{array}{c}\text { SD of the } \\
\text { exp. error, g/mL }\end{array}$ & 0.02 & 0.04 & 0.01 & 0.04 & 0.005 & 0.12 \\
\hline
\end{tabular}

"S $=$ significant variation at the $5 \%$ significance level; NS $=$ nonsignificant variation at the $5 \%$ significance level.

${ }^{b}$ Maximum changes of average density biases $(\mathrm{g} / \mathrm{mL})$ for different levels of the experimental factors are given in parentheses.

\subsubsection{Precision of Density Measurements for Slurry Flow-Rate Experiments}

Table 5.4 shows the standard deviations of the density measurements for the slurry flow-rate experiment. The standard deviations were calculated from the density readings made during each experimental run (approximately 15 minutes). Figure 5.4 shows a box plot of the standard deviations of the density readings for each instrument.

Table 5.5 list the results of an ANOVA analysis to identify the significant experimental factors that caused variation in the standard deviations of density readings. MPOINT and PROMASS had very stable density readings for all experimental factors. ANL and ORNL also had stable readings for all experimental factors; the standard deviations ranged from 0.00 to $0.06 \mathrm{~g} / \mathrm{mL}$ (with one unusually high value of $0.30 \mathrm{~g} / \mathrm{mL}$ ) and from 0.00 to $0.03 \mathrm{~g} / \mathrm{mL}$ for ANL and ORNL, respectively. PNNL_P had standard deviations that ranged from 0.00 to $0.10 \mathrm{~g} / \mathrm{mL}$. The ULOOP was not stable for many experimental factor combinations; the deviations ranged from 0.00 to $0.45 \mathrm{~g} / \mathrm{mL}$, and the ANOVA analysis showed that the matrix of kaolin/water caused large-precision variations, especially at a concentration of $20 \mathrm{wt} \%$. While flow rate was the most 
Table 5.4. Standard deviations $(\mathrm{g} / \mathrm{mL})$ averaged over flow rates for the slurry flow-rate experiment ${ }^{a}$

\begin{tabular}{|c|c|c|c|c|c|c|c|c|c|c|c|c|c|c|c|}
\hline \multirow[b]{2}{*}{ Instrument } & \multirow{2}{*}{$\begin{array}{l}\text { Temp. } \\
\left({ }^{\circ} \mathrm{C}\right) \\
\end{array}$} & \multicolumn{3}{|c|}{ Sugar (wt \%) } & \multicolumn{3}{|c|}{ Kaolin/water $(w t \%)$} & \multicolumn{3}{|c|}{ Kaolin/sugar (wt \%) } & \multicolumn{3}{|c|}{ Kaolin/sand $d^{h}(w t \%)$} & \multicolumn{2}{|c|}{ Kaolin/sand/gravel" (wt \%) } \\
\hline & & 40 & 50 & 60 & 10 & 20 & 30 & 8.5 & 15 & 22 & 10 & 20 & 30 & 10 & 20 \\
\hline \multirow[t]{2}{*}{ ANL } & 25 & 0.01 & 0.05 & 0.00 & 0.00 & 0.00 & 0.01 & 0.00 & 0.01 & 0.00 & & & 0.01 & 0.00 & \\
\hline & 50 & 0.01 & 0.01 & 0.01 & 0.01 & 0.01 & 0.02 & 0.01 & 0.01 & 0.00 & & & 0.01 & 0.00 & 0.00 \\
\hline \multirow[t]{2}{*}{ MPOINT } & 25 & 0.00 & 0.00 & 0.00 & 0.00 & 0.00 & 0.00 & 0.00 & 0.00 & 0.00 & 0.00 & 0.00 & 0.00 & 0.00 & 0.00 \\
\hline & 50 & 0.00 & 0.00 & 0.00 & 0.00 & 0.00 & 0.00 & 0.00 & 0.00 & 0.00 & 0.00 & 0.00 & 0.00 & 0.00 & 0.00 \\
\hline \multirow[t]{2}{*}{ ORNL } & 25 & 0.02 & 0.02 & 0.02 & 0.01 & 0.01 & 0.02 & 0.02 & 0.02 & 0.02 & 0.02 & 0.02 & 0.02 & 0.01 & 0.01 \\
\hline & 50 & 0.02 & 0.02 & 0.02 & 0.02 & 0.02 & 0.01 & 0.02 & 0.02 & 0.01 & 0.02 & 0.02 & 0.02 & 0.02 & 0.01 \\
\hline \multirow[t]{2}{*}{ PNNL_P } & 25 & & & & & & 0.02 & 0.01 & 0.05 & 0.01 & 0.02 & 0.04 & 0.01 & 0.01 & 0.01 \\
\hline & 50 & & & & & 0.01 & 0.01 & 0.04 & 0.01 & 0.01 & 0.04 & 0.02 & 0.01 & 0.02 & 0.03 \\
\hline \multirow[t]{2}{*}{ PROMASS } & 25 & 0.00 & 0.00 & 0.00 & 0.00 & 0.00 & 0.00 & 0.00 & 0.00 & 0.00 & 0.00 & 0.00 & 0.00 & 0.00 & 0.00 \\
\hline & 50 & 0.00 & 0.00 & 0.00 & 0.00 & 0.00 & 0.00 & 0.00 & 0.00 & 0.00 & 0.00 & 0.00 & 0.00 & 0.00 & 0.00 \\
\hline \multirow[t]{2}{*}{ ULOOP } & 25 & 0.00 & 0.00 & 0.00 & 0.02 & 0.19 & 0.00 & 0.03 & 0.01 & 0.00 & & 0.04 & 0.02 & & \\
\hline & 50 & 0.00 & 0.00 & 0.00 & 0.01 & 0.12 & 0.08 & 0.02 & 0.02 & 0.02 & & 0.02 & 0.01 & & \\
\hline
\end{tabular}

${ }^{c}$ Values are rounded to two decimal places.

${ }^{b}$ Matrix was suspended in $50 \mathrm{wt} \%$ sugar water. 


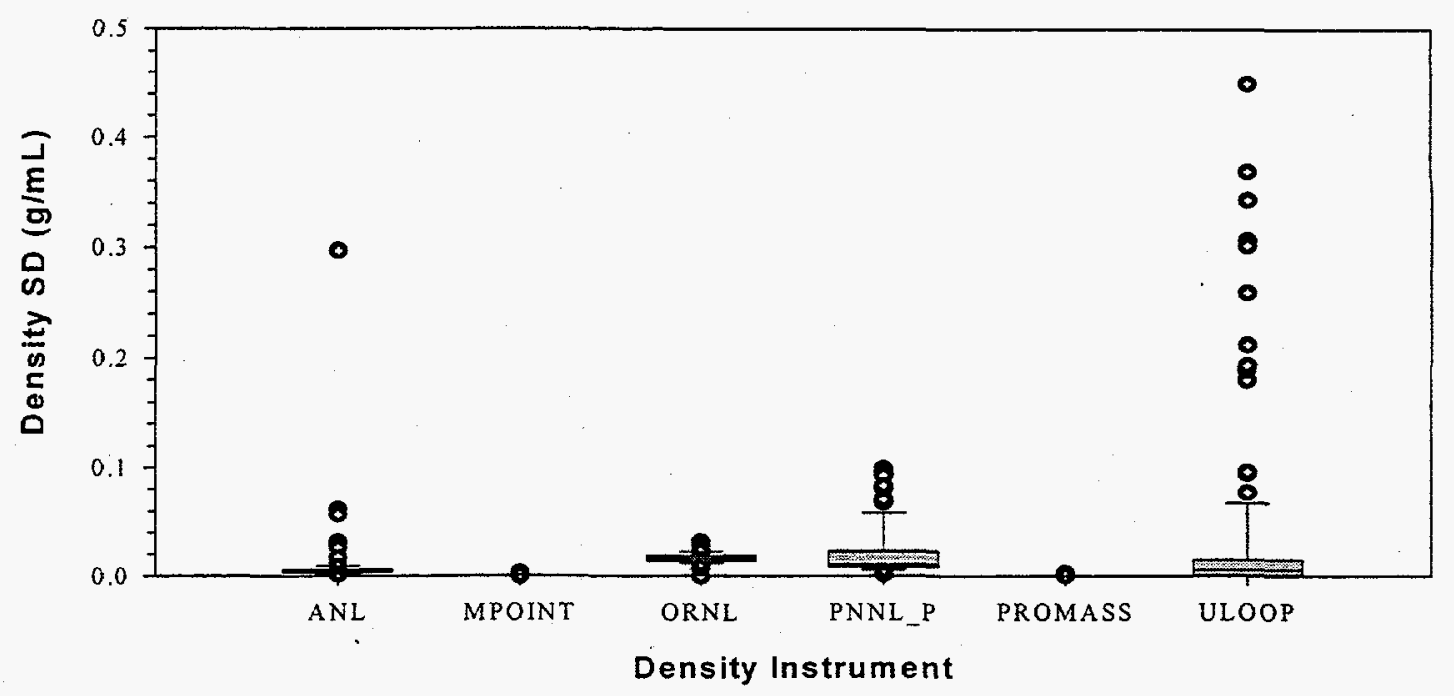

Fig. 5.4. Box plot of standard deviations (SD) of density readings from the slurry flow-rate experiment.

Table 5.5. Significant sources of variation for density precision at the $5 \%$ significance level for the slurry flow-rate experiment ${ }^{\circ}$

\begin{tabular}{|c|c|c|c|c|c|c|}
\hline \multirow{2}{*}{$\begin{array}{c}\text { Sources of } \\
\text { variation in } \\
\text { density precision }\end{array}$} & \multirow[b]{2}{*}{ ANL } & \multirow[b]{2}{*}{ MPONT } & \multicolumn{2}{|c|}{ Density instrument } & \multirow[b]{2}{*}{$\begin{array}{c}\text { PROMAS } \\
\mathrm{S} \\
\end{array}$} & \multirow[b]{2}{*}{ ULOOP } \\
\hline & & & ORNL & PNNL_P & & \\
\hline Temperature & NS & NS & NS & NS & $S$ & NS \\
\hline Matrix & NS & NS & NS & NS & $S$ & S \\
\hline Wt_Pct (matrix) & NS & $S$ & NS & NS & NS & $S$ \\
\hline$\beta$ & $\begin{array}{c}\text { NS(1.7E- } \\
3 \text { ) }\end{array}$ & $S(-1.7 \mathrm{E}-5)$ & $\begin{array}{c}\mathrm{NS}(6.8 \mathrm{E}- \\
5)\end{array}$ & $S(-2.1 E-3)$ & $S(-2.9 \mathrm{E}-5)$ & $S(-4.3 E-3)$ \\
\hline SD of the & & 0.0003 & & 0.022 & 0.0003 & 0.060 \\
\hline Exp. Error $(\mathrm{g} / \mathrm{mL})$ & 0.027 & & 0.005 & & & \\
\hline
\end{tabular}


statistically significant experimental factor for variation in the standard deviations of density readings for MPONT, PNNL_P, and PROMASS, it should be emphasized that the actual influence of this factor was very small and had no practical importance. This factor also made a significant contribution to the instability of the ULOOP density readings.

\subsubsection{Density Bias for the Experiments with Different Air Flows}

Experiments were performed to examine the effect of air flow on the density measurements. At a constant matrix slurry flow of $5 \mathrm{ft} / \mathrm{s}$, air was introduced into the slurry matrix at the rates of $0,0.33$, and $0.66 \mathrm{cfm}$. Table 5.6 shows the combination of experimental factors for each instrument where density measurements were recorded. The MPOINT, ORNL, PROMASS, and ULOOP instruments completed all 57 runs; the ANL and PNNL-P instruments completed 44 runs and 47 runs, respectively. Instrument PNNL-T did not complete any of the runs.

Table 5.6. Completed runs in the air flow-rate experiment

\begin{tabular}{|c|c|c|c|c|c|c|c|}
\hline \multirow{2}{*}{$\begin{array}{l}\text { Slurry } \\
\text { matrix }\end{array}$} & \multirow{2}{*}{$\begin{array}{l}\text { Nominal } \\
\text { solids } \\
\text { conc. } \\
\text { (wt \%) }\end{array}$} & \multicolumn{3}{|c|}{$\begin{array}{l}\text { Temp. }=25^{\circ} \mathrm{C} \\
\text { Air flow (cfm) }\end{array}$} & \multicolumn{3}{|c|}{$\begin{array}{l}\text { Temp. }=50^{\circ} \mathrm{C} \\
\text { Air flow (cfm) }\end{array}$} \\
\hline & & 0 & 0.33 & 0.66 & 0 & 0.33 & 0.66 \\
\hline Kaolin/water & $\begin{array}{l}10 \\
20 \\
30\end{array}$ & $\begin{array}{l}X, P \\
X, P \\
X\end{array}$ & $\begin{array}{l}X, P \\
X, P\end{array}$ & $X$ & $\begin{array}{l}X, P \\
X \\
X\end{array}$ & $\begin{array}{l}X, P \\
X \\
X\end{array}$ & $\begin{array}{l}X, P \\
X \\
X\end{array}$ \\
\hline Kaolin/sugar & $\begin{array}{l}8.5 \\
15 \\
22\end{array}$ & $\begin{array}{l}X \\
X \\
X\end{array}$ & $\begin{array}{l}X \\
X\end{array}$ & $\begin{array}{l}X \\
X\end{array}$ & $\begin{array}{c}X \\
X \\
X, U\end{array}$ & $\begin{array}{c}X \\
X \\
X, U\end{array}$ & $\begin{array}{l}X \\
X\end{array}$ \\
\hline Kaolin/sand ${ }^{b}$ & $\begin{array}{l}10 \\
20 \\
30\end{array}$ & $\begin{array}{c}X, A, U \\
X, A \\
X, U\end{array}$ & $\begin{array}{c}X, A, U \\
X, A \\
X, U\end{array}$ & $\begin{array}{l}X, A \\
X, U\end{array}$ & $\begin{array}{c}\mathrm{X}, \mathrm{A}, \mathrm{U} \\
\mathrm{X}, \mathrm{A} \\
\mathrm{X}\end{array}$ & $\begin{array}{c}X, A, U \\
X, A \\
X\end{array}$ & $\mathrm{X}, \mathrm{A}$ \\
\hline Kaolin/sand/gravel ${ }^{b}$ & $\begin{array}{l}10 \\
20\end{array}$ & $\begin{array}{c}X, U \\
X, A, U\end{array}$ & $\begin{array}{c}X, U \\
X, A, U\end{array}$ & $\begin{array}{c}X, U \\
X, A, U\end{array}$ & $\begin{array}{l}X, U \\
X, U\end{array}$ & $\begin{array}{l}X, U \\
X, U\end{array}$ & $\begin{array}{l}X, U \\
X, U\end{array}$ \\
\hline
\end{tabular}

${ }^{a} \mathrm{X}=$ runs by ANL, MPOINT, ORNL, PNNL_P, PROMASS, and ULOOP except where noted; $A=A N L$ did participate in this run; $P=P N N L+P$ did not participate in this run; $U=U L O O P$ did not participate in this run.

${ }^{b}$ Matrix included $50 \mathrm{wt} \%$ sugar water. 
The effects of the different experimental factors on density bias in the air-effects experiment were analyzed by the ANOVA method. ${ }^{4}$ An ANOVA model was used to represent the sources of variation for density bias. These sources of variation were then compared with the experimental error to test for effects at the $5 \%$ significance level.

The ANOVA model to represent density bias variation is

Density Bias $=$ Mean + Temp + Matrix + Wt_Pct $($ matrix $)+$ Air + Error, where

Air $=$ air flow effect.

Table 5.7 shows the results of the ANOVA by identifying the significant sources of variation in the density biases. Large standard deviations of the experimental error indicate that either additional unknown experimental factors were influencing the density bias variation or the density bias measurements have a large random error component. Small standard deviations indicate that even small effects in the sources of variation can be detected as significant. The table also shows the maximum change of density bias among the levels of each experimental factor.

Table 5.7. Significant sources of variation at the $5 \%$ significance level for the air effects experiment $t^{a, b}$

\begin{tabular}{|c|c|c|c|c|c|c|}
\hline \multirow{2}{*}{$\begin{array}{l}\text { Sources of } \\
\text { variation in } \\
\text { density bias }\end{array}$} & \multicolumn{6}{|c|}{ Density instrument } \\
\hline & ANL & MPOINT & ORNL & PNNL_P & PROMASS & ULOOP \\
\hline Temperature & $S(0.08)$ & NS $(0.06)$ & $S(0.04)$ & $S(0.23)$ & NS $(0.01)$ & NS (0.04) \\
\hline Matrix & $\mathrm{S}(0.12)$ & $S(0.13)$ & $S(0.11)$ & $S(0.08)$ & $S(0.10)$ & $\mathrm{S}(0.10)$ \\
\hline Wt_Pct (matrix) & $\mathrm{S}(0.10)$ & NS $(0.17)$ & $S(0.07)$ & $S(0.34)$ & NS $(0.06)$ & $S(0.44)$ \\
\hline Air flow & $\mathrm{S}(0.05)$ & $S(0.34)$ & $S(0.06)$ & NS (0.04) & NS $(0.06)$ & NS $(0.06)$ \\
\hline $\begin{array}{l}\text { SD of the } \\
\text { exp. error }\end{array}$ & 0.05 & 0.09 & 0.01 & 0.06 & 0.09 & 0.15 \\
\hline
\end{tabular}

${ }^{a} \mathrm{~S}=$ significant variation at the $5 \%$ significance level; NS = nonsignificant variation at the $5 \%$ significance level.

${ }^{h}$ Maximum changes in density biases $(\mathrm{g} / \mathrm{mL})$ averaged over different levels of the experimental factors in parentheses. 
Table 5.7 indicates that the ANOVA model best explains the density bias variations for the ANL, ORNL, and PNNL_P density instruments; moderately explains the density bias variations for the MPOINT and PROMASS instruments; and poorly explains the density bias variation for the ULOOP instrument.

Temperature effects were statistically significant for density biases from the ANL, PNNL_P, and ORNL instrument readings. A large difference $(0.25 \mathrm{~g} / \mathrm{mL})$ occurred between the average density biases for $25^{\circ} \mathrm{C}$ and those for $50^{\circ} \mathrm{C}$ in the case of PNNL_P. Temperature changes caused about the same amount of maximum change in density bias for ANL, MPOINT, ORNL, and ULOOP density instruments but only a minimal effect on the PROMASS density instrument.

Matrix effects were statistically significant for all density instruments, regardless of how small or how large the standard deviation for the experimental error. The maximum change in density biases for different matrix ty'pes was about $0.12 \mathrm{~g} / \mathrm{mL}$ for each of the instruments. Generally, the kaolin/sand/gravel matrix caused a positive density bias (overestimate), while the kaolin/water matrix caused either a much lower density bias or a negative density bias (underestimate).

The weight percents for each slurry matrix had significant effects on the density biases for ANL, ORNL, PNNL_P, and ULOOP but not on those for MPOINT and PROMASS. It was the most influential experimental factor on PNNL_P, with the maximum change in density bias $(0.34 \mathrm{~g} / \mathrm{mL})$ occurring between the 15 and $22 \mathrm{wt} \%$ of the kaolin/sugar matrix. The maximum change in density bias for ANL and ULOOP occurred in the kaolin/water matrix and for OFNL in the kaolin/sand matrix.

Air flow significantly affected the density biases for the ANL, MPOINT, and ORNL instruments but not for the PNNL_P, PROMASS, and ULOOP instruments. Air flow affected the MPOINT instrument the most and the PNNL_P the least. The effect of air flow on the ANL, ORNL, PROMASS, and UL,OOP instruments caused about the same maximum change $(0.06 \mathrm{~g} / \mathrm{mL})$ in density bias in each case. Figure 5.5 shows the density bias relative to air flow. 


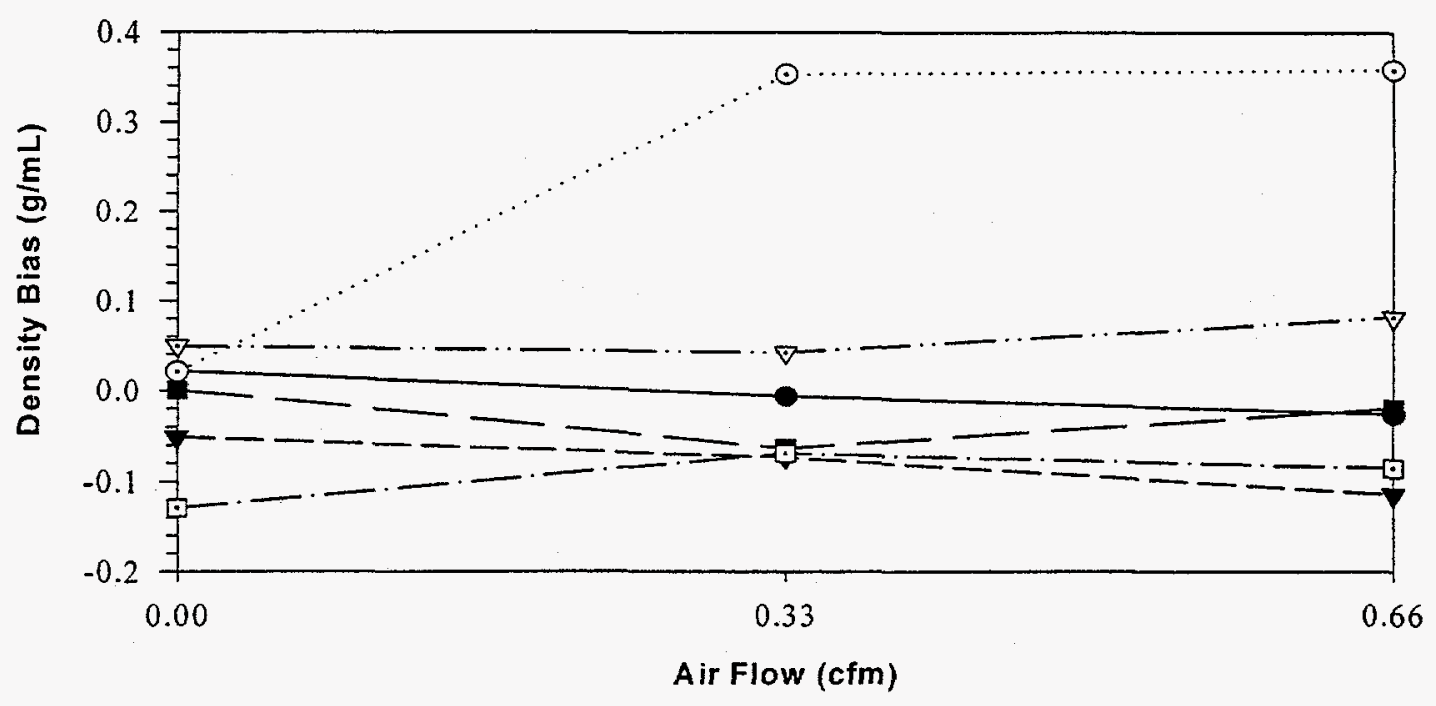

Fig. 5.5. Average density biases vs air flow for ANL (solid circle), MPOINT (open circle), ORNL (solid triangle), PNNL_P (open triangle), PROMASS (solid square), and ULOOP (open square).

\subsubsection{Precision for the Experiments with Different Air Flows}

Table 5.8 identifies the significant experimental factors affecting the standard deviations of density readings using an ANOVA analysis. ANL, MPOINT, ORNL, and PNNL_P have small experimental errors but could not detect any significant experimental factors that affected the variation of density standard deviations. Only PROMASS and ULOOP have the significant factors of Weight Percent and Air Flow. The air flow increased the variability of PROMASS readings from an average standard deviation of 0.0002 for a 0 -cfm air flow to 0.0681 for a 0.66 -cfm air flow. For ULOOP, the air flow decreased the variability from an average standard deviation of 0.0572 for 0 -cfm air flow to 0.0086 for 0.66 -cfm air flow.

Table 5.9 shows the standard deviations of the density measurements for the air flowrate experiment. Figure 5.6 shows a box plot of the standard deviations of the density readings for each instrument. These results indicate that the MPOINT instrument showed 
essentially zero deviation. Normally, such results would indicate that this instrument exhibited the best performance for the test; however, the zero-deviation result is misleading. In actuality, the MPOINT instrurnent went into an error mode when air was introduced into the slurry. The MPOINT was programmed to respond with the highest value of the range when it encountered an error mode. Since the instrument responded with the same value at each interval, the standard-deviation calculations correspondingly indicated a very low standard deviation.

Table 5.8. Significant sources of variation in the standard deviations of the density readings at the $5 \%$ significance level for the air flow-rate experiment ${ }^{a}$

\begin{tabular}{|c|c|c|c|c|c|c|}
\hline \multirow{2}{*}{$\begin{array}{c}\text { Sources of } \\
\text { variation for } \\
\text { density SD }\end{array}$} & \multicolumn{6}{|c|}{ Density instrument } \\
\hline & ANL & MPOINT & ORNLL & PNNL_P & PROMASS & ULOOP \\
\hline Temperature & NS & NS & $\mathrm{NS}$ & NS & NS & NS \\
\hline Matrix & NS & NS & $\mathrm{NS}$ & NS & NS & NS \\
\hline $\begin{array}{l}\text { Wt_Pct } \\
\text { (matrix) }\end{array}$ & NS & NS & $\mathrm{NG}$ & NS & $\mathrm{S}$ & $S$ \\
\hline Air flow & NS & NS & $\mathrm{NS}$ & NS & $\mathrm{S}$ & S \\
\hline $\begin{array}{l}\mathrm{SD} \text { of the } \\
\text { exp. error }\end{array}$ & 0.01 & 0.02 & 0.03 & 0.03 & 0.03 & 0.06 \\
\hline
\end{tabular}


Table 5.9. Standard deviations $(\mathrm{g} / \mathrm{mL})$ for air flow-rate experiment

\begin{tabular}{|c|c|c|c|c|c|c|c|c|c|c|c|c|c|}
\hline \multirow{2}{*}{$\begin{array}{l}\text { Density } \\
\text { instrument }\end{array}$} & \multirow{2}{*}{$\begin{array}{l}\text { Temp. } \\
\left({ }^{\circ} \mathrm{C}\right)\end{array}$} & \multirow{2}{*}{$\begin{array}{c}\text { Air } \\
\text { flow } \\
\text { (cfm) }\end{array}$} & \multicolumn{3}{|c|}{ Kaolin/water (wt \%) } & \multicolumn{3}{|c|}{ Kaolin/sugar (wt \%) } & \multicolumn{3}{|c|}{ Kaolin/sand (wt \%) } & \multicolumn{2}{|c|}{ Kaolin/sand/gravel (wt \%) } \\
\hline & & & 10 & 20 & 30 & 8.5 & 15 & 22 & 10 & 20 & 30 & 10 & 20 \\
\hline \multirow[t]{6}{*}{ ANL } & 25 & 0 & 0.002 & 0.003 & 0.003 & 0.003 & 0.005 & 0.005 & & & 0.007 & 0.001 & \\
\hline & & 0.33 & 0.003 & 0.002 & & 0.006 & 0.004 & & & & 0.012 & 0.006 & \\
\hline & & 0.66 & & 0.003 & & 0.006 & 0.007 & & & & 0.009 & 0.004 & \\
\hline & 50 & 0 & 0.006 & 0.005 & 0.004 & 0.004 & 0.004 & 0.005 & & & 0.018 & 0.004 & 0.004 \\
\hline & & 0.33 & 0.004 & 0.003 & 0.056 & 0.007 & 0.009 & 0.005 & & & 0.008 & 0.009 & 0.007 \\
\hline & & 0.66 & 0.003 & 0.008 & 0.003 & 0.005 & 0.007 & & & & & 0.008 & 0.006 \\
\hline \multirow[t]{6}{*}{ MPOINT } & 25 & 0 & 0.000 & 0.001 & 0.001 & 0.000 & 0.000 & 0.000 & 0.000 & 0.001 & 0.001 & 0.001 & 0.000 \\
\hline & & 0.33 & 0.000 & 0.000 & & 0.000 & 0.000 & & 0.000 & 0.000 & 0.000 & 0.000 & 0.000 \\
\hline & & 0.66 & & 0.000 & & 0.000 & 0.000 & & & 0.000 & 0.000 & 0.000 & 0.000 \\
\hline & 50 & 0 & 0.000 & 0.000 & 0.001 & 0.001 & 0.001 & 0.001 & 0.000 & 0.000 & 0.000 & 0.001 & 0.001 \\
\hline & & 0.33 & 0.000 & 0.000 & 0.136 & 0.000 & 0.000 & 0.000 & 0.000 & 0.000 & 0.000 & 0.000 & 0.000 \\
\hline & & 0.66 & 0.000 & 0.000 & 0.000 & 0.000 & 0.000 & & & 0.000 & & 0.000 & 0.000 \\
\hline \multirow{6}{*}{ ORNL } & 25 & 0 & 0.013 & 0.013 & 0.013 & 0.024 & 0.012 & 0.022 & 0.016 & 0.014 & 0.018 & 0.014 & 0.012 \\
\hline & & 0.33 & 0.008 & 0.015 & & 0.023 & 0.020 & & 0.014 & 0.020 & 0.016 & 0.016 & 0.030 \\
\hline & & 0.66 & & 0.015 & & 0.018 & 0.019 & & & 0.010 & 0.010 & 0.211 & 0.019 \\
\hline & 50 & 0 & 0.023 & 0.024 & 0.009 & 0.015 & 0.014 & 0.014 & 0.015 & 0.0160 & 0.019 & 0.023 & 0.012 \\
\hline & & 0.33 & 0.020 & 0.018 & 0.015 & 0.017 & 0.016 & 0.013 & 0.016 & 0.018 & 0.014 & 0.021 & 0.023 \\
\hline & & 0.66 & 0.023 & 0.016 & 0.030 & 0.013 & 0.011 & & & 0.029 & & 0.023 & 0.011 \\
\hline \multirow[t]{6}{*}{ PNNL_P } & 25 & 0 & & & 0.013 & 0.007 & 0.092 & 0.023 & 0.015 & 0.011 & 0.009 & 0.009 & 0.010 \\
\hline & & 0.33 & & & & 0.016 & 0.008 & & 0.018 & 0.096 & 0.045 & 0.026 & 0.012 \\
\hline & & 0.66 & & & & 0.013 & 0.011 & & & 0.019 & 0.049 & 0.024 & 0.039 \\
\hline & 50 & 0 & & 0.012 & & 0.038 & 0.006 & 0.003 & 0.007 & 0.006 & 0.028 & 0.008 & 0.034 \\
\hline & & 0.33 & & 0.011 & 0.012 & 0.007 & 0.008 & 0.015 & 0.063 & 0.067 & 0.028 & 0.090 & 0.029 \\
\hline & & 0.66 & & 0.015 & 0.014 & 0.071 & & & & 0.043 & & 0.090 & 0.055 \\
\hline
\end{tabular}


Table 5.9 (cont.)

\begin{tabular}{|c|c|c|c|c|c|c|c|c|c|c|c|c|c|}
\hline \multirow{2}{*}{$\begin{array}{l}\text { Density } \\
\text { instrument }\end{array}$} & \multirow{2}{*}{$\begin{array}{l}\text { Temp. } \\
\left({ }^{\circ} \mathrm{C}\right)\end{array}$} & \multirow{2}{*}{$\begin{array}{l}\text { Air } \\
\text { flow } \\
\text { (cfm) }\end{array}$} & \multicolumn{3}{|c|}{ Kaolin/water (wt \%) } & \multicolumn{3}{|c|}{ Kaolin/sugar (wt \%) } & \multicolumn{3}{|c|}{ Kaolin/sand (wt \%) } & \multicolumn{2}{|c|}{ Kaolin/sand/gravel (wt \%) } \\
\hline & & & 10 & 20 & 30 & 8.5 & 15 & 22 & 10 & 20 & 30 & 10 & 20 \\
\hline \multirow[t]{6}{*}{ PROMASS } & 25 & 0 & 0.000 & 0.000 & 0.000 & 0.000 & 0.000 & 0.000 & 0.000 & 0.000 & 0.000 & 0.000 & 0.000 \\
\hline & & 0.33 & 0.001 & 0.002 & & 0.002 & 0.006 & & 0.001 & 0.072 & 0.064 & 0.001 & 0.040 \\
\hline & & 0.66 & & 0.087 & & 0.077 & 0.145 & & & 0.114 & 0.099 & 0.000 & 0.150 \\
\hline & 50 & 0 & 0.000 & 0.000 & 0.000 & 0.000 & 0.003 & 0.000 & 0.000 & 0.000 & 0.000 & 0.000 & 0.000 \\
\hline & & 0.33 & 0.001 & 0.002 & 0.1334 & 0.002 & 0.108 & 0.083 & 0.001 & 0.041 & 0.069 & 0.001 & 0.092 \\
\hline & & 0.66 & 0.035 & 0.063 & 0.113 & 0.003 & 0.065 & & & 0.002 & & 0.010 & 0.059 \\
\hline \multirow[t]{6}{*}{ ULOOP } & 25 & 0 & 0.063 & 0.096 & 0.000 & 0.097 & 0.040 & 0.002 & 0.095 & & & & \\
\hline & & 0.33 & 0.010 & 0.010 & & 0.013 & 0.011 & & 0.011 & & & & \\
\hline & & 0.66 & & 0.009 & & 0.012 & 0.008 & & 0.011 & & & & \\
\hline & 50 & 0 & 0.023 & 0.192 & 0.001 & 0.060 & 0.056 & & 0.073 & 0.003 & & & \\
\hline & & 0.33 & 0.009 & 0.010 & 0.002 & 0.010 & 0.009 & & 0.008 & 0.008 & & & \\
\hline & & 0.66 & 0.011 & 0.010 & 0.002 & 0.011 & 0.007 & & 0.006 & & & & \\
\hline
\end{tabular}




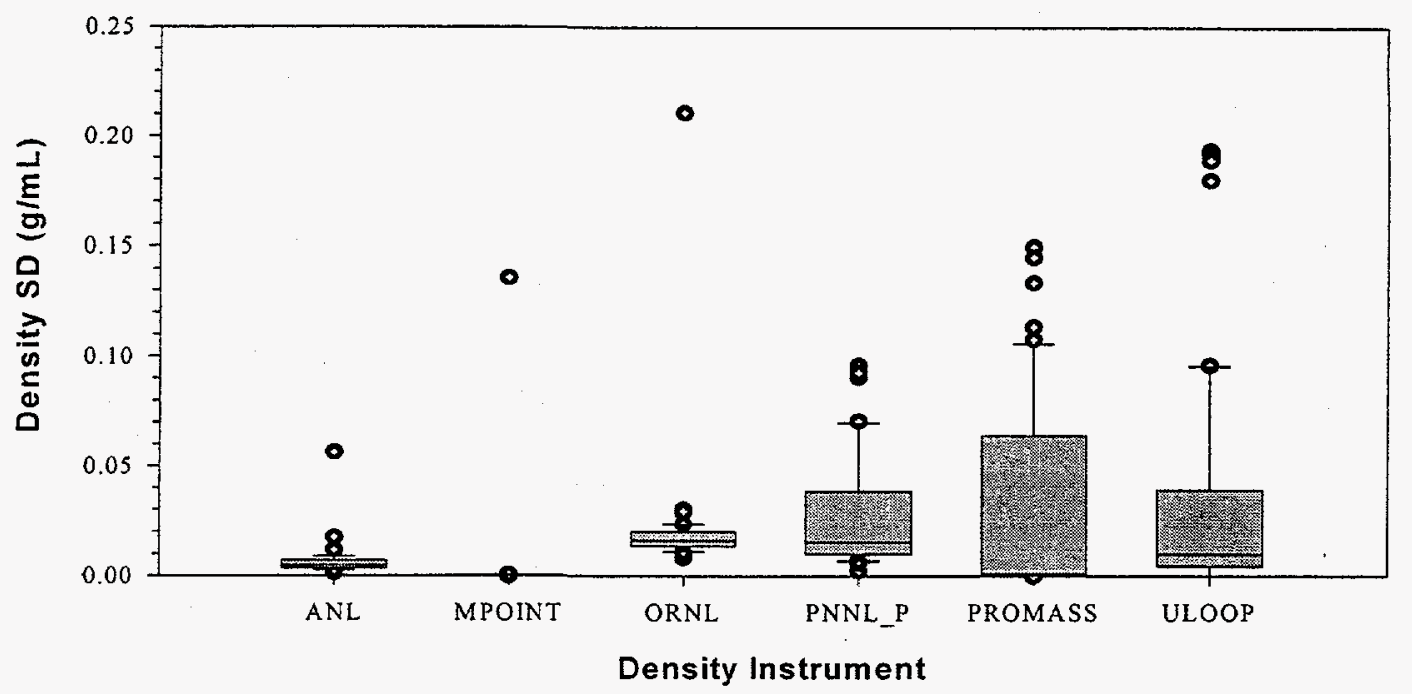

Fig. 5.6. Box plots of standard deviations (SD) of density measurements by different density instruments for all combinations of the factors examined in the air flow-rate experiments.

\subsection{VISCOSITY EVALUATION}

Two instrumentation methodologies (three instruments) were evaluated to measure the viscosities of the slurries. These included the ANL ultrasonic flow instrument and the SNL quartz resonator instruments (in-tank and pipeline). SNL had their data monitoring system setup to determine the density-viscosity product by separately evaluating a voltage signal and a frequency signal from each instrument; therefore, four data points were evaluated for the two SNL instruments.

The reference laboratory was only able to obtain viscosity data on the surrogate slurries that did not contain sand; therefore, the instrumentation results could only be compared for the kaolin/water and kaolin/sucrose slurries. Since the slurries were nonNewtonian, the viscosity of a given slurry was dependent on the shear rate at which the instrument operates. The ANL instrument developer estimated that the instrument operated at a shear rate of $5000 \mathrm{~s}^{-1}$. The SNL instrument developer estimated that the 
shear rate for the quartz resonator instruments; was between 100 and $1500 \mathrm{~s}^{-1}$. For the purposes of this evaluation, the ANL instrument was evaluated with the reference viscosity at $5000 \mathrm{~s}^{-1}$ and the SNL instrument-data were compared with the reference viscosity acquired at $800 \mathrm{~s}^{-1}$ (mid-point of range). In some instances, the viscosity reference data were determined by interpolation.

A box plot of the viscosity bias vs the instruments and slurry matrices is shown in Fig. 5.7. The data indicate that the instruments had large biases in determining the viscosity. The SNL in-tank instrument appeared to work satisfactorily for the kaolin/water slurry, but the bias became much larger when dealing with the slurries containing sugar water. Part of the influence on the bias of the SNL pipeline sensor may be due to the instrument's sensitivity to the system pressure.

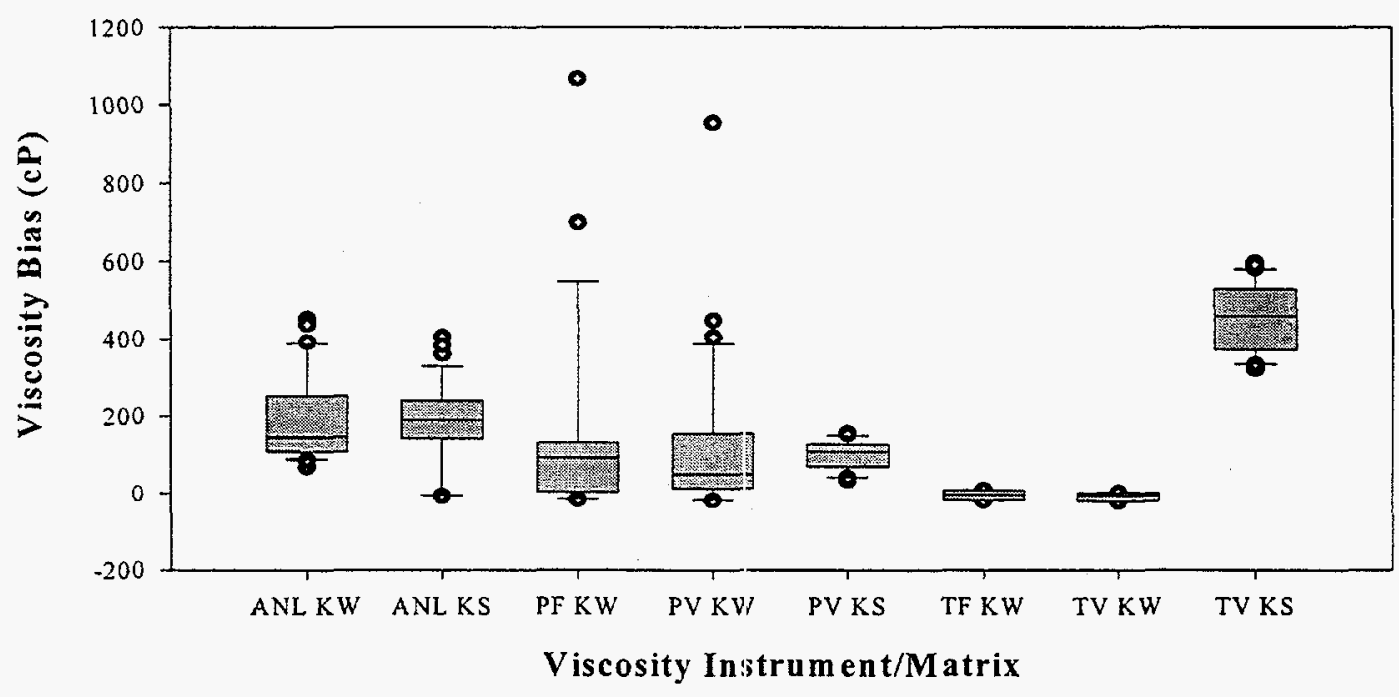

Fig. 5.7. Viscosity bias for different instruments and matrixes: $A N L=$ Argonne National Laboratory instrument; $P F=S N L$ pipeline frequency; $P V=S N L$ pipeline voltage; $\mathrm{TF}=\mathrm{SNL}$ tank frequency; $\mathrm{TV}=\mathrm{SNL}$ tank voltage; $\mathrm{KW}=$ kaolin/water; KS = kaolin/sugar. 
The viscosity feature of the ANL instrument did not appear to be working correctly. Thus, more development is probably needed on that feature for the instrument.

The SNL instrument could potentially be used to monitor viscosity changes - but not in an absolute sense. While sugar water solutions were being made up in the feed tank with the probe installed, step changes in the output were observed that corresponded with additions of sugar or water to the matrix. The disadvantage to the instrument is that it is sensitive to thin film deposits forming on the sensor and could need removing from the system for occasional cleaning. This is particularly a problem when dealing with slurries.

\subsection{PARTICLE-SIZE EVALUATION}

The PNNL ultrasonic attenuation in-tank instrument was the only one evaluated for monitoring particle size. This instrument, which worked on the methodology of ultrasonic attenuation, apparently had difficulties with entrained air in the slurry. During a given run, the mean particle size result provided by the instrument from each data point (i.e., 1-min intervals) was the same. Particle size data are shown in Appendix B. The instrument developer evaluated the data and found that the instrument response indicated if air was entrained in the slurry. The PNNL technical lead developer personally viewed the evaluation of the particle size probe in the slurry tank. Neither ORNL nor PNNL personnel could identify a source of air entering the slurry except for the runs where air was intentionally introduced into the slurry. As discussed in Section 3.5.11, PNNL personnel theorize that the air in the slurries was entrained when the kaolin clay powder was mixed with the liquid.

\subsection{SUSPENDED SOLIDS CONCENTRATION EVALUATION}

The instruments that were evaluated for measuring the suspended solids concentration included the BTG SMS-3000, the ANL ultrasonic flow instrument, and the PNNL in-tank particle size probe. 
Table 5.10 gives the average concentration (weight percent) of total suspended solids for the slurry flow-rate experiment, that is, slurries without induced air. An analysis of the data revealed the following:

1. The suspended solids concentrations were not affected by the slurry flow rates, thus indicating that the solids were not settling out of solution in the instrumentation section.

2. Compared with the reference data, the concentrations reported by the ANL instrument underestimated the concentration for the kaolin/water slurries and overestimated the concentration of the kaolin/sugar and kaolin/sand/sugar matrices. A change in slurry temperature from 25 to $50^{\circ} \mathrm{C}$ caused the concentration reported by ANL to double at the $22 \mathrm{wt} \%$ concentration of kaolin/sugar matrix and at the $30 \mathrm{wt} \%$ concentration of kaolin/sand/sugar matrix. The change in temperature levels did not affect the concentrations rejorted by the ANL instrument for other matrix and concentration combinations.

3. BTG's instrument was limited to slurries with a suspended solids concentration less than $20 \%$. The only valid data were from $\sim 10 \mathrm{wt} \%$ kaolin/water matrix, $\sim 8.5 \mathrm{wt} \%$ kaolin/sugar matrix, $\sim 10 \mathrm{wt} \% \mathrm{kaolin} / \mathrm{sand}$ matrix, and $\sim 10 \mathrm{wt} \% \mathrm{kaolin} / \mathrm{sand} /$ gravel matrix. Since it uses an optically based method, the probe had to be recalibrated with each slurry matrix. Initially, the instrument was calibrated by inserting the probe into buckets of slurries with known concentrations of suspended solids and composition. It was later decided, for convenience, to calibrate the instrument with the actual slurry flowing through the pipe and entering the concentration of suspended solids based on the density reported by the m-Point Coriolis meter (see Section 5.4.1). The operation manual for the instrument indicated that the pipeline calibration method is the preferred way for calibrating the instrument, and the performance of the instrument did improve (compared with the reference) after conversion to the on-line calibration. After the instrument had been calibrated on-line with the kaolin/sand and kaolin/sand/gravel slurries, there was no practical difference between the suspended solids concentration results for the BTG instrument and the reference 
Table 5.10. Total suspended solids concentration for slurry flow-rate experiment

\begin{tabular}{|c|c|c|c|c|c|c|c|c|c|c|c|c|c|c|c|}
\hline \multirow{2}{*}{$\begin{array}{l}\text { Density } \\
\text { instrument }\end{array}$} & \multirow{2}{*}{$\begin{array}{l}\text { Temp } \\
\left({ }^{\circ} \mathrm{C}\right)\end{array}$} & \multicolumn{3}{|c|}{ Sugar (wt \%) } & \multicolumn{3}{|c|}{ Kaolin/water (wt \%) } & \multicolumn{3}{|c|}{ Kaolin/sugar (wt \%) } & \multicolumn{3}{|c|}{ Kaolin/sand ${ }^{a}(\mathrm{wt} \%)$} & \multicolumn{2}{|c|}{ Kaolin/sand/graveP (wt \%) } \\
\hline & & 40 & 50 & 60 & 10 & 20 & 30 & 8.5 & 15 & 22 & 10 & 20 & 30 & 10 & 20 \\
\hline \multirow[t]{2}{*}{ Reference } & 25 & & & & 6.9 & 15.1 & 24.9 & 8.0 & 14.5 & 22.4 & 9.7 & 20.8 & 26.7 & 11.2 & 22.0 \\
\hline & 50 & & & & 7.1 & 15.1 & 24.6 & 8.7 & 14.2 & 22.1 & 9.3 & 20.7 & 26.7 & 11.9 & 20.9 \\
\hline \multirow[t]{2}{*}{ ANL } & 25 & 0.0 & 0.2 & 0.0 & 2.9 & 4.5 & 5.9 & 44.8 & 74.4 & 25.4 & & & 42.4 & 0.2 & \\
\hline & 50 & 0.0 & 0.0 & 0.4 & 2.9 & 4.7 & 6.2 & 43.8 & 78.7 & 50.1 & & & 84.1 & 0.2 & 0.2 \\
\hline \multirow[t]{2}{*}{ BTG } & 25 & & & & 11.3 & $b$ & $b$ & 4.4 & $b$ & $b$ & 10.7 & $b$ & $b$ & 11.5 & $b$ \\
\hline & 50 & & & & $b$ & $b$ & $b$ & 9.7 & $b$ & $b$ & $b$ & $b$ & $b$ & $b$ & $b$ \\
\hline \multirow[t]{2}{*}{ PNNL } & 25 & & & & 45.9 & & & 90.2 & 90.2 & 70.7 & & 83.9 & 71.6 & & \\
\hline & 50 & & & & & & & & & & & & & & \\
\hline
\end{tabular}

${ }^{a}$ This matrix was in $50 \mathrm{wt} \%$ sugar water medium.

${ }^{b}$ The instrument was out of range for these tests. 
laboratory's weight percent results at the $25^{\circ} \mathrm{C}$ level. However, the data also show that the BTG instrument was temperature sensitive. After the slurry temperature had been increased to $50^{\circ} \mathrm{C}$, the output increased beyond the range for the instrument.

4. PNNL's instrument (i.e., the particle size instrument) was restricted (by the developer) to measuring the suspended solids concentrations at $25^{\circ} \mathrm{C}$. As reported for the particle size measurement, the developer indicated that the instrument appeared to be affected by entrained air in the slurry matrix. Based on the concentration of suspended solids reported by the instrument, it appears that the percent solids output was also affected by the same problem. The concentrations of suspended solids obtained with the instrument were five to ten times larger than those reported by the reference laboratory.

Table 5.11 gives the average concentration of total suspended solids (wt \%) for the air flow-rate experiment, in which tests were performed by purposely introducing air into the slurry matrices. The data can be summarized as follows:

1. The suspended solids concentrations reported by the ANL instrument were significantly ( $5 \%$ significance level) affected by air flow. They also increased with increasing flow rates. The biggest increases occurred when the air flow rate was increased from $0 \mathrm{cfm}$ to $0.33 \mathrm{cfm}$. The ANL instrument underestimated the concentrations for both the kaolin/water and kaolin/sand/gravel matrices and overestimated the concentrations for the kaolin/sugar and kaolin/sand matrix. The concentration values significantly increased when the temperature was increased from $25^{\circ} \mathrm{C}$ to $50^{\circ} \mathrm{C}$.

2. No significant air flow-rate effects were detected for the suspended solids concentration results obtained by the $\mathrm{BTG}$ instrument. The concentrations were essentially the same as those obtained from the reference laboratory for $25^{\circ} \mathrm{C}$. As mentioned earlier, the BTG instrument was affected by the slurry temperature at $50^{\circ} \mathrm{C}$. 


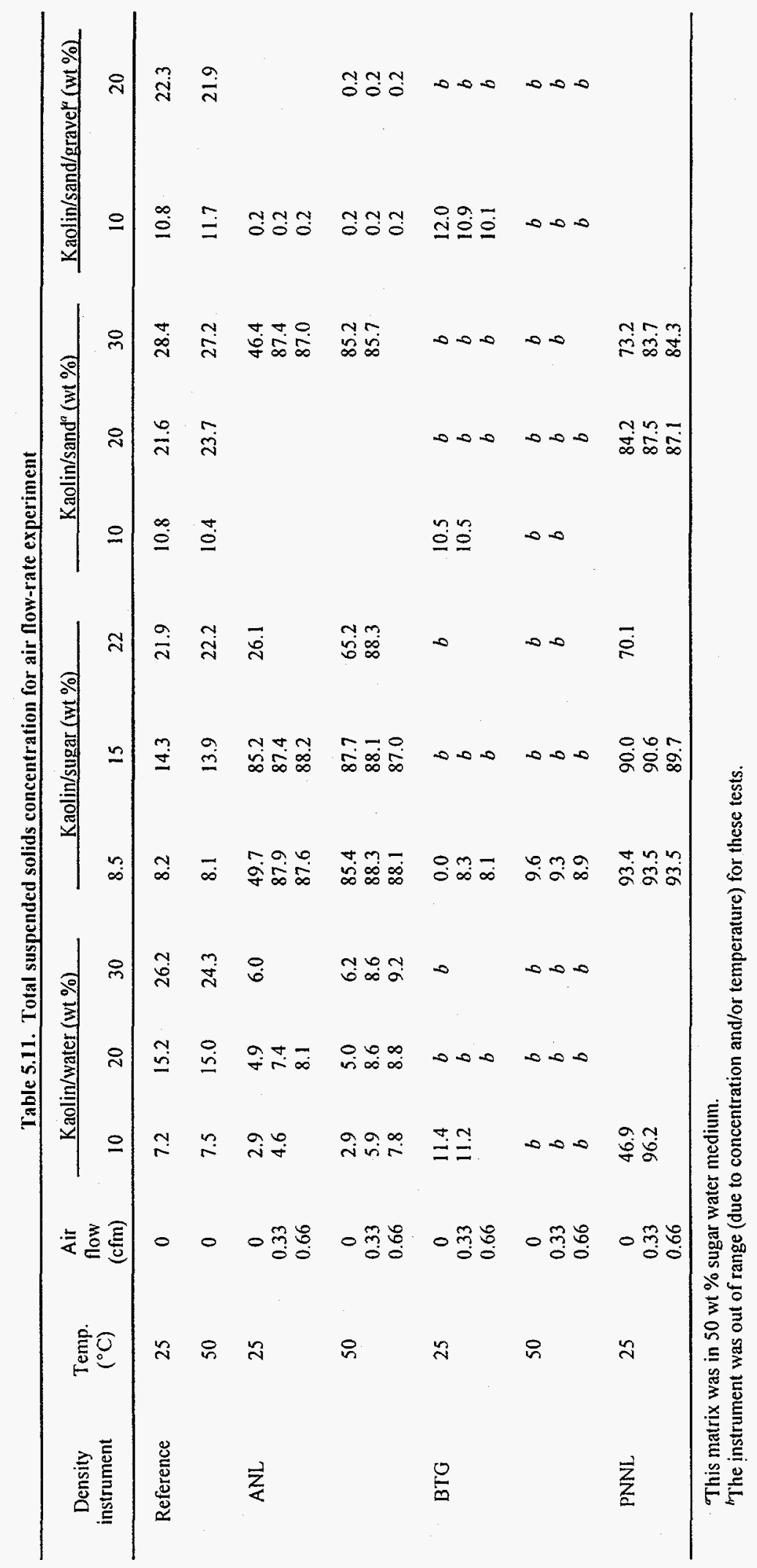




\subsubsection{Recommendations for Suspended Solids Monitor}

The BTG instrument worked well when the suspended solids concentration was less than $15 \mathrm{wt} \%$ and the temperature was $25^{\circ} \mathrm{C}$. However, the concentration range for the BTG instrument will vary, depending on the properties of the slurry to be evaluated. Based on comments from the sales representative of the current manufacturer for the instrument that the probe tip for the RDP-10/5 would not withstand radiation well, it is unlikely that any DOE site would want to use the instrument with this particular probe in a radioactive application unless the radioactivity level was very low. However, the manufacturer has other probes that work on the same principle, and one of them may be suitable for a particular application.

Both the ANL and the PNNL ultrasonic instruments need more development work to resolve the problems associated with measuring suspended solids concentration.

\subsubsection{Suspended Solids Concentration from Density Measurement}

An alternative to measuring percent solids directly is to calculate the percent suspended solids from the density of the slurry. The operation manual for the Endress + Hauser m-Point Coriolis meter provides the following equation to use for such calculations:

$$
\text { Suspended solids (wt \%) }=\frac{D_{s}\left(\rho-D_{L}\right)}{\rho\left(D_{s}-D_{L}\right)} \times 100 \text {, }
$$

where

$\rho=$ density of the slurry,

$D_{S}=$ density of solid particles (bone-dry),

$\mathrm{D}_{\mathrm{L}}=$ density of carrier liquid.

This equation can be rewritten as follows

$$
\text { Suspended solids (wt \%) }=\frac{D_{s} \times 100}{D_{s}-D_{L}}-\frac{D_{s} \times D_{L} \times 100}{\left(D_{s}-D_{L}\right)} \frac{1}{\rho} \text {. }
$$


The advantage of this format is that it clearly shows a linear relationship between the concentration of suspended solids and the reciprocal of the slurry density. This relationship is shown graphically in Fig. 5.8. The data presented in the figure assume that the suspended solids have a density of $2.65 \mathrm{~g} / \mathrm{mL}$ and show the difference between using carrier liquids with densities of $1.20 \mathrm{~g} / \mathrm{mL}$ and $1.23 \mathrm{~g} / \mathrm{mL}$. Theoretically, these lines will intersect at the $100 \mathrm{wt} \%$ suspended solids point. If the bone-dry density of the solid particles was unknown, a user could obtain an estimate of the solid particles density by evaluating the suspended solids concentrations and the densities of several concentrations of the slurries and extrapolating those data to the $100 \%$ point and finding the corresponding density.

In order to successfully determine the suspended solids concentration from the slurry density, it is important to note two important facts. First, the density of the carrier liquid and the density of the suspended solids (bone-dry) must be known. Second, the composition of the liquid and solid phases must remain relatively constant. For example, assume that a user is monitoring a slurry that has a carrier liquid with a density of $1.23 \mathrm{~g} / \mathrm{mL}$ and a suspended-solids phase with a density of $2.65 \mathrm{~g} / \mathrm{mL}$. The user decides to reduce the concentration of suspended solids in the mixing tank by adding water to the mixture. Assume further that the resulting slurry has a density of $1.30 \mathrm{~g} / \mathrm{mL}$ and the resulting carrier liquid density is $1.20 \mathrm{~g} / \mathrm{mL}$. Figure 5.8 shows that the suspended solids concentration would be interpreted as $10.0 \mathrm{wt} \%$ if the user ignored the change in the carrier liquid density. This figure also shows that the suspended solids concentration would be interpreted as $14.0 \mathrm{wt} \%$ if the proper liquid density is utilized. By ignoring the change in liquid density, the user would have underestimated the suspended solids concentration by $4 \mathrm{wt} \%$.

The accuracy of the suspended solids concentration will depend on the accuracy of the density instrument. This relationship was investigated for a density meter with assumed relative accuracies of $\pm 1 \%$ and $\pm 0.2 \%$ over a density range of 1.23 to $1.46 \mathrm{~g} / \mathrm{mL}$ (corresponding to a slurry containing 0 to $30 \mathrm{wt} \%$ suspended solids in a carrier fluid with a density of $1.23 \mathrm{~g} / \mathrm{mL}$ ). Figure 5.9 shows the relative potential difference between 


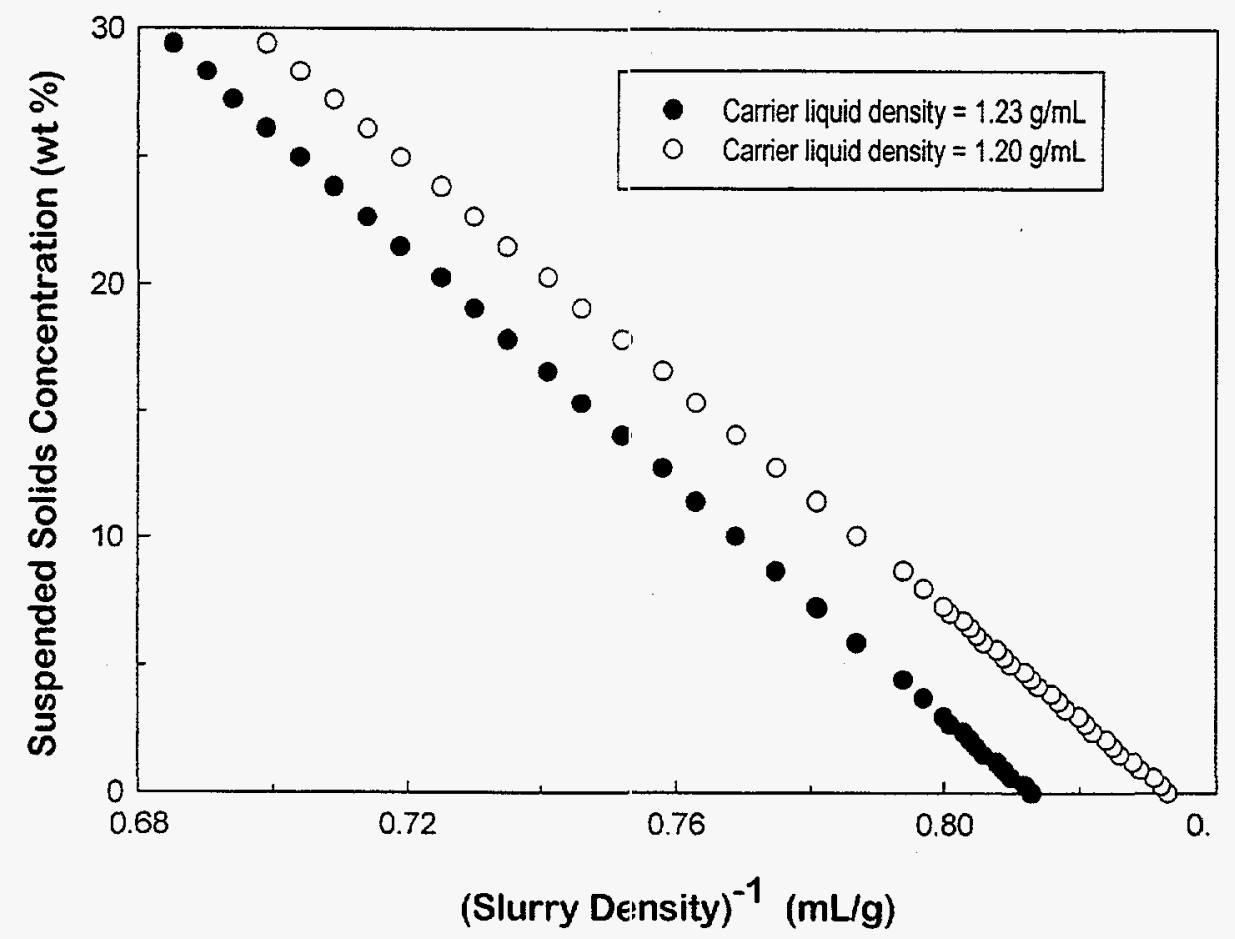

Fig. 5.8. Relationship between suspended solids concentration and density for a slurry (solid particle density $=2.65 \mathrm{~g} / \mathrm{mL}$ ).

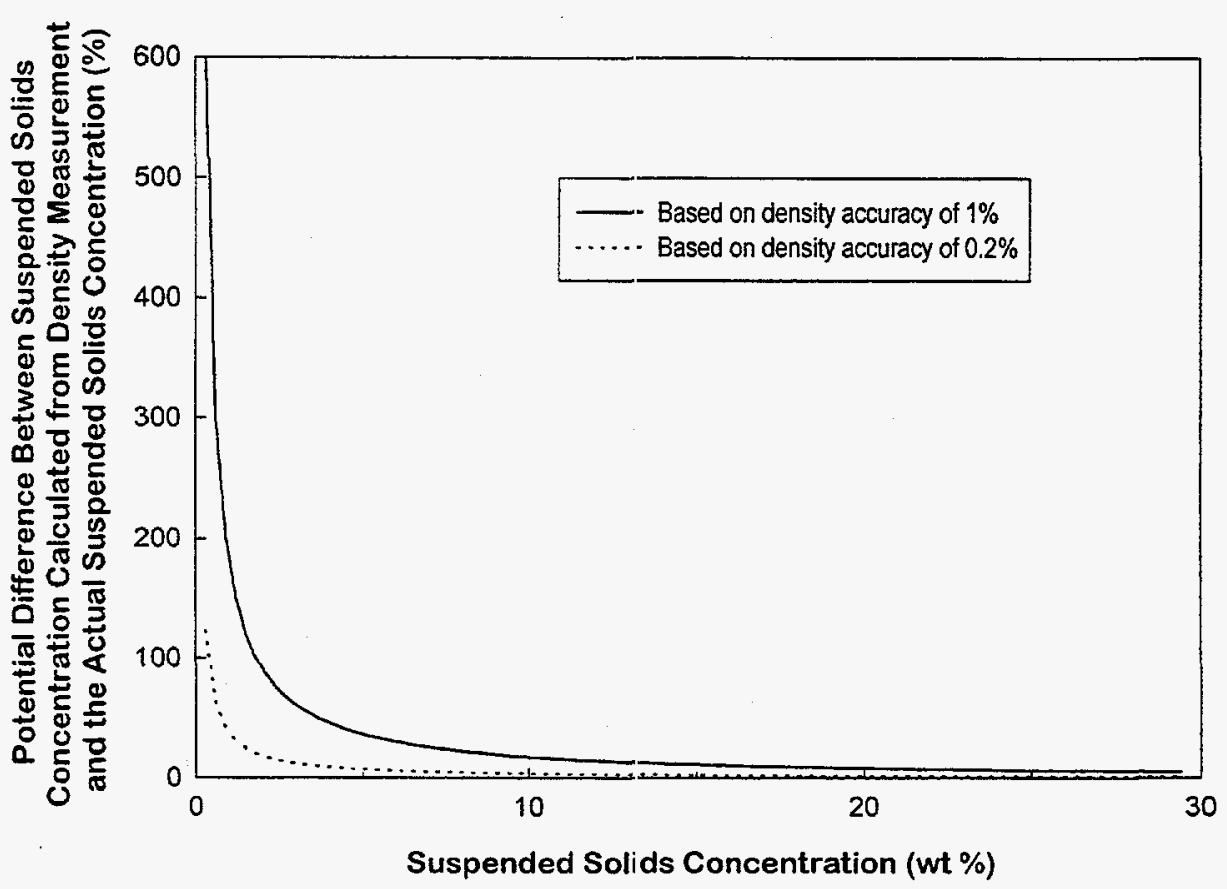

Fig. 5.9. Example illustrating the relative accuracy of using a density instrument to determine the suspended solids concentration. 
the suspended solids concentration calculated from the density measurement with regard to the actual suspended solids concentration. The results show that the difference escalates at the lower suspended solids concentrations. This escalation is partially due to the effect of dividing by a small number. Figure 5.10 shows the potential difference (i.e., calculated value - actual value) over the same range. It shows that while the potential difference between the calculated value and the actual value decreases slightly over the range, the relative magnitude remains the same.

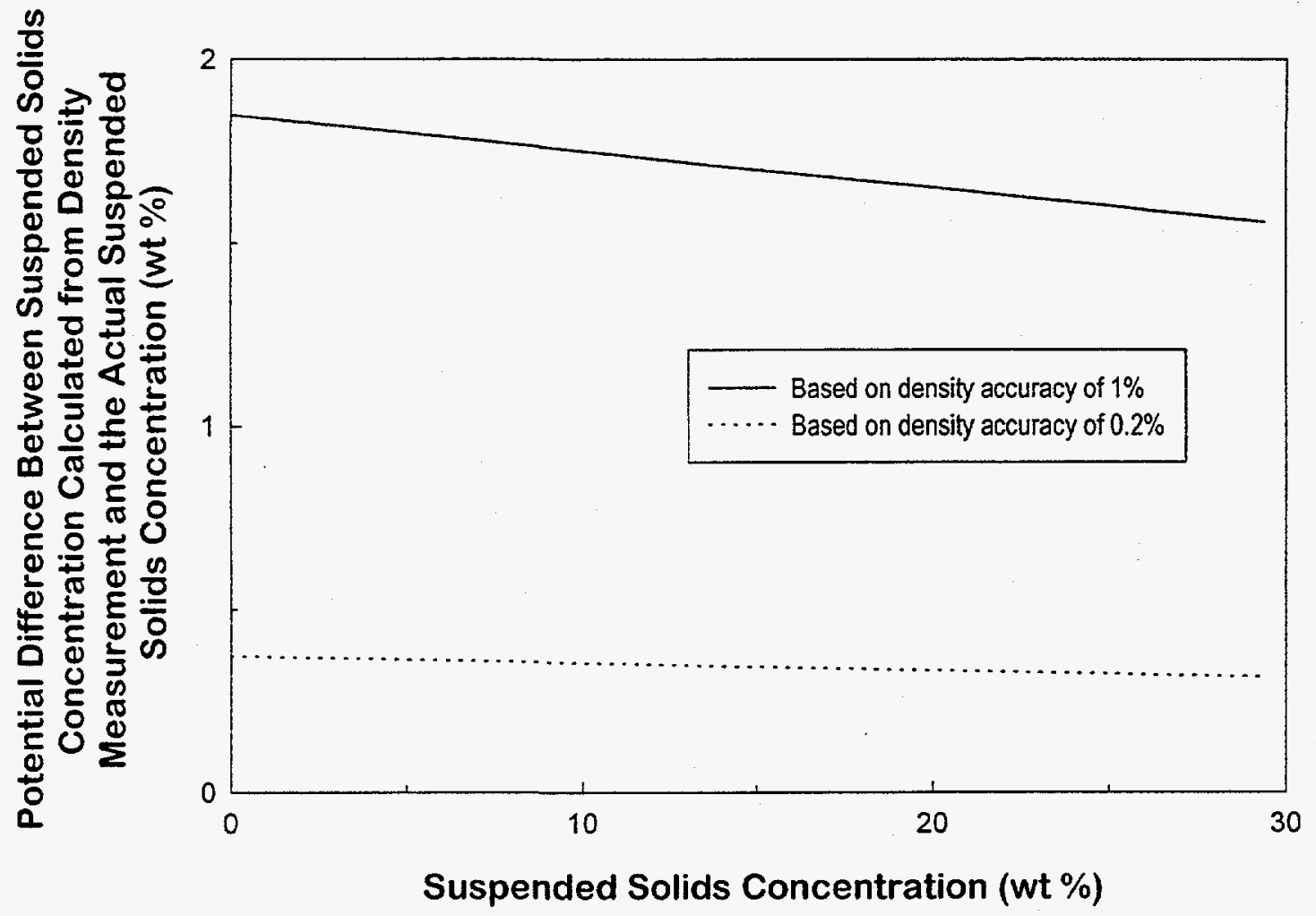

Fig. 5.10. Example illustrating the potential difference between the suspended solids concentration calculated from a density measurement vs the actual concentration.

The standard deviation of the calculated weight percent solids $\left(\mathrm{S}_{\mathrm{wt} \%}\right)$ can be related to the standard deviation of $\rho\left(S_{\rho}\right)$ by the following error propagation formula: 


$$
S_{w 2}=\frac{D_{s} \times D_{L} \times 100}{\left(D_{s}-D_{L}\right)} \frac{S_{\rho}}{\rho^{2}}
$$

The relative standard deviation of the weight percent solids (i.e., $\% \mathrm{RSD}_{\mathrm{w}_{\mathrm{t}} \%}=$ $100 \times S_{\mathrm{w} t} \%$ (wt \% solids) can be expressed in terms of the relative standard deviation of $\rho$ (i.e., $\% \mathrm{RSD}_{\mathrm{p}}$ ):

$$
\% \mathrm{RSD}_{\mathrm{wt} \%}=\frac{\mathrm{D}_{\mathrm{s}} \times \mathrm{D}_{\mathrm{L}} \times 100}{\left(\mathrm{D}_{\mathrm{s}}-\mathrm{D}_{\mathrm{L}}\right)} \frac{\% \mathrm{RSD}_{\rho}}{\rho \times \mathrm{wt} \%}
$$

Figure 5.11 is a graph that illustrates \% RSD of suspended solids concentration with regard to the concentration of the suspended solids concentration. The escalating increase at the lower concentrations results from the division by a small number. The $\% \mathrm{RSD}_{\mathrm{wt}} \%$ is equal to $\% \operatorname{RSD}_{\rho}$ at a value of $\rho=2 \mathrm{D}_{\mathrm{L}}$ or $w t \%=50 \% \times \mathrm{D}_{S} /\left(\mathrm{D}_{S}-\mathrm{D}_{\mathrm{L}}\right)$.

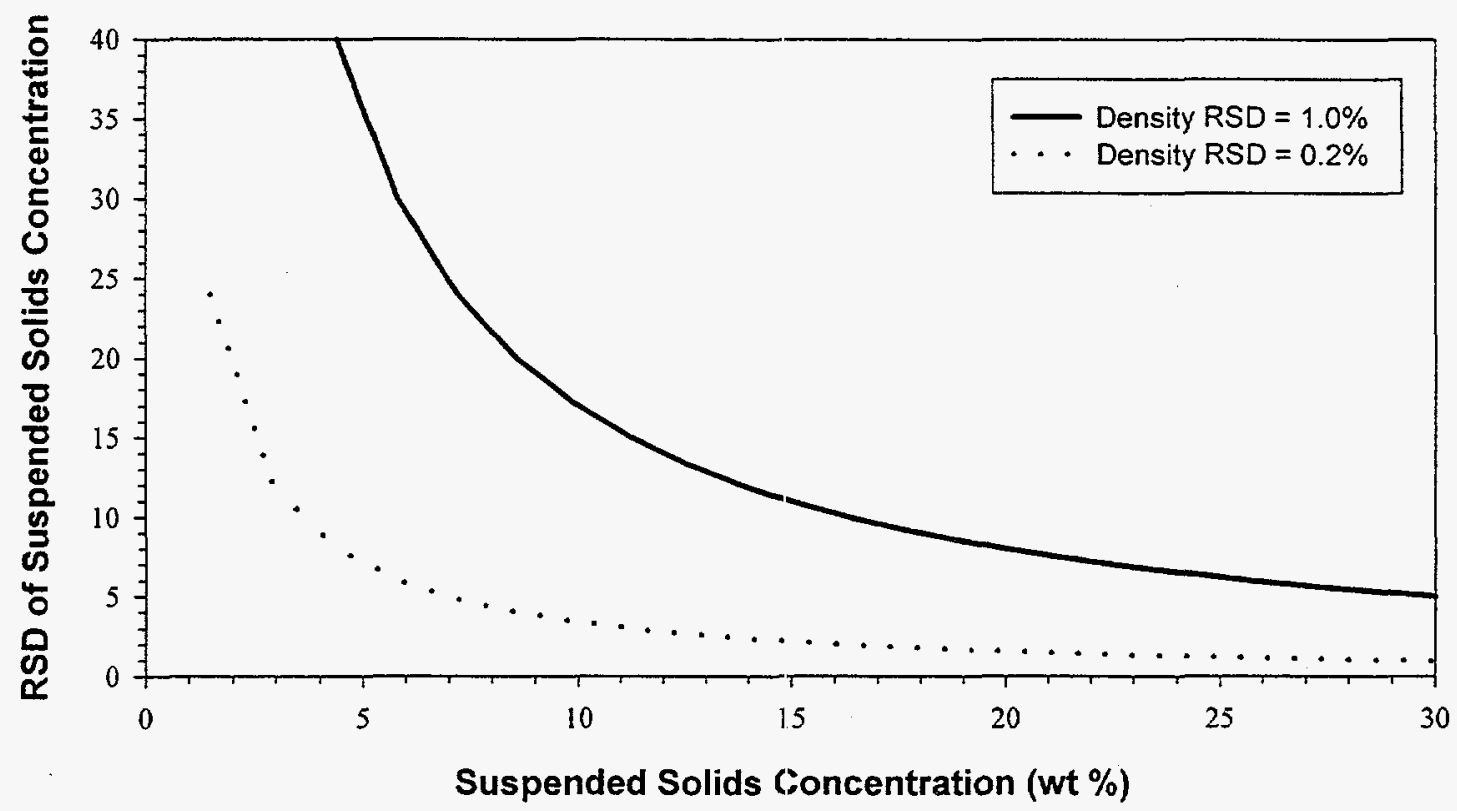

Fig. 5.11. Relative standard deviation of suspended solids concentration for density RSDs of $0.2 \%$ and $1.0 \%$. 


\subsection{PUMP CURRENT AND POWER VS SOLIDS CONCENTRATION}

\subsubsection{Current and Power Measurements}

Two pumps, which were identified as EM-300 and EM-400, were used to recirculate the slurry matrices in the test loop. EM-300 was only capable of pumping up to about $3 \mathrm{ft} / \mathrm{s}$; therefore, EM-400 was used for those runs with higher flow rates and also when EM-300 was not operating. For each pump, both the current $(A)$ and power $(\mathrm{kWh})$ were measured for each experimental run. DOE site users would like to be able to monitor current and power readings to identify physical property changes (e.g., viscosity) in a slurry while transporting the slurry. Changes in the current and power requirements for the pumps might indicate a problem (e.g, change in suspended solids concentration, change in density, change in viscosity) that operators could evaluate and take action as necessary to prevent the pipeline from plugging.

This study was made to identify the experimental factors that affect the variability of the current and power measurements to determine how large a measurement change would trigger an operator action. The variability of current and power measurements were adjusted for flow rates, matrix effects, and temperature. The remaining variability was assumed to be due to one of the three compositional factors (concentration of suspended solids, density, or viscosity) and experimental error. Changes in the slurry matrix can be monitored by current and power measurements if the variability of these measurements proved to be more sensitive to the compositional factors than to the experimental error.

Figure 5.12 shows box plots of current measurements for all runs in the slurry monitor experiment. The current averages, standard deviations, and percent relative standard deviations are $3.00 \mathrm{~A}, 0.12 \mathrm{~A}$, and $4.1 \%$ for EM-300 and $9.67 \mathrm{~A}, 0.41 \mathrm{~A}$, and $4.2 \%$ for EM-400, respectively. The variation of current data for EM-300 is much smaller than that for EM-400. This difference in variation is probably due to the difference in the flow rate ranges for the two pumps. 


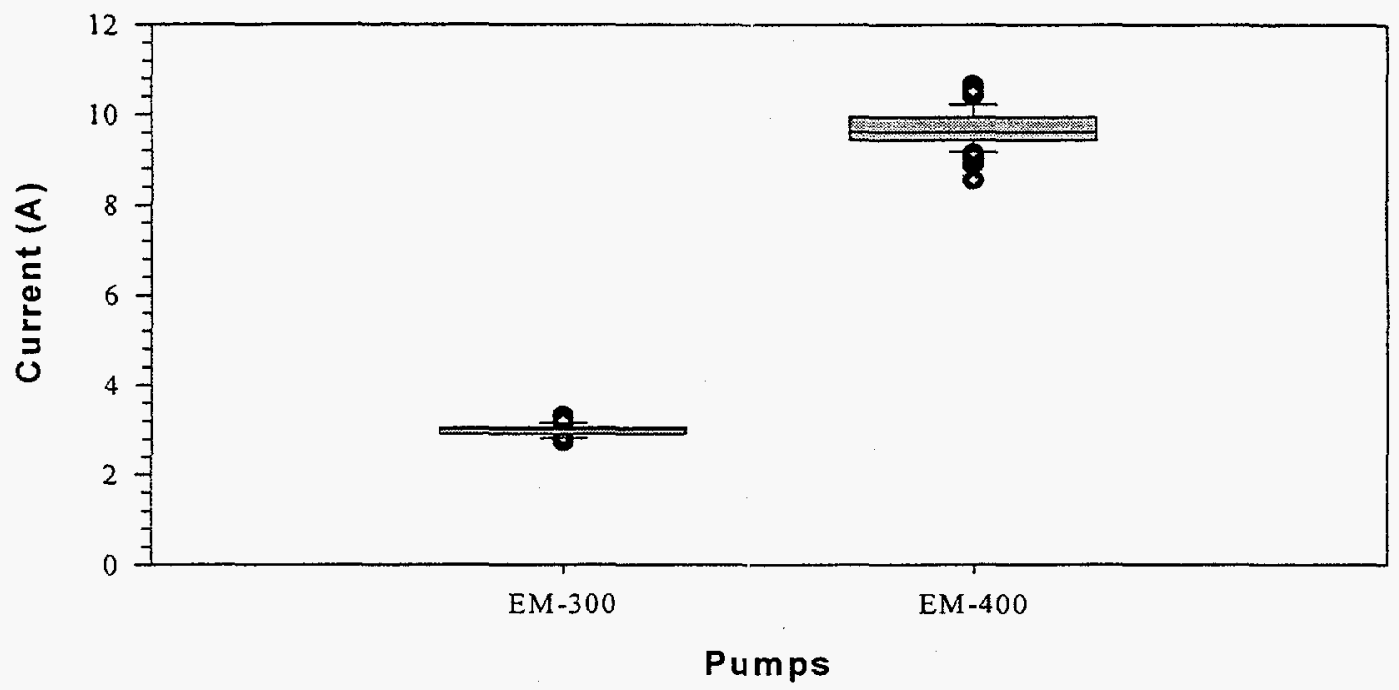

Fig. 5.12. Box plots of the current measured on pumps EM-300 and EM-400.

Figure 5.13 shows box plots of power measurements for all runs in the slurry monitor experiment. The power averages, standard deviations, and percent relative standard deviations are $0.52 \mathrm{kWh}, 0.34 \mathrm{kWh}$, and $65.2 \%$ for EM-300 and $2.24 \mathrm{kWh}, 0.65 \mathrm{kWh}$, and $30.0 \%$ for EM-400, respectively. Again, the difference in variation is probably due to the different flow-rate ranges for the two pumps.

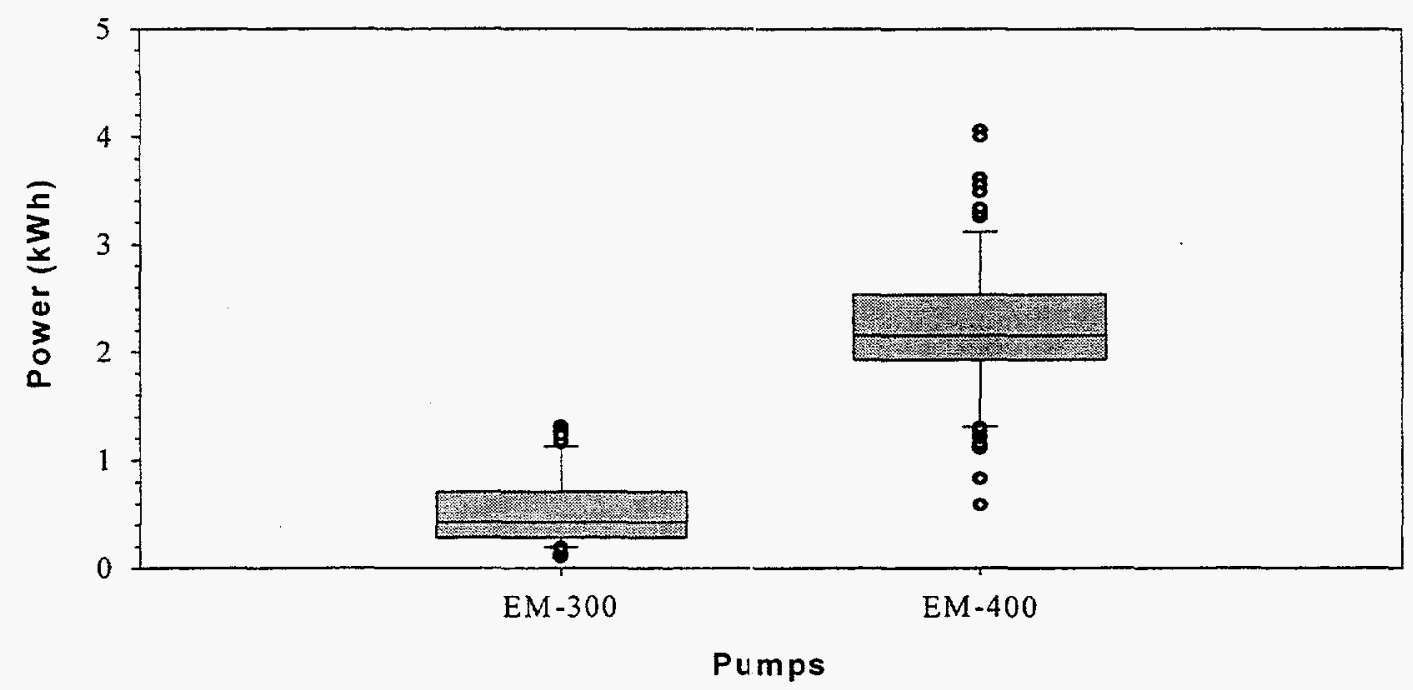

Fig. 5.13. Box plots of the power measured on pumps EM-300 and EM-400. 
The variations in the current and power measurements are affected by different experimental factors. The explanation of the percentage of the total variation (i.e., the sum of squared differences between each measurement and the average) and the reduction of standard deviation by accounting for flow rate, matrix, and temperature factors can show the influence of those factors. Identification of the factors that affect the variability of current and power measurements can provide essential information for the development of methods to monitor pumping operations.

\subsubsection{Flow Rate Effects}

Most of the variability in the current and power measurements was expected to be due to the increasing slurry flow rate during the slurry monitoring experiment. Figure 5.14 illustrates least-square fits of lines to current measurements for the two pumps. The equation of the fitted lines of the expected current to flow rate, with the coefficient standard deviations in parentheses are

and

$$
\begin{aligned}
E(A)= & 2.95+0.04(\mathrm{ft} / \mathrm{s}) \text { for } E M-300, \\
& (0.02)(0.01)
\end{aligned}
$$

$$
\begin{aligned}
E(A)= & 9.01+0.12(\mathrm{ft} / \mathrm{s}) \text { for } E M-400 \\
& (0.10)(0.02) .
\end{aligned}
$$

Accounting for the variability due to different slurry flow rates, the current variations are only slightly reduced to $\mathrm{SD}=0.12 \mathrm{~A}(\mathrm{RSD}=4.0 \%)$ for $\mathrm{EM}-300$ and to $\mathrm{SD}=0.35 \mathrm{~A}$ $(\mathrm{RSD}=3.6 \%)$ for $\mathrm{EM}-400$. The flow-rate factor only represents $7 \%$ of the current total variation for EM-300 and 27\% of the current total variation for EM- 400 . The current for the two pumps does not increase very rapidly with flow rate.

Figure 5.15 illustrates the change in power measurements due to slurry flow rates. The power measurements show a larger reduction in variability with $\mathrm{SD}=0.07 \mathrm{kWh}$ $(\mathrm{RSD}=14.0 \%)$ for $\mathrm{EM}-300$ and with $\mathrm{SD}=0.27 \mathrm{kWh}(\mathrm{RSD}=11.9 \%)$ for $\mathrm{EM}-400$. The equations of the fitted lines of the expected power to flow rate, with coefficient standard deviations in parentheses, are 


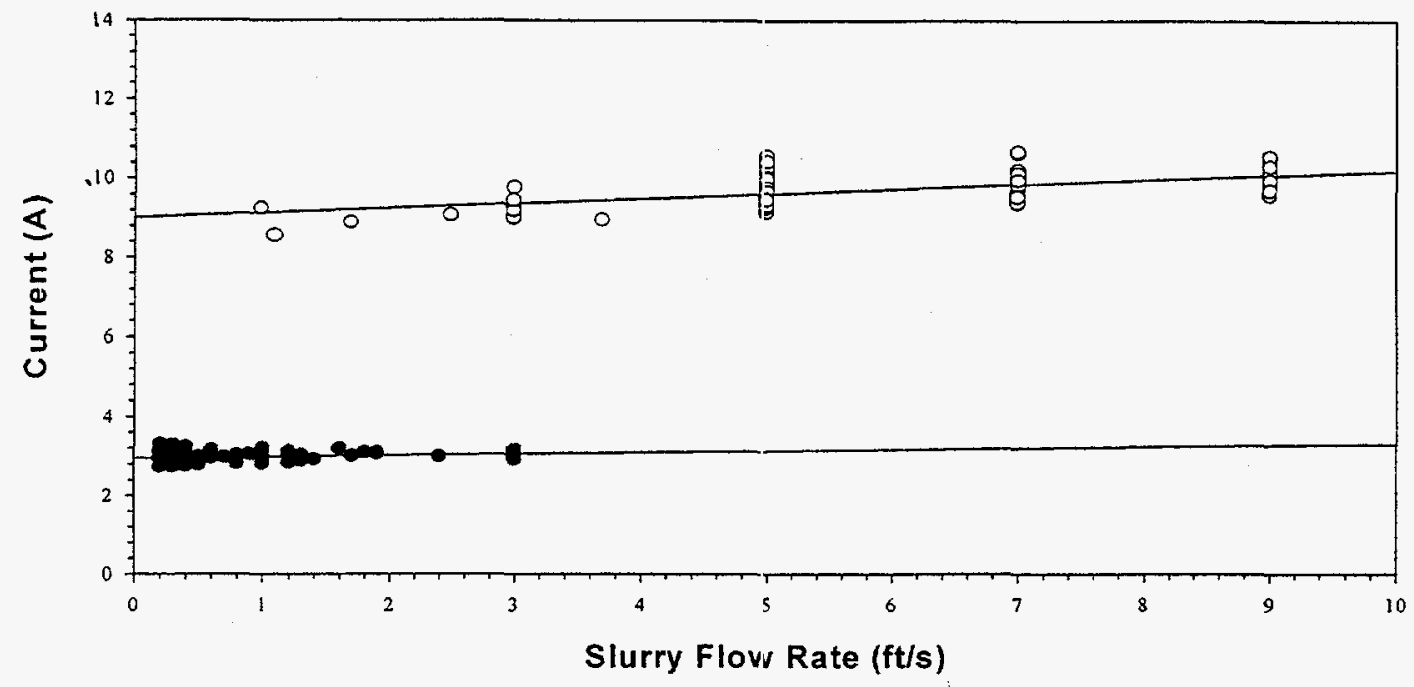

Fig. 5.14. Current as a function of sluriy flow rate for EM-300 (solid circles) and EM-400 (open circles).

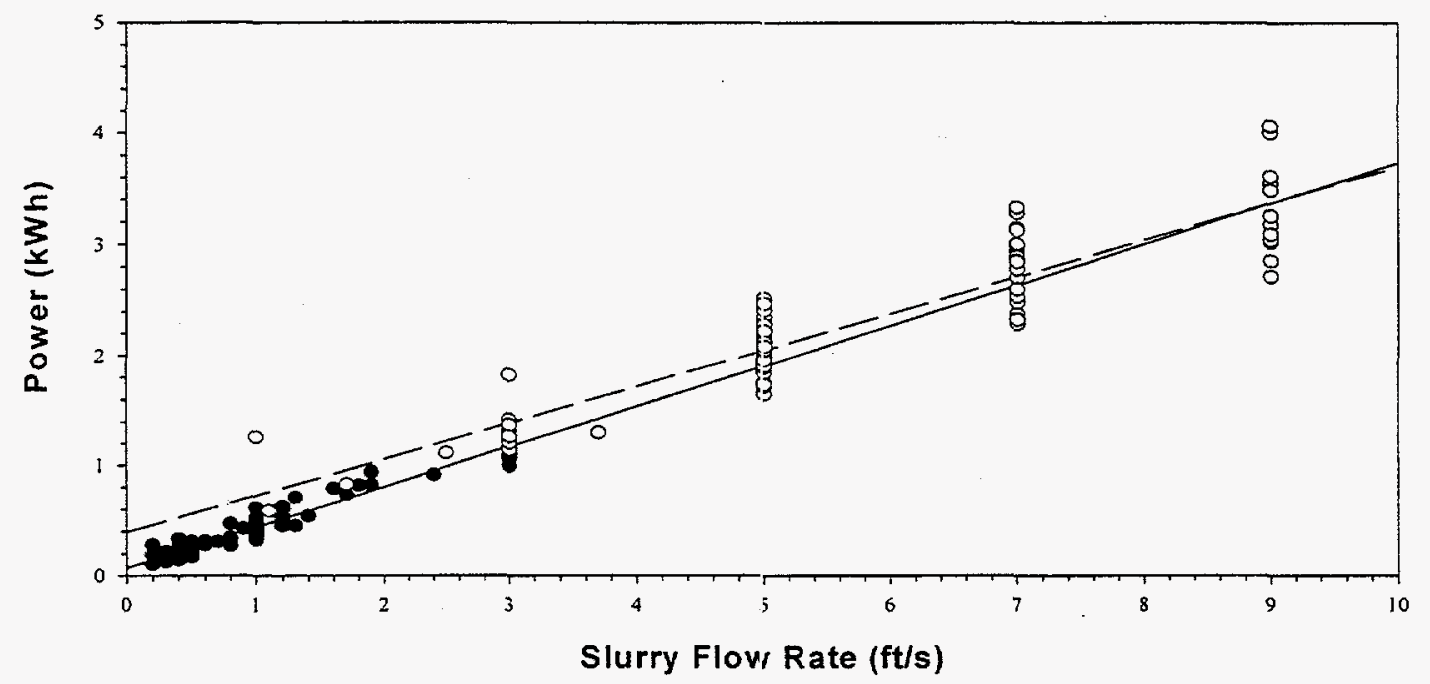

Fig. 5.15. Power as a function of slurry flow rate for EM-300 (solid circles, solid line) and EM-400 (open circles, dashed line). 


$$
\mathrm{E}(\mathrm{kWh})=\begin{gathered}
0.07+0.37(\mathrm{ft} / \mathrm{s}) \text { for } E M-300, \\
(0.01)(0.01)
\end{gathered}
$$

and

$$
\begin{aligned}
E(k W h)= & 0.38+0.33(\mathrm{ft} / \mathrm{s}) \text { for } E M-400 \\
& (0.08) \quad(0.01)
\end{aligned}
$$

The flow-rate factor explains $95.5 \%$ of the total variation in the power measurements for EM-300. This means that other experimental factors are limited to $4.5 \%$ of the total variation for this pump. The flow-rate factor explains $83.3 \%$ of the total variation in the power measurements for EM-400. Thus, flow rate is the experimental factor that accounts for the majority of the total variation in power measurements.

\subsubsection{Matrix Effects}

Different slurry matrices may affect the intercepts and slopes of the linear equations for flow rate. This effect was examined by fitting least-square lines with different intercepts and slopes for each slurry matrix to the current and power measurements. The matrix effect is added to the response model, which is represented by

$$
\text { Response }=\text { Intercept }(\text { matrix })+\text { Slope }(\text { matrix }) \times \text { Flow }+ \text { Error },
$$

where

$$
\begin{array}{ll}
\text { Response } & =\text { current or power measurements, } \\
\text { Intercept (matrix) } & =\text { different intercept for each slurry matrix, } \\
\text { Slope (matrix) } & =\text { different slope for each slurry matrix, } \\
\text { Flow } & =\text { slurry flow rate }(\mathrm{ft} / \mathrm{s}), \text { and } \\
\text { Error } & =\text { experimental error. }
\end{array}
$$

When this matrix effect model was fitted to the EM-300 current data, it reduced the original standard deviation by one-half [from $0.12 \mathrm{~A}(\mathrm{RSD}=4.1 \%)$ to $0.06 \mathrm{~A}(\mathrm{RSD}=$ $2.0 \%)]$. The matrix effect model explains $78 \%$ of the current total variation for EM-300; for EM-400, it explains $72 \%$ of the current total variation and also reduces the original standard deviation by about one-half [from $0.41 \mathrm{~A}(\mathrm{RSD}=4.2 \%)$ to $0.23 \mathrm{~A}$ 
$(\mathrm{RSD}=2.3 \%)]$. Matrix effects influenced the current variation more than did the flow rate. Table 5.12 gives the estimated intercepts and slopes for the different slurry matrices, with the slopes being given in decreasing order. The matrix with the largest slope (sucrose) for EM-300 is not the same matrix with the largest slope (kaolin/sand) for EM-400. Thus there does not appear to be a consistent pattern that would relate the matrix type and a large slope.

Table 5.12. Intercepts and slopes for the matrix effect models fitted to current data

\begin{tabular}{|c|c|c|c|c|c|}
\hline \multicolumn{3}{|c|}{ EM-300 data for current } & \multicolumn{3}{|c|}{ EM-400 data for current } \\
\hline Matrix $^{a}$ & Intercept ${ }^{n}$ & Slope ${ }^{u}$ & Matrix $^{a}$ & Intercept" & Slope $^{a}$ \\
\hline All matrices & $2.95(0.02)$ & $0.04(0.01)$ & All matrices & $9.01(0.10)$ & $0.12(0.02)$ \\
\hline Sucrose & $2.76(0.02)$ & $0.08(0.01)$ & Kaolin/sand ${ }^{b}$ & $8.61(0.35)$ & $0.21(0.03)$ \\
\hline Kaolin/sugar & $2.91(0.04)$ & $0.08(0.02)$ & $\mathrm{K}_{\mathrm{irolin} / \text { sand/gravel }}{ }^{b}$ & $8.79(0.49)$ & $0.13(0.07)$ \\
\hline Kaolin/sand ${ }^{h}$ & $3.02(0.04)$ & $0.07(0.04)^{c}$ & Sucrose & $8.53(0.23)$ & $0.13(0.04)$ \\
\hline \multirow[t]{4}{*}{ Kaolin/water } & $3.12(0.04)$ & $-0.02(0.01)^{c}$ & Kaolin/sugar & $9.02(0.36)$ & $0.11(0.03)$ \\
\hline & & & Water (initial) & $8.73(0.46)$ & $0.10(0.05)$ \\
\hline & & & Water (final) & $9.22(0.43)$ & $0.05(0.08)^{c}$ \\
\hline & & & Kaolin/water & $10.06(0.37)$ & $0.02(0.03)^{c}$ \\
\hline
\end{tabular}

${ }^{a}$ Matrices are ordered by largest to smallest slope value. Coefficient standard deviations are in parentheses.

${ }^{b}$ Matrix included $50 \mathrm{wt} \%$ sugar water.

'Not significantly different from zero at the $5 \%$ significance level.

The matrix effect model fitted to EM-300 power data only accounted for an additional $2.3 \%$ in the total variation (i.e., 95.5 to $97.8 \%$ ) because different flow rates account for most of the total variation. The additional matrix term only reduced the standard deviation from $0.07 \mathrm{kWh}$ to $0.05 \mathrm{~kW}$. For EM-400 power data, the matrix effect model accounted for an additional $10.8 \%$ of the total variation (i.e., increase from 83.3 to $94.1 \%$ ). The additional matrix term reduced the standard deviation of $0.27 \mathrm{kWh}$ to $0.17 \mathrm{kWh}$. Table 5.13 lists the intercepts and slopes for the matrix effect models that were fitted to the power data. The matrix effect seems to have more influence on the intercept values than the slope values for the power measurements. Again, there is no consistent pattern of relating matrix type to slope magnitude for the two pumps. 
Table 5.13. Intercepts and slopes for the matrix effect models fitted to power data

\begin{tabular}{|c|c|c|c|c|c|}
\hline \multicolumn{3}{|c|}{ EM-300 Power Data } & \multicolumn{3}{|c|}{ EM-400 Power Data } \\
\hline Matrix ${ }^{a}$ & Intercept ${ }^{a}$ & Slope $^{a}$ & Matrix $^{a}$ & Intercept $t^{a}$ & Slope ${ }^{a}$ \\
\hline All matrices & $0.07(0.01)$ & $0.37(0.01)$ & All matrices & $0.38(0.08)$ & $0.33(0.01)$ \\
\hline Kaolin/sand ${ }^{b}$ & $0.03(0.04)^{c}$ & $0.43(0.03)$ & Kaolin/sand/gravel ${ }^{b}$ & $0.06(0.36)^{c}$ & $0.41(0.05)$ \\
\hline Kaolin/sugar & $0.09(0.03)$ & $0.38(0.01)$ & Kaolin/sand ${ }^{h}$ & $0.10(0.26)^{c}$ & $0.40(0.02)$ \\
\hline Kaolin/water & $0.11(0.03)$ & $0.37(0.01)$ & Sucrose & $-0.04(0.17)^{c}$ & $0.35(0.03)$ \\
\hline \multirow[t]{4}{*}{ Sucrose } & $0.02(0.02)^{c}$ & $0.35(0.01)$ & Kaolin/water & $0.53(0.28)^{c}$ & $0.35(0.02)$ \\
\hline & & & Water (initial) & $0.15(0.34)^{c}$ & $0.32(0.04)$ \\
\hline & & & Kaolin/sugar & $0.35(0.27)^{c}$ & $0.31(0.02)$ \\
\hline & & & Water (final) & $0.94(0.32)$ & $0.30(0.06)$ \\
\hline
\end{tabular}

"Matrices are ordered by largest to smallest slope value. Coefficient standard deviations are in parentheses.

${ }^{b}$ Matrix included $50 \mathrm{wt} \%$ sugar water.

Not significantly different from zero at the $5 \%$ significance level.

\subsubsection{Temperature Effects}

The temperature factor can be added to the response model to evaluate its contribution to the variability of the current and power measurements. This additional term is represented by

$$
\text { Response }=\text { Intercept }(\text { matrix })+\beta_{\mathrm{T}} \times \text { Temp }+ \text { Slope }(\text { matrix }) \times \text { Flow }+ \text { Error, }
$$

where

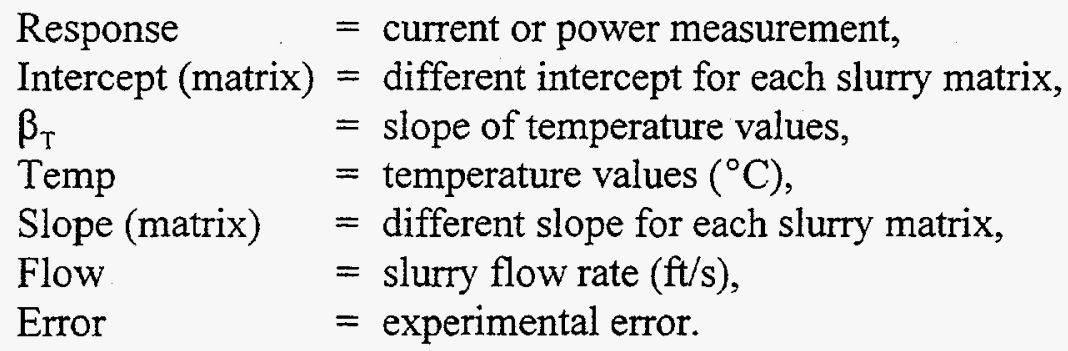

The additional temperature term has no significant effect on the current measurements but is a significant term for the power measurements of the EM-300 pump. The variability in both the current and power measurements for the EM-400 pumps is significantly affected by the temperature term; however, the magnitude of the reduction in variability is not 
large. Table 5.14 summarizes the reduction in the variability of current and power measurements for the flow rate, matrix type, and temperature factors.

The standard deviation of the remaining experimental error is reported in the last column of Table 5.14. This variability is assumed to be due to the matrix composition and other unknown factors that represent experimental error. Monitoring the variability of current and power can indicate changes in rnatrix composition if the variability due to matrix composition is sufficiently larger than the experimental error.

Table 5.14. Summary of experimental factors affecting current and power variations

\begin{tabular}{|c|c|c|c|c|c|c|}
\hline \multirow[b]{2}{*}{ Measurement } & \multirow[b]{2}{*}{ Pump } & \multirow[b]{2}{*}{$\begin{array}{l}\text { Variation } \\
\text { statistics }^{a}\end{array}$} & \multicolumn{4}{|c|}{ Experimental factors accounting for variation } \\
\hline & & & None & Flow rate & $\begin{array}{c}\text { Flow rate, } \\
\text { matrix }\end{array}$ & $\begin{array}{c}\text { Flow rate, } \\
\text { matrix, } \\
\text { temperature }\end{array}$ \\
\hline \multirow[t]{3}{*}{ Current } & \multirow[t]{3}{*}{$E M-300$} & $\mathrm{SD}(\mathrm{A})$ & 0.22 & 0.118 & 0.061 & 0.060 \\
\hline & & $\operatorname{RSD}(\%)$ & 4. & 4.0 & 2.0 & 2.0 \\
\hline & & Total Variation (\%) & 0 & 7.2 & 77.5 & 78.1 \\
\hline \multirow[t]{3}{*}{ Current } & \multirow[t]{3}{*}{$\mathrm{EM}-400$} & $\mathrm{SD}(\mathrm{A})$ & 0.406 & 0.348 & 0.226 & 0.185 \\
\hline & & $\operatorname{RSD}(\%)$ & 4.2 & 3.6 & 2.3 & 1.9 \\
\hline & & Total Variation (\%) & 0 & 26.9 & 72.2 & 81.7 \\
\hline \multirow[t]{3}{*}{ Power } & \multirow[t]{3}{*}{ EM-300 } & $\mathrm{SD}(\mathrm{A})$ & 0.339 & 0.073 & 0.053 & 0.052 \\
\hline & & $\operatorname{RSD}(\%)$ & 65.2 & 14.0 & 10.2 & 9.9 \\
\hline & & Total Variation (\%) & 0 & 95.5 & 97.8 & 97.9 \\
\hline \multirow[t]{3}{*}{ Power } & \multirow[t]{3}{*}{ EM-400 } & $\mathrm{SD}(\mathrm{A})$ & 0.1551 & 0.267 & 0.167 & 0.146 \\
\hline & & RSD (\%) & $29.1)$ & 11.9 & 7.5 & 6.5 \\
\hline & & Total Variation (\%) & 0 & 83.3 & 94.1 & 95.6 \\
\hline
\end{tabular}

${ }^{a} \mathrm{SD}=$ standard deviation; $\mathrm{RSD}=$ relative standard deviation.

\subsubsection{Matrix Composition Effects}

Matrix compositional factors can be added to the response equation to account for the variability due to these factors, as follows:

$$
\begin{aligned}
\text { Response }= & \text { Intercept (matrix } \left.)+\beta_{\mathrm{T}} \times \text { Temp }+ \text { Slope (matrix }\right) \times \text { Flow } \\
& +\beta_{\mathrm{MC}} \times(\text { Matrix composition })+\text { Error, }
\end{aligned}
$$


where

$\beta_{M C} \quad=$ slope of matrix composition parameter, and

Matrix composition = weight percent of suspended solids, or density, or viscosity.

\subsubsection{Concentration of Suspended Solids Effects}

The response model uses the term $\beta_{\mathrm{W}} \times\left(\%\right.$ weight) for $\beta_{\mathrm{MC}} \times$ (Matrix composition) to represent the contribution of the concentration of suspended solids (wt \%) to the variation of the power and current measurements.

The slope of the weight percent term for the current response of pump EM-400 is not significantly different from zero, indicating that weight percent changes would show little effect on the current variation. Therefore, monitoring of the current of EM-400 would not provide a good indication of changes in the suspended solids concentration in a slurry matrix. In addition, monitoring the current data as a means of predicting slurry changes has limited possibilities because EM-300 is restricted to a small flow-rate range and EM400 is not sensitive to slurry matrix concentration changes.

Table 5.15 gives the estimated least-squares coefficients for the response model that includes the term for the weight percent of suspended solids.

Suppose the power usage of pump EM-400 is being monitored for the matrix mixture $\mathrm{kaolin} / \mathrm{sand} / \mathrm{gravel}$ at $30^{\circ} \mathrm{C}$ with a flow rate of $5 \mathrm{ft} / \mathrm{s}$. The equation, in terms of weight percent, would be

$$
\mathrm{kWh}=-0.10+0.41 \times 5(\mathrm{ft} / \mathrm{s})+0.0065 \times 30^{\circ} \mathrm{C}-0.0058 \times \mathrm{Wt} \text { _Pct }
$$

which reduces to

$$
\mathrm{kWh}=2.145-0.0058 \times \mathrm{Wt} \_ \text {Pet. }
$$


Table 5.15. Intercepts and slopes for the response model with a term for concentration of suspended solids

\begin{tabular}{|c|c|c|c|c|c|}
\hline \multicolumn{3}{|c|}{ EM-300 data for power } & \multicolumn{3}{|c|}{ EM-400 data for power } \\
\hline Matrix $^{a}$ & Intercept $t^{r}$ & Slope $^{a}$ & Matrix $^{a}$ & Intercept ${ }^{a}$ & Slope $^{a}$ \\
\hline Kaolin/sand ${ }^{b}$ & $0.06(0.06)^{c}$ & $0.41(0.03)$ & Kaclin/sand/gravel ${ }^{b}$ & $-0.10(0.34)^{c}$ & $0.41(0.04)$ \\
\hline Kaolin/sugar & $0.11(0.06)$ & $0.38(0.01)$ & $\mathrm{Kaclin} / \mathrm{sand}^{b}$ & $0.08(0.26)^{c}$ & $0.38(0.02)$ \\
\hline Kaolin/water & $0.12(0.06)$ & $0.37(0.01)$ & Kaclin/water & $0.35(0.28)^{c}$ & $0.35(0.02)$ \\
\hline \multirow[t]{2}{*}{ Sucrose } & $-0.03(0.04)^{c}$ & $0.35(0.01)$ & Sucrose & $0.14(0.19)^{c}$ & $0.33(0.02)$ \\
\hline & & & Warer (initial) & $0.56(0.32)^{c}$ & $0.32(0.03)$ \\
\hline \multirow[t]{2}{*}{ Temperature } & & $-0.0012(0.004)$ & Kaclin/sugar & $0.21(0.27)^{c}$ & $0.31(0.02)$ \\
\hline & & & Warer (final) & $1.36(0.30)$ & $0.30(0.05)$ \\
\hline \multirow[t]{3}{*}{ Weight percent } & & 0.0018 & & & \\
\hline & & $(0.0008)$ & Temperature & & $0.0065(0.0011)$ \\
\hline & & & Weight percent & & $-0.0058(0.0019)$ \\
\hline $\begin{array}{l}\text { Variation } \\
\text { statistics }\end{array}$ & $\begin{array}{c}\mathrm{SD}=0.052 \\
\mathrm{RSD}=9.9 \%\end{array}$ & $\% \mathrm{R}^{2}=97.9 \%$ & $\begin{array}{l}\text { Variation } \\
\text { statistics }\end{array}$ & $\begin{array}{l}\mathrm{SD}=0.146 \\
\mathrm{RSD}=6.5 \%\end{array}$ & $\% \mathrm{R}^{2}=95.6 \%$ \\
\hline
\end{tabular}

"Matrices are ordered by largest to smallest slope value. Coefficient standard deviations are in parentheses.

${ }^{h}$ Matrix included $50 \mathrm{wt} \%$ sugar water.

'Not significantly different than zero at the $5 \%$ significance level.

Figure 5.16 shows the line for a suspended solids concentration range of 10 to $50 \mathrm{wt} \%$. A change of $\pm 2 \times \mathrm{SD}( \pm 0.29)$ in a power reading may indicate a problem; however, these action limits are greater than the range of power value due to suspended solids concentration increases from 10 to $50 \mathrm{wt} \%$. The sensitivity of power requirements to suspended solids concentration is not strong enough to be used as a quality control (QC) monitoring device. 


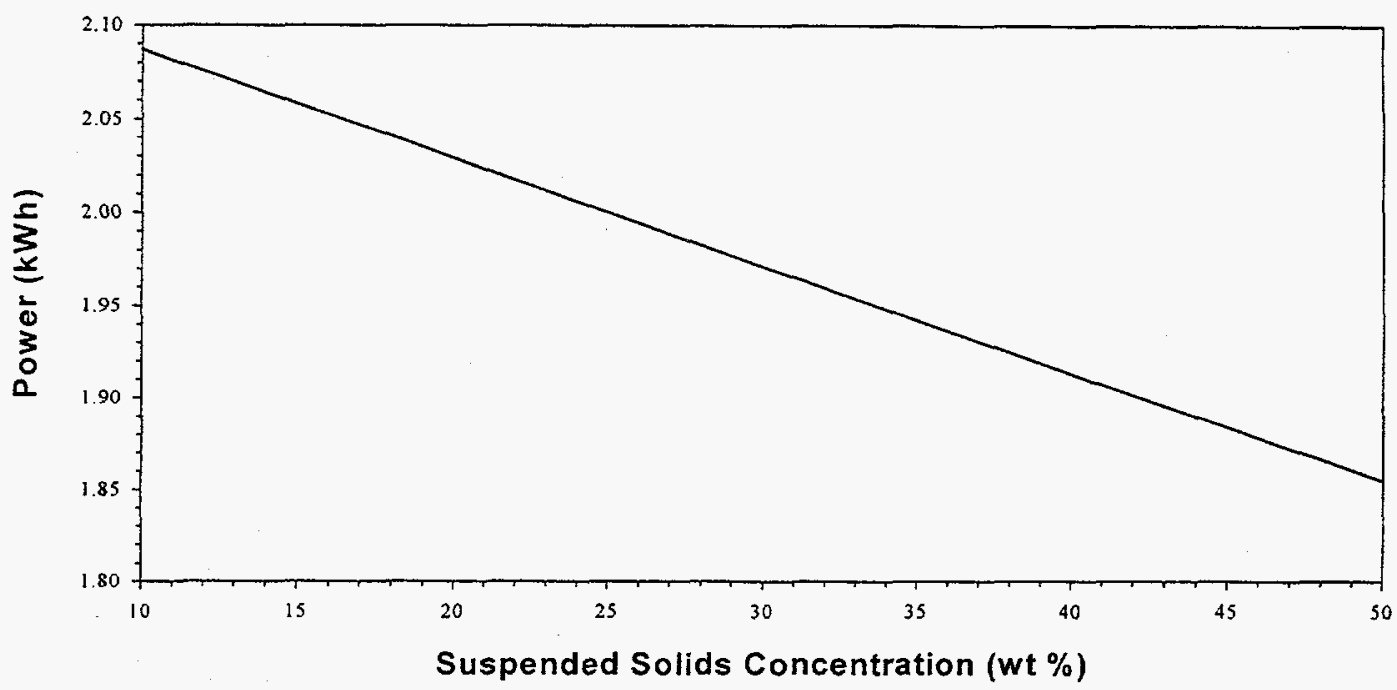

Fig. 5.16. Example of power vs solids concentration for EM-400 pumping $\mathrm{kaolin} / \mathrm{sand} / \mathrm{gravel}$ mixture at $5 \mathrm{ft} / \mathrm{s}$ at $30^{\circ} \mathrm{C}$.

\subsubsection{Density Effects}

The response model uses the term $\beta_{\mathrm{D}} \times$ (Density) for $\beta_{\mathrm{MC}} \times$ (Matrix Composition) to represent the contribution of matrix density to the variation of the power and current measurements.

Estimated slopes for the density values are significantly different from zero for the current data on EM-300 and the power data on EM-400. The density slope was not significant for EM-300 power data or for EM-400 current data. Table 5.16 gives the estimated coefficients for these two cases. Monitoring the current data on EM-300 as a means of predicting slurry changes has limited possibilities because EM-300 is restricted to a small flow-rate range. 
Table 5.16. Intercepts and slopes for the response model with the density term

\begin{tabular}{|c|c|c|c|c|c|}
\hline \multicolumn{3}{|c|}{ EM-300 data for current } & \multicolumn{3}{|c|}{ EM-400 data for power } \\
\hline Matrix $^{a}$ & Intercept ${ }^{a}$ & Slope ${ }^{a}$ & Matrix $^{a}$ & Intercept $t^{a}$ & Slope ${ }^{a}$ \\
\hline Sucrose & $2.11(0.16)$ & $0.08(0.01)$ & $\mathrm{Kaolin} /$ sand/gravel ${ }^{h}$ & $0.85(0.48)^{c}$ & $0.41(0.04)$ \\
\hline Kaolin/sugar & $2.22(0.16)$ & $0.07(0.01)$ & Kaolin/sand ${ }^{h}$ & $1.03(0.43)^{c}$ & $0.38(0.02)$ \\
\hline Kaolin/sand ${ }^{b}$ & $2.34(0.16)$ & $0.04(0.03)^{c}$ & Kaolin/water & $1.13(0.43)^{c}$ & $0.35(0.02)$ \\
\hline \multirow[t]{3}{*}{ Kaolin/water } & $2.53(0.16)$ & $-0.02(0.01)$ & Sucrose & $0.78(0.39)^{c}$ & $0.33(0.02)$ \\
\hline & & & Water (initial) & $0.76(0.47)^{c}$ & $0.32(0.03)$ \\
\hline & & & Kaolin/sucrose & $1.18(0.43)$ & $0.31(0.02)$ \\
\hline Temperature & & $0.0007(0.0005)^{c}$ & Water (final) & $1.36(0.30)$ & $0.30(0.05)$ \\
\hline \multirow[t]{2}{*}{ Density } & & $0.5000(0.1287)$ & Temperature & & $\begin{array}{c}0.0061 \\
(0.0011)\end{array}$ \\
\hline & & & Density & & $-0.77(0.28)$ \\
\hline $\begin{array}{l}\text { Variation } \\
\text { statistics }\end{array}$ & $\begin{array}{r}\mathrm{SD}=0.056 \\
\mathrm{RSD}=1.9 \%\end{array}$ & $\% R^{2}=81.6$ & $\begin{array}{l}\text { Variation } \\
\text { statistics }\end{array}$ & $\begin{array}{c}\mathrm{SD}=0.141 \\
\mathrm{RSD}=6.3 \%\end{array}$ & $\% \mathrm{R}^{2}=95.9$ \\
\hline
\end{tabular}

${ }^{a}$ Matrices are ordered by largest to smallest slope value. Coefficient standard deviations are in parentheses.

${ }^{b}$ Matrix was suspended in $50 \mathrm{wt} \%$ sugar water.

Not significantly different from zero at the $5 \%$ signnificance level.

Suppose the power usage of pump EM-400 was being monitored at a flow rate of $5 \mathrm{ft} / \mathrm{s}$ for the matrix mixture kaolin/sand /gravel at $30^{\circ} \mathrm{C}$. The equation in terms of density is:

$$
\mathrm{kWh}=0.85+0.42 \times 5(\mathrm{ft} / \mathrm{s})+0.0061 \times 30^{\circ} \mathrm{C}-0.77 \times \text { Density }
$$

which reduces to

$$
\mathrm{kWh}=3.13-0.77 \times \text { Density }
$$

Figure 5.17 shows the power-vs-density line for a density range of 1.0 to $1.5 \mathrm{~g} / \mathrm{mL}$. A change of $\pm 2 \times \mathrm{SD}$ (i.e., \pm 0.28 ) in a power reading may indicate a problem. For an average power reading of $2.15 \mathrm{kWh}$, the $\pm 2 \times \mathrm{SD}$ change represents a lower limit of 1.87 and an upper limit of $2.43 \mathrm{kWh}$. Both of these limits are outside the range of the powervs-density plot. In conclusion, the sensitivity of power to the change in density is not strong enough to be used as a QC monitoring device. 


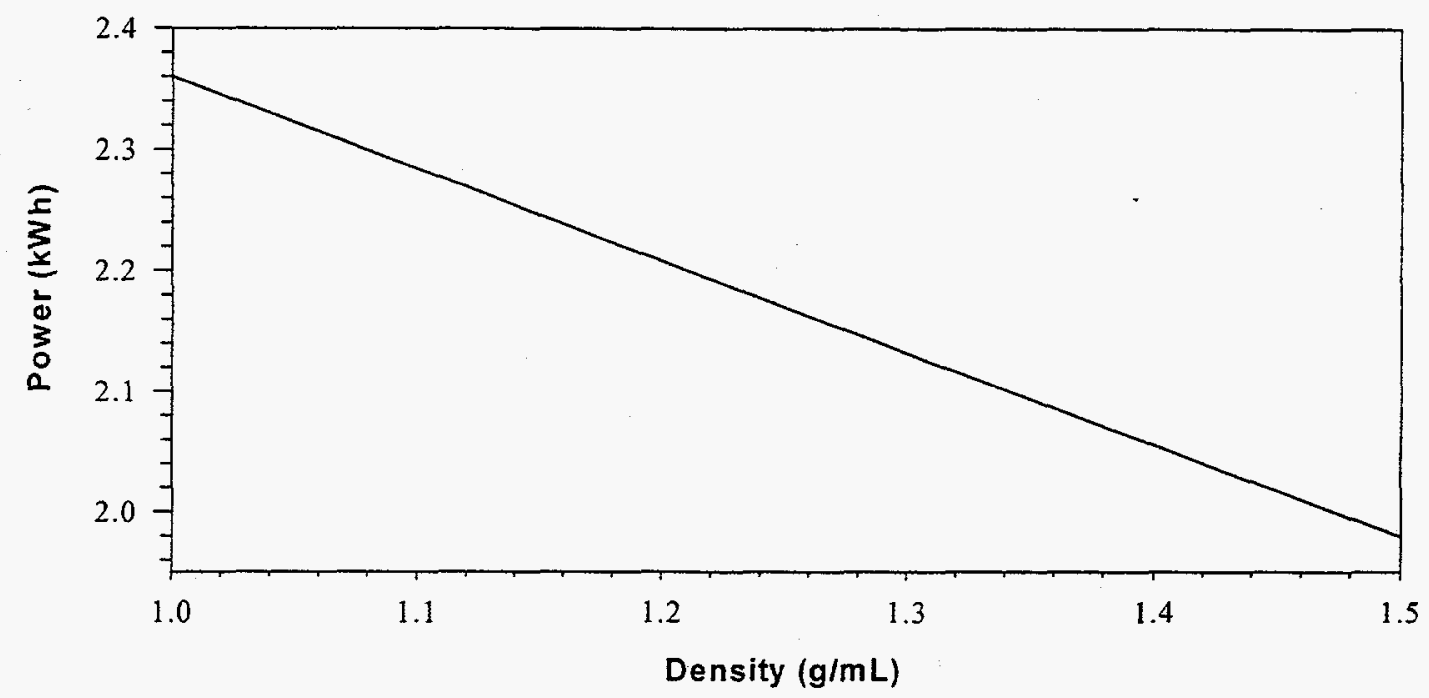

Fig. 5.17. Example of power vs density for EM-400 for pumping a kaolin/sand/gravel mixture at $5 \mathrm{ft} / \mathrm{s}$ at a temperature of $30^{\circ} \mathrm{C}$.

\subsubsection{Viscosity Effects}

The response model uses the term $\beta_{\mathrm{v}} \times$ (Viscosity) for $\beta_{\mathrm{MC}} \times$ (Matrix Composition) to represent the contribution of viscosity to the variation of the power and current measurements. The only significant viscosity coefficient $(0.0010)$ is for the current data on pump EM-300. The current would be significantly influenced by the viscosity but not to the extent that it would have any practical QC applications. Thus, monitoring of the pump current and/or power for a change in viscosity does not appear to be a viable candidate for a $\mathrm{QC}$ monitoring device.

\subsubsection{Summary of Current and Power Variation}

Table 5.17 gives a summary of the experimental factors that affect the variation of current and power for the EM-300 and the EM-400 pumps. Current and power measurements from the EM-300 and EM-400 pumps are not affected by, or have low 
sensitivity to, the matrix compositional parameters. The results of this analysis indicate that current and power measurements are not suitable indications for $\mathrm{QC}$ monitoring.

Table 5.17. Summary of variation statistics for the response model that includes matrix composition effects

\begin{tabular}{|c|c|c|c|c|c|}
\hline \multirow{2}{*}{ Measurement } & \multirow{2}{*}{ Pump } & \multirow{2}{*}{$\begin{array}{l}\text { Variation } \\
\text { statistics }\end{array}$} & \multicolumn{3}{|c|}{$\begin{array}{l}\text { Additional factor after adjusting for matrix, } \\
\text { temperature, and flow rate }\end{array}$} \\
\hline & & & Concentration & Density & Viscosity \\
\hline \multirow[t]{3}{*}{ Current } & \multirow[t]{3}{*}{$E M-300$} & $\mathrm{SD}(\mathrm{A})$ & 0.056 & 0.056 & 0.059 \\
\hline & & RSD (\%) & 1.9 & 1.9 & 2.0 \\
\hline & & Total variation $(\%)$ & 81.4 & 81.6 & 76.1 \\
\hline \multirow[t]{3}{*}{ Current } & \multirow[t]{3}{*}{ EM-400 } & $\mathrm{SD}(\mathrm{A})$ & 0.184 & 0.184 & 0.211 \\
\hline & & $\mathrm{RSD}(\%)$ & 1.9 & 1.9 & 2.2 \\
\hline & & Total variation $(\%)$ & 82.1 & 81.9 & 80.7 \\
\hline \multirow[t]{3}{*}{ Power } & \multirow[t]{3}{*}{$E M-300$} & $\mathrm{SD}(\mathrm{kWh})$ & 0.050 & 0.051 & 0.058 \\
\hline & & RSD (\%) & 9.7 & 9.8 & 10.3 \\
\hline & & Total variation (\%) & 98.0 & 98.0 & 97.9 \\
\hline \multirow[t]{3}{*}{ Power } & \multirow[t]{3}{*}{ EM-400 } & $\mathrm{SD}(\mathrm{kWh})$ & 0.141 & 0.142 & 0.168 \\
\hline & & $\operatorname{RSD}(\%)$ & 6.3 & 6.3 & 7.2 \\
\hline & & Total variation $(\%)$ & 95.9 & 95.9 & 94.8 \\
\hline
\end{tabular}




\section{QUALITATIVE EVALUATION}

A qualitative evaluation was also performed by the ORNL operations staff (two individuals) on each of the instruments that had been quantitatively evaluated. The purpose of this evaluation was to report on parameters that cannot easily be quantified. The opinions in this section are strictly those of the evaluators. It is hoped that the experience that was gained by directly using the various instruments will be of benefit to the user organizations.

The criteria that the instruments were evaluated against are listed below. Included with the criteria are the definitions and the data by which the instruments were evaluated. The numbers shown in the list below correspond to the values shown in Table 6.1. Some comments regarding each of the instruments are also provided in Sect. 6.2.

\subsection{DEFINITIONS}

Portability: Is the instrument easily transported?

1. Additional equipment (e.g., forklift) must be used to transport the instrument.

2. Extra equipment may be critical to getting the job done.

3. Can be carried by hand.

Internal Ruggedness: Can the instrument withstand internal conditions such as temperature, pressure, or solids without mechanical failure?

1. Failure is likely under one or more circumstances.

2. There is a reasonable chance of failure under one or more circumstances.

3. Failure is unlikely under test conditions.

External Ruggedness: Can the instrument withstand external conditions such as moisture, temperature, or RF fields without mechanical failure?

1. Failure is likely under one or more circumstances. 
Table 6.1. Qualitative evaluation of the instruments ${ }^{a}$

\begin{tabular}{|c|c|c|c|c|c|c|c|c|}
\hline Instrument & Portability & $\begin{array}{c}\text { Internal } \\
\text { ruggedness }\end{array}$ & $\begin{array}{c}\text { External } \\
\text { ruggedness }\end{array}$ & Installation & $\begin{array}{c}\text { Maintenance } \\
\text { difficulty }\end{array}$ & $\begin{array}{c}\text { Operating } \\
\text { cost }\end{array}$ & $\begin{array}{l}\text { Output } \\
\text { clarity }\end{array}$ & Total \\
\hline Promass & 3 & 3 & 3 & 3 & 2 & 3 & 3 & 20 \\
\hline ORNL & 3 & 2 & 3 & 3 & 3 & 3 & 3 & 20 \\
\hline SNL Tank & 3 & 3 & 3 & 3 & 2 & 3 & 3 & 20 \\
\hline m-Point & 3 & 3 & 3 & 3 & 2 & 3 & 3 & 20 \\
\hline SNL pipeline & 3 & 2 & 3 & 3 & 2 & 3 & 3 & 19 \\
\hline BTG & 3 & 1 & 3 & 3 & 2 & 3 & 3 & 18 \\
\hline ANL & 3 & 3 & 2 & 2 & 2 & 3 & 3 & 18 \\
\hline $\begin{array}{l}\text { PNNL } \\
\text { Densitometer }\end{array}$ & 3 & 2 & 3 & 2 & 2 & 2 & 3 & 17 \\
\hline U-Loop & 1 & 2 & 3 & 2 & 2 & 3 & 3 & 16 \\
\hline $\begin{array}{l}\text { PNNL Particle } \\
\text { size }\end{array}$ & 3 & 1 & 2 & 2 & 2 & 1 & 3 & 14 \\
\hline
\end{tabular}

"Numbers shown in the columns correspond to those under the respective headings in Sect. 6.1. 
2. There is a reasonable chance of failure under one or more circumstances.

3. Failure is unlikely under test conditions.

Installation: Is it easy to get the instrument up and running?

1. It is difficult to install without added labor or instructions.

2. One or more installation steps may require added labor or instructions.

3. Instructions are straightforward, and setup is minimal.

Maintenance Difficulty: How difficult would it be to restore the instrument after a minor mishap?

1. No mishap would be minor, given this instrument's design.

2. Special precautions would need to be taken in restoring instrument capability.

3. Instrument would be relatively easy to repair and get back on-line.

Operating Cost: How costly is it, from the time/labor standpoint, to monitor equipment?

1. This instrument is labor-intensive and requires "baby-sitting."

2. Some monitoring is required for this instrument.

3. This instrument is "plug-and-play."

Output Clarity: Are data reports easy to read and concise?

1. Output is not streamlined and is difficult to read.

2. Output is inconsistent.

3. Output is in proper form and is clear to read.

\subsection{COMMENTS}

Promass: A failure of components would likely require a high degree of exposure or complete replacement of the instrument.

PNNL_D: Sealant may deteriorate in radioactive environment; a total of eight cables must be accounted for in installation; radioactive failure would require replacement; user must manually and visually set up output signals. 
m-Point: A failure of components would likely require a high degree of exposure or complete replacement of the instrument. Other: air caused prolonged error output.

BTG: $\quad$ Manufacturer indicates that light sensor cannot withstand radioactive environment; failure due to presence of radioactivity would require replacement. Other: limited concentration range.

SNL_pipe: Pressurization caused sensor movement; thin film created by slurry content; radioactive failure would require replacement; $20-\mu \mathrm{m}$ particle limitation stated by developer. Other: pressure and temperature effects on output.

ORNL: $\quad$ Radioactive fluid may cause interference with sensor (untested).

ANL: $\quad$ Electromagnetic frequency caused noticeable change in signal strength; temperature had uncalibrated effect on viscosity output; solids concentration limits signal strength; installation consisted of many cables and poorly integrated $\mathrm{I} / \mathrm{O}$ system; radioactive failure would require replacement.

SNL_tank: Radioactive failure would require replacement. Other: thin film possible; $20-\mu \mathrm{m}$ particle limitation stated by developer.

PNNL_PS: Sensors degrade with time in fluid, sensor plastic mount susceptible to high-temperature deformation $\left(>25^{\circ} \mathrm{C}\right)$; external cables and connections are exposed to process fluid; six cables required in installation; radioactive failure would require replacement; user must manually and visually set up output signals, which change frequently with matrix change, and manually recompile output program; no on-line indication of instrument performance. 


\section{RECOMMENDATIONS}

Nine pipeline and three in-tank instruments were evaluated with slurries for the measurement of density, suspended solids concentration, viscosity, and particle size under conditions similar to a field environment. In addition to these instruments, the pump current and power were monitored to determine if these parameters could be used to monitor the transport conditions. Surrogate slurries that had transport properties similar to those expected to be encountered with the actual radioactive wastes were used for the evaluation. The evaluation was performed at temperatures of 25 and $50^{\circ} \mathrm{C}$ with slurries ranging from $\sim 10$ to $30 \mathrm{wt} \%$ suspended solids. Some of the tests were performed to evaluate the performance of the instruments when air was intentionally introduced into the slurry (to simulate entrained air in user processes). The results obtained from the various instruments were then compared with those obtained from laboratory analyses and evaluated statistically. These results are summarized in the paragraphs that follow.

\subsection{DENSITY}

Seven instruments were evaluated for their ability to measure density of the slurries. The statistical analysis indicated that the instruments that showed the least bias (i.e., highest accuracy) and the least variance for slurries without induced air were the Endress + Hauser Promass Coriolis meter, the Endress + Hauser m-Point Coriolis meter, the ORNL gamma densitometer, and the Argonne National Laboratory ultrasonic flow instrument. When air was induced into the slurry, this group, remained the best performers with the exception of the $\mathrm{m}$-Point Coriolis meter.

\subsection{SUSPENDED SOLIDS CONCENTRATION}

Three instruments were evaluated for measuring the concentrations of suspended solids of the slurries. The BTG instrument worked well when the suspended solids concentration was less than $15 \mathrm{wt} \%$ and the temperature was $25^{\circ} \mathrm{C}$. However, the concentration range for the BTG instrument varied, depending on the properties of the 
slurry to be evaluated. There is uncertainty as to whether the probe will withstand radiation. Both the ANL and the PNNL ultrasonic instruments need more development work to resolve the problems associated with measuring the suspended solids concentration.

\subsection{VISCOSITY}

Three instruments were evaluated for measuring the viscosities of the slurries. Two of these instruments, which were based on quartz-crystal resonation technology, were developed by Sandia National Laboratories. One was installed in the pipeline, and one was installed in the tank. The other instrumerit, which was based on the technology of ultrasonic impedance and scattering, was developed by Argonne National Laboratory. It was installed in the pipeline. The results obtained in the evaluation showed that none of these instruments reported the true absolute viscosity of a slurry. However, it may be possible to use the quartz-resonator instrument as a qualitative indicator of viscosity. Since this instrument is pressure sensitive, it is probably better suited for use in an in-tank application. If used in a pipeline, the system pressure should be maintained at a low level (e.g., $<60$ psig), but the exact pressure limitation is not known. The SNL in-tank instrument is not likely to be subjected to high pressures unless the tank is a pressurized vessel.

The SNL pipeline density-viscosity probe cannot be recommended for deployment in the next phase of this project because of the pressure sensitivity of the SNL pipeline probe. The SNL in-tank density-viscosity prcibe appeared to be rugged enough to be considered for use in a radioactive application; however, the users could only expect to obtain transient slurry information with the instrument (i.e., it would provide evidence as to whether the conditions were remaining constant or were changing).

\subsection{PARTICLE SIZE DISTRIBUTION}

Only one instrument was evaluated for monitoring particle size, and it was mounted in the tank. This instrument, which was based on the methodology of ultrasonic 
attenuation, responded with the same particle size for each test that was performed, regardless of the slurry matrix. The instrument developer evaluated the data and indicated that the instrument was responding as if air was entrained in the slurry. As delivered for our testing, the instrument cannot be recommended for deployment in the next phase of the project. Although the air entrainment problem was the most significant issue, the unit needs some other modifications with regard to limitations of temperature and submersed time.

\subsection{PUMP CURRENT AND POWER}

The results from the testing indicated that the pump current and power were not sensitive indicators of the transport properties of the slurries.

\subsection{WORK PLAN FOR FY 1998}

The work plan for FY 1998 includes the installation of and the performance of selected instruments in a radioactive slurry application. Based on the results obtained in this evaluation, it is recommended that the following instrumentation be considered for additional development and testing in FY 1998.

\subsubsection{Density}

The Endress + Hauser Promass Coriolis meter provided the best results and should be evaluated in the next phase. The Argonne ultrasonic flow instrument measured density quite well. It is more compact than the Promass and may work in applications for which the Promass would not be suited. The ORNL gamma attenuation densitometer also performed well and should be considered for further development. It is also compact but has the advantage that it attaches to a pipe and does not directly contact the slurry.

\subsubsection{Suspended Solids Concentration}

Of the instruments evaluated, the BTG SMS-3000 system performed the best and should be considered for additional evaluation; however, the instrument has certain 
limitations. Potentials users are advised to evaluate the suspended solids concentration range, temperature, and radiation effects for their process. The pressure limitation of the probe was not evaluated in this study, but the potential user should also inquire about the pressure limitation of the probe with the manufacturer.

\subsubsection{Viscosity}

If the ANL instrument is selected for further evaluation (e.g., as an instrument to measure density), then it is reasonable that the ANL instrument could also be evaluated as an on-line viscosity sensor in a radioactive application. Of course, more development is needed on this function.

\subsubsection{Particle Size}

Unless the air interference problem can be resolved, this study cannot recommend the deployment of the PNNL particle size probe in the next phase of this project.

\subsubsection{Pump Current and Power}

The results from the testing indicated that the pump current and power were not sensitive indicators; however, the testing was performed with positive displacement pumps. The DOE site users anticipate using nonpositive displacement pumps. The current and power requirements for these pumps may be more sensitive to changes in the transport properties. The equipment required to monitor the pump current and/or power requirements is relatively inexpensive and should be considered for deployment ion the next phase of this project. 


\section{REFERENCES}

1. J. D. Hudson, Defining Waste Acceptance Criteria for the Hanford Replacement Cross-Site Transfer System, PNNL-11146, Pacific Northwest National Laboratory, Richland, Washington, April 1996.

2. B. Hill, Zellweger Analytics, Inc., League City, Texas, personal communication, March 21, 1997.

3. M. Boise, Endress + Hauser, Scottsville, New York, personal communication, July 28, 1997.

4. R. Clift and D. H. M. Clift, "Continuous Measurement of the Density of Flowing Slurries," Int. J. Multiphase Flow 7(5), 555-61 (1981).

5. L. A. Sachs, Applied Statistics: A Handbook of Techniques, 2nd ed., SpringerVerlag, New York, 1984, pp. 563-64.

6. G. W. Snedecor and W. G. Cochran, Statistical Methods, Iowa State University Press, Ames, Iowa, 1967, pp. 285-89.

7. Standard Test Method for Specific Gravity and Density of Semi-Solid Bituminous Materials, Procedure D70-82, American Society for Testing and Materials, Reapproved 1990.

8. Standard Methods for the Examination of Water and Wastewater, 18th ed., Procedure 2540D, published for the American Public Health Association, American Water Works Association, and the Water Environment Federation, Washington, D.C., 1985. 
Appendix A

VISCOSITY REPORT FROM PNNL

\author{
by \\ Lynette Jagoda \\ Pacific Northwest National Laboratory
}





\section{SIMULANT VISCOSITY}

\section{Basic Principles of Measurement and Fluid Flow}

Viscosity is a measure of fluid flow parameters. Viscosity data are presented in the form of a rheogram, which is a plot of the shear stress vs the shear rate. In layman's terms, this a measure of the resistance to motion a fluid exerts when a force is applied. To measure viscosity, the resistance to fluid flow must be quantified. This is accomplished through a variety of techniques which measure flow time, torque, dampening, or pressure drop. Each technique has advantages and drawbacks which must be considered when performing analytical testing on samples. The ORNL slurry test loop samples were analyzed with both torque and capillary viscometers.

Force or torque viscometers measure stress and/or strain. They induce a shear force and measure the resulting torque or vice versa. The most common form of this viscometer has a rotational cup and bob (torque sensor) type of measuring system, either couette (cup rotates) or searle (sensor rotates). The Haake M5 is a searle-type viscometer and CV20 is a couette. The couette is a more sensitive instrument but has a very limited range with a maximum shear rate of about $300 \mathrm{~s}^{-1}$. The searle can reach shear rates of $1200 \mathrm{~s}^{-1}$ but loses sensitivity.

Capillary viscometers measure pressure drop through a well-defined section of piping. The pressure drop through a capillary tube is directly proportional to the dynamic viscosity of a substance. By forcing a small amount of fluid into a capillary and measuring the pressure drop, viscosity can be obtained. Varying the flow rate induces different shear rates which are measured to gain knowledge of the overall rheological nature of the fluid. The HVA-6 is a capillary rheometer made by Paar Physica. It was utilized to measure high shear rates, $1 \times 10^{3}$ to $1 \times 10^{6}$. The model used to evaluate the ORNL slurry samples is fitted with a special anti-settling device specifically designed for the measurement of slurries.

Fluids can exhibit a wide range of flow behaviors. The most simple is Newtonian flow in which the viscosity is a direct proportional relationship between the shear stress 
and the shear rate. Water is a Newtonian fluid; however, even very dilute slurries usually exhibit some non-Newtonian behavior. The most common slurry fluid type is called a pseudoplastic liquid. In pseudoplastic flow, the resistance to flow decreases with larger applied forces. Since viscosity is a measure of resistance to flow, the viscosity therefore decreases with shear rate. The ORNL slurries exhibited a pseudoplastic liquid flow behavior, with the divergence from Newtonian increasing with heavier solids loading.

When measuring slurries, particle fallout during testing can be a significant source of error with traditional viscometers. For this reason, a special anti-settling device was designed by Paar Physica specifically for the measurement of slurries. A small mixing blade keeps the sample in the chamber uniforrn until it is sent through the capillary tube. The entrance length of the tube is sufficiently long to allow for the full development of a laminar flow profile in the required areas. Laminar flow is essential to viscosity measurements. This device was tested rigorously by Paar Physica and Battelle before being utilized for the ORNL analysis.

\section{Testing}

The ORNL slurry samples were shipped to PNNL for analysis after each set of pipe loop tests was completed. They were stored in a refrigerator to inhibit biological growth until testing was completed. The samples were run in three viscometers to gather data across a broad shear rate range.

The three viscometers were all validated with standardized silicone oils of various ranges before ORNL samples were run. Simulants were also prepared and tested to ensure that no unexpected problems would arise. Sample preparations and testing were done according to manufacturers' recommended procedures.

Settling of the slurries was noticeable in the torque viscometers. Therefore, short run times were utilized to minimize the problem. The settling became a significant issue with the samples containing sand. The large particle size limited the testing to only one viscometer, the Haake M5, with a sensor system having a large gap. 
There was no measurable settling in the capillary viscometer. The anti-settling device on the capillary device was validated continuously throughout testing. A moisture analysis was performed on the each $50 \mathrm{~mL}$ of sample after it was run through the viscometer and compared with the baseline analysis done at the start of testing. The moisture content varied by less then $2 \%$ throughout testing.

To ensure the accuracy of the data, all the samples were run in duplicate or triplicate. The curves were overlaid in the viscometer software to validate repeatability before exportation into EXCEL to be combined into complete rheograms and viscosity curves.

\section{Data Analysis}

In the rheograms, an overall fluid behavior can be observed by combining the data from the various viscometers. The ORNL slurries exhibited a pseudoplastic liquid flow behavior, with the divergence from Newtonian behavior increasing with heavier solids loading.

Rheograms and viscosity curves are included for every sample. The data below $100 \mathrm{~s}^{-1}$ have a tendency to be affected by mechanical noise since it is out of the accepted range for the sensors used and is useful only for establishing a pattern. Actual viscosity values from this range are unreliable and should not be utilized. Viscosities at specific shear rates are shown in Table A-1. Because of the pseudoplastic nature of the fluid, the viscosities are constantly changing with the shear rate. Settling was observed to occur in all the slurry recipes during testing with the Haake viscometers. This could also increase the vagary of the actual observed values. Therefore, the viscosities given are only approximate values. At the lower shear rates, the values are accurate to about $+/-10 \%$. At the higher shear rates, the values usually vary less than $1 \mathrm{cP}$ from the reported value upon repeated testing.

As would be expected, the viscosity increased with solids loading and the addition of sugar to the water. For the samples containing sugar, the viscosity decreased with increased temperature. In the samples consisting of only kaolin and water, the increased

temperature produced an unexpected rise in viscosity at some shear rate ranges. A slight 
dilatant tendency was observed at very high shear rates, especially in the heavily loaded slurries. This is not uncommon, especially in kaolin or silica slurries.

Table A-1. Approximate slurry viscosities (+/- $2 \mathrm{cP}$ to $10 \%)$ at selected shear rates

\begin{tabular}{|c|c|c|c|c|c|}
\hline ORNL Slurry & $100 \mathrm{~s}^{-1}$ & $440 \mathrm{~s}^{-1}$ & $10^{3} \mathrm{~s}^{-1}$ & $10^{4} \mathrm{~s}^{-1}$ & $10^{5} \mathrm{~s}^{-1}$ \\
\hline 10 wt\% Kaolin@25ㄷ & 5.6 & 2.8 & NA & 1.6 & 1.3 \\
\hline 10 wt\%Kaolin@50C & 7 & 4 & NA & 1.4 & 1.4 \\
\hline 20 wt \% Kaolin@25ㄷ & 48 & 18 & 11 & 3.4 & 2.1 \\
\hline 20 wt \% Kaolin@ @ $50^{\circ} \mathrm{C}$ & 47 & 13 & 7.5 & 1.7 & 2 \\
\hline 30 wt\%Kaolin@25ㄷ & 118 & 38 & 21 & 4.4 & 2.7 \\
\hline 30 wt \% Kaolin@ @ 50 C & 126 & 44 & 20 & 3.7 & 2 \\
\hline $9 \mathrm{wt} \%$ Kaolin-sugar@ $25^{\circ} \mathrm{C}$ & 35 & 25 & 22 & 16 & 14 \\
\hline 9 wt \% Kaolin-sugar@ @ 50 $\mathrm{C}$ & 25 & 15.5 & 12 & 7.5 & 6.5 \\
\hline 14.5 wt \% Kaolin-ugar@25 $25^{\circ}$ & 90 & 44 & 34 & 20 & 16 \\
\hline 14.5 wt \% Kaolin-sugar@ $00^{\circ} \mathrm{C}$ & 68 & 30 & 21 & 11 & 7.5 \\
\hline 22.1 wt \% Kaolin-sugar@25. C & 269 & 117 & 84 & 36 & 30 \\
\hline 22.1 wt \% Kaolin-sugar@ $90^{\circ} \mathrm{C}$ & 239 & 92 & 59 & 23 & 16 \\
\hline $10 \mathrm{wt} \%$ Kaolin-sugar-sand @ $25^{\circ} \mathrm{C}$ & 45 & 26 & 24 & $\mathrm{NA}$ & $\mathrm{NA}$ \\
\hline 10 wt \% Kaolin-sugar-sand @ $50^{\circ} \mathrm{C}$ & 36 & 133 & NA & $\mathrm{NA}$ & $\mathrm{NA}$ \\
\hline 20 wt \% Kaolin-sugar-sand @ $25^{\circ} \mathrm{C}$ & 122 & 61 & NA & $\mathrm{NA}$ & $\mathrm{NA}$ \\
\hline 20 wt \% Kaolin-sugar-sand @ $50^{\circ} \mathrm{C}$ & 112 & 56 & NA & $\mathrm{NA}$ & $\mathrm{NA}$ \\
\hline 30 wt \% Kaolin-sugar-sand @ $25^{\circ} \mathrm{C}$ & 255 & 100 & NA & $\mathrm{NA}$ & $\mathrm{NA}$ \\
\hline 30 wt \% Kaolin-sugar-sand @ 50 $\mathrm{C}$ & 246 & 98 & NA & $\mathrm{NA}$ & $\mathrm{NA}$ \\
\hline
\end{tabular}




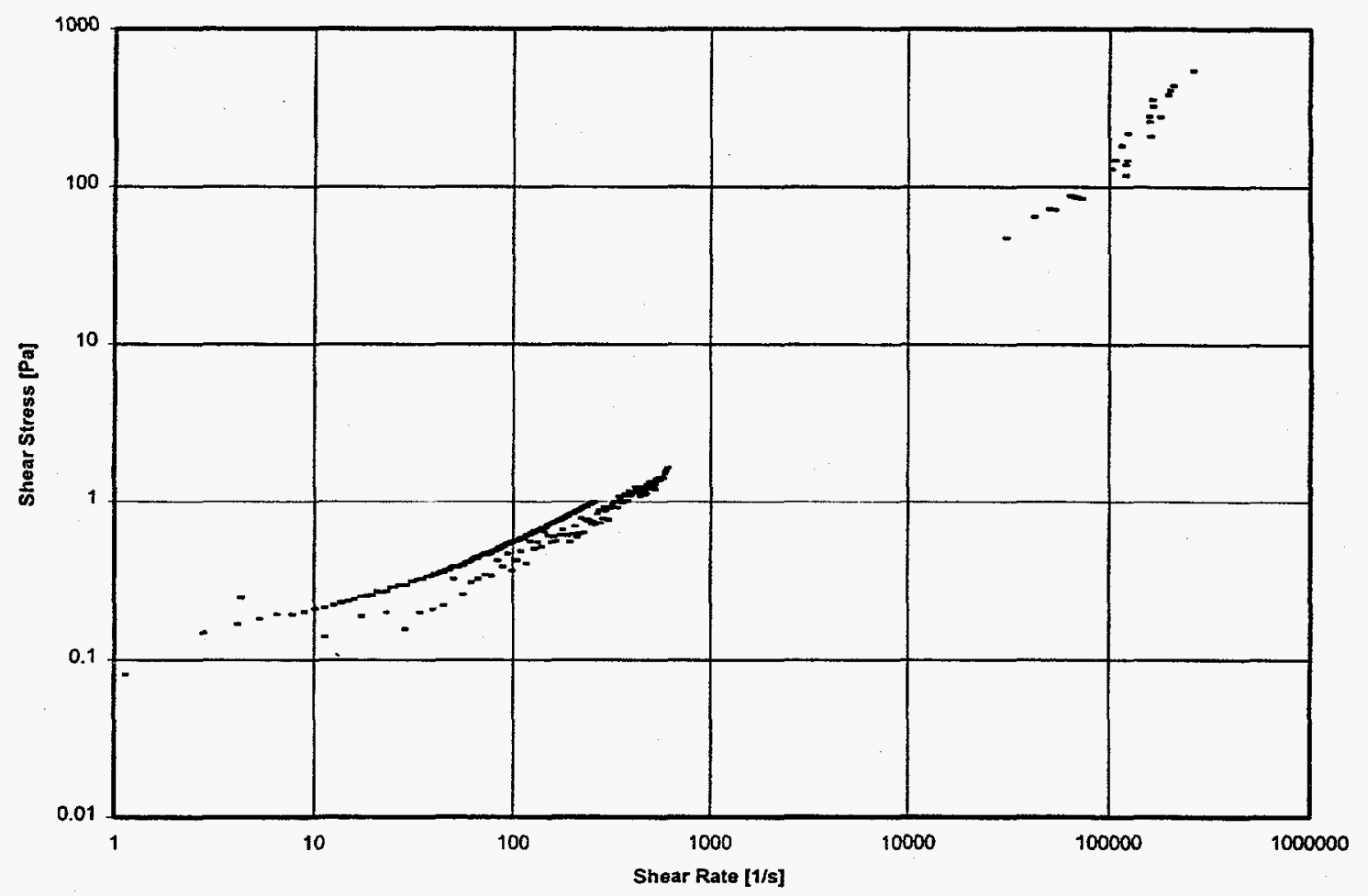

Fig. A-1. Rheogram for $\sim 10 \mathrm{wt} \%$ kaolin and water slurry at $25^{\circ} \mathrm{C}$.

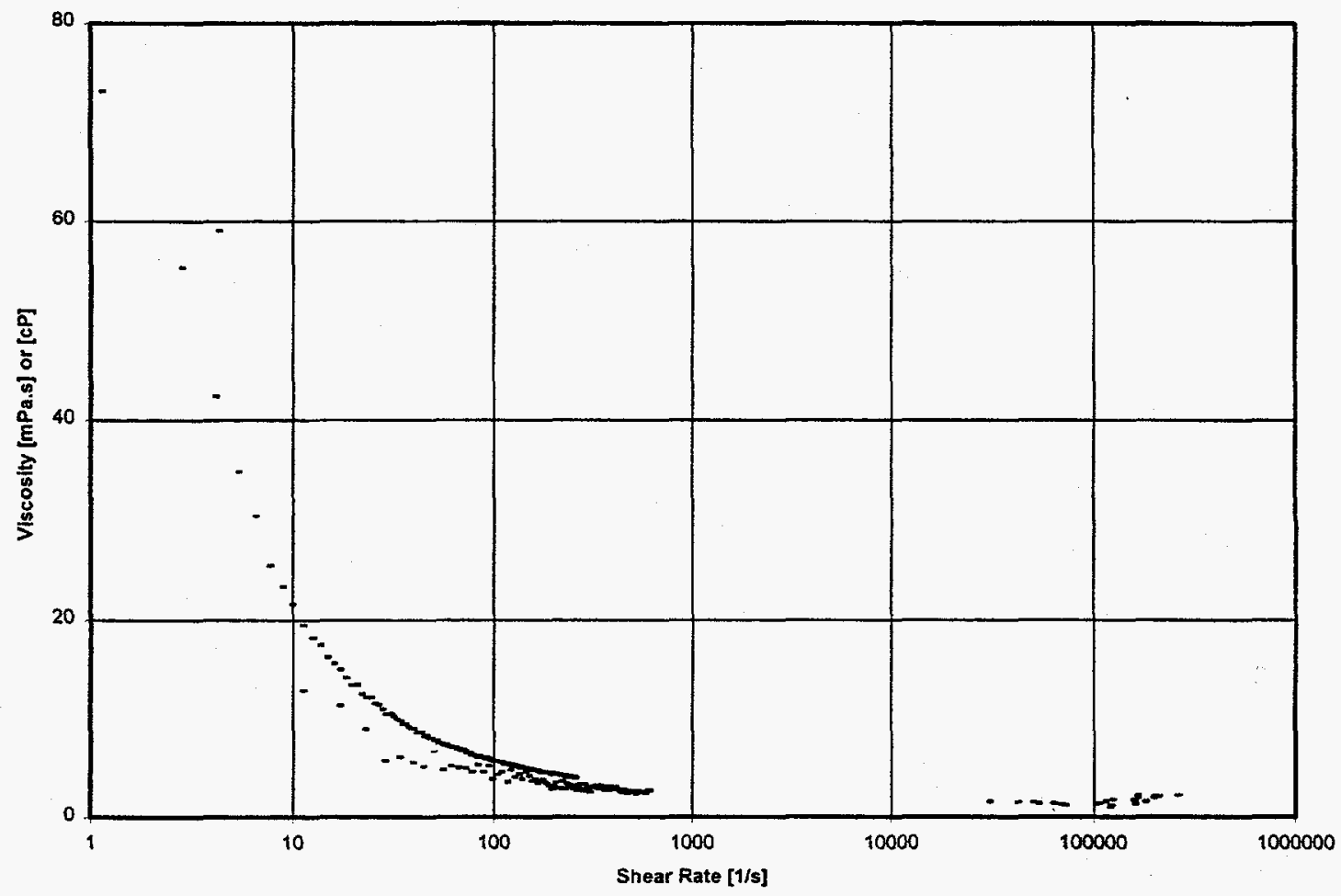

Fig. A-2. Viscosity curve for $\sim 10 \mathrm{wt} \%$ kaolin and water slurry at $25^{\circ} \mathrm{C}$. 


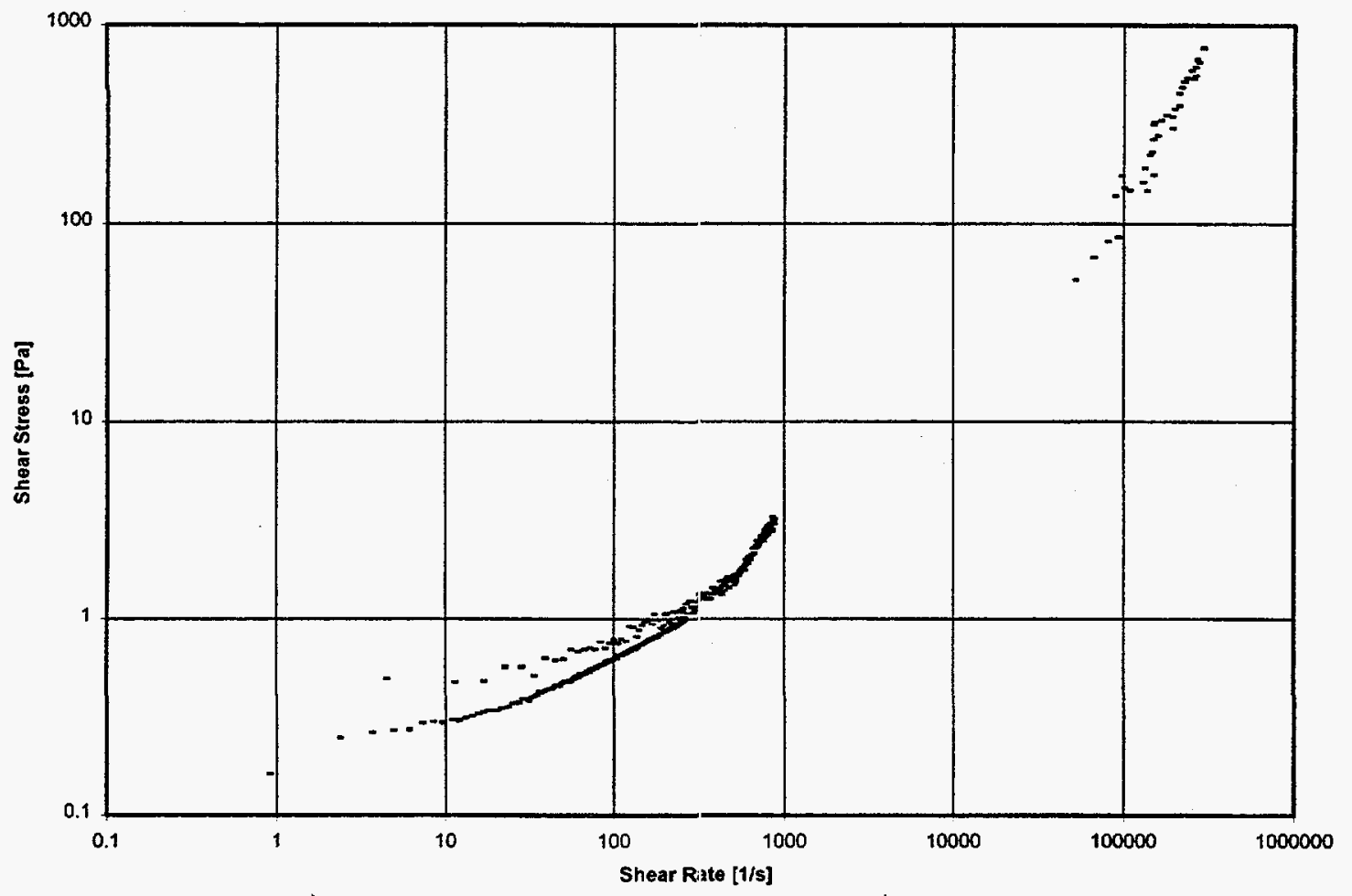

Fig. A-3. Rheogram for $\sim 10 \mathrm{wt} \%$ kaolin and water slurry at $50^{\circ} \mathrm{C}$.

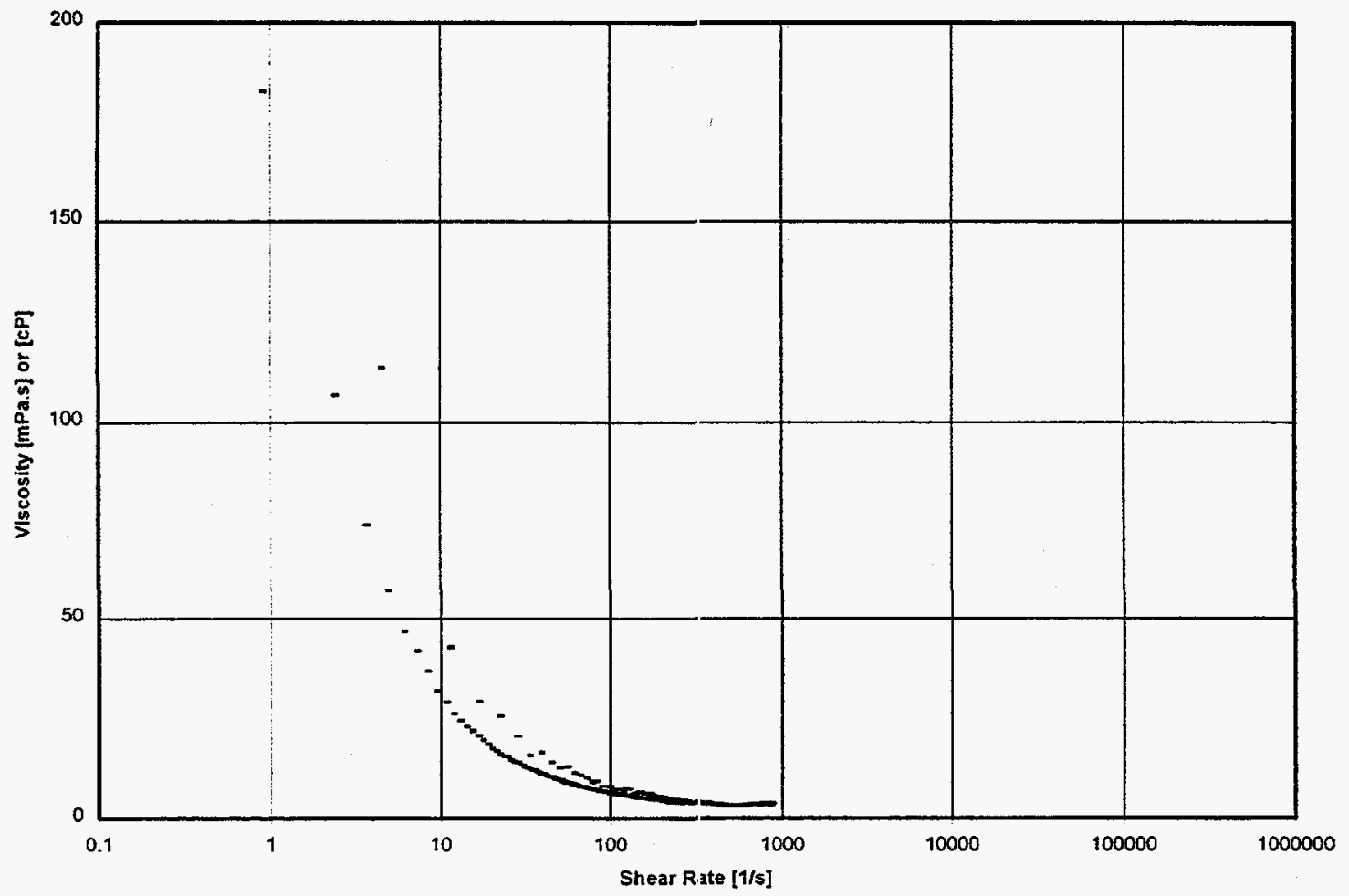

Fig. A-4. Viscosity curve for $\sim 10 \mathrm{wt} \%$ kaolin and water slurry at $50^{\circ} \mathrm{C}$. 


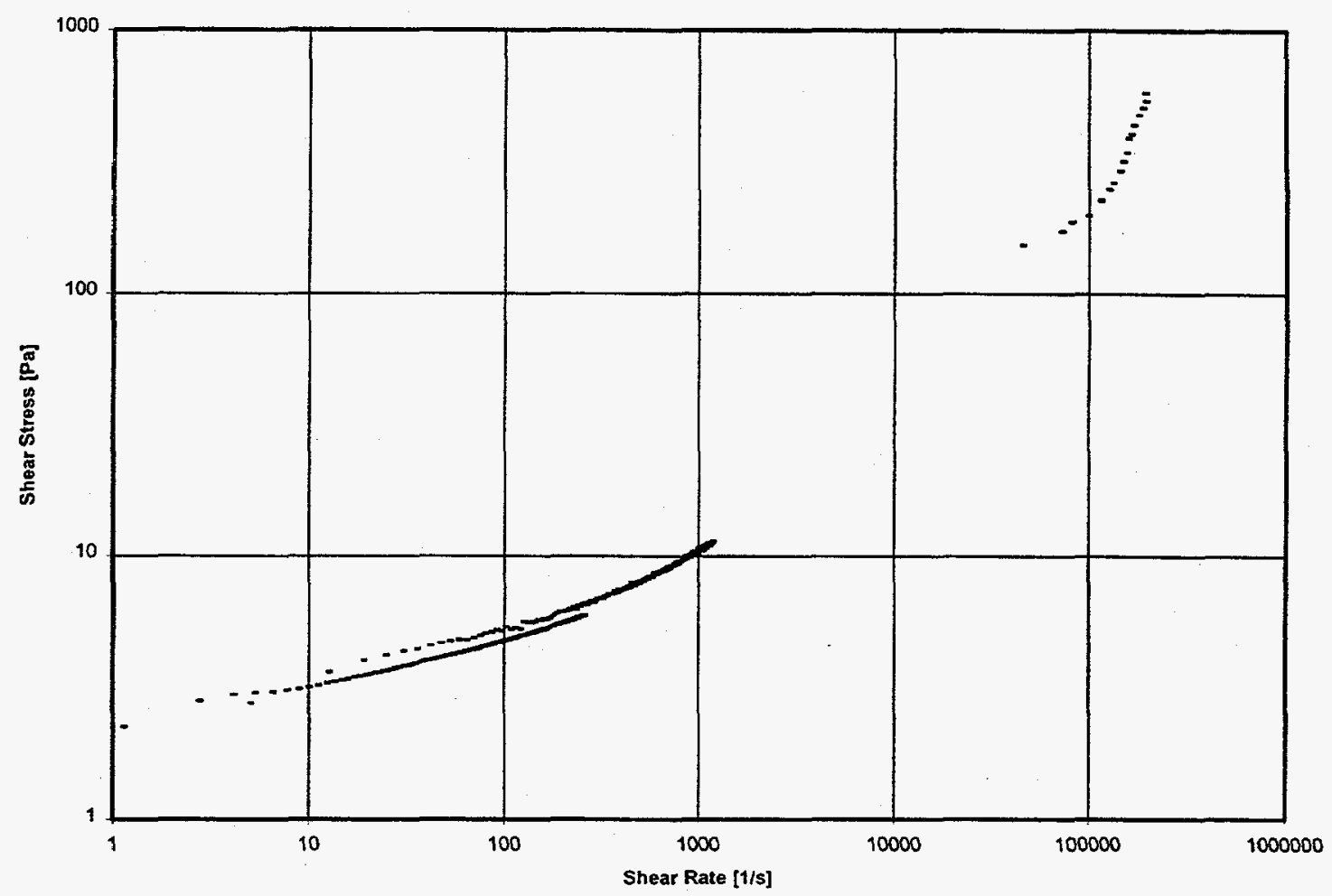

Fig. A-5. Rheogram for $\sim 20 \mathrm{wt} \%$ kaolin and water slurry at $25^{\circ} \mathrm{C}$.

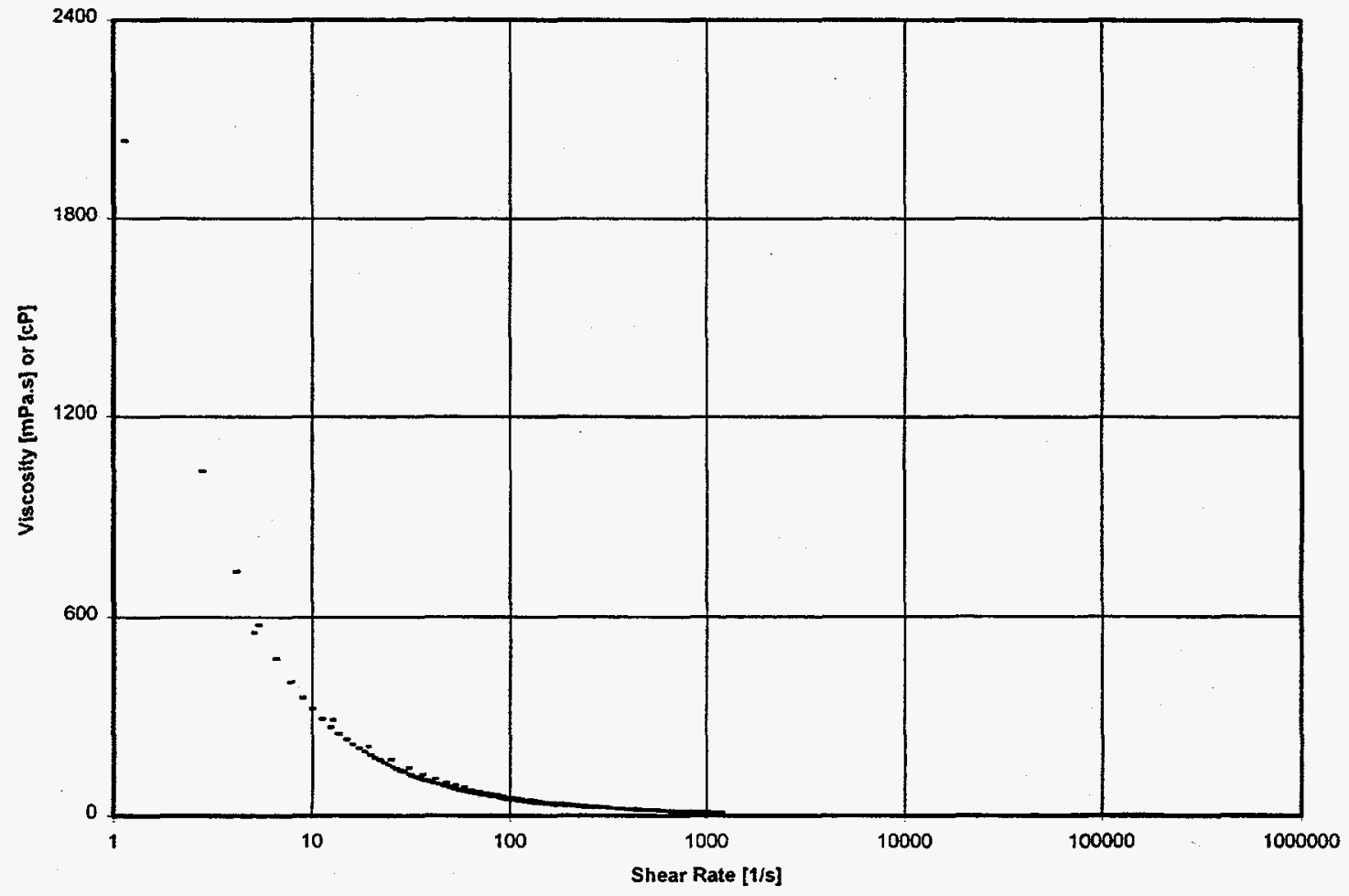

Fig. A-6. Viscosity curve for $\sim 20 \mathrm{wt} \%$ kaolin and water slurry at $25^{\circ} \mathrm{C}$. 


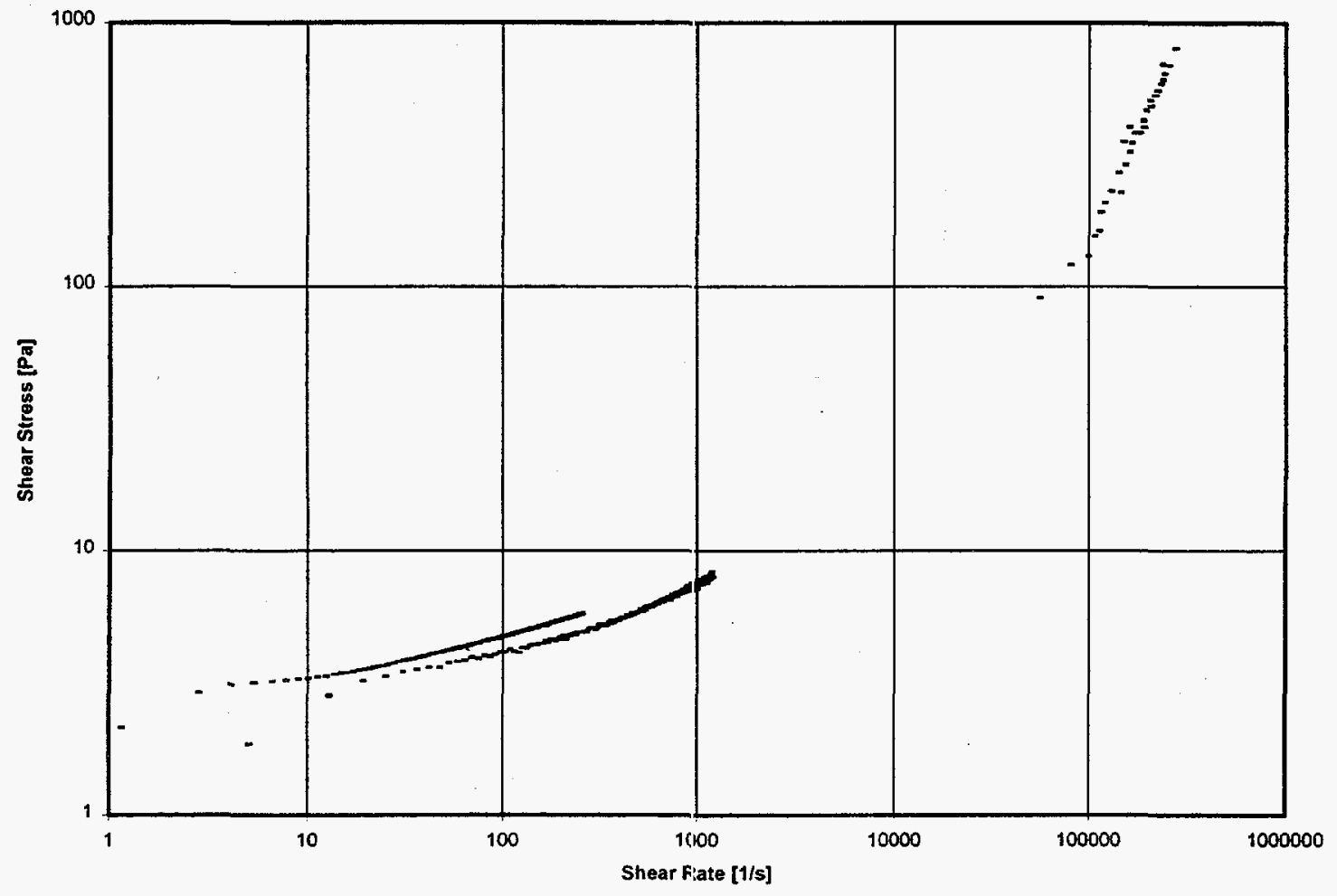

Fig. A-7. Rheogram for $\sim 20 \mathrm{wt} \%$ kaolin and water slurry at $50^{\circ} \mathrm{C}$.

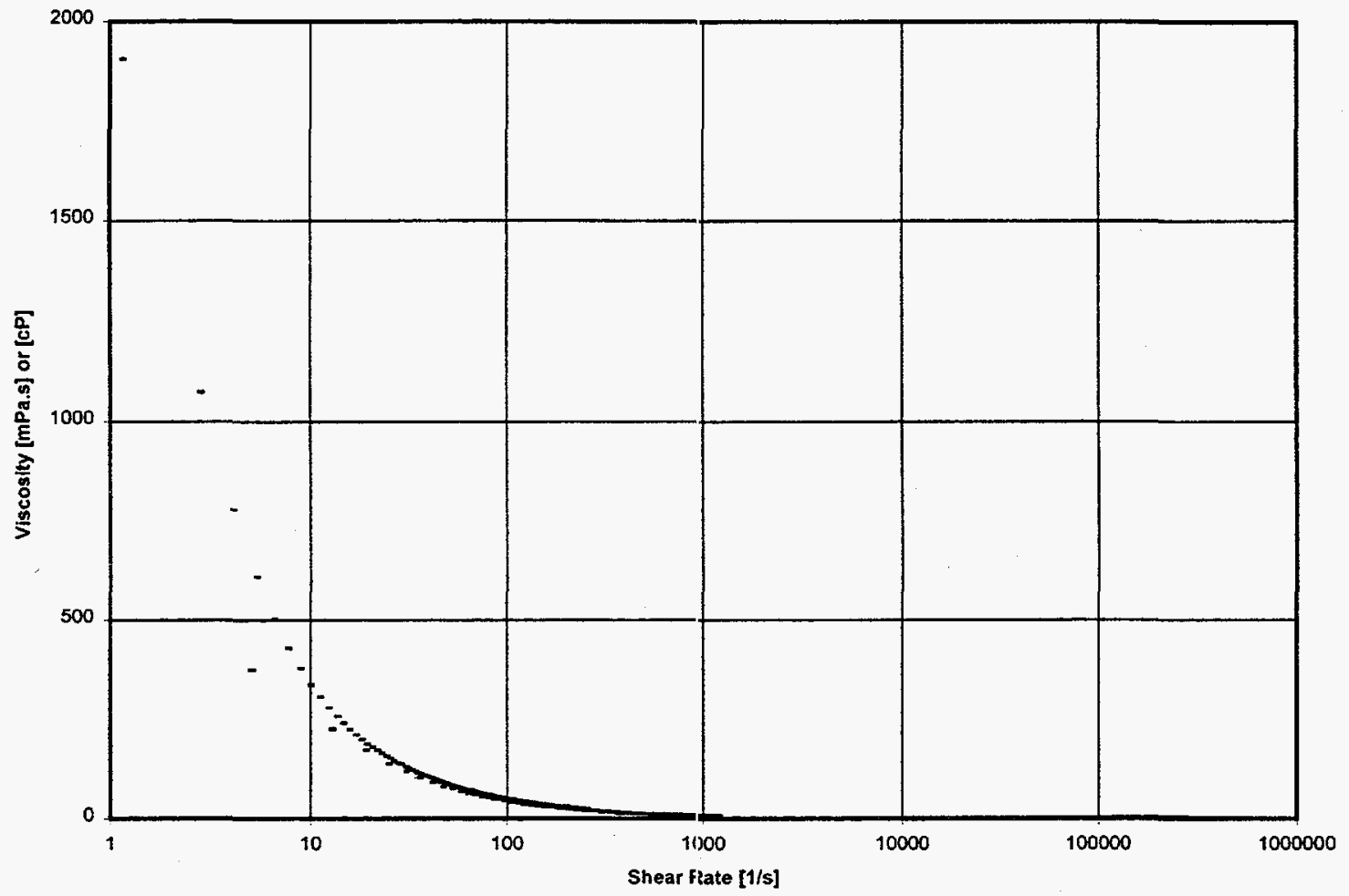

Fig. A-8. Viscosity curve for $\sim 20 \mathrm{wt} \%$ kaolin and water slurry at $50^{\circ} \mathrm{C}$. 


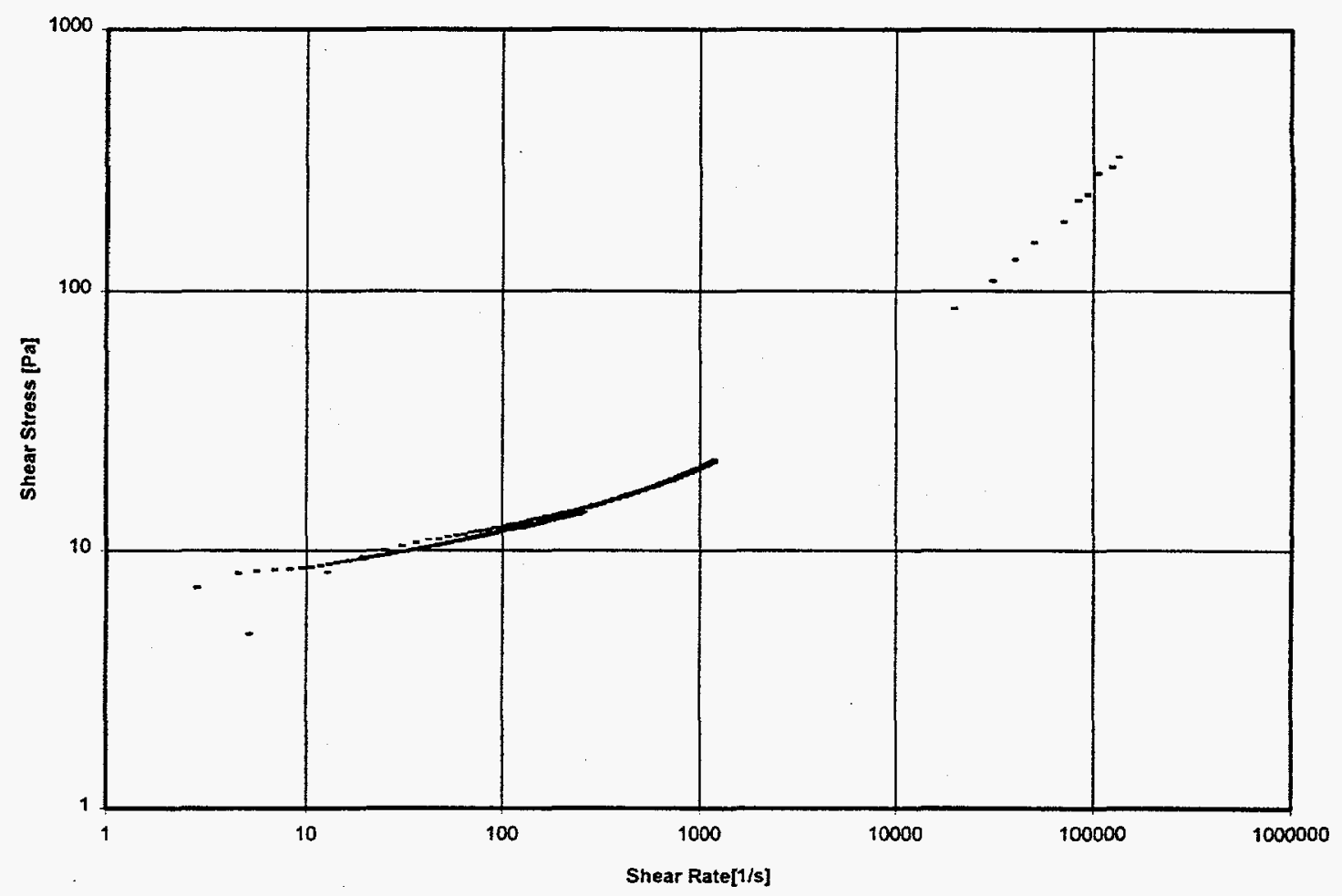

Fig. A-9. Rheogram for $\sim 30 \mathrm{wt} \%$ kaolin and water slurry at $25^{\circ} \mathrm{C}$.

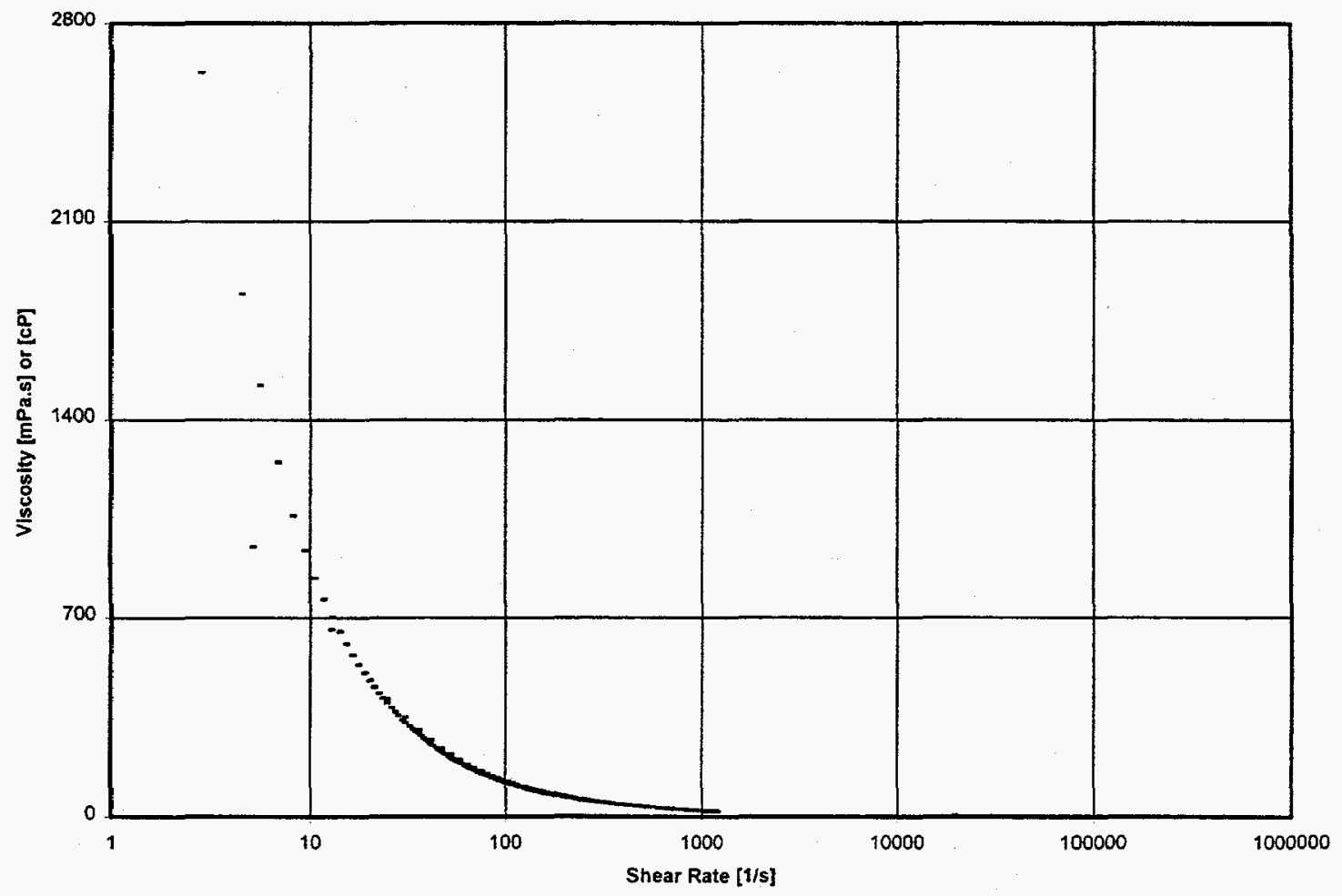

Fig. A-10. Viscosity curve for $\sim 30 \mathrm{wt} \%$ kaolin and water slurry at $25^{\circ} \mathrm{C}$. 


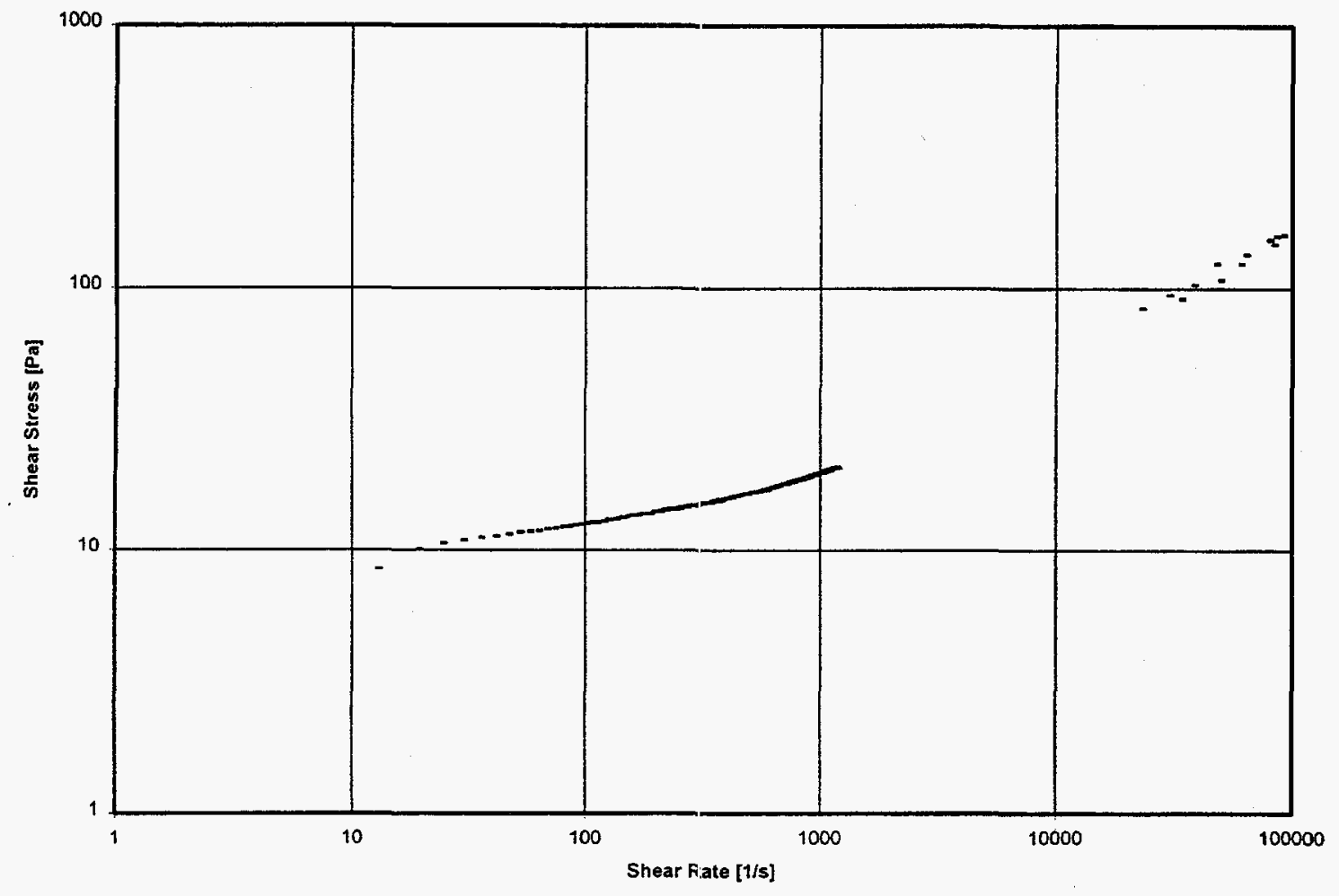

Fig. A-11. Rheogram for $\sim 30 \mathrm{wt} \% \mathrm{k}$ kaolin and water slurry at $50^{\circ} \mathrm{C}$.

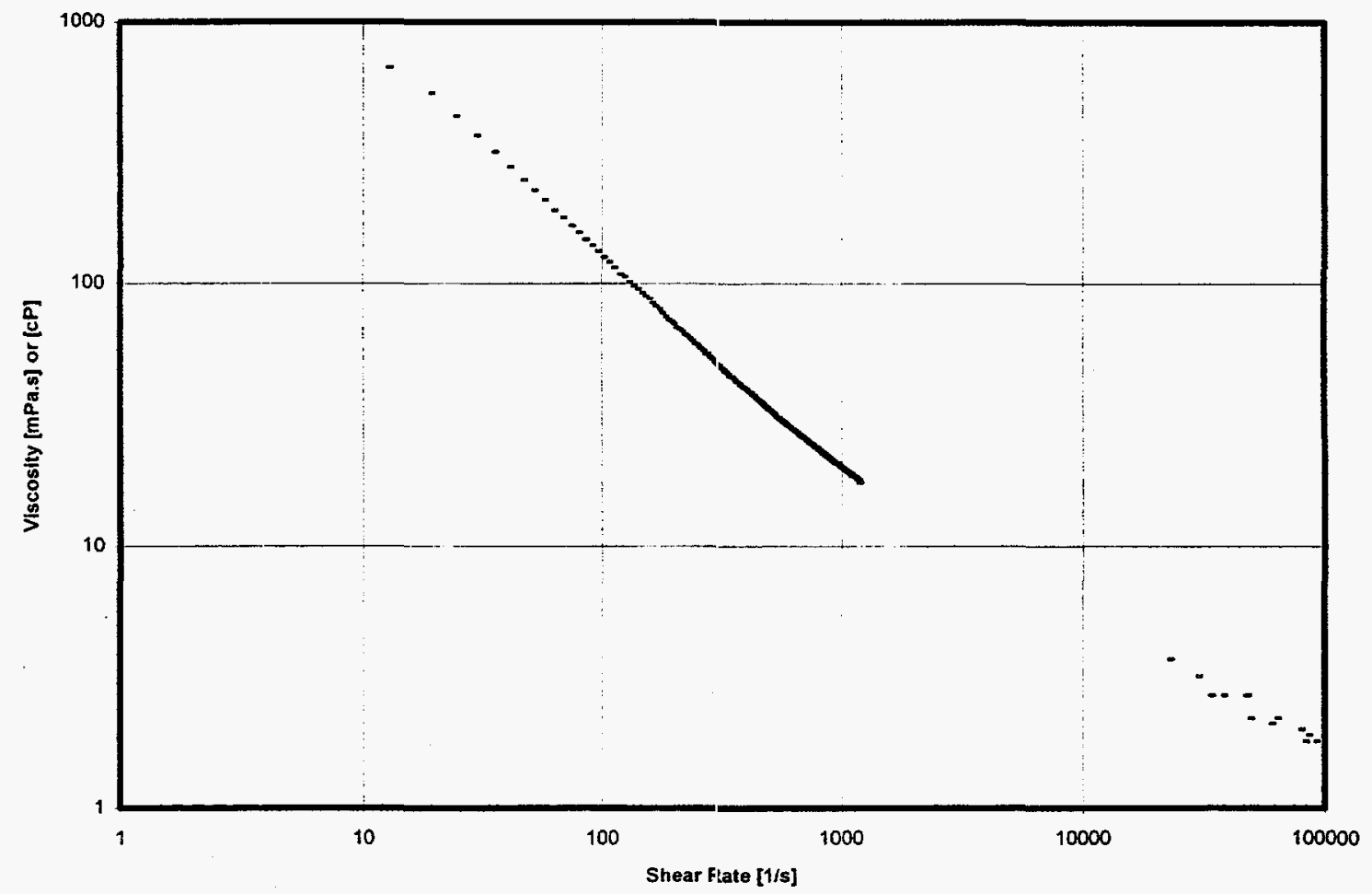

Fig. A-12. Viscosity curve for $-30 \mathrm{wt} \%$ kaolin and water slurry at $50^{\circ} \mathrm{C}$. 


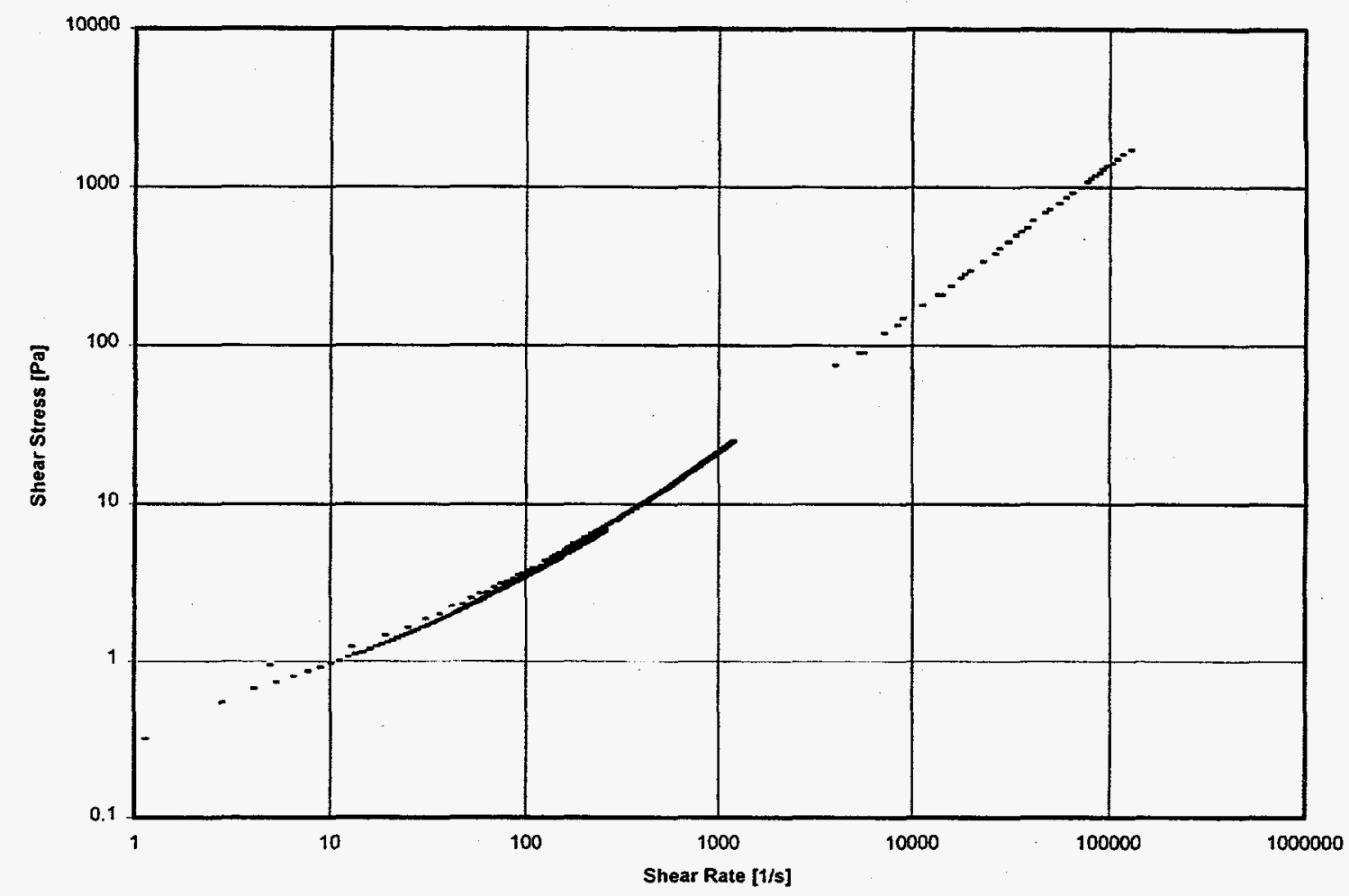

Fig. A-13. Rheogram for $\sim 9 \mathrm{wt} \%$ kaolin and sugar water slurry at $25^{\circ} \mathrm{C}$.

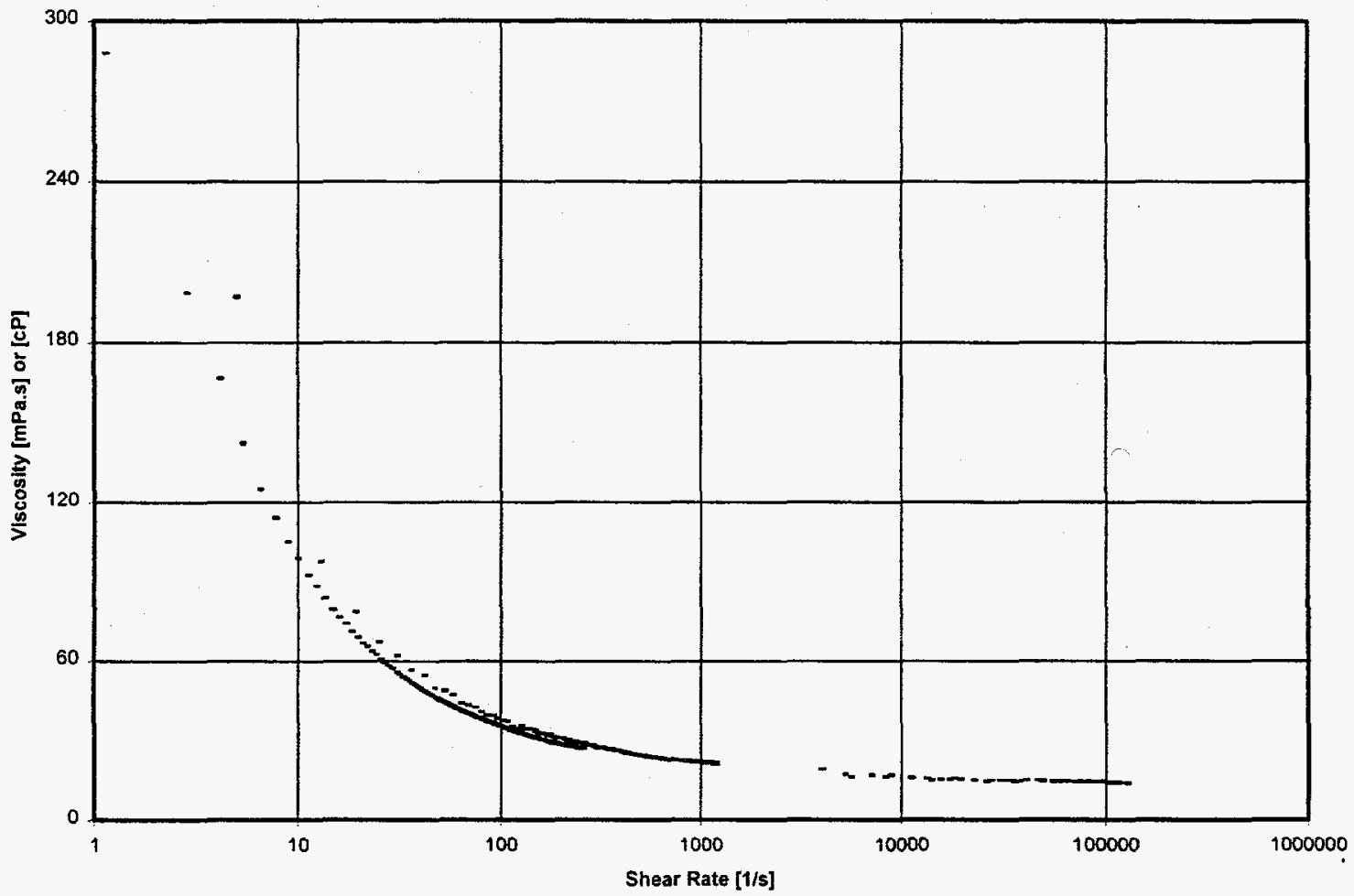

Fig. A-14. Viscosity curve for $\sim 9 \mathrm{wt} \%$ kaolin and water slurry at $25^{\circ} \mathrm{C}$. 


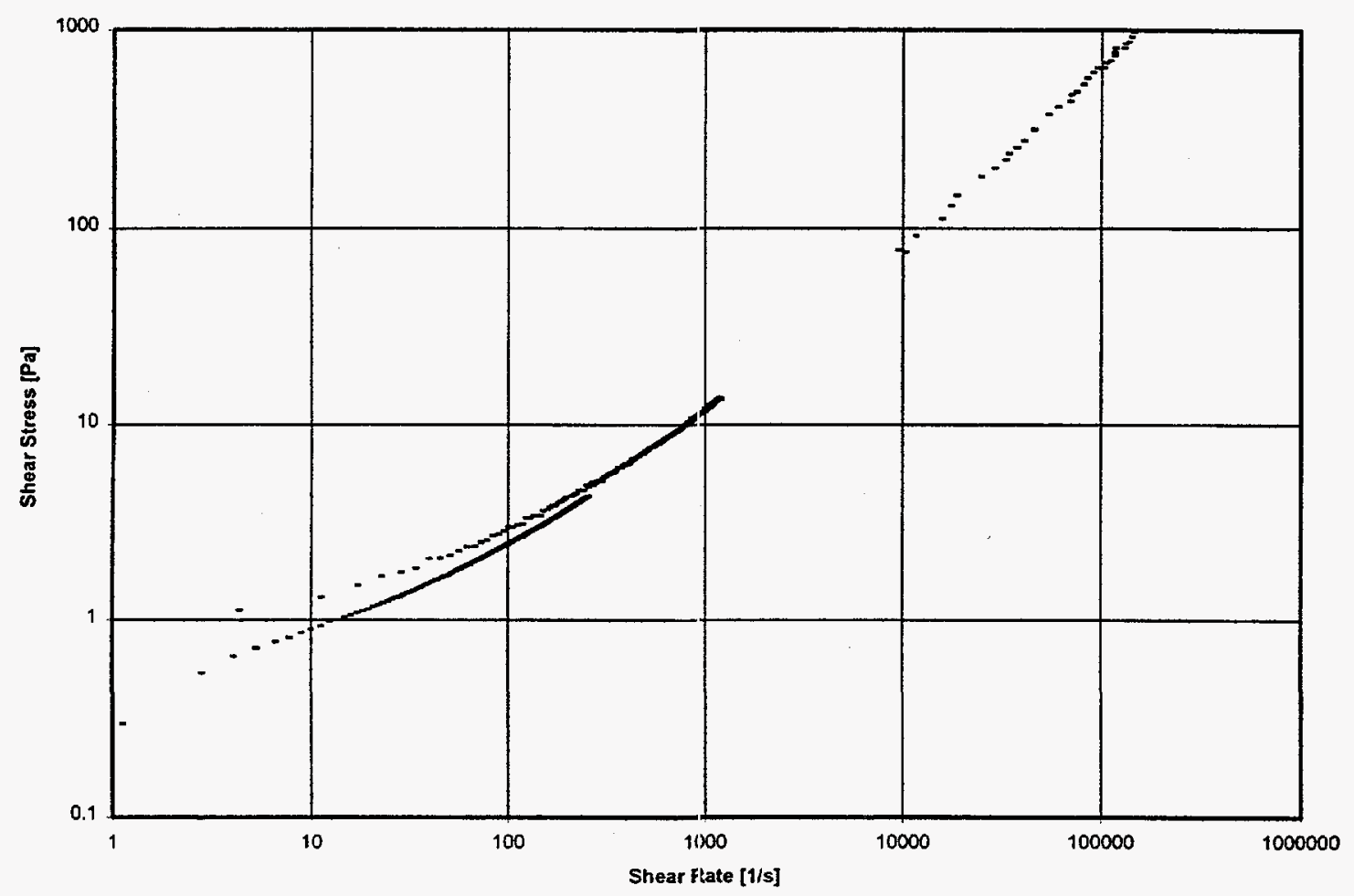

Fig. A-15. Rheogram for $\sim 9 \mathrm{wt} \%$ kaolin and sugar water slurry at $50^{\circ} \mathrm{C}$.

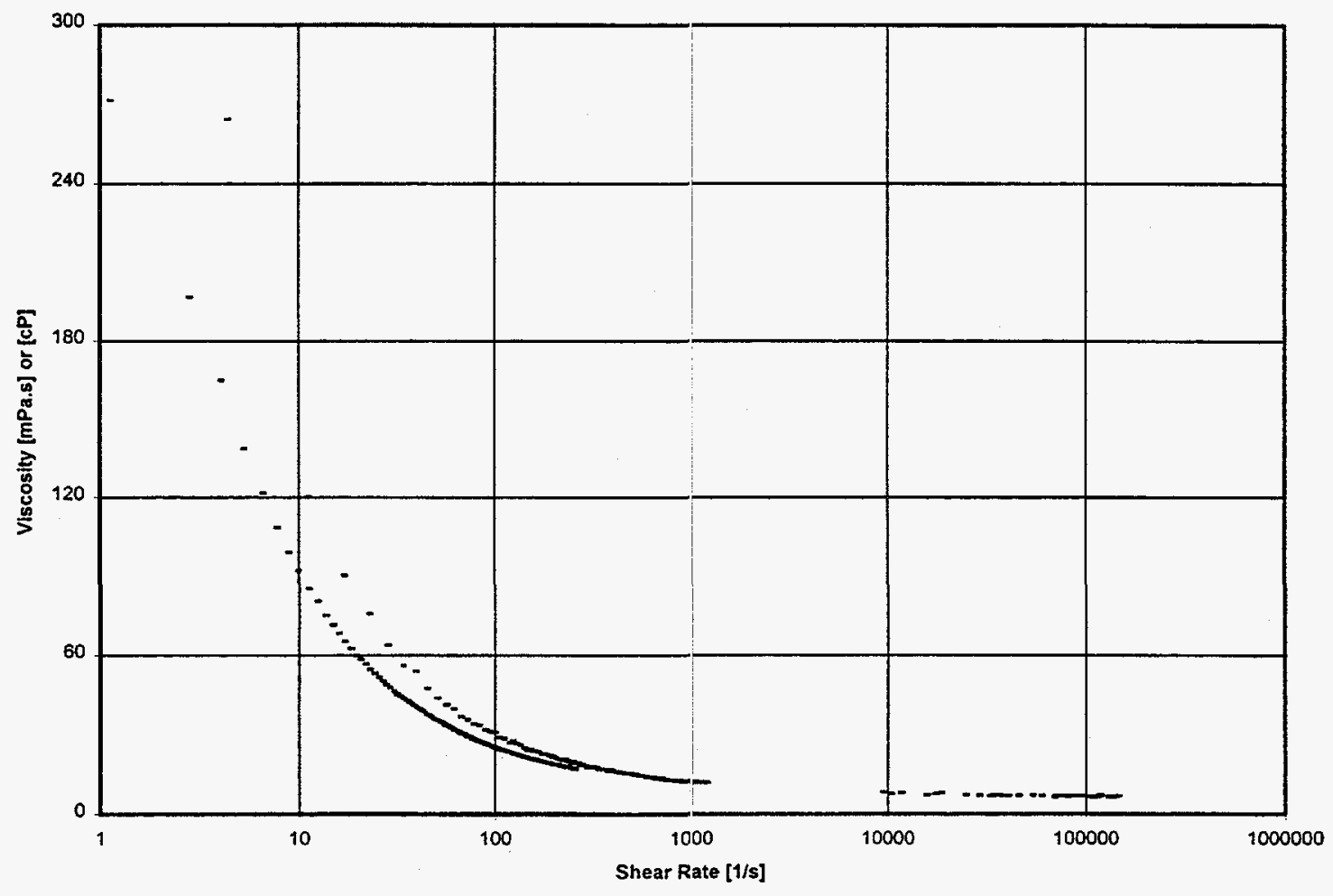

Fig. A-16. Viscosity curve for $\sim 9 \mathrm{wt} \%$ kaolin and water slurry at $50^{\circ} \mathrm{C}$. 


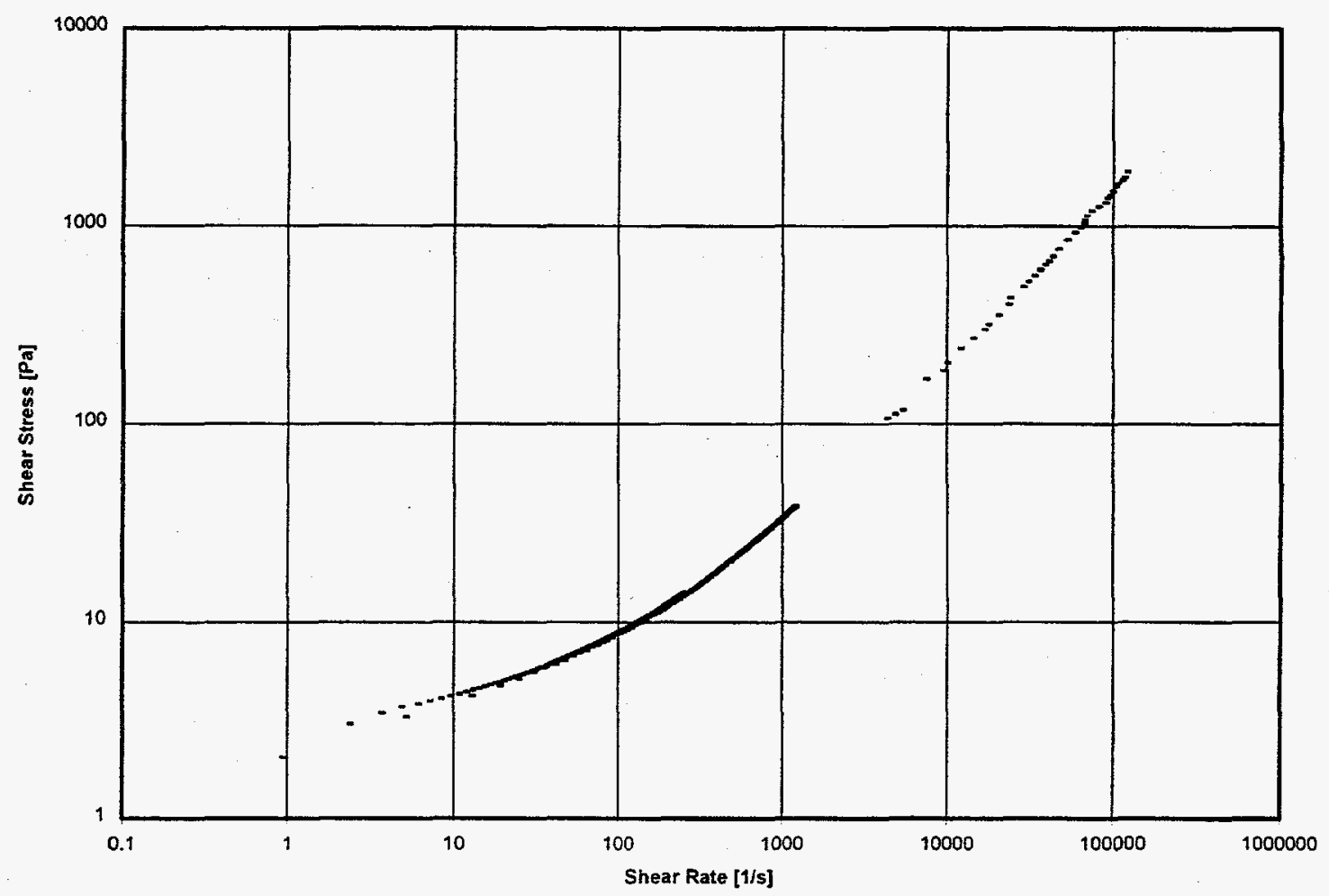

Fig. A-17. Rheogram for $\sim 15 \mathrm{wt} \%$ kaolin and sugar water slurry at $25^{\circ} \mathrm{C}$.

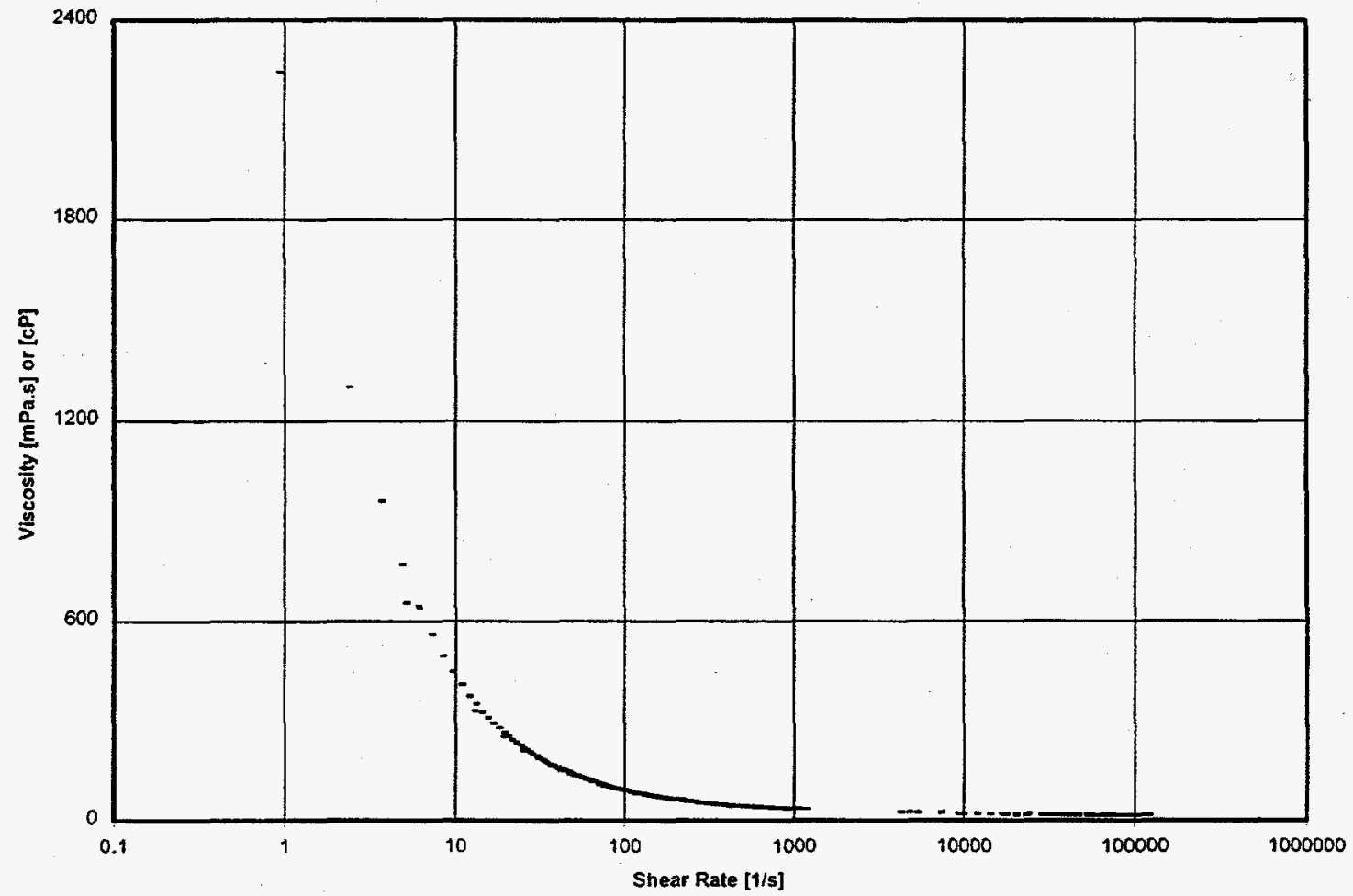

Fig. A-18. Viscosity curve for $\sim 15 \mathrm{wt} \%$ kaolin and water slurry at $25^{\circ} \mathrm{C}$. 


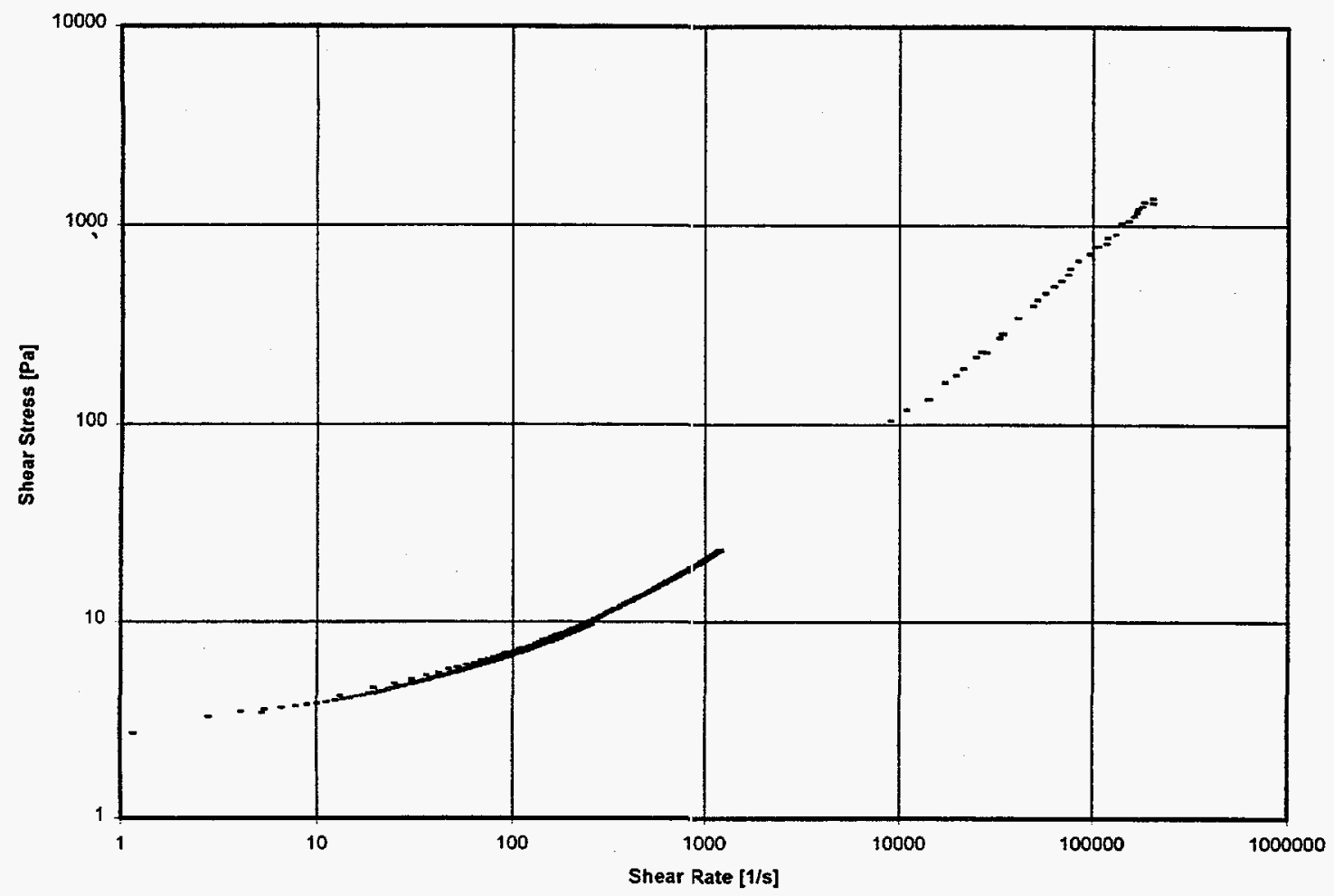

Fig. A-19. Rheogram for $\sim 15 \mathrm{wt} \%$ kaolin and sugar water slurry at $50^{\circ} \mathrm{C}$.

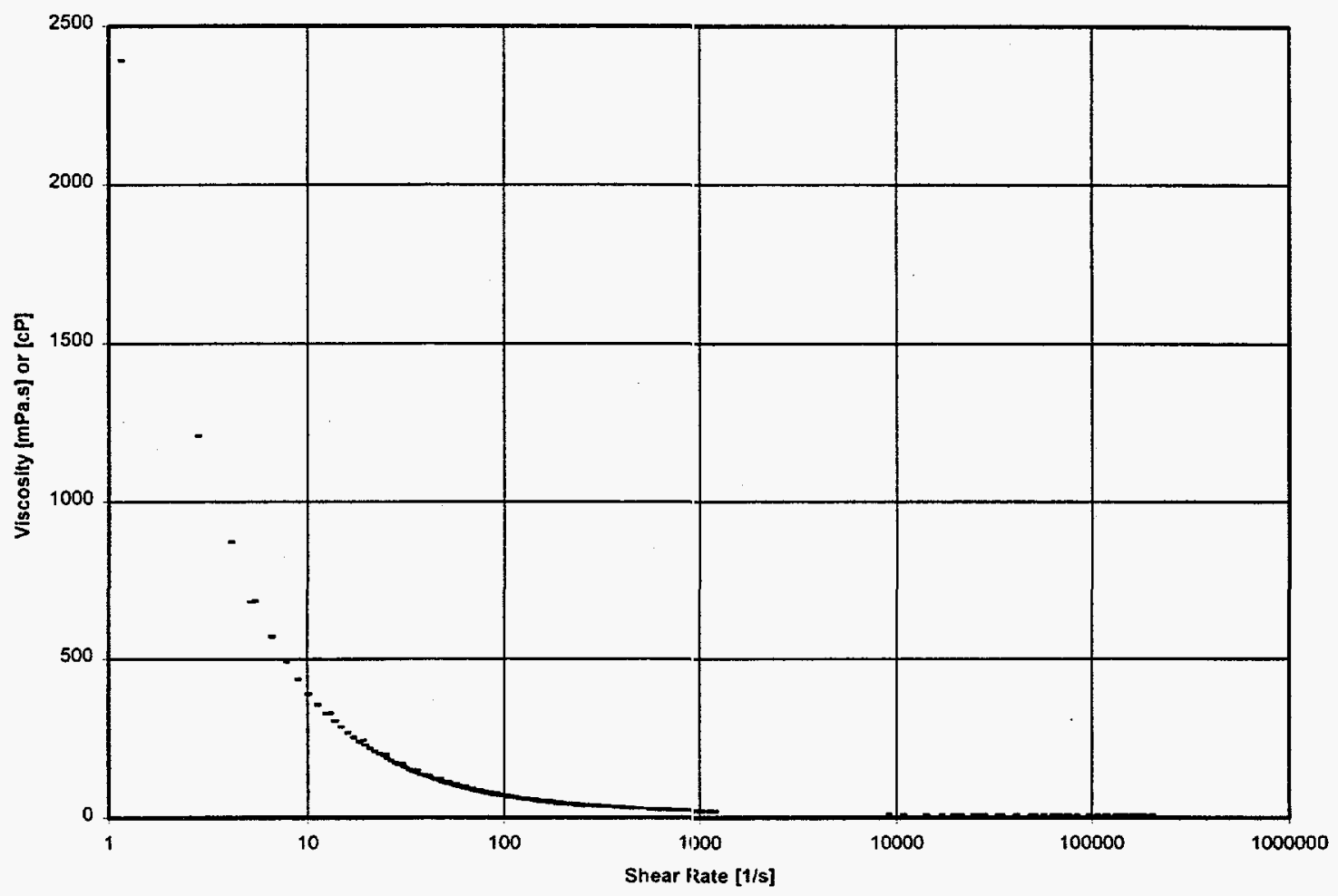

Fig. A-20. Viscosity curve for $\sim 15 \mathrm{wt} \%$ kaolin and water slurry at $50^{\circ} \mathrm{C}$. 


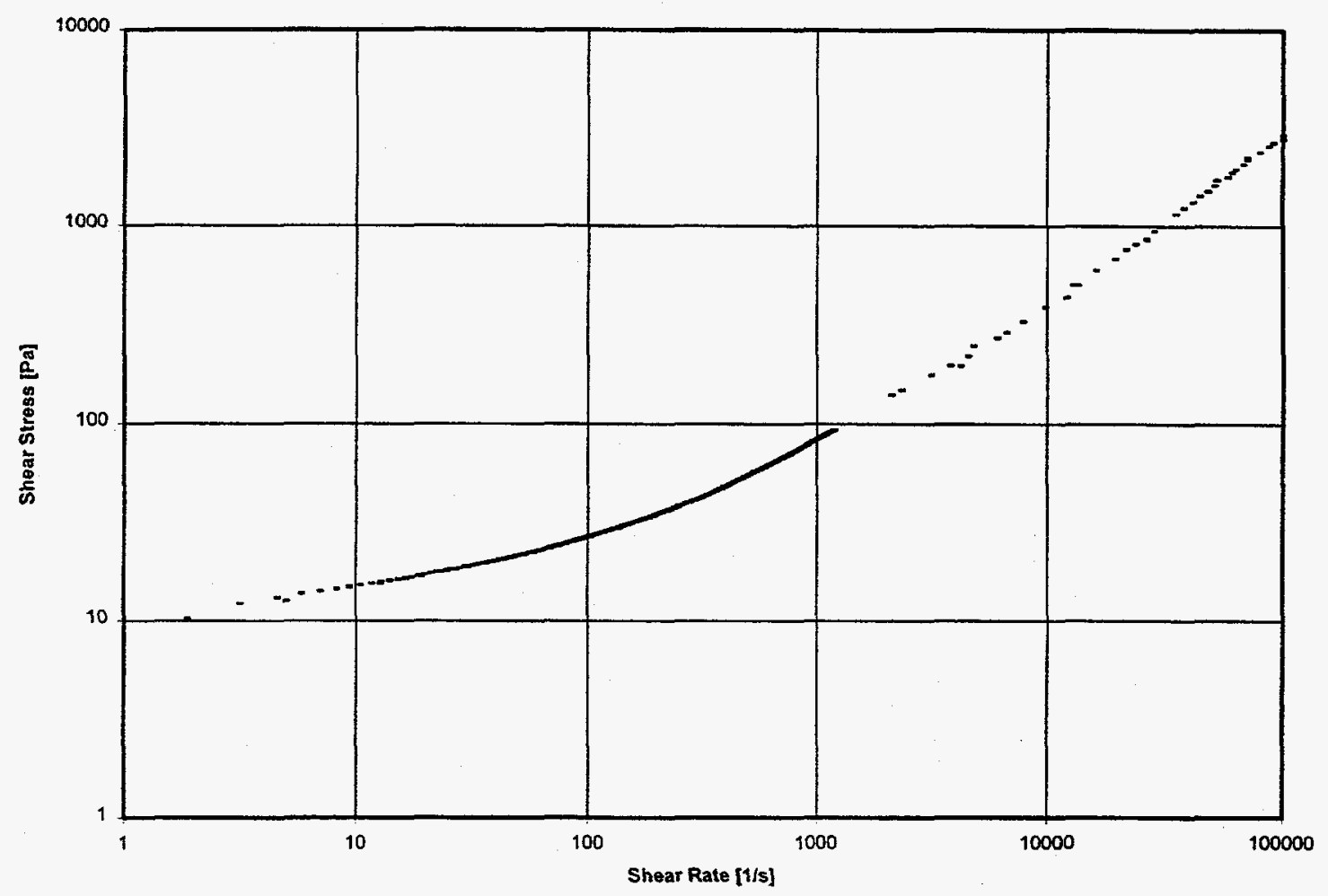

Fig. A-21. Rheogram for $\sim 22 \mathrm{wt} \%$ kaolin and sugar water slurry at $50^{\circ} \mathrm{C}$.

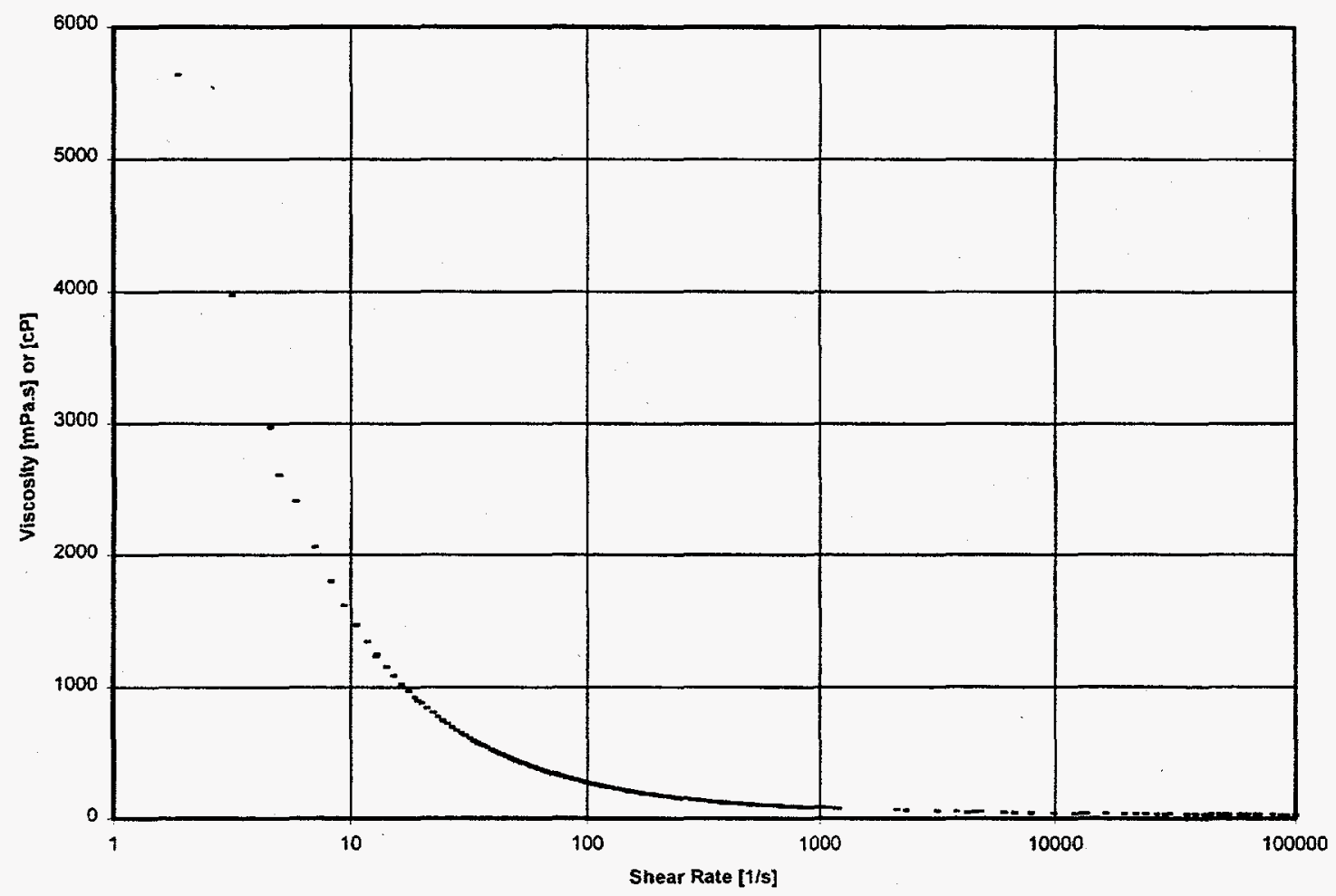

Fig. A-22. Viscosity curve for $\sim 22 \mathrm{wt} \%$ kaolin and water slurry at $25^{\circ} \mathrm{C}$. 


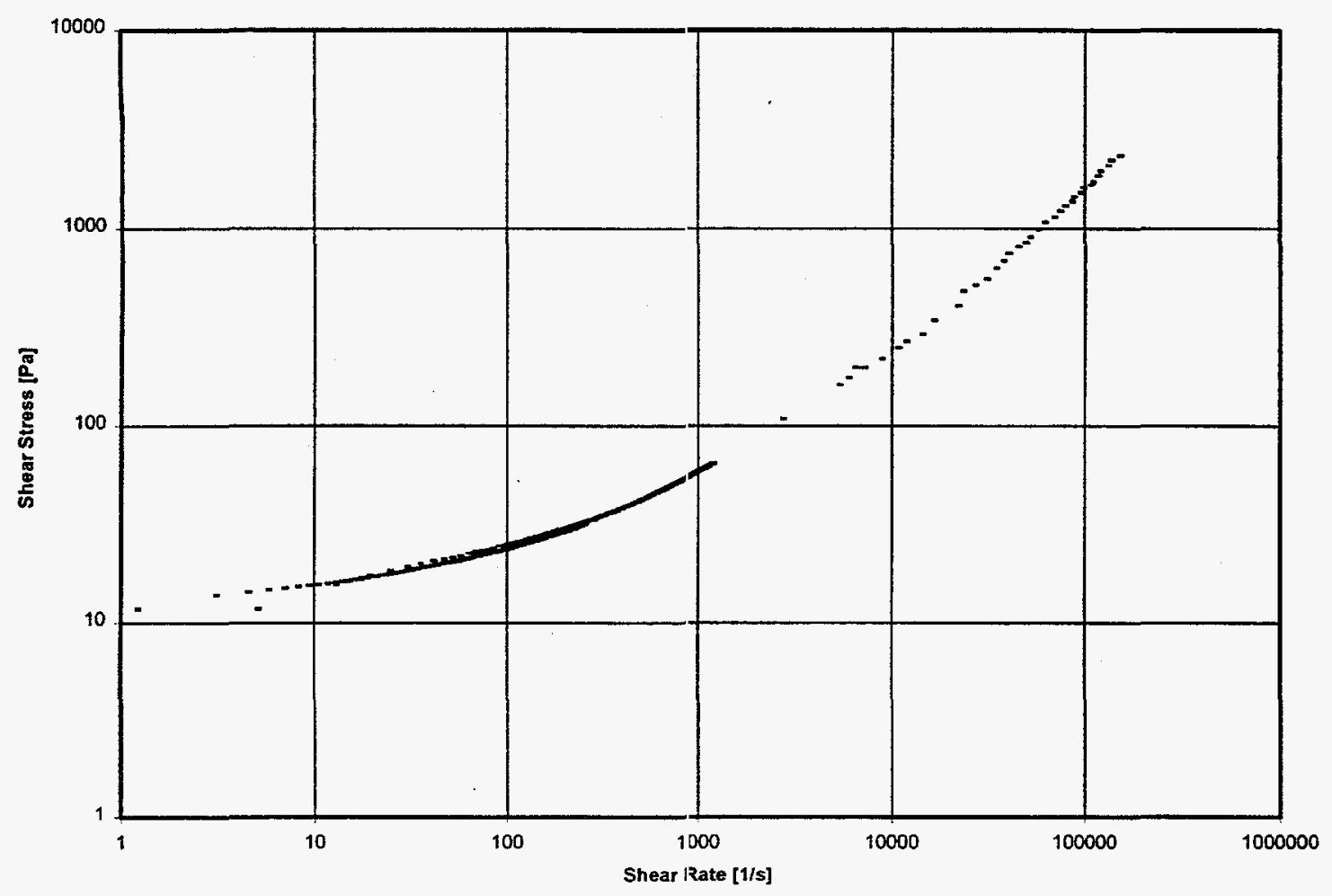

Fig. A-23. Rheogram for $\sim 22$ wt $\%$ kaolin and sugar water slurry at $25^{\circ} \mathrm{C}$.

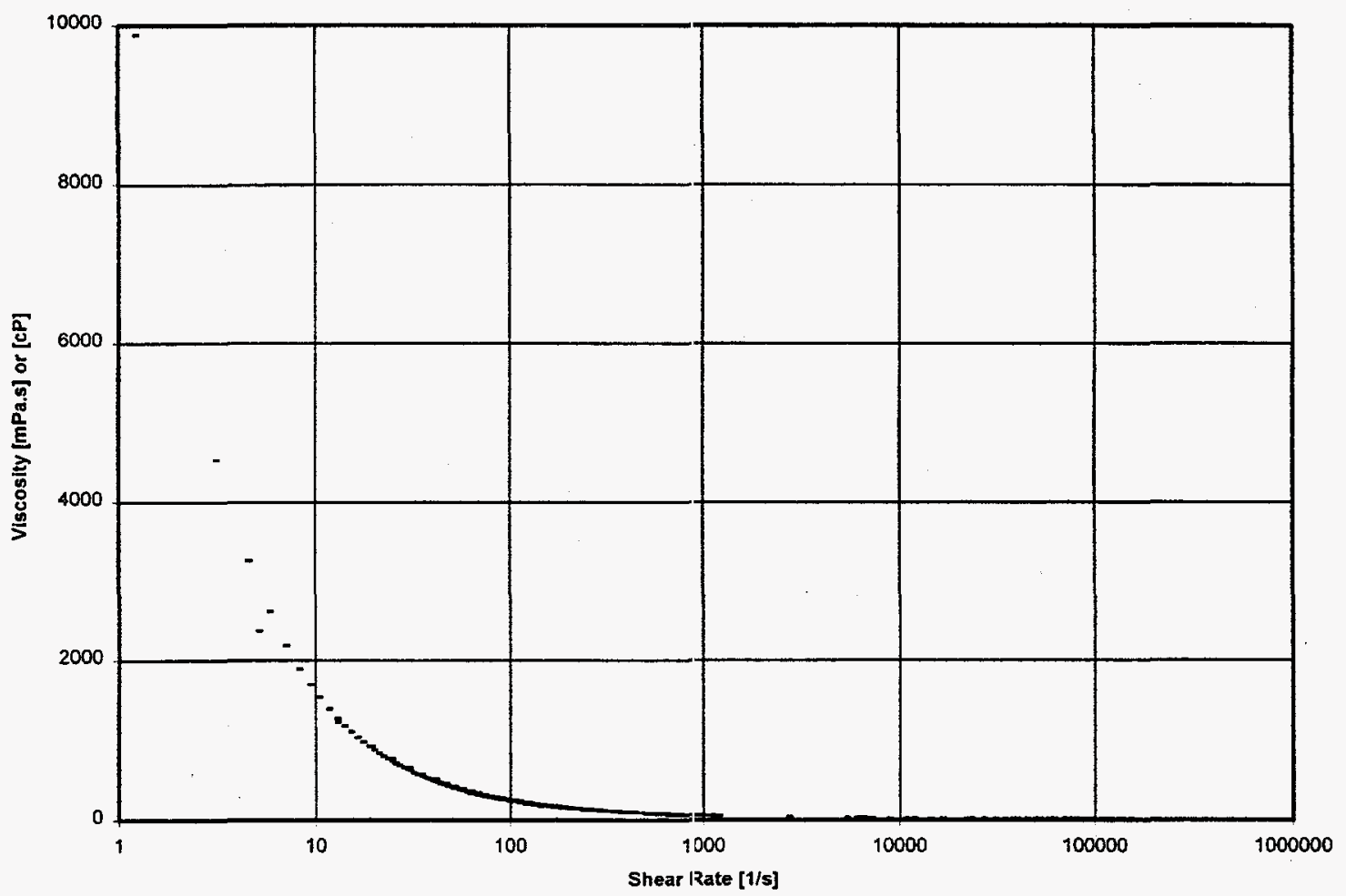

Fig. A-24. Viscosity curve for $\sim 22 \mathrm{wt} \%$ kaolin and water slurry at $50^{\circ} \mathrm{C}$. 
Appendix B

DENSITY DATA 



\section{REFERENCE LABORATORY DENSITY MEASUREMENTS}

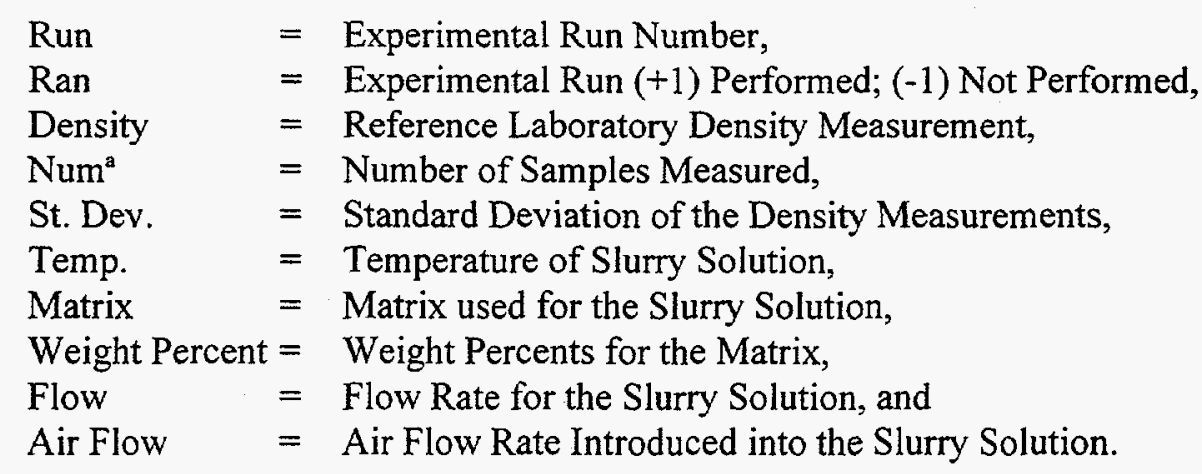

\footnotetext{
${ }^{\mathrm{a}} \mathrm{A}$ number in this column indicates the number of samples that was analyzed by the laboratory for the run, and the density value shown is an average of the reported values. If a density value is reported for a run, but a number is not shown in the "Num" column, then the density value was estimated from a linear regression of density vs flow rate for the particular matrix type, solids concentration, and temperature.
} 
Table B-1. Density $(\mathrm{g} / \mathrm{mL})$ values that were measured by the reference laboratory

\begin{tabular}{|c|c|c|c|c|c|c|c|c|c|}
\hline $\begin{array}{l}\text { Run } \\
\text { number }\end{array}$ & Ran & $\begin{array}{l}\text { Density } \\
(\mathrm{g} / \mathrm{mL})\end{array}$ & Num & $\begin{array}{c}\text { STD } \\
(\mathrm{g} / \mathrm{mL})\end{array}$ & $\begin{array}{l}\text { Temp. } \\
\left({ }^{\circ} \mathrm{C}\right)\end{array}$ & Matrix & Wt \% & $\begin{array}{l}\text { Flow } \\
(\mathrm{ft} / \mathrm{s})\end{array}$ & $\begin{array}{l}\text { Air flow } \\
\text { (cfm) }\end{array}$ \\
\hline $\begin{array}{l}1 \\
2 \\
3 \\
4 \\
5\end{array}$ & $\begin{array}{l}1 \\
1 \\
1 \\
1 \\
1\end{array}$ & $\begin{array}{l}0.9970 \\
0.9970 \\
0.9970 \\
0.9970 \\
0.9970\end{array}$ & : & : & $\begin{array}{l}25 \\
25 \\
25 \\
25 \\
25\end{array}$ & $\begin{array}{l}\text { Pre-water } \\
\text { Pre-water } \\
\text { Pre-water } \\
\text { Pre-water } \\
\text { Pre-water }\end{array}$ & $\begin{array}{l}100.0 \\
100.0 \\
100.0 \\
100.0 \\
100.0\end{array}$ & $\begin{array}{l}1.0 \\
7.0 \\
5.0 \\
9.0 \\
3.0\end{array}$ & $\begin{array}{l}0.00 \\
0.00 \\
0.00 \\
0.00 \\
0.00\end{array}$ \\
\hline $\begin{array}{r}6 \\
7 \\
8 \\
9 \\
10 \\
11 \\
12 \\
13\end{array}$ & $\begin{array}{r}1 \\
1 \\
1 \\
1 \\
-1 \\
1 \\
1 \\
1\end{array}$ & $\begin{array}{l}1.2868 \\
1.2868 \\
1.2868 \\
1.2868 \\
1.2868 \\
1.2868 \\
1.2868\end{array}$ & $\begin{array}{l}1 \\
\dot{.} \\
\dot{.} \\
\dot{.} \\
.\end{array}$ & $\begin{array}{l}\dot{5} \\
\dot{5} \\
\dot{5} \\
\dot{ }\end{array}$ & $\begin{array}{l}25 \\
25 \\
25 \\
25 \\
25 \\
25 \\
25 \\
25\end{array}$ & $\begin{array}{l}\text { Sucrose } \\
\text { Sucrose } \\
\text { Sucrose } \\
\text { Sucrose } \\
\text { Sucrose } \\
\text { Sucrose } \\
\text { Sucrose } \\
\text { Sucrose }\end{array}$ & $\begin{array}{l}60.0 \\
60.0 \\
60.0 \\
60.0 \\
60.0 \\
60.0 \\
60.0 \\
60.0\end{array}$ & $\begin{array}{l}3.0 \\
5.0 \\
7.0 \\
1.0 \\
9.0 \\
2.4 \\
3.7 \\
1.4\end{array}$ & $\begin{array}{l}0.00 \\
0.00 \\
0.00 \\
0.00 \\
0.00 \\
0.00 \\
0.00 \\
0.00\end{array}$ \\
\hline $\begin{array}{l}14 \\
15 \\
16 \\
17 \\
18 \\
19 \\
20 \\
21\end{array}$ & $\begin{array}{r}-1 \\
1 \\
1 \\
1 \\
1 \\
1 \\
1 \\
1\end{array}$ & $\begin{array}{l}1.2688 \\
1.2688 \\
1.2688 \\
1.2688 \\
1.2688 \\
1.2688 \\
1.2688\end{array}$ & $\begin{array}{l}i \\
\dot{.} \\
\dot{.} \\
\dot{.}\end{array}$ & $\begin{array}{l}: \\
: \\
: \\
: \\
:\end{array}$ & $\begin{array}{l}50 \\
50 \\
50 \\
50 \\
50 \\
50 \\
50 \\
50\end{array}$ & $\begin{array}{l}\text { Sucrose } \\
\text { Sucrose } \\
\text { Sucrose } \\
\text { Sucrose } \\
\text { Sucrose } \\
\text { Sucrose } \\
\text { Sucrose } \\
\text { Sucrose }\end{array}$ & $\begin{array}{l}60.0 \\
60.0 \\
60.0 \\
60.0 \\
60.0 \\
60.0 \\
60.0 \\
60.0\end{array}$ & $\begin{array}{l}9.0 \\
3.0 \\
1.0 \\
7.0 \\
5.0 \\
1.3 \\
0.8 \\
0.4\end{array}$ & $\begin{array}{l}0.00 \\
0.00 \\
0.00 \\
0.00 \\
0.00 \\
0.00 \\
0.00 \\
0.00\end{array}$ \\
\hline $\begin{array}{l}22 \\
23 \\
24 \\
25 \\
26 \\
27 \\
28 \\
29\end{array}$ & $\begin{array}{r}1 \\
1 \\
-1 \\
1 \\
1 \\
1 \\
1 \\
1\end{array}$ & $\begin{array}{l}1.2316 \\
1.2316 \\
1.2316 \\
1.2316 \\
1.2316 \\
1.2316 \\
1.2316\end{array}$ & $\begin{array}{l}1 \\
: \\
: \\
: \\
: \\
.\end{array}$ & $\begin{array}{l}\dot{ } \\
: \\
\dot{5} \\
\dot{5}\end{array}$ & $\begin{array}{l}25 \\
25 \\
25 \\
25 \\
25 \\
25 \\
25 \\
25\end{array}$ & $\begin{array}{l}\text { Sucrose } \\
\text { Sucrose } \\
\text { Sucrose } \\
\text { Sucrose } \\
\text { Sucrose } \\
\text { Sucrose } \\
\text { Sucrose } \\
\text { Sucrose }\end{array}$ & $\begin{array}{l}50.0 \\
50.0 \\
50.0 \\
50.0 \\
50.0 \\
50.0 \\
50.0 \\
50.0\end{array}$ & $\begin{array}{l}3.0 \\
7.0 \\
9.0 \\
5.0 \\
1.0 \\
1.2 \\
0.4 \\
0.8\end{array}$ & $\begin{array}{l}0.00 \\
0.00 \\
0.00 \\
0.00 \\
0.00 \\
0.00 \\
0.00 \\
0.00\end{array}$ \\
\hline $\begin{array}{l}30 \\
31 \\
32 \\
33 \\
34 \\
35 \\
36 \\
37\end{array}$ & $\begin{array}{l}1 \\
1 \\
1 \\
1 \\
1 \\
1 \\
1 \\
1\end{array}$ & $\begin{array}{l}1.2147 \\
1.2147 \\
1.2147 \\
1.2147 \\
1.2147 \\
1.2147 \\
1.2147 \\
1.2147\end{array}$ & $\begin{array}{l}1 \\
: \\
: \\
: \\
.\end{array}$ & $\begin{array}{l}\dot{.} \\
\dot{.} \\
\dot{.} \\
\dot{.}\end{array}$ & $\begin{array}{l}50 \\
50 \\
50 \\
50 \\
50 \\
50 \\
50 \\
50\end{array}$ & $\begin{array}{l}\text { Sucrose } \\
\text { Sucrose } \\
\text { Sucrose } \\
\text { Sucrose } \\
\text { Sucrose } \\
\text { Sucrose } \\
\text { Sucrose } \\
\text { Sucrose }\end{array}$ & $\begin{array}{l}50.0 \\
50.0 \\
50.0 \\
50.0 \\
50.0 \\
50.0 \\
50.0 \\
50.0\end{array}$ & $\begin{array}{l}7.0 \\
3.0 \\
9.0 \\
5.0 \\
1.0 \\
0.5 \\
0.2 \\
0.3\end{array}$ & $\begin{array}{l}0.00 \\
0.00 \\
0.00 \\
0.00 \\
0.00 \\
0.00 \\
0.00 \\
0.00\end{array}$ \\
\hline $\begin{array}{l}38 \\
39 \\
40 \\
41 \\
42 \\
43 \\
44 \\
45\end{array}$ & $\begin{array}{l}1 \\
1 \\
1 \\
1 \\
1 \\
1 \\
1 \\
1\end{array}$ & $\begin{array}{l}1.1964 \\
1.1964 \\
1.1964 \\
1.1964 \\
1.1964 \\
1.1964 \\
1.1964 \\
1.1964\end{array}$ & $\begin{array}{l}1 \\
\dot{ } \\
\dot{5} \\
\dot{.} \\
\dot{.}\end{array}$ & $\begin{array}{l}\dot{ } \\
: \\
\dot{5} \\
\dot{.}\end{array}$ & $\begin{array}{l}25 \\
25 \\
25 \\
25 \\
25 \\
25 \\
25 \\
25\end{array}$ & $\begin{array}{l}\text { Sucrose } \\
\text { Sucrose } \\
\text { Sucrose } \\
\text { Sucrose } \\
\text { Sucrose } \\
\text { Sucrose } \\
\text { Sucrose } \\
\text { Sucrose }\end{array}$ & $\begin{array}{l}40.0 \\
40.0 \\
40.0 \\
40.0 \\
40.0 \\
40.0 \\
40.0 \\
40.0\end{array}$ & $\begin{array}{l}9.0 \\
7.0 \\
3.0 \\
5.0 \\
1.0 \\
0.5 \\
0.3 \\
0.4\end{array}$ & $\begin{array}{l}0.00 \\
0.00 \\
0.00 \\
0.00 \\
0.00 \\
0.00 \\
0.00 \\
0.00\end{array}$ \\
\hline $\begin{array}{l}46 \\
47 \\
48 \\
49 \\
50 \\
51 \\
52 \\
53\end{array}$ & $\begin{array}{r}1 \\
1 \\
1 \\
1 \\
1 \\
-1 \\
-1 \\
-1\end{array}$ & $\begin{array}{l}1.1816 \\
1.1816 \\
1.1816 \\
1.1816 \\
1.1816 \\
. \\
.\end{array}$ & $\begin{array}{l}1 \\
\dot{5} \\
\dot{.} \\
\dot{.}\end{array}$ & $\begin{array}{l}\dot{5} \\
\dot{5} \\
\dot{5}\end{array}$ & $\begin{array}{l}50 \\
50 \\
50 \\
50 \\
50 \\
50 \\
50 \\
50\end{array}$ & $\begin{array}{l}\text { Sucrose } \\
\text { Sucrose } \\
\text { Sucrose } \\
\text { Sucrose } \\
\text { Sucrose } \\
\text { Sucrose } \\
\text { Sucrose } \\
\text { Sucrose }\end{array}$ & $\begin{array}{l}40.0 \\
40.0 \\
40.0 \\
40.0 \\
40.0 \\
40.0 \\
40.0 \\
40.0\end{array}$ & $\begin{array}{r}3.0 \\
9.0 \\
5.0 \\
7.0 \\
1.0 \\
-1.0 \\
-1.0 \\
-1.0\end{array}$ & $\begin{array}{l}0.00 \\
0.00 \\
0.00 \\
0.00 \\
0.00 \\
0.00 \\
0.00 \\
0.00\end{array}$ \\
\hline
\end{tabular}


Table B-1 (cont.)

\begin{tabular}{|c|c|c|c|c|c|c|c|c|c|}
\hline $\begin{array}{c}\text { Run } \\
\text { number }\end{array}$ & Ran & $\begin{array}{l}\text { Density } \\
(\mathrm{g} / \mathrm{mL})\end{array}$ & Num & $\begin{array}{c}\text { STD } \\
(\mathrm{g} / \mathrm{mL})\end{array}$ & $\begin{array}{l}\text { Temp. } \\
\left({ }^{\circ} \mathrm{C}\right)\end{array}$ & Matrix & wt \% & $\begin{array}{l}\text { Flow } \\
(\mathrm{ft} / \mathrm{s})\end{array}$ & $\begin{array}{l}\text { Air flow } \\
\text { (cfm) }\end{array}$ \\
\hline $\begin{array}{l}54 \\
55 \\
56 \\
57 \\
58 \\
59 \\
60 \\
61 \\
62 \\
63\end{array}$ & $\begin{array}{r}1 \\
1 \\
1 \\
1 \\
1 \\
-1 \\
-1 \\
-1 \\
-1 \\
-1\end{array}$ & $\begin{array}{l}1.1966 \\
1.1975 \\
1.1903 \\
1.2021 \\
1.1977 \\
. \\
. \\
. \\
.\end{array}$ & $\begin{array}{l}\dot{2} \\
2 \\
2 \\
2 \\
\dot{.} \\
\dot{.} \\
.\end{array}$ & $\begin{array}{l}0.0033 \\
0.0059 \\
0.0187 \\
0.0001 \\
: \\
: \\
:\end{array}$ & $\begin{array}{l}25 \\
25 \\
25 \\
25 \\
25 \\
25 \\
25 \\
25 \\
25 \\
25\end{array}$ & $\begin{array}{l}\text { Kaol in/water } \\
\text { Kaol in/water } \\
\text { Kaol in/water } \\
\text { Kaol in/water } \\
\text { Kaol in/water } \\
\text { Kaol in/water } \\
\text { Kaol in/water } \\
\text { Kaol in/water } \\
\text { Kaol in/water } \\
\text { Kaol in/water }\end{array}$ & $\begin{array}{l}30.0 \\
30.0 \\
30.0 \\
30.0 \\
30.0 \\
30.0 \\
30.0 \\
30.0 \\
30.0 \\
30.0\end{array}$ & $\begin{array}{r}7.0 \\
5.0 \\
3.0 \\
1.0 \\
9.0 \\
-1.0 \\
-1.0 \\
-1.0 \\
5.0 \\
5.0\end{array}$ & $\begin{array}{l}0.00 \\
0.00 \\
0.00 \\
0.00 \\
0.00 \\
0.00 \\
0.00 \\
0.00 \\
0.33 \\
0.66\end{array}$ \\
\hline $\begin{array}{l}64 \\
65 \\
66 \\
67 \\
68 \\
69 \\
70 \\
71 \\
72 \\
73\end{array}$ & $\begin{array}{r}1 \\
1 \\
1 \\
1 \\
1 \\
-1 \\
-1 \\
-1 \\
1 \\
1\end{array}$ & $\begin{array}{l}1.1931 \\
1.1918 \\
1.1967 \\
1.1927 \\
1.1936 \\
. \\
. \\
1.1936 \\
1.1936\end{array}$ & $\begin{array}{l}\dot{2} \\
2 \\
2 \\
2 \\
. \\
. \\
\text {. } \\
\text {. }\end{array}$ & $\begin{array}{l}0.0007 \\
0.0061 \\
0.0015 \\
0.0006 \\
: \\
: \\
:\end{array}$ & $\begin{array}{l}50 \\
50 \\
50 \\
50 \\
50 \\
50 \\
50 \\
50 \\
50 \\
50\end{array}$ & $\begin{array}{l}\text { Kaol in/water } \\
\text { Kaol in/water } \\
\text { Kaol in/water } \\
\text { Kaol in/water } \\
\text { Kaol in/water } \\
\text { Kaol in/water } \\
\text { Kaol in/water } \\
\text { Kaol in/water } \\
\text { Kaol in/water } \\
\text { Kaol in/water }\end{array}$ & $\begin{array}{l}30.0 \\
30.0 \\
30.0 \\
30.0 \\
30.0 \\
30.0 \\
30.0 \\
30.0 \\
30.0 \\
30.0\end{array}$ & $\begin{array}{r}7.0 \\
3.0 \\
1.0 \\
5.0 \\
9.0 \\
-1.0 \\
-1.0 \\
-1.0 \\
5.0 \\
5.0\end{array}$ & $\begin{array}{l}0.00 \\
0.00 \\
0.00 \\
0.00 \\
0.00 \\
0.00 \\
0.00 \\
0.00 \\
0.33 \\
0.66\end{array}$ \\
\hline $\begin{array}{l}74 \\
75 \\
76 \\
77 \\
78 \\
79 \\
80 \\
81 \\
82 \\
83\end{array}$ & $\begin{array}{r}1 \\
1 \\
1 \\
1 \\
1 \\
-1 \\
1 \\
1 \\
1 \\
1\end{array}$ & $\begin{array}{l}1.1291 \\
1.1434 \\
1.1205 \\
1.1317 \\
1.1356 \\
1.1401 \\
1.1413 \\
1.1323 \\
1.1323\end{array}$ & $\begin{array}{l}\dot{2} \\
2 \\
2 \\
\dot{.} \\
\dot{2} \\
\dot{-}\end{array}$ & $\begin{array}{c}0.0002 \\
0.0103 \\
0.0062 \\
: \\
0.0049 \\
0\end{array}$ & $\begin{array}{l}25 \\
25 \\
25 \\
25 \\
25 \\
25 \\
25 \\
25 \\
25 \\
25\end{array}$ & $\begin{array}{l}\text { Kaol in/water } \\
\text { Kaol in/water } \\
\text { Kaol in/water } \\
\text { Kaol in/water } \\
\text { Kaol in/water } \\
\text { Kaol in/water } \\
\text { Kaol in/water } \\
\text { Kaol in/water } \\
\text { Kaol in/water } \\
\text { Kaol in/water }\end{array}$ & $\begin{array}{l}20.0 \\
20.0 \\
20.0 \\
20.0 \\
20.0 \\
20.0 \\
20.0 \\
20.0 \\
20.0 \\
20.0\end{array}$ & $\begin{array}{r}7.0 \\
5.0 \\
9.0 \\
1.0 \\
3.0 \\
-1.0 \\
0.2 \\
0.4 \\
5.0 \\
5.0\end{array}$ & $\begin{array}{l}0.00 \\
0.00 \\
0.00 \\
0.00 \\
0.00 \\
0.00 \\
0.00 \\
0.00 \\
0.33 \\
0.66\end{array}$ \\
\hline $\begin{array}{l}84 \\
85 \\
86 \\
87 \\
88 \\
89 \\
90 \\
91 \\
92 \\
93\end{array}$ & $\begin{array}{l}1 \\
1 \\
1 \\
1 \\
1 \\
1 \\
1 \\
1 \\
1 \\
1\end{array}$ & $\begin{array}{l}1.1333 \\
1.1278 \\
1.1278 \\
1.1326 \\
1.1241 \\
1.1339 \\
1.1341 \\
1.1344 \\
1.1292 \\
1.1292\end{array}$ & $\begin{array}{l}\dot{2} \\
2 \\
2 \\
2 \\
. \\
i \\
\text {. } \\
\text {. }\end{array}$ & $\begin{array}{c}0.0004 \\
0.0081 \\
0.0001 \\
0.0084 \\
\vdots \\
0.0001 \\
\dot{.}\end{array}$ & $\begin{array}{l}50 \\
50 \\
50 \\
50 \\
50 \\
50 \\
50 \\
50 \\
50 \\
50\end{array}$ & $\begin{array}{l}\text { Kaol in/water } \\
\text { Kaol in/water } \\
\text { Kaol in/water } \\
\text { Kaol in/water } \\
\text { Kaol in/water } \\
\text { Kaol in/water } \\
\text { Kaol in/water } \\
\text { Kaol in/water } \\
\text { Kaol in/water } \\
\text { Kaol in/water }\end{array}$ & $\begin{array}{l}20.0 \\
20.0 \\
20.0 \\
20.0 \\
20.0 \\
20.0 \\
20.0 \\
20.0 \\
20.0 \\
20.0\end{array}$ & $\begin{array}{l}1.0 \\
5.0 \\
9.0 \\
3.0 \\
7.0 \\
0.4 \\
0.2 \\
0.3 \\
5.0 \\
5.0\end{array}$ & $\begin{array}{l}0.00 \\
0.00 \\
0.00 \\
0.00 \\
0.00 \\
0.00 \\
0.00 \\
0.00 \\
0.33 \\
0.66\end{array}$ \\
\hline $\begin{array}{r}94 \\
95 \\
96 \\
97 \\
98 \\
99 \\
100 \\
101 \\
102 \\
103\end{array}$ & $\begin{array}{r}1 \\
1 \\
1 \\
1 \\
1 \\
-1 \\
1 \\
-1 \\
1 \\
-1\end{array}$ & $\begin{array}{l}1.0646 \\
1.0610 \\
1.0583 \\
1.0641 \\
1.0647 \\
1.0663 \\
1.0625 \\
.\end{array}$ & $\begin{array}{l}2 \\
\dot{2} \\
\dot{2} \\
\dot{5} \\
\dot{ } \\
\dot{.}\end{array}$ & $\begin{array}{l}0.0002 \\
0.0023 \\
0.0034 \\
\therefore \\
\therefore\end{array}$ & $\begin{array}{l}25 \\
25 \\
25 \\
25 \\
25 \\
25 \\
25 \\
25 \\
25 \\
25\end{array}$ & $\begin{array}{l}\text { Kaol in/water } \\
\text { Kaol in/water } \\
\text { Kaol in/water } \\
\text { Kaol in/water } \\
\text { Kaol in/water } \\
\text { Kaol in/water } \\
\text { Kaol in/water } \\
\text { Kaol in/water } \\
\text { Kaol in/water } \\
\text { Kaol in/water }\end{array}$ & $\begin{array}{l}10.0 \\
10.0 \\
10.0 \\
10.0 \\
10.0 \\
10.0 \\
10.0 \\
10.0 \\
10.0 \\
10.0\end{array}$ & $\begin{array}{r}1.0 \\
7.0 \\
9.0 \\
3.0 \\
5.0 \\
-1.0 \\
0.2 \\
-1.0 \\
5.0 \\
5.0\end{array}$ & $\begin{array}{l}0.00 \\
0.00 \\
0.00 \\
0.00 \\
0.00 \\
0.00 \\
0.00 \\
0.00 \\
0.33 \\
0.66\end{array}$ \\
\hline $\begin{array}{l}104 \\
105 \\
106 \\
107 \\
108 \\
109\end{array}$ & $\begin{array}{r}1 \\
1 \\
1 \\
1 \\
1 \\
-1\end{array}$ & $\begin{array}{l}1.0556 \\
1.0548 \\
1.0547 \\
1.0562 \\
1.0548 \\
.\end{array}$ & $\begin{array}{l}\dot{2} \\
2 \\
2 \\
.\end{array}$ & $\begin{array}{l}0.0000 \\
0.0013 \\
0.0036 \\
.\end{array}$ & $\begin{array}{l}50 \\
50 \\
50 \\
50 \\
50 \\
50\end{array}$ & $\begin{array}{l}\text { Kaol in/water } \\
\text { Kaol in/water } \\
\text { Kaol in/water } \\
\text { Kaol in/water } \\
\text { Kaol in/water } \\
\text { Kaol in/water }\end{array}$ & $\begin{array}{l}10.0 \\
10.0 \\
10.0 \\
10.0 \\
10.0 \\
10.0\end{array}$ & $\begin{array}{r}7.0 \\
5.0 \\
1.0 \\
9.0 \\
3.0 \\
-1.0\end{array}$ & $\begin{array}{l}0.00 \\
0.00 \\
0.00 \\
0.00 \\
0.00 \\
0.00\end{array}$ \\
\hline
\end{tabular}


Table B-1 (cont.)

\begin{tabular}{|c|c|c|c|c|c|c|c|c|c|}
\hline $\begin{array}{l}\text { Run } \\
\text { number }\end{array}$ & Ran & $\begin{array}{l}\text { Density } \\
(\mathrm{g} / \mathrm{mL})\end{array}$ & Num & $\begin{array}{c}\text { STD } \\
(\mathrm{g} / \mathrm{mL})\end{array}$ & $\begin{array}{l}\text { Temp. } \\
\left({ }^{\circ} \mathrm{C}\right)\end{array}$ & Matrix & Wt $\%$ & $\begin{array}{c}F(\mathrm{ow} \\
(\mathrm{ft} / \mathrm{s})\end{array}$ & $\begin{array}{c}\text { Air flow } \\
\text { (cfm) }\end{array}$ \\
\hline $\begin{array}{l}110 \\
111 \\
112 \\
113\end{array}$ & $\begin{array}{r}-1 \\
-1 \\
1 \\
1\end{array}$ & $\begin{array}{l}\dot{.} \\
1.0552 \\
1.0552\end{array}$ & $\begin{array}{l}\dot{.} \\
\dot{.}\end{array}$ & $\dot{.}$ & $\begin{array}{l}50 \\
50 \\
50 \\
50\end{array}$ & $\begin{array}{l}\text { Kaol in/water } \\
\text { Kaol in/water } \\
\text { Kaol in/water } \\
\text { Kaol in/water }\end{array}$ & $\begin{array}{l}10.0 \\
10.0 \\
10.0 \\
10.0\end{array}$ & $\begin{array}{r}-1.0 \\
-1.0 \\
5.0 \\
5.0\end{array}$ & $\begin{array}{l}0.00 \\
0.00 \\
0.33 \\
0.66\end{array}$ \\
\hline $\begin{array}{l}114 \\
115 \\
116 \\
117 \\
118 \\
119 \\
120 \\
121 \\
122 \\
123\end{array}$ & $\begin{array}{r}1 \\
-1 \\
1 \\
1 \\
-1 \\
1 \\
-1 \\
1 \\
-1 \\
-1\end{array}$ & $\begin{array}{l}1.4302 \\
1.4285 \\
1.4298 \\
1.4079 \\
1.4263 \\
\dot{0}\end{array}$ & $\begin{array}{l}1 \\
\vdots \\
i \\
\vdots \\
i \\
\vdots\end{array}$ & $\begin{array}{l}: \\
: \\
\dot{ } \\
\dot{ } \\
:\end{array}$ & $\begin{array}{l}25 \\
25 \\
25 \\
25 \\
25 \\
25 \\
25 \\
25 \\
25 \\
25\end{array}$ & 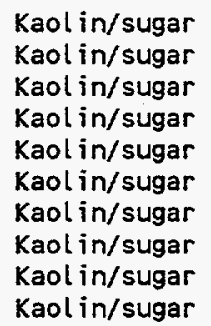 & $\begin{array}{l}22.0 \\
22.0 \\
22.0 \\
22.0 \\
22.0 \\
22.0 \\
22.0 \\
22.0 \\
22.0 \\
22.0\end{array}$ & $\begin{array}{r}1.0 \\
7.0 \\
5.0 \\
3.0 \\
9.0 \\
1.8 \\
-1.0 \\
0.5 \\
5.0 \\
5.0\end{array}$ & $\begin{array}{l}0.00 \\
0.00 \\
0.00 \\
0.00 \\
0.00 \\
0.00 \\
0.00 \\
0.00 \\
0.33 \\
0.66\end{array}$ \\
\hline $\begin{array}{l}124 \\
125 \\
126 \\
127 \\
128 \\
129 \\
130 \\
131 \\
132 \\
133\end{array}$ & $\begin{array}{r}-1 \\
1 \\
1 \\
1 \\
-1 \\
1 \\
1 \\
-1 \\
1 \\
-1\end{array}$ & $\begin{array}{l}1.4147 \\
1.4145 \\
1.4139 \\
1.4171 \\
1.4162 \\
1.4146 \\
.\end{array}$ & $\begin{array}{l}i \\
1 \\
1 \\
i \\
1 \\
. \\
.\end{array}$ & $\begin{array}{l}: \\
: \\
: \\
: \\
: \\
.\end{array}$ & $\begin{array}{l}50 \\
50 \\
50 \\
50 \\
50 \\
50 \\
50 \\
50 \\
50 \\
50\end{array}$ & $\begin{array}{l}\text { Kaol in/sugar } \\
\text { Kaol in/sugar } \\
\text { Kaol in/sugar } \\
\text { Kaol in/sugar } \\
\text { Kaol in/sugar } \\
\text { Kaol in/sugar } \\
\text { Kaol in/sugar } \\
\text { Kaol in/sugar } \\
\text { Kaol in/sugar } \\
\text { Kaol in/sugar }\end{array}$ & $\begin{array}{l}22.0 \\
22.0 \\
22.0 \\
22.0 \\
22.0 \\
22.0 \\
22.0 \\
22.0 \\
22.0 \\
22.0\end{array}$ & $\begin{array}{r}7.0 \\
3.0 \\
5.0 \\
1.0 \\
9.0 \\
1.9 \\
0.5 \\
-1.0 \\
5.0 \\
5.0\end{array}$ & $\begin{array}{l}0.00 \\
0.00 \\
0.00 \\
0.00 \\
0.00 \\
0.00 \\
0.00 \\
0.00 \\
0.33 \\
0.66\end{array}$ \\
\hline $\begin{array}{l}134 \\
135 \\
136 \\
137 \\
138 \\
139 \\
140 \\
141 \\
142 \\
143\end{array}$ & $\begin{array}{l}1 \\
1 \\
1 \\
1 \\
1 \\
1 \\
1 \\
1 \\
1 \\
1\end{array}$ & $\begin{array}{l}1.3426 \\
1.3398 \\
1.3407 \\
1.3421 \\
1.3420 \\
1.3423 \\
1.3422 \\
1.3427 \\
1.3414 \\
1.3414\end{array}$ & $\begin{array}{l}\dot{2} \\
\dot{3} \\
2 \\
2 \\
2 \\
\dot{.} \\
.\end{array}$ & $\begin{array}{l}0.0034 \\
0.0006 \\
0.0004 \\
0.0001 \\
0.0004 \\
. \\
.\end{array}$ & $\begin{array}{l}25 \\
25 \\
25 \\
25 \\
25 \\
25 \\
25 \\
25 \\
25 \\
25\end{array}$ & $\begin{array}{l}\text { Kaol in/sugar } \\
\text { Kaol in/sugar } \\
\text { Kaol in/sugar } \\
\text { Kaol in/sugar } \\
\text { Kaol in/sugar } \\
\text { Kaol in/sugar } \\
\text { Kaol in/sugar } \\
\text { Kaol in/sugar } \\
\text { Kaol in/sugar } \\
\text { Kaol in/sugar }\end{array}$ & $\begin{array}{l}15.0 \\
15.0 \\
15.0 \\
15.0 \\
15.0 \\
15.0 \\
15.0 \\
15.0 \\
15.0 \\
15.0\end{array}$ & $\begin{array}{l}1.0 \\
9.0 \\
7.0 \\
3.0 \\
5.0 \\
1.2 \\
1.9 \\
0.5 \\
5.0 \\
5.0\end{array}$ & $\begin{array}{l}0.00 \\
0.00 \\
0.00 \\
0.00 \\
0.00 \\
0.00 \\
0.00 \\
0.00 \\
0.33 \\
0.66\end{array}$ \\
\hline $\begin{array}{l}144 \\
145 \\
146 \\
147 \\
148 \\
149 \\
150 \\
151 \\
152 \\
153\end{array}$ & $\begin{array}{l}1 \\
1 \\
1 \\
1 \\
1 \\
1 \\
1 \\
1 \\
1 \\
1\end{array}$ & $\begin{array}{l}1.3201 \\
1.3232 \\
1.3229 \\
1.3198 \\
1.3243 \\
1.3238 \\
1.3244 \\
1.3248 \\
1.3220 \\
1.3220\end{array}$ & $\begin{array}{l}2 \\
2 \\
2 \\
. \\
\dot{2} \\
\dot{2} \\
.\end{array}$ & $\begin{array}{l}0.0011 \\
0.0005 \\
0.0008 \\
. \\
0.0008 \\
.0018 \\
.\end{array}$ & $\begin{array}{l}50 \\
50 \\
50 \\
50 \\
50 \\
50 \\
50 \\
50 \\
50 \\
50\end{array}$ & $\begin{array}{l}\text { Kaol in/sugar } \\
\text { Kaol in/sugar } \\
\text { Kaol in/sugar } \\
\text { Kaol in/sugar } \\
\text { Kaol in/sugar } \\
\text { Kaol in/sugar } \\
\text { Kaol in/sugar } \\
\text { Kaol in/sugar } \\
\text { Kaol in/sugar } \\
\text { Kaol in/sugar }\end{array}$ & $\begin{array}{l}15.0 \\
15.0 \\
15.0 \\
15.0 \\
15.0 \\
15.0 \\
15.0 \\
15.0 \\
15.0 \\
15.0\end{array}$ & $\begin{array}{l}7.0 \\
5.0 \\
3.0 \\
9.0 \\
1.0 \\
0.4 \\
0.8 \\
1.7 \\
5.0 \\
5.0\end{array}$ & $\begin{array}{l}0.00 \\
0.00 \\
0.00 \\
0.00 \\
0.00 \\
0.00 \\
0.00 \\
0.00 \\
0.33 \\
0.66\end{array}$ \\
\hline $\begin{array}{l}154 \\
155 \\
156 \\
157 \\
158 \\
159 \\
160 \\
161 \\
162 \\
163\end{array}$ & $\begin{array}{l}1 \\
1 \\
1 \\
1 \\
1 \\
1 \\
1 \\
1 \\
1 \\
1\end{array}$ & $\begin{array}{l}1.2923 \\
1.2920 \\
1.2921 \\
1.2912 \\
1.2913 \\
1.2924 \\
1.2924 \\
1.2923 \\
1.2918 \\
1.2918\end{array}$ & $\begin{array}{l}\dot{2} \\
2 \\
\dot{2} \\
2 \\
\dot{2} \\
\dot{.}\end{array}$ & $\begin{array}{l}0.0001 \\
0.0003 \\
0.0013 \\
0.0004 \\
0.0015 \\
.\end{array}$ & $\begin{array}{l}25 \\
25 \\
25 \\
25 \\
25 \\
25 \\
25 \\
25 \\
25 \\
25\end{array}$ & $\begin{array}{l}\text { Kaol in/sugar } \\
\text { Kaol in/sugar } \\
\text { Kaol in/sugar } \\
\text { Kaol in/sugar } \\
\text { Kaol in/sugar } \\
\text { Kaol in/sugar } \\
\text { Kaol in/sugar } \\
\text { Kaol in/sugar } \\
\text { Kaol in/sugar } \\
\text { Kaol in/sugar }\end{array}$ & $\begin{array}{l}8.5 \\
8.5 \\
8.5 \\
8.5 \\
8.5 \\
8.5 \\
8.5 \\
8.5 \\
8.5 \\
8.5\end{array}$ & $\begin{array}{l}1.0 \\
5.0 \\
3.0 \\
9.0 \\
7.0 \\
1.3 \\
0.8 \\
0.4 \\
5.0 \\
5.0\end{array}$ & $\begin{array}{l}0.00 \\
0.00 \\
0.00 \\
0.00 \\
0.00 \\
0.00 \\
0.00 \\
0.00 \\
0.33 \\
0.66\end{array}$ \\
\hline
\end{tabular}


Table B-1 (cont.)

\begin{tabular}{|c|c|c|c|c|c|c|c|c|c|}
\hline $\begin{array}{l}\text { Run } \\
\text { number }\end{array}$ & Ran & $\begin{array}{l}\text { Density } \\
(\mathrm{g} / \mathrm{mL})\end{array}$ & Num & $\begin{array}{c}\text { STD } \\
(\mathrm{g} / \mathrm{mL})\end{array}$ & $\begin{array}{l}\text { Temp. } \\
\left({ }^{\circ} \mathrm{C}\right)\end{array}$ & Matrix & Wt $\%$ & $\begin{array}{l}\text { Flow } \\
(\mathrm{ft} / \mathrm{s})\end{array}$ & $\begin{array}{l}\text { Air blow } \\
\text { (cfm) }\end{array}$ \\
\hline $\begin{array}{l}164 \\
165 \\
166 \\
167 \\
168 \\
169 \\
170 \\
171 \\
172 \\
173\end{array}$ & $\begin{array}{l}1 \\
1 \\
1 \\
1 \\
1 \\
1 \\
1 \\
1 \\
1 \\
1\end{array}$ & $\begin{array}{l}1.2782 \\
1.2801 \\
1.2789 \\
1.2792 \\
1.2810 \\
1.2808 \\
1.2816 \\
1.2807 \\
1.2797 \\
1.2797\end{array}$ & $\begin{array}{l}2 \\
\dot{3} \\
\dot{2} \\
2 \\
2 \\
\dot{.} \\
.\end{array}$ & $\begin{array}{l}0.0011 \\
0.0014 \\
0.0016 \\
0.0004 \\
0.0010 \\
. \\
.\end{array}$ & $\begin{array}{l}50 \\
50 \\
50 \\
50 \\
50 \\
50 \\
50 \\
50 \\
50 \\
50\end{array}$ & $\begin{array}{l}\text { Kaol in/sugar } \\
\text { Kaol in/sugar } \\
\text { Kaol in/sugar } \\
\text { Kaol in/sugar } \\
\text { Kaol in/sugar } \\
\text { Kaol in/sugar } \\
\text { Kaol in/sugar } \\
\text { Kaol in/sugar } \\
\text { Kaol in/sugar } \\
\text { Kaol in/sugar }\end{array}$ & $\begin{array}{l}8.5 \\
8.5 \\
8.5 \\
8.5 \\
8.5 \\
8.5 \\
8.5 \\
8.5 \\
8.5 \\
8.5\end{array}$ & $\begin{array}{l}9.0 \\
3.0 \\
1.0 \\
7.0 \\
5.0 \\
0.3 \\
0.6 \\
0.5 \\
5.0 \\
5.0\end{array}$ & $\begin{array}{l}0.00 \\
0.00 \\
0.00 \\
0.00 \\
0.00 \\
0.00 \\
0.00 \\
0.00 \\
0.33 \\
0.66\end{array}$ \\
\hline $\begin{array}{l}174 \\
175 \\
176 \\
177 \\
178 \\
179 \\
180 \\
181 \\
182 \\
183\end{array}$ & $\begin{array}{r}1 \\
-1 \\
1 \\
1 \\
-1 \\
1 \\
1 \\
1 \\
1 \\
1\end{array}$ & $\begin{array}{l}1.4385 \\
1.4410 \\
1.4536 \\
1.4412 \\
1.4330 \\
1.4385 \\
1.4456 \\
1.4456\end{array}$ & $\begin{array}{l}: \\
i \\
1 \\
i \\
1 \\
1 \\
.\end{array}$ & $\begin{array}{l}\dot{.} \\
\dot{.} \\
\dot{5} \\
\dot{5} \\
\dot{.}\end{array}$ & $\begin{array}{l}25 \\
25 \\
25 \\
25 \\
25 \\
25 \\
25 \\
25 \\
25 \\
25\end{array}$ & $\begin{array}{l}\mathrm{KaOl} \mathrm{in} / \mathrm{sand} \\
\mathrm{KaOl} \mathrm{in} / \mathrm{sand} \\
\mathrm{KaOl} \mathrm{in} / \mathrm{sand} \\
\mathrm{KaOl} \mathrm{in} / \mathrm{sand} \\
\mathrm{KaOl} \mathrm{in} / \mathrm{sand} \\
\mathrm{Kaol} \mathrm{in} / \mathrm{sand} \\
\mathrm{KaOl} \mathrm{in} / \mathrm{sand} \\
\mathrm{KaOl} \mathrm{in} / \mathrm{sand} \\
\mathrm{KaOl} \mathrm{in} / \mathrm{sand} \\
\mathrm{KaOl} \mathrm{in} / \mathrm{sand}\end{array}$ & $\begin{array}{l}30.0 \\
30.0 \\
30.0 \\
30.0 \\
30.0 \\
30.0 \\
30.0 \\
30.0 \\
30.0 \\
30.0\end{array}$ & $\begin{array}{l}1.0 \\
7.0 \\
5.0 \\
3.0 \\
9.0 \\
2.5 \\
1.7 \\
1.1 \\
5.0 \\
5.0\end{array}$ & $\begin{array}{l}0.00 \\
0.00 \\
0.00 \\
0.00 \\
0.00 \\
0.00 \\
0.00 \\
0.00 \\
0.33 \\
0.66\end{array}$ \\
\hline $\begin{array}{l}184 \\
185 \\
186 \\
187 \\
188 \\
189 \\
190 \\
191 \\
192 \\
193\end{array}$ & $\begin{array}{r}-1 \\
1 \\
1 \\
1 \\
1 \\
1 \\
1 \\
1 \\
1 \\
-1\end{array}$ & $\begin{array}{l}1.4192 \\
1.4203 \\
1.4270 \\
1.4132 \\
1.4016 \\
1.4268 \\
1.4123 \\
1.4224 \\
.\end{array}$ & $\begin{array}{l}i \\
1 \\
1 \\
i \\
1 \\
. \\
.\end{array}$ & $\begin{array}{l}. \\
. \\
. \\
. \\
. \\
.\end{array}$ & $\begin{array}{l}50 \\
50 \\
50 \\
50 \\
50 \\
50 \\
50 \\
50 \\
50 \\
50\end{array}$ & 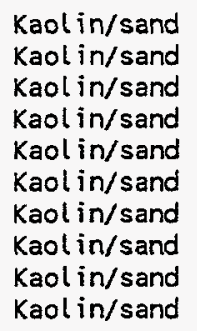 & $\begin{array}{l}30.0 \\
30.0 \\
30.0 \\
30.0 \\
30.0 \\
30.0 \\
30.0 \\
30.0 \\
30.0 \\
30.0\end{array}$ & $\begin{array}{l}9.0 \\
5.0 \\
3.0 \\
7.0 \\
1.0 \\
1.0 \\
1.6 \\
0.6 \\
5.0 \\
5.0\end{array}$ & $\begin{array}{l}0.00 \\
0.00 \\
0.00 \\
0.00 \\
0.00 \\
0.00 \\
0.00 \\
0.00 \\
0.33 \\
0.66\end{array}$ \\
\hline $\begin{array}{l}194 \\
195 \\
196 \\
197 \\
198 \\
199 \\
200 \\
201 \\
202 \\
203\end{array}$ & $\begin{array}{r}1 \\
-1 \\
1 \\
1 \\
1 \\
1 \\
1 \\
1 \\
1 \\
1\end{array}$ & $\begin{array}{l}1.3880 \\
1.3934 \\
1.4189 \\
1.3830 \\
1.3886 \\
1.3873 \\
1.3904 \\
1.3984 \\
1.3984\end{array}$ & $\begin{array}{l}\dot{ } \\
2 \\
2 \\
2 \\
. \\
. \\
.\end{array}$ & $\begin{array}{l}: \\
0.0141 \\
0.0148 \\
0.0035 \\
: \\
: \\
:\end{array}$ & $\begin{array}{l}25 \\
25 \\
25 \\
25 \\
25 \\
25 \\
25 \\
25 \\
25 \\
25\end{array}$ & 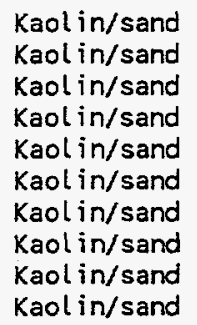 & $\begin{array}{l}20.0 \\
20.0 \\
20.0 \\
20.0 \\
20.0 \\
20.0 \\
20.0 \\
20.0 \\
20.0 \\
20.0\end{array}$ & $\begin{array}{l}1.0 \\
9.0 \\
7.0 \\
5.0 \\
3.0 \\
1.2 \\
0.7 \\
1.9 \\
5.0 \\
5.0\end{array}$ & $\begin{array}{l}0.00 \\
0.00 \\
0.00 \\
0.00 \\
0.00 \\
0.00 \\
0.00 \\
0.00 \\
0.33 \\
0.66\end{array}$ \\
\hline $\begin{array}{l}204 \\
205 \\
206 \\
207 \\
208 \\
209 \\
210 \\
211 \\
212 \\
213\end{array}$ & $\begin{array}{r}1 \\
1 \\
1 \\
-1 \\
1 \\
1 \\
1 \\
1 \\
1 \\
1\end{array}$ & $\begin{array}{l}1.3680 \\
1.3788 \\
1.3478 \\
1.3717 \\
1.3525 \\
1.3568 \\
1.3512 \\
1.3717 \\
1.3717\end{array}$ & $\begin{array}{l}2 \\
2 \\
2 \\
: \\
: \\
3 \\
. \\
.\end{array}$ & $\begin{array}{l}0.0008 \\
0.0032 \\
0.0004 \\
: \\
: \\
0.0052 \\
:\end{array}$ & $\begin{array}{l}50 \\
50 \\
50 \\
50 \\
50 \\
50 \\
50 \\
50 \\
50 \\
50\end{array}$ & 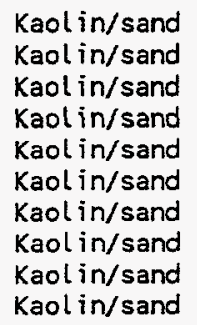 & $\begin{array}{l}20.0 \\
20.0 \\
20.0 \\
20.0 \\
20.0 \\
20.0 \\
20.0 \\
20.0 \\
20.0 \\
20.0\end{array}$ & $\begin{array}{l}3.0 \\
7.0 \\
1.0 \\
9.0 \\
5.0 \\
0.6 \\
0.9 \\
0.3 \\
5.0 \\
5.0\end{array}$ & $\begin{array}{l}0.00 \\
0.00 \\
0.00 \\
0.00 \\
0.00 \\
0.00 \\
0.00 \\
0.00 \\
0.33 \\
0.66\end{array}$ \\
\hline $\begin{array}{l}214 \\
215 \\
216 \\
217 \\
218 \\
219 \\
220\end{array}$ & $\begin{array}{r}1 \\
1 \\
-1 \\
1 \\
1 \\
1 \\
1\end{array}$ & $\begin{array}{l}1.2900 \\
1.3145 \\
1.2953 \\
1.3050 \\
1.2862 \\
1.2879\end{array}$ & $\begin{array}{l}2 \\
2 \\
\dot{2} \\
2 \\
.\end{array}$ & $\begin{array}{l}0.0006 \\
0.0005 \\
0.0007 \\
0.0016 \\
.\end{array}$ & $\begin{array}{l}25 \\
25 \\
25 \\
25 \\
25 \\
25 \\
25\end{array}$ & $\begin{array}{l}\text { Kaol in/sand } \\
\mathrm{KaOl} \text { in/sand } \\
\mathrm{Kaol} \text { in/sand } \\
\mathrm{KaOl} \text { in/sand } \\
\mathrm{KaOl} \mathrm{in/sand} \\
\mathrm{KaOl} \text { in/sand } \\
\mathrm{KaOl} \text { in/sand }\end{array}$ & $\begin{array}{l}10.0 \\
10.0 \\
10.0 \\
10.0 \\
10.0 \\
10.0 \\
10.0\end{array}$ & $\begin{array}{l}1.0 \\
7.0 \\
9.0 \\
3.0 \\
5.0 \\
0.4 \\
0.8\end{array}$ & $\begin{array}{l}0.00 \\
0.00 \\
0.00 \\
0.00 \\
0.00 \\
0.00 \\
0.00\end{array}$ \\
\hline
\end{tabular}


Table B-1 (cont.)

\begin{tabular}{|c|c|c|c|c|c|c|c|c|c|}
\hline $\begin{array}{l}\text { Run } \\
\text { number }\end{array}$ & Ran & $\begin{array}{l}\text { Density } \\
(\mathrm{g} / \mathrm{mL})\end{array}$ & Num & $\begin{array}{c}\text { STD } \\
(\mathrm{g} / \mathrm{mL})\end{array}$ & $\begin{array}{l}\text { Temp. } \\
\left({ }^{\circ} \mathrm{C}\right)\end{array}$ & Matrix & Wt \% & $\begin{array}{c}F(\mathrm{ow} \\
(\mathrm{ft} / \mathrm{s})\end{array}$ & $\begin{array}{l}\text { Air Flow } \\
(\mathrm{cfm})\end{array}$ \\
\hline $\begin{array}{l}221 \\
222 \\
223\end{array}$ & $\begin{array}{r}1 \\
1 \\
-1\end{array}$ & $\begin{array}{c}1.2896 \\
1.3053 \\
.\end{array}$ & $\dot{.}$ & $\dot{.}$ & $\begin{array}{l}25 \\
25 \\
25\end{array}$ & $\begin{array}{l}\mathrm{Kaol} \mathrm{in} / \mathrm{sand} \\
\mathrm{Kaol} \mathrm{in} / \mathrm{sand} \\
\mathrm{KaOL} \mathrm{in} / \mathrm{sand}\end{array}$ & $\begin{array}{l}10.0 \\
10.0 \\
10.0\end{array}$ & $\begin{array}{l}1.2 \\
5.0 \\
5.0\end{array}$ & $\begin{array}{l}0.00 \\
0.33 \\
0.66\end{array}$ \\
\hline $\begin{array}{l}224 \\
225 \\
226 \\
227 \\
228 \\
229 \\
230 \\
231 \\
232 \\
233\end{array}$ & $\begin{array}{r}1 \\
1 \\
1 \\
-1 \\
1 \\
1 \\
-1 \\
1 \\
1 \\
-1\end{array}$ & $\begin{array}{l}1.2927 \\
1.3043 \\
1.2757 \\
1.2866 \\
1.2787 \\
1.2777 \\
1.2933 \\
.\end{array}$ & $\begin{array}{l}2 \\
2 \\
2 \\
i \\
2 \\
: \\
: \\
.\end{array}$ & $\begin{array}{l}0.0025 \\
0.0072 \\
0.0010 \\
: \\
0.0018 \\
: \\
: \\
.\end{array}$ & $\begin{array}{l}50 \\
50 \\
50 \\
50 \\
50 \\
50 \\
50 \\
50 \\
50 \\
50\end{array}$ & $\begin{array}{l}\mathrm{KaOl} \mathrm{in} / \mathrm{sand} \\
\mathrm{Kaol} \mathrm{in} / \mathrm{sand} \\
\mathrm{Kaol} \mathrm{in} / \mathrm{sand} \\
\mathrm{Kaol} \mathrm{in} / \mathrm{sand} \\
\mathrm{Kaol} \mathrm{in} / \mathrm{sand} \\
\mathrm{KaOl} \mathrm{in} / \mathrm{sand} \\
\mathrm{KaOl} \mathrm{in} / \mathrm{sand} \\
\mathrm{KaOl} \mathrm{in} / \mathrm{sand} \\
\mathrm{KaOl} \mathrm{in} / \mathrm{sand} \\
\mathrm{KaOl} \mathrm{in} / \mathrm{sand}\end{array}$ & $\begin{array}{l}10.0 \\
10.0 \\
10.0 \\
10.0 \\
10.0 \\
10.0 \\
10.0 \\
10.0 \\
10.0 \\
10.0\end{array}$ & $\begin{array}{r}7.0 \\
5.0 \\
1.0 \\
9.0 \\
3.0 \\
0.6 \\
-1.0 \\
0.4 \\
5.0 \\
5.0\end{array}$ & $\begin{array}{l}0.00 \\
0.00 \\
0.00 \\
0.00 \\
0.00 \\
0.00 \\
0.00 \\
0.00 \\
0.33 \\
0.66\end{array}$ \\
\hline $\begin{array}{l}234 \\
235 \\
236 \\
237 \\
238\end{array}$ & $\begin{array}{l}-1 \\
-1 \\
-1 \\
-1 \\
-1\end{array}$ & : & $\dot{.}$ & $\begin{array}{l}\dot{.} \\
\dot{.} \\
\dot{\cdot}\end{array}$ & $\begin{array}{l}25 \\
25 \\
25 \\
25 \\
25\end{array}$ & $\begin{array}{l}\mathrm{K} / \text { sand/gravel } \\
\mathrm{K} / \mathrm{sand} / \mathrm{gravel} \\
\mathrm{K} / \mathrm{sand} / \mathrm{gravel} \\
\mathrm{K} / \text { sand/gravel } \\
\mathrm{K} / \text { sand/gravel }\end{array}$ & $\begin{array}{l}30.0 \\
30.0 \\
30.0 \\
30.0 \\
30.0\end{array}$ & $\begin{array}{l}7.0 \\
9.0 \\
5.0 \\
5.0 \\
5.0\end{array}$ & $\begin{array}{l}0.00 \\
0.00 \\
0.00 \\
0.33 \\
0.66\end{array}$ \\
\hline $\begin{array}{l}239 \\
240 \\
241 \\
242 \\
243\end{array}$ & $\begin{array}{l}-1 \\
-1 \\
-1 \\
-1 \\
-1\end{array}$ & $\dot{:}$ & $\dot{.}$ & $\begin{array}{l}\dot{.} \\
\dot{\cdot} \\
\dot{\cdot}\end{array}$ & $\begin{array}{l}50 \\
50 \\
50 \\
50 \\
50\end{array}$ & $\begin{array}{l}\mathrm{K} / \text { sand/gravel } \\
\mathrm{K} / \mathrm{sand} / \mathrm{gravel} \\
\mathrm{K} / \text { sand/gravel } \\
\mathrm{K} / \mathrm{sand} / \mathrm{gravel} \\
\mathrm{K} / \mathrm{s} \text { and/gravel }\end{array}$ & $\begin{array}{l}30.0 \\
30.0 \\
30.0 \\
30.0 \\
30.0\end{array}$ & $\begin{array}{l}5.0 \\
7.0 \\
9.0 \\
5.0 \\
5.0\end{array}$ & $\begin{array}{l}0.00 \\
0.00 \\
0.00 \\
0.33 \\
0.66\end{array}$ \\
\hline $\begin{array}{l}244 \\
245 \\
246 \\
247 \\
248\end{array}$ & $\begin{array}{r}-1 \\
1 \\
1 \\
1 \\
1\end{array}$ & $\begin{array}{l}1.3952 \\
1.3941 \\
1.3952 \\
1.3952\end{array}$ & $\begin{array}{l}\dot{3} \\
3 \\
\dot{.}\end{array}$ & $\begin{array}{l}0.0196 \\
0.0170 \\
.\end{array}$ & $\begin{array}{l}25 \\
25 \\
25 \\
25 \\
25\end{array}$ & $\begin{array}{l}\mathrm{K} / \mathrm{sand} / \mathrm{gravel} \\
\mathrm{K} / \mathrm{sand} / \mathrm{gravel} \\
\mathrm{K} / \mathrm{sand} / \mathrm{gravel} \\
\mathrm{K} / \mathrm{s} \text { and/gravel } \\
\mathrm{K} / \mathrm{sand} / \mathrm{gravel}\end{array}$ & $\begin{array}{l}20.0 \\
20.0 \\
20.0 \\
20.0 \\
20.0\end{array}$ & $\begin{array}{l}9.0 \\
5.0 \\
7.0 \\
5.0 \\
5.0\end{array}$ & $\begin{array}{l}0.00 \\
0.00 \\
0.00 \\
0.33 \\
0.66\end{array}$ \\
\hline $\begin{array}{l}249 \\
250 \\
259 \\
252 \\
253\end{array}$ & $\begin{array}{r}1 \\
-1 \\
1 \\
1 \\
1\end{array}$ & $\begin{array}{l}1.3640 \\
- \\
1.3617 \\
1.3640 \\
1.3640\end{array}$ & $\begin{array}{l}3 \\
\dot{3} \\
\dot{.}\end{array}$ & $\begin{array}{l}0.0058 \\
.0 .0065 \\
.\end{array}$ & $\begin{array}{l}50 \\
50 \\
50 \\
50 \\
50\end{array}$ & $\begin{array}{l}\mathrm{K} / \mathrm{sand} / \mathrm{gravel} \\
\mathrm{K} / \mathrm{s} \text { and/gravel } \\
\mathrm{K} / \mathrm{sand} / \mathrm{gravel} \\
\mathrm{K} / \mathrm{s} \text { and/gravel } \\
\mathrm{K} / \mathrm{s} \text { and/gravel }\end{array}$ & $\begin{array}{l}20.0 \\
20.0 \\
20.0 \\
20.0 \\
20.0\end{array}$ & $\begin{array}{l}5.0 \\
9.0 \\
7.0 \\
5.0 \\
5.0\end{array}$ & $\begin{array}{l}0.00 \\
0.00 \\
0.00 \\
0.33 \\
0.66\end{array}$ \\
\hline $\begin{array}{l}254 \\
255 \\
256 \\
257 \\
258\end{array}$ & $\begin{array}{r}-1 \\
1 \\
1 \\
1 \\
1\end{array}$ & $\begin{array}{l}1.3093 \\
1.3020 \\
1.3020 \\
1.3020\end{array}$ & $\begin{array}{l}\dot{3} \\
3 \\
\dot{.}\end{array}$ & $\begin{array}{l}0.0020 \\
0.0033 \\
.\end{array}$ & $\begin{array}{l}25 \\
25 \\
25 \\
25 \\
25\end{array}$ & $\begin{array}{l}\mathrm{K} / \mathrm{s} \text { and/gravel } \\
\mathrm{K} / \mathrm{s} \text { and/gravel } \\
\mathrm{K} / \mathrm{s} \text { and/gravel } \\
\mathrm{K} / \mathrm{sand} / \mathrm{gravel} \\
\mathrm{K} / \mathrm{s} \text { and/gravel }\end{array}$ & $\begin{array}{l}10.0 \\
10.0 \\
10.0 \\
10.0 \\
10.0\end{array}$ & $\begin{array}{l}9.0 \\
7.0 \\
5.0 \\
5.0 \\
5.0\end{array}$ & $\begin{array}{l}0.00 \\
0.00 \\
0.00 \\
0.33 \\
0.66\end{array}$ \\
\hline $\begin{array}{l}259 \\
260 \\
261 \\
262 \\
263\end{array}$ & $\begin{array}{r}1 \\
-1 \\
1 \\
1 \\
1\end{array}$ & $\begin{array}{l}1.2977 \\
1.2891 \\
1.2891 \\
1.2891\end{array}$ & $\begin{array}{l}3 \\
\dot{3} \\
\dot{.}\end{array}$ & $\begin{array}{l}0.0087 \\
0.0014 \\
.\end{array}$ & $\begin{array}{l}50 \\
50 \\
50 \\
50 \\
50\end{array}$ & $\begin{array}{l}\mathrm{K} / \mathrm{sand} \text { /gravel } \\
\mathrm{K} / \mathrm{sand} / \mathrm{gravel} \\
\mathrm{K} / \mathrm{s} \text { and/gravel } \\
\mathrm{K} / \mathrm{sand} \text { /gravel } \\
\mathrm{K} / \mathrm{sand} \text { /gravel }\end{array}$ & $\begin{array}{l}10.0 \\
10.0 \\
10.0 \\
10.0 \\
10.0\end{array}$ & $\begin{array}{l}7.0 \\
9.0 \\
5.0 \\
5.0 \\
5.0\end{array}$ & $\begin{array}{l}0.00 \\
0.00 \\
0.00 \\
0.33 \\
0.66\end{array}$ \\
\hline $\begin{array}{l}264 \\
265 \\
266\end{array}$ & $\begin{array}{l}1 \\
1 \\
1\end{array}$ & $\begin{array}{l}0.9970 \\
0.9970 \\
0.9970\end{array}$ & : & $\dot{.}$ & $\begin{array}{l}25 \\
25 \\
25\end{array}$ & $\begin{array}{l}\text { Post-water } \\
\text { Post-water } \\
\text { Post-water }\end{array}$ & $\begin{array}{l}100.0 \\
100.0 \\
100.0\end{array}$ & $\begin{array}{l}1.0 \\
3.0 \\
5.0\end{array}$ & $\begin{array}{l}0.00 \\
0.00 \\
0.00\end{array}$ \\
\hline
\end{tabular}


Table B-2. Suspended solids concentrations (wt \%) reported by the reference laboratory and three instruments $(A N L=A N L$ ultrasonic cross-scatter; BTG = BTG SMS-3000; PNNL = PNNL in-tank particle size probe)

\begin{tabular}{|c|c|c|c|c|c|c|c|c|}
\hline $\begin{array}{l}\text { Temp. } \\
\left({ }^{\circ} \mathrm{C}\right)\end{array}$ & Matrix & $\begin{array}{l}\text { Nominal } \\
\text { weight } \\
(\%)\end{array}$ & $\begin{array}{r}\text { Flow } \\
(\mathrm{ft} / \mathrm{s})\end{array}$ & $\begin{array}{c}\text { Air } \\
(\mathrm{cfm})\end{array}$ & $\begin{array}{l}\text { Reference } \\
\text { sol ids } \\
(\%)\end{array}$ & $\begin{array}{l}\text { ANL } \\
\text { solids } \\
(\%)\end{array}$ & $\begin{array}{l}\text { BTG } \\
\text { solids } \\
(\%)\end{array}$ & $\begin{array}{l}\text { PNNL } \\
\text { solids } \\
(\%)\end{array}$ \\
\hline $\begin{array}{l}25 \\
25 \\
25\end{array}$ & $\begin{array}{l}\text { Pre-water } \\
\text { Pre-water } \\
\text { Sucrose }\end{array}$ & $\begin{array}{r}100 \\
100 \\
50\end{array}$ & $\begin{array}{l}3.00 \\
9.0 \\
7.0\end{array}$ & $\begin{array}{l}0 \\
0 \\
0\end{array}$ & $\dot{.}$ & $\begin{array}{l}6.4 \\
4.1 \\
1.1\end{array}$ & $\dot{.}$ & $\begin{array}{l}\cdot \\
\cdot \\
\cdot\end{array}$ \\
\hline $\begin{array}{l}25 \\
25 \\
25 \\
25 \\
25 \\
25 \\
25\end{array}$ & $\begin{array}{l}\text { Kaol in/water } \\
\text { Kaol in/water } \\
\text { Kaol in/water } \\
\text { Kaol in/water } \\
\text { Kaol in/water } \\
\text { Kaol in/water } \\
\text { Kaol in/water }\end{array}$ & $\begin{array}{l}10 \\
10 \\
10 \\
10 \\
10 \\
10 \\
10\end{array}$ & $\begin{array}{l}0.2 \\
1.0 \\
3.0 \\
5.0 \\
5.0 \\
7.0 \\
9.0\end{array}$ & $\begin{array}{c}0 \\
0 \\
0 \\
0 \\
0.33 \\
0 \\
0\end{array}$ & $\begin{array}{l}6.7 \\
7.2 \\
. \\
6.9\end{array}$ & $\begin{array}{l}2.9 \\
2.9 \\
2.9 \\
2.9 \\
4.6 \\
2.9 \\
2.9\end{array}$ & $\begin{array}{l}11.8 \\
11.1 \\
11.4 \\
11.4 \\
11.2 \\
11.1 \\
11.2\end{array}$ & $\begin{array}{c}44.8 \\
. \\
46.9 \\
96.2 \\
.\end{array}$ \\
\hline $\begin{array}{l}25 \\
25 \\
25 \\
25 \\
25 \\
25 \\
25 \\
25 \\
25\end{array}$ & $\begin{array}{l}\text { Kaol in/water } \\
\text { Kaol in/water } \\
\text { Kaol in/water } \\
\text { Kaol in/water } \\
\text { Kaol in/water } \\
\text { Kaol in/water } \\
\text { Kaol in/water } \\
\text { Kaol in/water } \\
\text { Kaol in/water }\end{array}$ & $\begin{array}{l}20 \\
20 \\
20 \\
20 \\
20 \\
20 \\
20 \\
20 \\
20\end{array}$ & $\begin{array}{l}0.2 \\
0.4 \\
1.0 \\
3.0 \\
5.0 \\
5.0 \\
5.0 \\
7.0 \\
9.0\end{array}$ & $\begin{array}{l}0 \\
0 \\
0 \\
0 \\
0 \\
0.33 \\
0.66 \\
0 \\
0\end{array}$ & $\begin{array}{c}14.5 \\
16.0 \\
15.2 \\
. \\
\dot{.} \\
14.5\end{array}$ & $\begin{array}{l}4.1 \\
4.1 \\
4.4 \\
4.4 \\
4.9 \\
7.3 \\
8.1 \\
5.0 \\
4.5\end{array}$ & $\begin{array}{l}20.0 \\
20.0 \\
20.0 \\
20.0 \\
20.0 \\
20.0 \\
19.7 \\
20.0 \\
20.0\end{array}$ & $\begin{array}{l}: \\
: \\
: \\
: \\
: \\
: \\
:\end{array}$ \\
\hline $\begin{array}{l}25 \\
25 \\
25 \\
25 \\
25\end{array}$ & $\begin{array}{l}\text { Kaol in/water } \\
\text { Kaol in/water } \\
\text { Kaol in/water } \\
\text { Kaol in/water } \\
\text { Kaol in/water }\end{array}$ & $\begin{array}{l}30 \\
30 \\
30 \\
30 \\
30\end{array}$ & $\begin{array}{l}1.0 \\
3.0 \\
5.0 \\
7.0 \\
9.0\end{array}$ & $\begin{array}{l}0 \\
0 \\
0 \\
0 \\
0\end{array}$ & $\begin{array}{c}23.9 \\
24.4 \\
26.2 \\
. \\
25.0\end{array}$ & $\begin{array}{l}5.7 \\
5.8 \\
6.0 \\
6.3 \\
5.8\end{array}$ & $\dot{.}$. & : \\
\hline $\begin{array}{l}25 \\
25 \\
25 \\
25 \\
25 \\
25 \\
25 \\
25 \\
25 \\
25\end{array}$ & $\begin{array}{l}\text { Kaol in/sugar } \\
\text { Kaol in/sugar } \\
\mathrm{Kaol} \mathrm{in/sugar} \\
\mathrm{Kaol} \mathrm{in/sugar} \\
\mathrm{KaOl} \mathrm{in/sugar} \\
\mathrm{Kaol} \mathrm{in/sugar} \\
\mathrm{Kaol} \mathrm{in/sugar} \\
\mathrm{Kaol} \mathrm{in/sugar} \\
\mathrm{KaOl} \mathrm{in/sugar} \\
\mathrm{KaOl} \text { in/sugar }\end{array}$ & $\begin{array}{l}9 \\
9 \\
9 \\
9 \\
9 \\
9 \\
9 \\
9 \\
9 \\
9\end{array}$ & $\begin{array}{l}0.4 \\
0.8 \\
1.0 \\
1.3 \\
3.0 \\
5.0 \\
5.0 \\
5.0 \\
7.0 \\
9.0\end{array}$ & $\begin{array}{l}0 \\
0 \\
0 \\
0 \\
0 \\
0 \\
0.33 \\
0.66 \\
0 \\
0\end{array}$ & $\begin{array}{c}8.0 \\
: \\
7.7 \\
8.4 \\
8.2 \\
: \\
7.7 \\
.\end{array}$ & $\begin{array}{l}27.2 \\
53.1 \\
16.9 \\
67.0 \\
69.7 \\
49.7 \\
87.9 \\
87.6 \\
44.8 \\
30.0\end{array}$ & $\begin{array}{c}8.9 \\
9.0 \\
8.6 \\
: \\
8.3 \\
8.1 \\
8.3 \\
\vdots\end{array}$ & $\begin{array}{l}92.8 \\
92.9 \\
84.5 \\
92.9 \\
92.9 \\
93.4 \\
93.5 \\
93.5 \\
89.6 \\
82.7\end{array}$ \\
\hline $\begin{array}{l}25 \\
25 \\
25 \\
25 \\
25 \\
25 \\
25 \\
25 \\
25 \\
25\end{array}$ & $\begin{array}{l}\text { Kaol in/sugar } \\
\text { Kaol in/sugar } \\
\text { Kaol in/sugar } \\
\text { Kaol in/sugar } \\
\text { Kaol in/sugar } \\
\text { Kaol in/sugar } \\
\text { Kaol in/sugar } \\
\text { Kaol in/sugar } \\
\text { Kaol in/sugar } \\
\text { Kaol in/sugar }\end{array}$ & $\begin{array}{l}15 \\
15 \\
15 \\
15 \\
15 \\
15 \\
15 \\
15 \\
15 \\
15\end{array}$ & $\begin{array}{l}0.5 \\
1.0 \\
1.2 \\
1.9 \\
3.0 \\
5.0 \\
5.0 \\
5.0 \\
7.0 \\
9.0\end{array}$ & $\begin{array}{c}0 \\
0 \\
0 \\
0 \\
0 \\
0 \\
0.33 \\
0.66 \\
0 \\
0\end{array}$ & $\begin{array}{c}\cdot \\
14.4 \\
14.9 \\
14.7 \\
14.3 \\
: \\
\dot{0} \\
14.5\end{array}$ & $\begin{array}{l}70.1 \\
53.5 \\
79.0 \\
85.2 \\
86.6 \\
85.2 \\
87.4 \\
88.2 \\
72.1 \\
63.6\end{array}$ & $\begin{array}{l}. \\
\dot{.} \\
\dot{.} \\
\dot{.} \\
\dot{.}\end{array}$ & $\begin{array}{l}90.5 \\
90.0 \\
90.2 \\
90.2 \\
90.0 \\
90.0 \\
90.6 \\
89.7 \\
90.0 \\
90.2\end{array}$ \\
\hline $\begin{array}{l}25 \\
25 \\
25 \\
25 \\
25\end{array}$ & $\begin{array}{l}\text { Kaol in/sugar } \\
\text { Kaol in/sugar } \\
\text { Kaol in/sugar } \\
\text { Kaol in/sugar } \\
\text { Kaol in/sugar }\end{array}$ & $\begin{array}{l}22 \\
22 \\
22 \\
22 \\
22\end{array}$ & $\begin{array}{l}0.5 \\
1.0 \\
1.8 \\
3.0 \\
5.0\end{array}$ & $\begin{array}{l}0 \\
0 \\
0 \\
0 \\
0\end{array}$ & $\begin{array}{l}21.8 \\
23.9 \\
21.6 \\
23.0 \\
21.9\end{array}$ & $\begin{array}{l}25.0 \\
26.6 \\
25.0 \\
24.6 \\
26.1\end{array}$ & $\begin{array}{l}\dot{.} \\
\dot{.} \\
\dot{.}\end{array}$ & $\begin{array}{c}70.5 \\
70.4 \\
71.9 \\
70.1\end{array}$ \\
\hline
\end{tabular}


Table B-2 (cont.)

\begin{tabular}{|c|c|c|c|c|c|c|c|c|}
\hline $\begin{array}{l}\text { Temp. } \\
\left({ }^{\circ} \mathrm{C}\right)\end{array}$ & Matrix & $\begin{array}{l}\text { Nominal } \\
\text { weight } \\
(\%)\end{array}$ & $\begin{array}{r}\text { Flow } \\
(\mathrm{ft} / \mathrm{s})\end{array}$ & $\begin{array}{c}\text { Air } \\
\text { (cfin) }\end{array}$ & $\begin{array}{c}\text { Reference } \\
\text { solids } \\
(\%)\end{array}$ & $\begin{array}{l}\text { ANL } \\
\text { solids } \\
(\%)\end{array}$ & $\begin{array}{l}\text { BTG } \\
\text { sol ids } \\
(\%)\end{array}$ & $\begin{array}{l}\text { PNNL } \\
\text { solids } \\
(\%)\end{array}$ \\
\hline 25 & Kaol in/sand & 10 & 0.4 & 0 & . & . & 11.1 & . \\
\hline 25 & Kaol in/sand & 10 & 0.8 & 0 & . & - & 11.1 & . \\
\hline 25 & Kaolin/sand & 10 & 1.0 & 0 & 8.0 & - & 10.7 & . \\
\hline 25 & Kaol in/sand & 10 & 1.2 & 0 & . & - & 10.6 & . \\
\hline 25 & Kaol in/sand & 10 & 3.0 & 0 & 8.9 & . & 10.5 & . \\
\hline 25 . & Kaol in/sand & 10 & 5.0 & 0 & 10.8 & - & 10.5 & . \\
\hline 25 & Kaol in/sand & 10 & 5.0 & 0.33 & . & . & 10.5 & . \\
\hline 25 & Kaol in/sand & 10 & 7.0 & 0 & 11.2 & - & 10.3 & . \\
\hline 25 & Kaol in/sand & 20 & 0.7 & 0 & - & - & 20.0 & 87.1 \\
\hline 25 & Kaol in/sand & 20 & 1.0 & 0 & . & . & 20.0 & 72.8 \\
\hline 25 & Kaol in/sand & 20 & 1.2 & 0 & . & . & 20.0 & 87.3 \\
\hline 25 & $\mathrm{Kaol}$ in/sand & 20 & 1.9 & 0 & . & . & 20.0 & 87.2 \\
\hline 25 & Kaol in/sand & 20 & 3.0 & 0 & 20.5 & . & 20.0 & 88.1 \\
\hline 25 & Kaol in/sand & 20 & 5.0 & 0 & 21.6 & . & 20.0 & 84.2 \\
\hline 25 & Kaol in/sand & 20 & 5.0 & 0.33 & . & . & 20.0 & 87.5 \\
\hline 25 & Kaol in/sand & 20 & 5.0 & 0.66 & . & . & 20.0 & 87.1 \\
\hline 25 & $\mathrm{Kaol}$ in/sand & 20 & 7.0 & 0 & 20.2 & . & 20.0 & 80.3 \\
\hline 25 & Kaol in/sand & 30 & 1.0 & 0 & $\bullet$ & 42.4 & 20.0 & \\
\hline 25 & Kaol in/sand & 30 & 1.1 & 0 & 29.6 & 43.8 & 19.5 & 73.1 \\
\hline 25 & Kaol in/sand & 30 & 1.7 & 0 & 22.8 & 40.1 & 19.5 & 71.1 \\
\hline 25 & Kaol in/sand & 30 & 2.5 & 0 & . & 40.6 & 20.0 & 70.7 \\
\hline 25 & Kaol in/sand & 30 & 3.0 & 0 & 25.9 & 41.2 & 20.0 & 70.1 \\
\hline 25 & Kaol in/sand & 30 & 5.0 & 0 & 28.4 & 46.4 & 20.0 & 73.2 \\
\hline 25 & Kaol in/sand & 30 & 5.0 & 0.33 & . & 87.4 & 20.0 & 83.7 \\
\hline 25 & Kaol in/sand & 30 & 5.0 & 0.66 & - & 87.0 & 20.0 & 84.3 \\
\hline 25 & Kaol in/sand/gravel & 10 & 5.0 & 0 & 10.8 & - & 12.0 & - \\
\hline 25 & Kaol in/sand/gravel & 10 & 5.0 & 0.33 & . & . & 10.9 & . \\
\hline 25 & Kaol in/sand/gravel & 10 & 5.0 & 0.66 & . & . & 10.1 & . \\
\hline 25 & Kaol in/sand/gravel & 10 & 7.0 & 0 & 11.6 & - & 10.9 & - \\
\hline 25 & Kaol in/sand/gravel & 20 & 5.0 & 0 & 22.3 & - & 19.4 & . \\
\hline 25 & Kaol in/sand/gravel & 20 & 5.0 & 0.33 & . & . & 19.4 & . \\
\hline 25 & Kaol in/sand/gravel & 20 & 5.0 & 0.66 & . & - & 19.9 & - \\
\hline 25 & $\mathrm{Kaol}$ in/sand/gravel & 20 & 7.0 & 0 & 21.6 & - & 20.0 & - \\
\hline 50 & Sucrose & 60 & 3.0 & 0 & - & 1.5 & - & - \\
\hline 50 & Sucrose & 60 & 5.0 & 0 & - & 1.5 & - & - \\
\hline 50 & Kaol in/water & 10 & 1.0 & 0 & 6.4 & 2.9 & 20.0 & . \\
\hline 50 & Kaol in/water & 10 & 3.0 & 0 & . & 2.9 & 19.3 & . \\
\hline 50 & Kaol in/water & 10 & 5.0 & 0 & 7.5 & 2.9 & 19.8 & . \\
\hline 50 & Kaol in/water & 10 & 5.0 & 0.33 & . & 5.9 & 17.6 & . \\
\hline 50 & Kaol in/water & 10 & 5.0 & 0.66 & . & 7.8 & 16.2 & . \\
\hline 50 & Kaol in/water & 10 & 7.0 & 0 & . & 2.9 & 20.0 & - \\
\hline 50 & Kaol in/water & 10 & 9.0 & 0 & 7.4 & 2.9 & 20.0 & - \\
\hline 50 & Kaolin/water & 20 & 0.2 & 0 & & 4.6 & 20.0 & - \\
\hline 50 & Kaol in/water & 20 & 0.3 & 0 & 14.5 & 4.6 & 20.0 & . \\
\hline 50 & Kaolin/water & 20 & 0.4 & 0 & . & 4.6 & 20.0 & . \\
\hline 50 & Kaolin/water & 20 & 1.0 & 0 & . & 4.6 & 20.0 & - \\
\hline 50 & Kaolin/water & 20 & 3.0 & 0 & 14.0 & 4.7 & 20.0 & . \\
\hline 50 & Kaol in/water & 20 & 5.0 & 0 & 15.0 & 5.0 & 20.0 & . \\
\hline 50 & Kaol in/water & 20 & 5.0 & 0.33 & . & 8.6 & 20.0 & . \\
\hline 50 & Kaol in/water & 20 & 5.0 & 0.66 & . & 8.8 & 20.0 & . \\
\hline 50 & Kaol in/water & 20 & 7.0 & 0 & 15.4 & 4.8 & 20.0 & . \\
\hline 50 & $\mathrm{Kaol}$ in/water & 20 & 9.0 & 0 & 16.3 & 4.7 & 20.0 & . \\
\hline
\end{tabular}


Table B-2 (cont.)

\begin{tabular}{|c|c|c|c|c|c|c|c|c|}
\hline $\begin{array}{l}\text { Temp } \\
\left({ }^{\circ} \mathrm{C}\right)\end{array}$ & Matrix & $\begin{array}{c}\text { Nominal } \\
\text { weight } \\
(\%)\end{array}$ & $\begin{array}{c}F \text { low } \\
(\mathrm{ft} / \mathrm{s})\end{array}$ & $\begin{array}{l}\text { Air } \\
\text { (cfm) }\end{array}$ & $\begin{array}{c}\text { Reference } \\
\text { sol ids } \\
(\%)\end{array}$ & $\begin{array}{c}\text { ANL } \\
\text { sol ids } \\
(\%)\end{array}$ & $\begin{array}{l}\text { BTG } \\
\text { solids } \\
(\%)\end{array}$ & $\begin{array}{l}\text { PNNL } \\
\text { solids } \\
(\%)\end{array}$ \\
\hline $\begin{array}{l}50 \\
50 \\
50 \\
50 \\
50 \\
50 \\
50\end{array}$ & $\begin{array}{l}\text { Kaolin/water } \\
\text { Kaol in/water } \\
\text { Kaol in/water } \\
\text { Kaol in/water } \\
\text { Kaol in/water } \\
\text { Kaol in/water } \\
\text { Kaol in/water }\end{array}$ & $\begin{array}{l}30 \\
30 \\
30 \\
30 \\
30 \\
30 \\
30\end{array}$ & $\begin{array}{l}1.0 \\
3.0 \\
5.0 \\
5.0 \\
5.0 \\
7.0 \\
9.0\end{array}$ & $\begin{array}{l}0 \\
0 \\
0 \\
0.33 \\
0.66 \\
0 \\
0\end{array}$ & $\begin{array}{c}25.5 \\
24.8 \\
24.3 \\
. \\
. \\
23.6\end{array}$ & $\begin{array}{l}6.0 \\
6.1 \\
6.2 \\
8.6 \\
9.2 \\
6.4 \\
6.2\end{array}$ & $\begin{array}{l}\dot{.} \\
\dot{.} \\
\dot{.} \\
\dot{.}\end{array}$ & : \\
\hline $\begin{array}{l}50 \\
50 \\
50 \\
50 \\
50 \\
50 \\
50 \\
50 \\
50 \\
50\end{array}$ & $\begin{array}{l}\text { Kaol in/sugar } \\
\text { Kaol in/sugar } \\
\text { Kaol in/sugar } \\
\text { Kaol in/sugar } \\
\text { Kaol in/sugar } \\
\text { Kaol in/sugar } \\
\text { Kaol in/sugar } \\
\text { Kaol in/sugar } \\
\text { Kaol in/sugar } \\
\text { Kaol in/sugar }\end{array}$ & $\begin{array}{l}9 \\
9 \\
9 \\
9 \\
9 \\
9 \\
9 \\
9 \\
9 \\
9\end{array}$ & $\begin{array}{l}0.3 \\
0.5 \\
0.6 \\
1.0 \\
3.0 \\
5.0 \\
5.0 \\
5.0 \\
7.0 \\
9.0\end{array}$ & $\begin{array}{l}0 \\
0 \\
0 \\
0 \\
0 \\
0 \\
0.33 \\
0.66 \\
0 \\
0\end{array}$ & $\begin{array}{l}8.8 \\
\dot{9.1} \\
8.8 \\
8.1 \\
. \\
\dot{8.8}\end{array}$ & $\begin{array}{l}27.8 \\
24.9 \\
30.2 \\
32.0 \\
43.5 \\
85.4 \\
88.3 \\
88.1 \\
80.8 \\
26.1\end{array}$ & $\begin{array}{r}9.5 \\
10.1 \\
10.0 \\
9.7 \\
9.5 \\
9.6 \\
9.3 \\
8.9 \\
9.6 \\
9.6\end{array}$ & $\begin{array}{l}\dot{5} \\
\dot{5} \\
\dot{5} \\
\dot{5} \\
\dot{5}\end{array}$ \\
\hline $\begin{array}{l}50 \\
50 \\
50 \\
50 \\
50 \\
50 \\
50 \\
50 \\
50 \\
50\end{array}$ & $\begin{array}{l}\text { Kaol in/sugar } \\
\text { Kaol in/sugar } \\
\text { Kaol in/sugar } \\
\text { Kaol in/sugar } \\
\text { Kaol in/sugar } \\
\text { Kaol in/sugar } \\
\text { Kaol in/sugar } \\
\text { Kaol in/sugar } \\
\text { Kaol in/sugar } \\
\text { Kaol in/sugar }\end{array}$ & $\begin{array}{l}15 \\
15 \\
15 \\
15 \\
15 \\
15 \\
15 \\
15 \\
15 \\
15\end{array}$ & $\begin{array}{l}0.4 \\
0.8 \\
1.0 \\
1.7 \\
3.0 \\
5.0 \\
5.0 \\
5.0 \\
7.0 \\
9.0\end{array}$ & $\begin{array}{l}0 \\
0 \\
0 \\
0 \\
0 \\
0 \\
0.33 \\
0.66 \\
0 \\
0\end{array}$ & $\begin{array}{c}13.9 \\
\dot{0} \\
14.6 \\
14.3 \\
13.9 \\
\dot{0} \\
14.2 \\
\dot{0}\end{array}$ & $\begin{array}{l}63.8 \\
72.1 \\
69.0 \\
83.2 \\
84.3 \\
87.7 \\
88.1 \\
87.0 \\
83.9 \\
85.9\end{array}$ & $\begin{array}{l}: \\
: \\
: \\
: \\
:\end{array}$ & $\begin{array}{l}\dot{5} \\
\dot{5} \\
\dot{5} \\
\dot{5}\end{array}$ \\
\hline $\begin{array}{l}50 \\
50 \\
50 \\
50 \\
50 \\
50\end{array}$ & $\begin{array}{l}\text { Kaol in/sugar } \\
\text { Kaol in/sugar } \\
\text { Kaol in/sugar } \\
\text { Kaol in/sugar } \\
\text { Kaol in/sugar } \\
\text { Kaol in/sugar }\end{array}$ & $\begin{array}{l}22 \\
22 \\
22 \\
22 \\
22 \\
22\end{array}$ & $\begin{array}{l}0.5 \\
1.0 \\
1.9 \\
3.0 \\
5.0 \\
5.0\end{array}$ & $\begin{array}{l}0 \\
0 \\
0 \\
0 \\
0 \\
0.33\end{array}$ & $\begin{array}{c}23.4 \\
21.3 \\
21.3 \\
22.3 \\
22.2 \\
.\end{array}$ & $\begin{array}{l}45.7 \\
54.7 \\
44.9 \\
40.0 \\
65.2 \\
88.3\end{array}$ & $\dot{.}$ & : \\
\hline $\begin{array}{l}50 \\
50 \\
50 \\
50 \\
50 \\
50 \\
50\end{array}$ & $\begin{array}{l}\text { Kaol in/sand } \\
\mathrm{Kaol} \text { in/sand } \\
\mathrm{KaOl} \text { in/sand } \\
\mathrm{Kaol} \text { in/sand } \\
\mathrm{KaOl} \text { in/sand } \\
\mathrm{KaOl} \text { in/sand } \\
\mathrm{KaOl} \text { in/sand }\end{array}$ & $\begin{array}{l}10 \\
10 \\
10 \\
10 \\
10 \\
10 \\
10\end{array}$ & $\begin{array}{l}0.4 \\
0.6 \\
1.0 \\
3.0 \\
5.0 \\
5.0 \\
7.0\end{array}$ & $\begin{array}{l}0 \\
0 \\
0 \\
0 \\
0 \\
0.33 \\
0\end{array}$ & $\begin{array}{c}. \\
8.5 \\
8.7 \\
10.4 \\
9.8\end{array}$ & $\begin{array}{l}\dot{.} \\
\dot{.} \\
\dot{.} \\
\dot{.}\end{array}$ & $\begin{array}{l}18.2 \\
19.4 \\
19.9 \\
20.0 \\
19.6 \\
19.9 \\
20.0\end{array}$ & 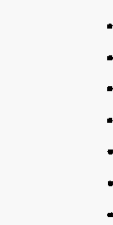 \\
\hline $\begin{array}{l}50 \\
50 \\
50 \\
50 \\
50 \\
50 \\
50 \\
50 \\
50\end{array}$ & 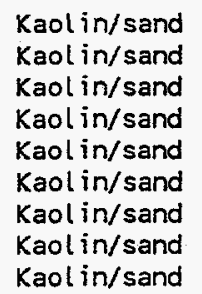 & $\begin{array}{l}20 \\
20 \\
20 \\
20 \\
20 \\
20 \\
20 \\
20 \\
20\end{array}$ & $\begin{array}{l}0.3 \\
0.6 \\
0.9 \\
1.0 \\
3.0 \\
5.0 \\
5.0 \\
5.0 \\
7.0\end{array}$ & $\begin{array}{l}0 \\
0 \\
0 \\
0 \\
0 \\
0 \\
0.33 \\
0.66 \\
0\end{array}$ & $\begin{array}{c}. \\
19.0 \\
16.7 \\
21.6 \\
23.7 \\
\dot{.} \\
22.2\end{array}$ & $\begin{array}{l}\text { : } \\
\text {. } \\
\text {. } \\
\text {. }\end{array}$ & $\begin{array}{l}20.0 \\
20.0 \\
20.0 \\
20.0 \\
20.0 \\
20.0 \\
20.0 \\
20.0 \\
20.0\end{array}$ & $\begin{array}{l}. \\
. \\
. \\
. \\
. \\
.\end{array}$ \\
\hline
\end{tabular}


Table B-2 (cont.)

\begin{tabular}{|c|c|c|c|c|c|c|c|c|}
\hline $\begin{array}{l}\text { Temp } \\
\left({ }^{\circ} \mathrm{C}\right)\end{array}$ & Matrix & $\begin{array}{l}\text { Nominal } \\
\text { Weight } \\
\text { (\%) }\end{array}$ & $\begin{array}{c}F(\text { ow } \\
(\mathrm{ft} / \mathrm{s})\end{array}$ & $\underset{\text { (cfin) }}{A i r}$ & $\begin{array}{l}\text { Reference } \\
\text { solids } \\
\text { (\%) }\end{array}$ & $\begin{array}{c}\text { ANL } \\
\text { solids } \\
(\%)\end{array}$ & $\begin{array}{c}\text { BTG } \\
\text { solids } \\
(\%)\end{array}$ & $\begin{array}{c}\text { PNNL } \\
\text { solids } \\
(\%)\end{array}$ \\
\hline $\begin{array}{l}50 \\
50 \\
50 \\
50 \\
50 \\
50 \\
50 \\
50\end{array}$ & $\begin{array}{l}\text { Kaol in/sand } \\
\mathrm{Kaol} \text { in/sand } \\
\mathrm{Kaol} \mathrm{in/sand} \\
\mathrm{Kaol} \text { in/sand } \\
\mathrm{Kaol} \text { in/sand } \\
\mathrm{Kaol} \text { in/sand } \\
\mathrm{Kaol} \text { in/sand } \\
\mathrm{KaOl} \text { in/sand }\end{array}$ & $\begin{array}{l}30 \\
30 \\
30 \\
30 \\
30 \\
30 \\
30 \\
30\end{array}$ & $\begin{array}{l}0.6 \\
1.0 \\
1.0 \\
1.6 \\
3.0 \\
5.0 \\
5.0 \\
7.0\end{array}$ & $\begin{array}{l}0 \\
0 \\
0 \\
0 \\
0 \\
0 \\
0.33 \\
0\end{array}$ & $\begin{array}{c}27.0 \\
\dot{0} \\
24.9 \\
28.5 \\
27.2 \\
25.8\end{array}$ & $\begin{array}{l}79.1 \\
85.3 \\
82.5 \\
82.8 \\
86.7 \\
85.2 \\
85.7 \\
86.7\end{array}$ & $\begin{array}{l}19.8 \\
20.0 \\
19.5 \\
19.9 \\
20.0 \\
19.5 \\
20.0 \\
20.0\end{array}$ & . \\
\hline $\begin{array}{l}50 \\
50 \\
50 \\
50\end{array}$ & $\begin{array}{l}\text { Kaol in/sand/gravel } \\
\text { Kaol in/sand/gravel } \\
\text { Kaol in/sand/gravel } \\
\text { Kaol in/sand/gravel }\end{array}$ & $\begin{array}{l}10 \\
10 \\
10 \\
10\end{array}$ & $\begin{array}{l}5.0 \\
5.0 \\
5.0 \\
7.0\end{array}$ & $\begin{array}{l}0 \\
0.33 \\
3.66 \\
0\end{array}$ & $\begin{array}{c}11.7 \\
\vdots \\
12.2\end{array}$ & $\dot{.}$ & $\begin{array}{l}19.1 \\
17.2 \\
16.6 \\
17.2\end{array}$ & . \\
\hline $\begin{array}{l}50 \\
50 \\
50 \\
50\end{array}$ & $\begin{array}{l}\mathrm{Kaol} \text { in/sand/gravel } \\
\mathrm{Kaol} \text { in/sand/gravel } \\
\mathrm{Kaol} \text { in/sand/gravel } \\
\mathrm{KaOl} \text { in/sand/gravel }\end{array}$ & $\begin{array}{l}20 \\
20 \\
20 \\
20\end{array}$ & $\begin{array}{l}5.0 \\
5.0 \\
5.0 \\
7.0\end{array}$ & $\begin{array}{l}0 \\
0.33 \\
0.66 \\
0\end{array}$ & $\begin{array}{c}21.9 \\
\dot{0} \\
20.0\end{array}$ & $\dot{.}$ & $\begin{array}{l}20.0 \\
20.0 \\
20.0 \\
20.0\end{array}$ & . \\
\hline
\end{tabular}


Table B-3. Viscosity values (centipoises at shear rate) at $25^{\circ} \mathrm{C}$ reported by the reference laboratory and five viscosity instruments: SNL in-pipe instrument using either frequency or voltage signals, SNL in-tank instrument using either frequency or voltage signals, and ANL ultrasonic flow in-pipe instrument

\begin{tabular}{|c|c|c|c|c|c|c|c|c|c|c|}
\hline Matrix & $\begin{array}{l}\text { Nominal } \\
\text { weight } \\
(\%)\end{array}$ & $\begin{array}{r}F \text { low } \\
(\mathrm{ft} / \mathrm{s})\end{array}$ & $\begin{array}{l}\text { Air } \\
(\mathrm{cfm})\end{array}$ & $\begin{array}{l}\text { Reference } \\
\text { viscosity } \\
\text { (cP at } 800 / s)\end{array}$ & $\begin{array}{l}\text { SNL pipe } \\
\text { frequency } \\
\text { (cP) }\end{array}$ & $\begin{array}{l}\text { SNL pipe } \\
\text { voltage } \\
\text { (CP) }\end{array}$ & $\begin{array}{l}\text { SNL tank } \\
\text { frequency } \\
\text { (cP) }\end{array}$ & $\begin{array}{l}\text { SNL tank } \\
\text { vol tage } \\
\text { (CP) }\end{array}$ & $\begin{array}{c}\text { Reference } \\
\text { Viscosity } \\
\text { (cP at } 5000 / s)\end{array}$ & $\begin{array}{l}\text { ANL } \\
\text { (cP) }\end{array}$ \\
\hline $\begin{array}{l}\text { Pre-water } \\
\text { Pre-water } \\
\text { Pre-water } \\
\text { Pre-water } \\
\text { Pre-water }\end{array}$ & $\begin{array}{l}100 \\
100 \\
100 \\
100 \\
100\end{array}$ & $\begin{array}{l}1.0 \\
3.0 \\
5.0 \\
7.0 \\
9.0\end{array}$ & $\begin{array}{l}0 \\
0 \\
0 \\
0 \\
0\end{array}$ & $\begin{array}{l}0.9 \\
0.9 \\
0.9 \\
0.9 \\
0.9\end{array}$ & $\begin{array}{l}6.1 \\
6.7 \\
6.7 \\
6.4 \\
5.7\end{array}$ & $\begin{array}{l}2.3 \\
2.3 \\
2.3 \\
2.2 \\
2.1\end{array}$ & $\begin{array}{l}2.6 \\
2.6 \\
2.6 \\
2.6 \\
2.6\end{array}$ & $\begin{array}{l}1.4 \\
1.4 \\
1.4 \\
1.4 \\
1.4\end{array}$ & $\begin{array}{l}0.9 \\
0.9 \\
0.9 \\
0.9 \\
0.9\end{array}$ & $\begin{array}{r}68.8 \\
216.7 \\
60.2 \\
65.7 \\
65.6\end{array}$ \\
\hline $\begin{array}{l}\text { Sucrose } \\
\text { Sucrase } \\
\text { Sucrose } \\
\text { Sucrose } \\
\text { Sucrose } \\
\text { Sucrose } \\
\text { Sucrose } \\
\text { Sucrose. }\end{array}$ & $\begin{array}{l}40 \\
40 \\
40 \\
40 \\
40 \\
40 \\
40 \\
40\end{array}$ & $\begin{array}{l}0.3 \\
0.4 \\
0.5 \\
1.0 \\
3.0 \\
5.0 \\
7.0 \\
9.0\end{array}$ & $\begin{array}{l}0 \\
0 \\
0 \\
0 \\
0 \\
0 \\
0 \\
0\end{array}$ & $\begin{array}{l}5.2 \\
5.2 \\
5.2 \\
5.2 \\
5.2 \\
5.2 \\
5.2 \\
5.2\end{array}$ & $\begin{array}{l}8.1 \\
7.8 \\
8.1 \\
8.2 \\
8.3 \\
7.7 \\
7.6 \\
7.3\end{array}$ & $\begin{array}{l}10.2 \\
10.3 \\
10.4 \\
10.6 \\
10.7 \\
10.4 \\
10.3 \\
10.3\end{array}$ & $\begin{array}{l}8.6 \\
8.7 \\
8.7 \\
8.8 \\
8.8 \\
8.8 \\
8.8 \\
8.9\end{array}$ & $\begin{array}{l}7.9 \\
7.9 \\
7.9 \\
8.0 \\
8.0 \\
8.0 \\
8.0 \\
8.1\end{array}$ & $\begin{array}{l}5.2 \\
5.2 \\
5.2 \\
5.2 \\
5.2 \\
5.2 \\
5.2 \\
5.2\end{array}$ & $\begin{array}{c}: \\
\dot{0} \\
\dot{0} \\
\dot{5}\end{array}$ \\
\hline $\begin{array}{l}\text { Sucrose } \\
\text { Sucrose } \\
\text { Sucrose } \\
\text { Sucrose } \\
\text { Sucrose } \\
\text { Sucrose } \\
\text { Sucrose }\end{array}$ & $\begin{array}{l}50 \\
50 \\
50 \\
50 \\
50 \\
50 \\
50\end{array}$ & $\begin{array}{l}0.4 \\
0.8 \\
1.0 \\
1.2 \\
3.0 \\
5.0 \\
7.0\end{array}$ & $\begin{array}{l}0 \\
0 \\
0 \\
0 \\
0 \\
0 \\
0\end{array}$ & : & $\begin{array}{r}9.7 \\
9.6 \\
10.0 \\
9.8 \\
9.6 \\
9.1 \\
9.2\end{array}$ & $\begin{array}{l}18.4 \\
18.2 \\
19.4 \\
19.2 \\
20.4 \\
19.6 \\
19.6\end{array}$ & $\begin{array}{l}11.6 \\
11.3 \\
11.7 \\
11.6 \\
11.8 \\
11.6 \\
11.7\end{array}$ & $\begin{array}{l}13.2 \\
12.8 \\
13.4 \\
13.3 \\
13.9 \\
13.5 \\
13.8\end{array}$ & : & $\begin{array}{r}8.9 \\
7.2 \\
10.1 \\
13.8 \\
25.9 \\
12.7 \\
15.6\end{array}$ \\
\hline $\begin{array}{l}\text { Sucrose } \\
\text { Sucrose } \\
\text { Sucrose } \\
\text { Sucrose } \\
\text { Sucrose } \\
\text { Sucrose } \\
\text { Sucrose }\end{array}$ & $\begin{array}{l}60 \\
60 \\
60 \\
60 \\
60 \\
60 \\
60\end{array}$ & $\begin{array}{l}1.0 \\
1.4 \\
2.4 \\
3.0 \\
3.7 \\
5.0 \\
7.0\end{array}$ & $\begin{array}{l}0 \\
0 \\
0 \\
0 \\
0 \\
0 \\
0\end{array}$ & $\begin{array}{l}44.0 \\
44.0 \\
44.0 \\
44.0 \\
44.0 \\
44.0 \\
44.0\end{array}$ & $\begin{array}{l}1.3 \\
3.3 \\
2.1 \\
. \\
2.6 \\
0.3 \\
1.0\end{array}$ & $\begin{array}{l}133.5 \\
101.2 \\
120.0 \\
297.2 \\
109.4 \\
167.1 \\
137.9\end{array}$ & $\begin{array}{l}21.9 \\
21.3 \\
21.6 \\
22.2 \\
21.5 \\
22.1 \\
22.0\end{array}$ & $\begin{array}{l}37.9 \\
35.8 \\
37.1 \\
40.2 \\
36.4 \\
39.3 \\
38.4\end{array}$ & $\begin{array}{l}44.0 \\
44.0 \\
44.0 \\
44.0 \\
44.0 \\
44.0 \\
44.0\end{array}$ & $\begin{array}{r}63.8 \\
75.3 \\
60.0 \\
113.6 \\
60.4 \\
106.5 \\
82.3\end{array}$ \\
\hline
\end{tabular}


Table B-3 (cont.)

\begin{tabular}{|c|c|c|c|c|c|c|c|c|c|c|}
\hline Matrix & $\begin{array}{l}\text { Nominal } \\
\text { weight } \\
(\%)\end{array}$ & $\begin{array}{r}\text { Flow } \\
(\mathrm{ft} / \mathrm{s})\end{array}$ & $\begin{array}{l}\text { Air } \\
(\mathrm{cfm})\end{array}$ & $\begin{array}{l}\text { Reference } \\
\text { viscosity } \\
\text { (cP at } 800 / \mathrm{s})\end{array}$ & $\begin{array}{l}\text { SNL pipe } \\
\text { frequency } \\
\text { (cP) }\end{array}$ & $\begin{array}{l}\text { SNL pipe } \\
\text { vol tage } \\
\text { (CP) }\end{array}$ & $\begin{array}{l}\text { SNL tank } \\
\text { frequency } \\
\text { (cP) }\end{array}$ & $\begin{array}{l}\text { SNL tank } \\
\text { vol tage } \\
\text { (cP) }\end{array}$ & $\begin{array}{c}\text { Reference } \\
\text { viscosity } \\
\text { (cP at } 5000 / \mathrm{s})\end{array}$ & $\begin{array}{l}\text { ANL } \\
\text { (CP) }\end{array}$ \\
\hline $\begin{array}{l}\text { Kaol in/water } \\
\text { Kaol in/water } \\
\text { Kaol in/water } \\
\text { Kaol in/water } \\
\text { Kaol in/water } \\
\text { Kaol in/water } \\
\text { Kaol in/water }\end{array}$ & $\begin{array}{l}10 \\
10 \\
10 \\
10 \\
10 \\
10 \\
10\end{array}$ & $\begin{array}{l}0.2 \\
1.0 \\
3.0 \\
5.0 \\
5.0 \\
7.0 \\
9.0\end{array}$ & $\begin{array}{c}0 \\
0 \\
0 \\
0 \\
0.33 \\
0 \\
0\end{array}$ & $\begin{array}{l}2.4 \\
2.4 \\
2.4 \\
2.4 \\
2.4 \\
2.4 \\
2.4\end{array}$ & $\begin{array}{l}: \\
: \\
:\end{array}$ & $\begin{array}{c}957.0 \\
. \\
. \\
783.2 \\
. \\
.\end{array}$ & $\begin{array}{l}11.7 \\
10.5 \\
11.0 \\
11.3 \\
11.5 \\
10.9 \\
10.8\end{array}$ & $\begin{array}{l}4.0 \\
3.5 \\
3.8 \\
4.1 \\
3.8 \\
3.6 \\
3.5\end{array}$ & $\begin{array}{l}2.0 \\
2.0 \\
2.0 \\
2.0 \\
2.0 \\
2.0 \\
2.0\end{array}$ & $\begin{array}{l}125.3 \\
153.8 \\
149.8 \\
129.5 \\
125.3 \\
152.3 \\
143.1\end{array}$ \\
\hline $\begin{array}{l}\text { Kaol in/water } \\
\text { Kaol in/water } \\
\text { Kaol in/water } \\
\text { Kaol in/water } \\
\text { Kaol in/water } \\
\text { Kaol in/water } \\
\text { Kaol in/water } \\
\text { Kaol in/water } \\
\text { Kaol in/water }\end{array}$ & $\begin{array}{l}20 \\
20 \\
20 \\
20 \\
20 \\
20 \\
20 \\
20 \\
20\end{array}$ & $\begin{array}{l}0.2 \\
0.4 \\
1.0 \\
3.0 \\
5.0 \\
5.0 \\
5.0 \\
7.0 \\
9.0\end{array}$ & $\begin{array}{c}0 \\
0 \\
0 \\
0 \\
0 \\
0.33 \\
0.66 \\
0 \\
0\end{array}$ & $\begin{array}{l}12.0 \\
12.0 \\
12.0 \\
12.0 \\
12.0 \\
12.0 \\
12.0 \\
12.0 \\
12.0\end{array}$ & $\begin{array}{r}. \\
. \\
1422.5 \\
176.0 \\
. \\
.\end{array}$ & $\begin{array}{r}182.9 \\
184.6 \\
333.5 \\
259.5 \\
416.2 \\
128.6 \\
81.1 \\
458.6 \\
387.2\end{array}$ & $\begin{array}{l}3.2 \\
3.2 \\
3.3 \\
3.3 \\
3.4 \\
3.2 \\
3.2 \\
3.3 \\
3.2\end{array}$ & $\begin{array}{l}1.7 \\
1.7 \\
1.7 \\
1.7 \\
1.7 \\
1.6 \\
1.6 \\
1.6 \\
1.6\end{array}$ & $\begin{array}{l}6.0 \\
6.0 \\
6.0 \\
6.0 \\
6.0 \\
6.0 \\
6.0 \\
6.0 \\
6.0\end{array}$ & $\begin{array}{l}139.2 \\
140.4 \\
109.4 \\
130.0 \\
100.8 \\
150.0 \\
173.2 \\
98.1 \\
92.3\end{array}$ \\
\hline $\begin{array}{l}\text { Kaol in/water } \\
\text { Kaol in/water } \\
\text { Kaol in/water } \\
\text { Kaol in/water } \\
\text { Kaol in/water }\end{array}$ & $\begin{array}{l}30 \\
30 \\
30 \\
30 \\
30\end{array}$ & $\begin{array}{l}1.0 \\
3.0 \\
5.0 \\
7.0 \\
9.0\end{array}$ & $\begin{array}{l}0 \\
0 \\
0 \\
0 \\
0\end{array}$ & $\begin{array}{l}25.0 \\
25.0 \\
25.0 \\
25.0 \\
25.0\end{array}$ & $\begin{array}{r}7.4 \\
8.7 \\
8.7 \\
8.6 \\
16.7\end{array}$ & $\begin{array}{r}7.7 \\
6.4 \\
5.8 \\
6.1 \\
36.4\end{array}$ & $\begin{array}{l}4.1 \\
4.2 \\
4.3 \\
4.3 \\
4.0\end{array}$ & $\begin{array}{l}2.4 \\
2.5 \\
2.3 \\
2.2 \\
2.0\end{array}$ & $\begin{array}{l}8.0 \\
8.0 \\
8.0 \\
8.0 \\
8.0\end{array}$ & $\begin{array}{r}92.4 \\
105.8 \\
123.8 \\
125.2 \\
77.0\end{array}$ \\
\hline
\end{tabular}


Table B-3 (cont.)

\begin{tabular}{|c|c|c|c|c|c|c|c|c|c|c|c|}
\hline & Matrix & $\begin{array}{l}\text { Nominal } \\
\text { weight } \\
(\%)\end{array}$ & $\begin{array}{r}\text { Flow } \\
(\mathrm{ft} / \mathrm{s})\end{array}$ & $\begin{array}{l}\text { Air } \\
(\mathrm{cfm})\end{array}$ & $\begin{array}{c}\text { Reference } \\
\text { viscosity } \\
(\mathrm{cP} \text { at } 800 / \mathrm{s})\end{array}$ & $\begin{array}{l}\text { SNL pipe } \\
\text { frequency } \\
\quad(C P)\end{array}$ & $\begin{array}{l}\text { SNL pipe } \\
\text { vol tage } \\
\text { (CP) }\end{array}$ & $\begin{array}{l}\text { SNL tank } \\
\text { frequency } \\
\text { (CP) }\end{array}$ & $\begin{array}{l}\text { SNL tank } \\
\text { vol tage } \\
\text { (CP) }\end{array}$ & $\begin{array}{c}\text { Reference } \\
\text { viscosity } \\
\text { (cP at } 5000 / s)\end{array}$ & $\begin{array}{l}\text { ANL } \\
(\mathrm{CP})\end{array}$ \\
\hline & $\begin{array}{l}\text { Kaol in/sugar } \\
\text { Kaol in/sugar } \\
\text { Kaol in/sugar } \\
\text { Kaol in/sugar } \\
\text { Kaol in/sugar } \\
\text { Kaol in/sugar } \\
\text { Kaol in/sugar } \\
\text { Kaol in/sugar } \\
\text { Kaol in/sugar } \\
\text { Kaol in/sugar }\end{array}$ & $\begin{array}{l}9 \\
9 \\
9 \\
9 \\
9 \\
9 \\
9 \\
9 \\
9 \\
9\end{array}$ & $\begin{array}{l}0.4 \\
0.8 \\
1.0 \\
1.3 \\
3.0 \\
5.0 \\
5.0 \\
5.0 \\
7.0 \\
9.0\end{array}$ & $\begin{array}{c}0 \\
0 \\
0 \\
0 \\
0 \\
0 \\
0.33 \\
0.66 \\
0 \\
0\end{array}$ & $\begin{array}{l}22.5 \\
22.5 \\
22.5 \\
22.5 \\
22.5 \\
22.5 \\
22.5 \\
22.5 \\
22.5 \\
22.5\end{array}$ & $\begin{array}{l}: \\
: \\
: \\
: \\
: \\
:\end{array}$ & $\begin{array}{l}121.5 \\
128.8 \\
174.6 \\
140.4 \\
176.0 \\
166.1 \\
128.4 \\
125.2 \\
154.2 \\
170.8\end{array}$ & $\begin{array}{l}: \\
: \\
: \\
: \\
: \\
.\end{array}$ & $\begin{array}{l}600.6 \\
596.3 \\
604.5 \\
596.5 \\
618.7 \\
613.4 \\
659.0 \\
652.6 \\
596.2 \\
603.6\end{array}$ & $\begin{array}{l}17.5 \\
17.5 \\
17.5 \\
17.5 \\
17.5 \\
17.5 \\
17.5 \\
17.5 \\
17.5 \\
17.5\end{array}$ & $\begin{array}{l}207.4 \\
210.2 \\
326.1 \\
224.4 \\
256.7 \\
286.6 \\
184.7 \\
185.8 \\
225.1 \\
248.3\end{array}$ \\
\hline 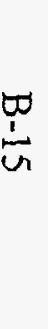 & $\begin{array}{l}\text { Kaol in/sugar } \\
\text { Kaol in/sugar } \\
\text { Kaol in/sugar } \\
\text { Kaol in/sugar } \\
\text { Kaol in/sugar } \\
\text { Kaol in/sugar } \\
\text { Kaol in/sugar } \\
\text { Kaol in/sugar } \\
\text { Kaol in/sugar } \\
\text { Kaol in/sugar }\end{array}$ & $\begin{array}{l}15 \\
15 \\
15 \\
15 \\
15 \\
15 \\
15 \\
15 \\
15 \\
15\end{array}$ & $\begin{array}{l}0.5 \\
1.0 \\
1.2 \\
1.9 \\
3.0 \\
5.0 \\
5.0 \\
5.0 \\
7.0 \\
9.0\end{array}$ & $\begin{array}{l}0 \\
0 \\
0 \\
0 \\
0 \\
0 \\
0.33 \\
0.66 \\
0 \\
0\end{array}$ & $\begin{array}{l}36.5 \\
36.5 \\
36.5 \\
36.5 \\
36.5 \\
36.5 \\
36.5 \\
36.5 \\
36.5 \\
36.5\end{array}$ & $\begin{array}{l}: \\
: \\
: \\
: \\
: \\
.\end{array}$ & $\begin{array}{l}136.1 \\
142.7 \\
172.3 \\
163.2 \\
153.1 \\
153.0 \\
147.3 \\
150.4 \\
167.3 \\
192.8\end{array}$ & $\begin{array}{l}: \\
: \\
: \\
\dot{.} \\
\dot{.} \\
.\end{array}$ & $\begin{array}{l}555.5 \\
565.7 \\
546.4 \\
550.6 \\
549.0 \\
546.3 \\
564.6 \\
555.3 \\
551.6 \\
563.1\end{array}$ & $\begin{array}{l}22.0 \\
22.0 \\
22.0 \\
22.0 \\
22.0 \\
22.0 \\
22.0 \\
22.0 \\
22.0 \\
22.0\end{array}$ & $\begin{array}{l}203.4 \\
257.5 \\
204.4 \\
210.2 \\
206.3 \\
202.2 \\
216.0 \\
214.3 \\
232.6 \\
240.2\end{array}$ \\
\hline & $\begin{array}{l}\text { Kaol in/sugar } \\
\text { Kaol in/sugar } \\
\text { Kaol in/sugar } \\
\text { Kaol in/sugar } \\
\text { Kaol in/sugar }\end{array}$ & $\begin{array}{l}22 \\
22 \\
22 \\
22 \\
22\end{array}$ & $\begin{array}{l}0.5 \\
1.0 \\
1.8 \\
3.0 \\
5.0\end{array}$ & $\begin{array}{l}0 \\
0 \\
0 \\
0 \\
0\end{array}$ & $\begin{array}{l}91.0 \\
91.0 \\
91.0 \\
91.0 \\
91.0\end{array}$ & : & $:$ & $\dot{:}$ & $\begin{array}{l}548.6 \\
623.5 \\
554.7 \\
534.2 \\
619.5\end{array}$ & $\begin{array}{l}52.0 \\
52.0 \\
52.0 \\
52.0 \\
52.0\end{array}$ & $\begin{array}{l}181.2 \\
267.8 \\
192.5 \\
218.6 \\
208.5\end{array}$ \\
\hline
\end{tabular}


Table B-3 (cont.)

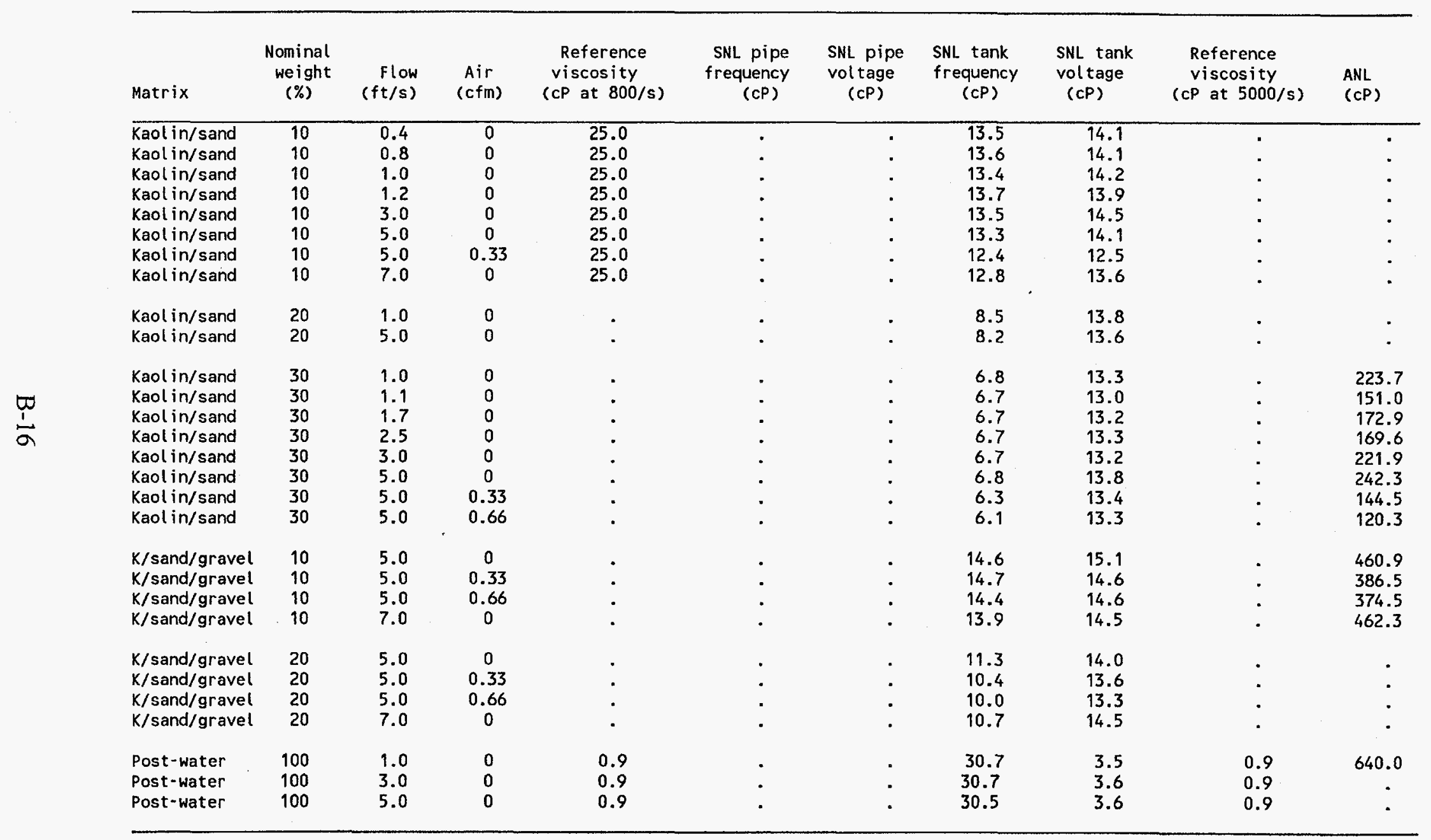


Table B-4. Viscosity values (centipoises at shear rate) at $50^{\circ} \mathrm{C}$ reported by the reference laboratory and five viscosity instruments: SNL in-pipe instrument using either frequency or voltage signals, SNL in-tank instrument using either frequency or voltage signals, and ANL ultrasonic flow instrument in-pipe

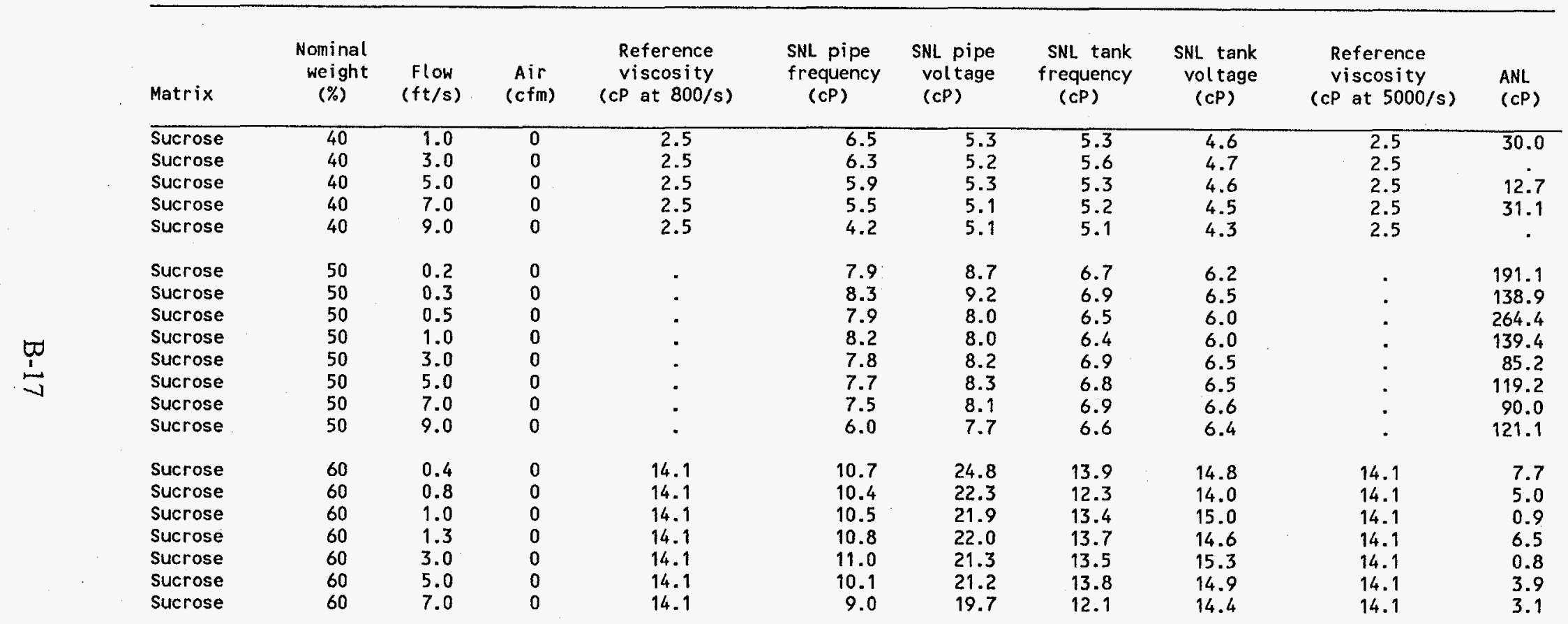


Table B-4 (cont.)

\begin{tabular}{|c|c|c|c|c|c|c|c|c|c|c|}
\hline Matrix & $\begin{array}{c}\text { Nominal } \\
\text { weight } \\
(\%)\end{array}$ & $\begin{array}{c}\text { Flow } \\
(f t / s)\end{array}$ & $\begin{array}{l}\text { Air } \\
\text { (cfm) }\end{array}$ & $\begin{array}{c}\text { Reference } \\
\text { viscosity } \\
\text { (cP at } 800 / s)\end{array}$ & $\begin{array}{l}\text { SNL pipe } \\
\text { frequency } \\
\text { (cP) }\end{array}$ & $\begin{array}{l}\text { SNL pipe } \\
\text { vol tage } \\
\text { (cP) }\end{array}$ & $\begin{array}{l}\text { SNL tank } \\
\text { frequency } \\
\text { (cP) }\end{array}$ & $\begin{array}{l}\text { SNL tank } \\
\text { vol tage } \\
\text { (cP) }\end{array}$ & $\begin{array}{c}\text { Reference } \\
\text { viscosity } \\
\text { (cP at } 5000 / s)\end{array}$ & $\begin{array}{r}\text { ANL } \\
\text { (cP) }\end{array}$ \\
\hline $\begin{array}{l}\text { Kaol in/water } \\
\text { Kaol in/water } \\
\text { Kaol in/water } \\
\text { Kaol in/water } \\
\text { Kaol in/water } \\
\text { Kaol in/water } \\
\text { Kaol in/water }\end{array}$ & $\begin{array}{l}10 \\
10 \\
10 \\
10 \\
10 \\
10 \\
10\end{array}$ & $\begin{array}{l}1.0 \\
3.0 \\
5.0 \\
5.0 \\
5.0 \\
7.0 \\
9.0\end{array}$ & $\begin{array}{l}0 \\
0 \\
0 \\
0.33 \\
0.66 \\
0 \\
0\end{array}$ & $\begin{array}{l}3.7 \\
3.7 \\
3.7 \\
3.7 \\
3.7 \\
3.7 \\
3.7\end{array}$ & $\begin{array}{r}514.4 \\
1071.3 \\
307.2 \\
356.6 \\
268.9 \\
179.0 \\
702.6\end{array}$ & $\begin{array}{r}100.4 \\
109.8 \\
90.5 \\
89.4 \\
83.3 \\
79.9 \\
106.0\end{array}$ & $\begin{array}{l}11.4 \\
11.0 \\
11.0 \\
11.0 \\
10.9 \\
10.4 \\
10.7\end{array}$ & $\begin{array}{l}4.2 \\
4.0 \\
4.3 \\
3.5 \\
3.5 \\
3.9 \\
3.6\end{array}$ & $\begin{array}{l}3.0 \\
3.0 \\
3.0 \\
3.0 \\
3.0 \\
3.0 \\
3.0\end{array}$ & $\begin{array}{l}364.6 \\
455.3 \\
349.5 \\
487.6 \\
518.3 \\
256.2 \\
440.0\end{array}$ \\
\hline $\begin{array}{l}\text { Kaol in/water } \\
\text { Kaol in/water } \\
\text { Kaol in/water } \\
\text { Kaol in/water } \\
\text { Kaol in/water } \\
\text { Kaol in/water } \\
\text { Kaol in/water } \\
\text { Kaol in/water } \\
\text { Kaol in/water } \\
\text { Kaol in/water }\end{array}$ & $\begin{array}{l}20 \\
20 \\
20 \\
20 \\
20 \\
20 \\
20 \\
20 \\
20 \\
20\end{array}$ & $\begin{array}{l}0.2 \\
0.3 \\
0.4 \\
1.0 \\
3.0 \\
5.0 \\
5.0 \\
5.0 \\
7.0 \\
9.0\end{array}$ & $\begin{array}{l}0 \\
0 \\
0 \\
0 \\
0 \\
0 \\
0.33 \\
0.66 \\
0 \\
0\end{array}$ & $\begin{array}{l}8.7 \\
8.7 \\
8.7 \\
8.7 \\
8.7 \\
8.7 \\
8.7 \\
8.7 \\
8.7 \\
8.7\end{array}$ & $\begin{array}{r}120.9 \\
116.5 \\
144.8 \\
99.0 \\
105.2 \\
90.3 \\
221.3 \\
96.1 \\
98.9 \\
121.1\end{array}$ & $\begin{array}{l}57.2 \\
56.1 \\
62.8 \\
58.0 \\
57.5 \\
54.3 \\
68.1 \\
51.1 \\
56.7 \\
60.0\end{array}$ & $\begin{array}{l}3.1 \\
3.1 \\
3.1 \\
3.1 \\
3.3 \\
3.3 \\
3.1 \\
3.1 \\
3.3 \\
3.2\end{array}$ & $\begin{array}{l}1.5 \\
1.5 \\
1.5 \\
1.5 \\
1.5 \\
1.6 \\
1.5 \\
1.4 \\
1.6 \\
1.5\end{array}$ & $\begin{array}{l}3.0 \\
3.0 \\
3.0 \\
3.0 \\
3.0 \\
3.0 \\
3.0 \\
3.0 \\
3.0 \\
3.0\end{array}$ & $\begin{array}{l}232.1 \\
223.5 \\
174.0 \\
243.1 \\
372.9 \\
393.4 \\
360.0 \\
331.1 \\
284.1 \\
395.5\end{array}$ \\
\hline $\begin{array}{l}\text { Kaol in/water } \\
\text { Kaol in/water } \\
\text { Kaol in/water } \\
\text { Kaol in/water } \\
\text { Kaol in/water } \\
\text { Kaol in/water } \\
\text { Kaol in/water }\end{array}$ & $\begin{array}{l}30 \\
30 \\
30 \\
30 \\
30 \\
30 \\
30\end{array}$ & $\begin{array}{l}1.0 \\
3.0 \\
5.0 \\
5.0 \\
5.0 \\
7.0 \\
9.0\end{array}$ & $\begin{array}{l}0 \\
0 \\
0 \\
0.33 \\
0.66 \\
0 \\
0\end{array}$ & $\begin{array}{l}23.0 \\
23.0 \\
23.0 \\
23.0 \\
23.0 \\
23.0 \\
23.0\end{array}$ & $\begin{array}{l}24.6 \\
27.6 \\
30.1 \\
28.7 \\
37.1 \\
27.3 \\
29.8\end{array}$ & $\begin{array}{l}35.3 \\
34.7 \\
33.6 \\
31.9 \\
35.1 \\
32.1 \\
33.5\end{array}$ & $\begin{array}{l}3.5 \\
3.6 \\
3.9 \\
3.4 \\
3.4 \\
3.7 \\
3.3\end{array}$ & $\begin{array}{l}2.0 \\
2.0 \\
2.1 \\
1.9 \\
1.8 \\
2.1 \\
1.8\end{array}$ & $\begin{array}{l}10.0 \\
10.0 \\
10.0 \\
10.0 \\
10.0 \\
10.0 \\
10.0\end{array}$ & $\begin{array}{r}105.1 \\
77.6 \\
169.6 \\
337.0 \\
314.8 \\
120.4 \\
261.6\end{array}$ \\
\hline
\end{tabular}


Table B-4 (cont.)

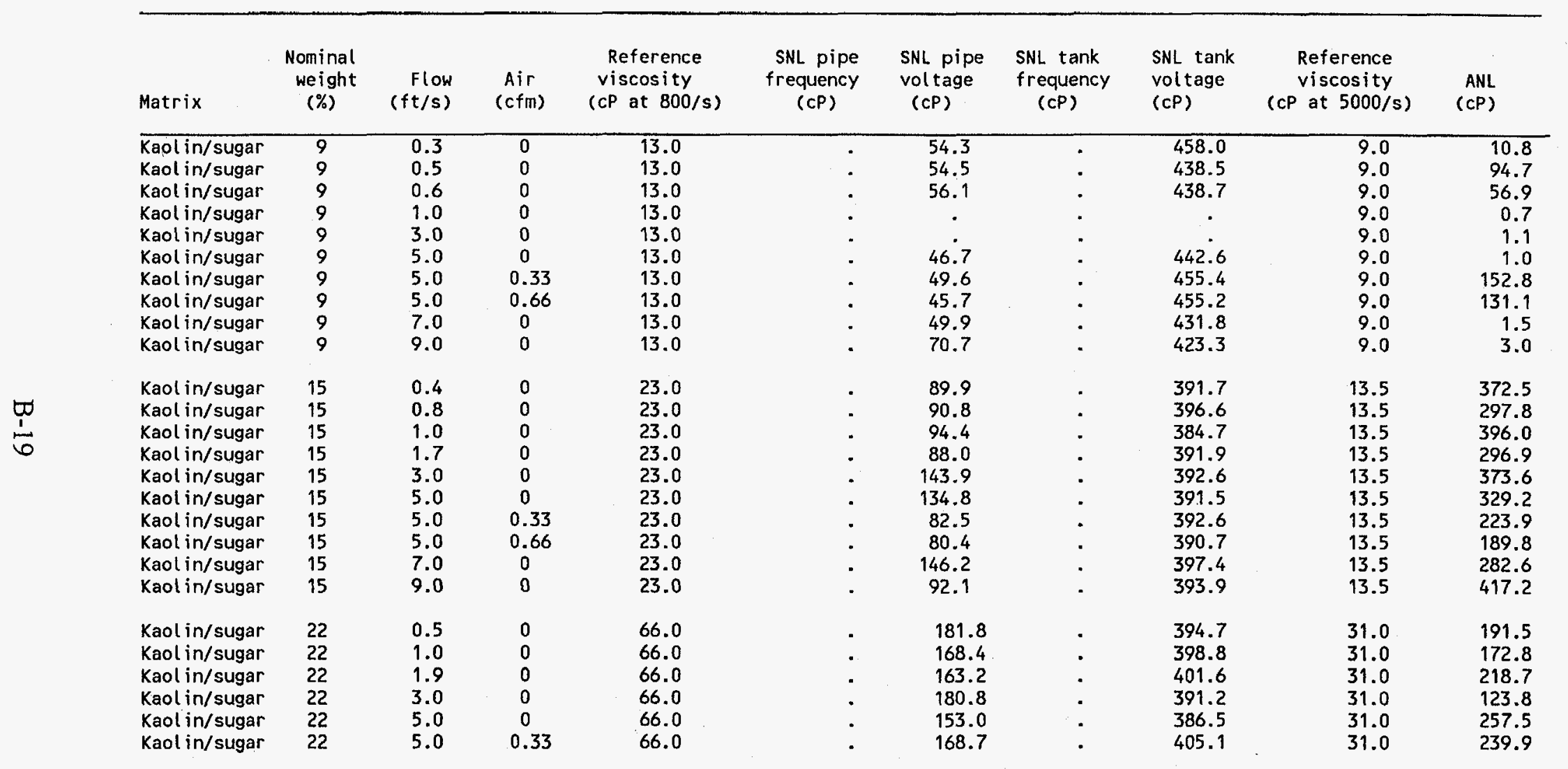


Table B-4 (cont.)

\begin{tabular}{|c|c|c|c|c|c|c|c|c|c|c|}
\hline Matrix & $\begin{array}{c}\text { Nominal } \\
\text { weight } \\
(\%)\end{array}$ & $\begin{array}{r}F \text { low } \\
(\mathrm{ft} / \mathrm{s})\end{array}$ & $\begin{array}{l}\text { Air } \\
(c f m)\end{array}$ & $\begin{array}{l}\text { Reference } \\
\text { viscosity } \\
\text { (cP at } 800 / s)\end{array}$ & $\begin{array}{l}\text { SNL pipe } \\
\text { frequency } \\
\text { (cP) }\end{array}$ & $\begin{array}{l}\text { SNL pipe } \\
\text { vol tage } \\
\text { (CP) }\end{array}$ & $\begin{array}{l}\text { SNL tank } \\
\text { frequency } \\
\text { (CP) }\end{array}$ & $\begin{array}{l}\text { SNL tank } \\
\text { vol tage } \\
\text { (cP) }\end{array}$ & $\begin{array}{c}\text { Reference } \\
\text { viscosity } \\
\text { (cP at } 5000 / s)\end{array}$ & $\begin{array}{r}\text { ANL } \\
(C P)\end{array}$ \\
\hline Kaol in/sand & 10 & 0.4 & 0 & . & . & . & 8.1 & 7.5 & . & . \\
\hline Kaol in/sand & 10 & 0.6 & 0 & . & . & . & 8.0 & 7.2 & . & . \\
\hline Kaol in/sand & 10 & 1.0 & 0 & . & . & . & 7.9 & 7.4 & . & . \\
\hline $\mathrm{Kaol}$ in/sand & 10 & 3.0 & 0 & . & . & . & 8.2 & 7.6 & . & . \\
\hline Kaol in/sand & 10 & 5.0 & 0 & . & . & . & 7.8 & 7.5 & . & . \\
\hline Kaol in/sand & 10 & 5.0 & 0.33 & . & . & . & 7.6 & 6.9 & . & $\dot{.}$ \\
\hline Kaol in/sand & 10 & 7.0 & 0 & . & . & . & 7.3 & 6.9 & . & . \\
\hline Kaol in/sand & 30 & 0.6 & 0 & . & . & . & 4.0 & 6.9 & . & 248.9 \\
\hline Kaol in/sand & 30 & 1.0 & 0 & . & . & . & 4.1 & 6.8 & . & 165.6 \\
\hline Kaol in/sand & 30 & 1.0 & 0 & . & . & . & 4.1 & 7.1 & . & 211.5 \\
\hline Kaol in/sand & 30 & 1.6 & 0 & . & . & . & 4.1 & 7.2 & . & 253.0 \\
\hline Kaol in/sand & 30 & 3.0 & 0 & . & . & . & 4.2 & 6.9 & . & 194.7 \\
\hline Kao! inf'sand & 30 & 5.0 & 0 & . & . & . & 4.2 & 7.2 & . & 173 \\
\hline Kaol in/sand & 30 & 5.0 & 0.33 & . & . & . & $4 . \overline{1}$ & $7 . \overline{9}$ & . & 248.1 \\
\hline $\mathrm{Kaol}$ in/sand & 30 & 7.0 & 0 & . & . & . & 4.1 & 6.7 & . & 209.2 \\
\hline $\mathrm{K} /$ sand/gravel & 10 & 5.0 & 0 & - & . & . & 9.0 & 7.6 & . & 147.8 \\
\hline $\mathrm{K} / \mathrm{s}$ and/gravel & 10 & 5.0 & 0.33 & . & $\dot{.}$ & . & 9.2 & 7.8 & . & 123.2 \\
\hline $\mathrm{K} /$ sand/gravel & 10 & 5.0 & 0.66 & . & . & . & 8.7 & 7.3 & . & 505.8 \\
\hline $\mathrm{K} /$ sand/gravel & 10 & 7.0 & 0 & . & . & . & 8.6 & 7.3 & . & 590.8 \\
\hline $\mathrm{K} /$ sand/gravel & 20 & 5.0 & 0 & . & " & . & 6.9 & 7.5 & . & 364.0 \\
\hline $\mathrm{K} /$ sand/gravel & 20 & 5.0 & 0.33 & . & . & . & 6.3 & 7.0 & . & 466.6 \\
\hline $\mathrm{K} /$ sand/gravel & 20 & 5.0 & 0.66 & . & . & . & 6.4 & 7.2 & . & 354.6 \\
\hline $\mathrm{K} /$ sand/gravel & 20 & 7.0 & 0 & . & . & . & 6.4 & 7.2 & . & 332.0 \\
\hline
\end{tabular}


Appendix C

RESPONSE FROM ARGONNE NATIONAL LABORATORY: ULTRASONIC FLOW INSTRUMENT 



\title{
Comments on ANL Ultrasonic Flow Instrument Performance
}

\author{
S. H. Sheen \\ Argonne National Laboratory
}

The comparative instrument performance evaluation test at ORNL was the first "field test" that the ANL ultrasonic flow instrument was evaluated under dynamic conditions. Before the test, our instrument had only been tested for fluid density and viscosity measurements under controlled laboratory conditions. However, based on our past experience in monitoring coal slurry, we were confident that the instrument could also monitor solid concentration through simple ultrasonic attenuation measurement. Thus, when we designed the instrument spool piece, we included the capability of measuring solid concentration in addition to density and viscosity measurements. Because of multiple sensing capability, we had to design a special purpose electronics for signal conditioning. This electronic package was also used for the first time in a field-test environment.

Based on the results obtained during the ORNL test, the problems the ANL instrument encountered were (1) EM interference, (2) baseline drift, (3) wrong values for viscosity and solid concentration, and (4) loss of signals for solid-concentration measurement. Based on our follow-up analysis, we have the following interpretation and remediation :

(1) EMI problem -- The primary EMI source was the mixer motor and we noticed that the EMI pickup was through the cables connecting transducers and the electronic box, very little pickup through the cables from the electronic box to the computer in the control room. Better shielding and grounding will be used to reduce the EMI. And perhaps an additional stage of filter (most likely a narrow band/notch filter) will improve $\mathrm{S} / \mathrm{N}$. It is also possible that the power line voltage fluctuation introduces noise to our electronics. A power isolation system has been purchased and integrated to our system.

(2) Baseline drift -- We noticed that our signal levels varied with the ambient temperature which typically changed more than thirty degrees in a day at the test facility. We are experiencing the similar problem in our lab. And we are conducting various tests to isolate the problem. At present, we believe that some of the carbon-based components (resistors, capacitors) in our control electronic circuit cause the problem. A new circuit board will be fabricated using metal-based components.

(3) Wrong readings for viscosity and solid concentration -- The inaccuracy in viscosity measurement is directly related to the temperature variation. If the baseline drift problem is corrected, we should be able to calibrate the instrument for better consistency. Our instrument was not calibrated for solid-concentration measurement during the test, thus, only relative changes had any meaning. We did measure some relative changes in attenuation for different solid concentrations during some of the tests. 
(4) Solid concentration measurement -- There were cases that our instrument didn't detect any transmitted signals because of high attenuation through the media. The problem may be caused by (a) low input voltage to the transmitter (only 40 volts but that was sufficient for density and viscosity measurements), and (2) excess attenuation due to entrained air bubbles or turbulent eddies (particularly for high flow tests). To increase the input power, we have modified our electronics, the new system can deliver $100 \mathrm{~V}$ to the transmitter. Our ongoing laboratory tests show that freshly prepared Kaolin/sugar water slurries give a high attenuation to $1 \mathrm{MHz}$ signals because of entrained bubbles. However, after most bubbles are driven out, attenuation can be measured a wide range of solid concentration (up to $60 \%$ ). Results from our laboratory tests of Kaolin/sugar-water slurries up to $30 \%$ by weight are shown in the attached figure. In an actual waste slurry, entrained gas bubbles may not be as much as the freshly mixed Kaolin/water slurry. However, we are currently developing a technique that may reduce the bubble content in the sonic sensing volume.

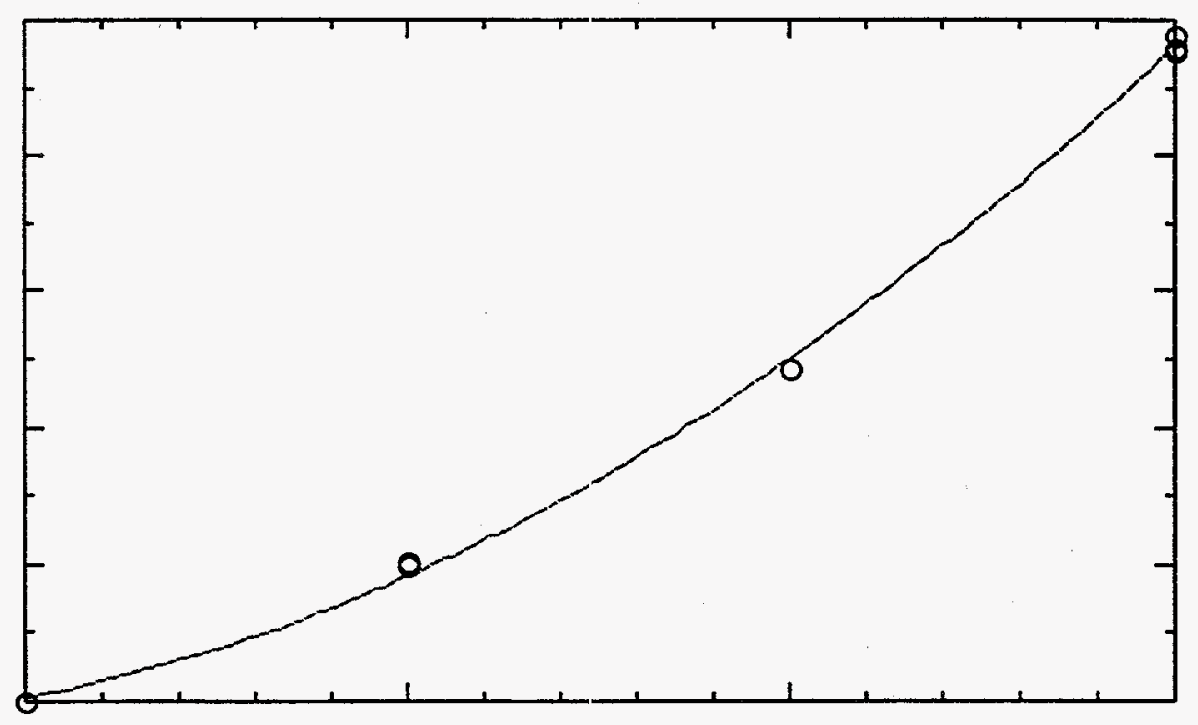

Other minor problems such as computer hard-disk crash and A/D board difficulty can be easily corrected and repaired. In conclusion, we believe that the ANL ultrasonic flow instrument will be able to provide on-line measurements of slurry density, viscosity, and solid concentration, provided that additional field tests can be made for us to calibrate the instrument. 
Appendix D

RESPONSE FROM PACIFIC NORTHWEST NATIONAL LABORATORY: ULTRASONIC REFLECTION COEFFICIENT DENSITOMETER 



\title{
PNNL Ultrasonic Densitometer \\ In-Situ Real-Time Monitoring of Radioactive Slurries in Pipelines and Vessels
}

\author{
Judith A. Bamberger and Margaret S. Greenwood \\ Pacific Northwest National Laboratory
}

The PNNL ultrasonic densitometer (Greenwood 1998) participated in the pipeline tests conducted at ORNL in 1997 and its performance was evaluated by the ORNL team. This text, prepared by the densitometer developers, provides additional detail to support the PNNL ultrasonic densitometer future deployment to measure radioactive slurry density in vessels and pipelines.

\section{Recommendations}

Based on analysis of the data obtained during the pipeline tests at ORNL, the developers recommend that the ultrasonic densitometer be included in the radioactive demonstration to be conducted at ORNL. This recommendation is supported by the analysis of the data taken at ORNL. ${ }^{1}$ The ultrasonic densitometer performance during operation in slurries with and without induced air was very good. The bias for these data was small, $0.04 \mathrm{~g} / \mathrm{ml}$ for slurries without induced air and $0.05 \mathrm{~g} / \mathrm{ml}$ for slurries with induced air. This level of stability is excellent for an in-situ real-time instrument.

Also the ultrasonic densitometer has features that enhance the ability of the sensor to function in slurries with even greater density variation than those investigated during the ORNL transport tests and in both vessels and pipelines. The PNNL ultrasonic densitometer:

- can interrogate extremely dense slurries and settled solids layers because the ultrasonic signal does not penetrate the slurry to evaluate the slurry density.

- $\quad$ simple and compact design allows deployment in short pipe spool pieces $\leq 12$ in. long, or in vessels by insertion of a single sensor probe into the fluid or by embedding the probe in the vessel wall.

- $\quad$ is not affected by electromagnetic noise and can be located in harsh environments such as pump pits or other areas crowded with machinery. These features are not provided by the other probes evaluated during the ORNL test so demonstration of a probe with these unique attributes will strengthen the DOE ability to interrogate dense slurries and sediments in tanks and pipelines.

1 The $25 \mathrm{C}$ data was analyzed as taken and reported by the probe at ORNL. The $50 \mathrm{C}$ data was renormalized after the tests at ORNL to reflect water reference conditions of 50C. These $50 \mathrm{C}$ reference files were not loaded into the probe density evaluation software prior to the $50 \mathrm{C}$ data runs. 


\section{Discussion}

The discussion focuses on three areas: 1) densitometer performance during the pipeline tests at ORNL, 2) recommendations to improve the densitometer accuracy, performance, and ease of operation based on implementation of minor densitometer design and operational improvements developed as a result of developer insight gained from the results of the pipeline demonstration, and 3) probe strengths not directly evaluated during the pipeline tests.

\section{Densitometer Performance During Tests}

The ORNL evaluation used two quantitative measures (bias and variance) and seven qualitative measures (portability, ruggedness, ease of operation, maintenance and training requirements, clarity of output, special requirements, and expected performance if used to monitor transport of radioactive slurry) to evaluate instrument performance during the pipeline evaluation of slurry monitors.

\section{Quantitative Evaluation}

The quantitative measurements of instrument performance were: bias difference between the average of the measurement readings by a slurry monitoring instrument and the accepted reference value, and variance - a measure of the dispersion of replicate measurement readings by a slurry monitoring instrument

The ultrasonic densitometer performance during operation in slurries with and without induced air was very good. The bias for these data was small, $0.04 \mathrm{~g} / \mathrm{ml}$ for slurries without induced air and $0.05 \mathrm{~g} / \mathrm{ml}$ for slurries with induced air. This level of stability is excellent for an in-situ real-time instrument. The standard deviation of the experimental error was also acceptably low. This data is summarized below.

\begin{tabular}{|c|c|c|c|}
\hline \multicolumn{4}{|c|}{ PNNL Ultrasonic Densitometer Statistics } \\
\hline $\begin{array}{l}\text { Average } \\
\text { density bias } \\
\text { (g/ml) for all } \\
\text { experimental } \\
\text { conditions from } \\
\text { Table } 5.2\end{array}$ & $\begin{array}{l}\text { Standard deviation } \\
\text { for density bias } \\
\text { (g/ml) over all } \\
\text { experimental } \\
\text { conditions from } \\
\text { Table } 5.2\end{array}$ & $\begin{array}{l}\text { Standard deviation } \\
\text { of experimental } \\
\text { error }(\mathrm{g} / \mathrm{ml}) \text { for } \\
\text { slurry flow rate } \\
\text { experiment from } \\
\text { Table } 5.5\end{array}$ & $\begin{array}{l}\text { Standard deviation } \\
\text { of experimental } \\
\text { error }(\mathrm{g} / \mathrm{ml}) \text { from } \\
\text { the air effects } \\
\text { experiment from } \\
\text { Table } 5.7\end{array}$ \\
\hline 0.05 & 0.16 & 0.022 & 0.05 \\
\hline
\end{tabular}




\section{Qualitative Evaluation}

The qualitative factors evaluated included: portability, ruggedness, ease of operation, maintenance and training requirements, clarity of output, special requirements, and expected performance if used to monitor transport of radioactive slurry. The PNNL ultrasonic densitometer received maximum ratings ( 3 out of 3 ) for portability, external ruggedness, and output clarity and intermediate ratings ( 2 out of 3 ) for the remainder. Additional information is provided to provide insight to the intermediate ratings that was not available to the ORNL researchers during the pipeline evaluation.

Internal Ruggedness: Early in the pipeline demonstration, the PNNL pipeline probe experienced a sealant failure and fluid leaked into the probe body. To remedy this the probe was returned to the fabricator and a gasket was installed. After this repair no additional problems relating to internal ruggedness were observed. This minor change will provide a major improvement in probe internal ruggedness and will be incorporated into other sensors as they are constructed. Therefore, based on the majority of the experiments conducted after probe repair, the probe developers estimate that the probe performed at the maximum rating ( 3 out of 3 ).

Installation: The PNNL sensor was manufactured as a pipe spool piece to be installed between two matching flanges. The probe installation was extremely simple. The probe developers rate this simplicity as 3 out of 3 .

The PNNL computer control system interfaces with the probe using 8 color coded leads connected to the top of the probe. For a field installation these leads could be encased into a plug that would mate with the top of the probe and the computer control system. This change would simplify probe connection in the field and increase its ruggedness. The probe developers rate this connection scheme as 3 out of 3 .

Maintenance and Operating Cost: During operation at ORNL the PNNL density sensor required some manual set up to adjust signal gains. Due to timing of the ultrasonic densitometer delivery to ORNL the ability to automatically set the signal gain was not incorporated into the density probe computer software. However, PNNL provided two probes for test at ORNL. The second probe, the particle size probe, did incorporate logic to automatically set the signal gain during probe operation.

Incorporating this method into the density sensor software would significantly reduce the operator attention to the sensor during operation. Incorporation of this logic would provide a "plug and play" device. This "plug and play" designation would reduce the probe operating cost by significantly reducing the need for operator interface. The probe developers rate incorporation of the automatic gain setting algorithm (that was already tested successfully at ORNL during the pipeline demonstration with a separate 
sensor) as improving the maintenance and operating cost evaluations to a level of 3 out of 3 .

\section{Recommended Densitometer Improvements Based on Pipeline Test Performance}

Based on the results of the ultrasonic densitometer pipeline demonstration at ORNL and brainstorming, an improved probe configuration that provides real-time online calibration was designed. It is proposed that these improvements also be incorporated into ultrasonic densitometer configurations deployed in future.

This new design has the following advantages:

1) provides real-time calibration using a temperature matched reference condition

2) provides a more compact probe design

3) operates with the same printed circuit board in the same computer as the probe evaluated at ORNL

4) reduces operator interface via automated set up and calibration.

5) increases probe accuracy based on the improved probe design.

On-line calibration requires a new design for the wedge but no other substantial changes to the current system. There is a simplicity to this new design that is very appealing!

\section{Real-Time Calibration}

Figures 1 and 2 illustrate the design of the revised rexolite ${ }^{\mathrm{tm}}$ wedge that can provide on-line calibration. The new design incorporates two nearly-identical sections, each with identical path length of the central ray for a given transducer. In the left section the ultrasound interrogates the slurry properties by striking the base immersed in the slurry. In the right section the ultrasound strikes air to provide the reference condition; an area has been milled out of the base to form an air pocket $(0.72$ in. long $x$ 0.41 in. wide $x 0.06$ in. deep). A stainless steel plate is sealed to the probe bottom to maintain the air pocket. The ultrasound strikes the top surface of the air pocket where it is reflected; ultrasound is not transmitted into the air pocket. By having the right section also immersed in the slurry the temperature distributions in the left and right sections are expected to be very close. That is the key feature of this new design.

The new probe goal is to obtain experimentally the reflection coefficients at $0^{\circ}$ and at $60^{\circ}$ so that the density and speed of sound in the slurry can be determined as described in Section 2.2.1. The reflection coefficients for a given incident angle are obtained from:

$$
\mathrm{RC}_{\text {exp }}=\left(\mathrm{V}_{\text {slurry }} / \mathrm{V}_{\text {ref }}\right)\left(\mathrm{RC}_{\text {ref }}\right)
$$


The reflection coefficient $\mathrm{RC}_{\mathrm{ref}}$ for the reference, air in this case, is calculated theoretically. In Equation 1 the voltage from the left section of the wedge is substituted for $\mathrm{V}_{\text {slurry }}$ and that from the right section, for $\mathrm{V}_{\text {ref }}$.
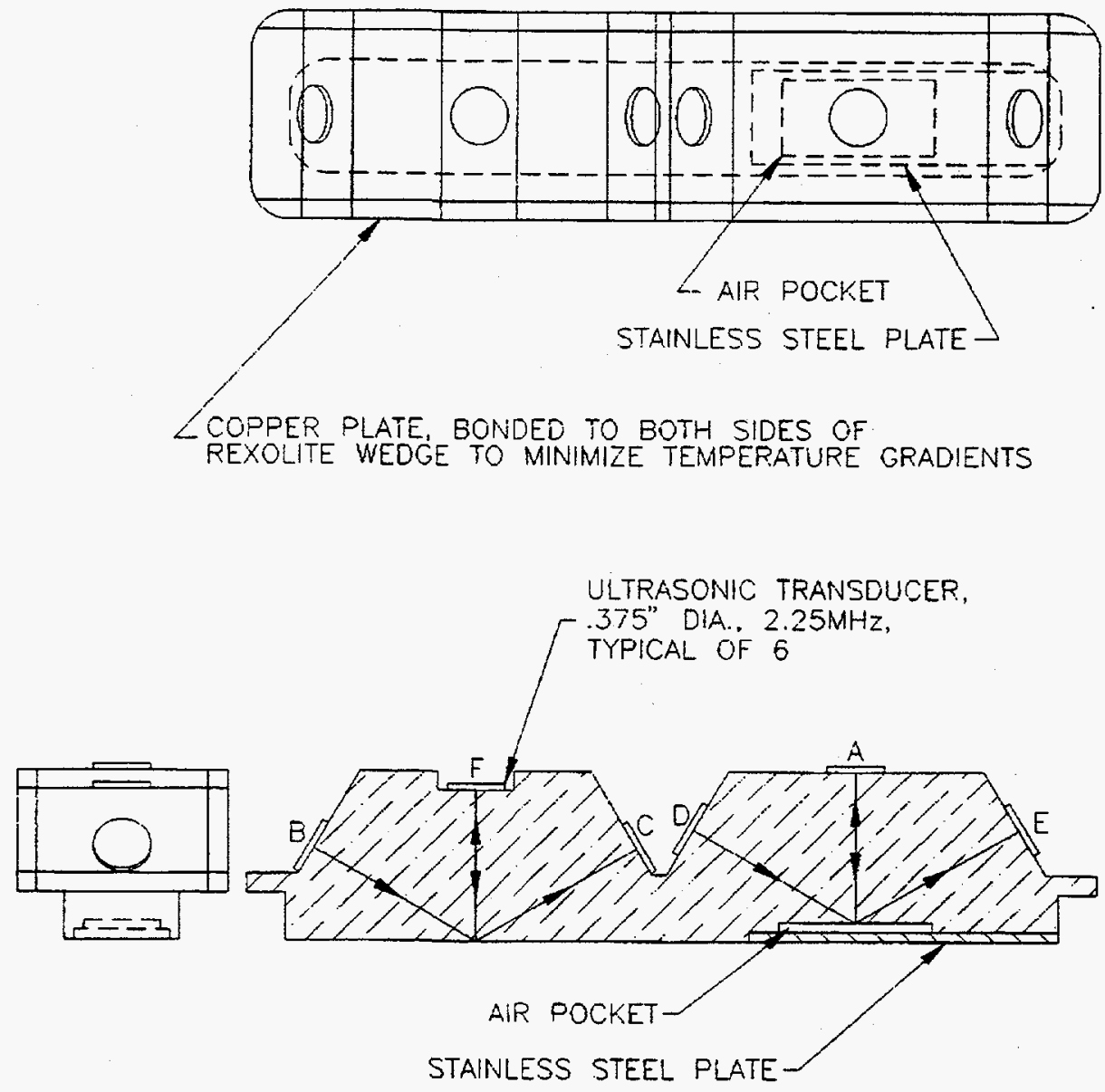

Figure 1. Ultrasonic density transducer wedge

\section{Compact Design}

By reducing the size of the wedge, this improved design provides a more uniform temperature distribution. For example, in Figure 1 the distance between transducer $\mathrm{F}$ and the wedge base is $1 \mathrm{in}$. This dimension was reduced from $1.8 \mathrm{in}$. in the wedge configuration tested at ORNL. In order that the distance from the transducer to the base exceed the near-field distance of the transducer, the diameter of the 2.25 $\mathrm{MHz}$ transducers was changed to $0.375 \mathrm{in}$. (from $0.5 \mathrm{in}$.). (The near field region of a transducer is characterized by regions of constructive and destructive interference. Beyond the near field distance the ultrasound has a uniform distribution.) 

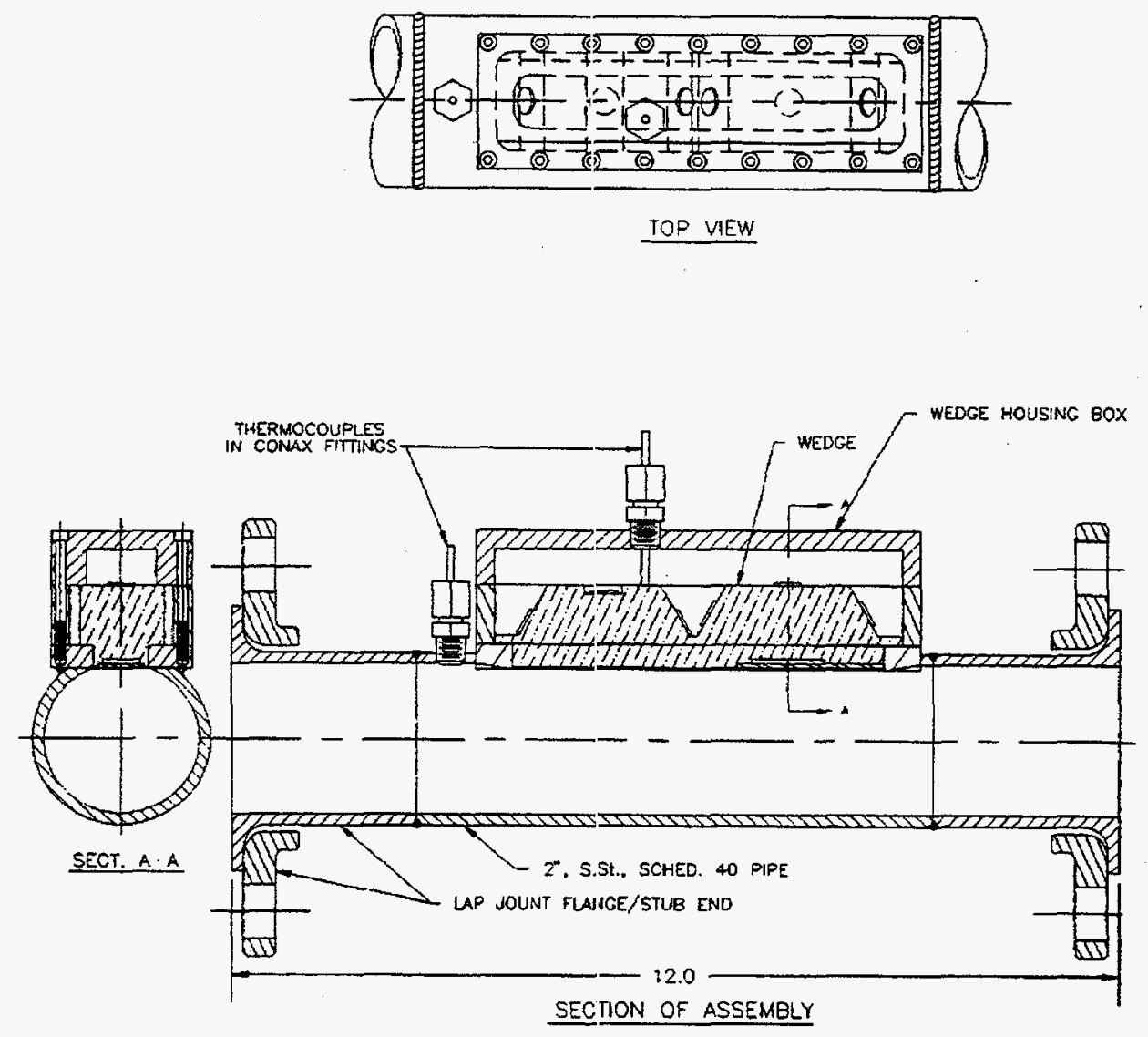

Figure 2. Ultrasonic densitometer installed in pipeline spoolpiece

Figure 2 shows the wedge mounted in a pipe spoolpiece. In the original design for the ORNL tests, an opening $3.75 \mathrm{in.}$ long and $0.75 \mathrm{in}$. wide was made in the pipe wall. The width of the wedge was 1.25 in. For the new design an opening of 5 in. $x$ $0.75 \mathrm{in}$. is needed in the pipe wall and the rexolite wedge would also be $1.25 \mathrm{in}$. in width. To aid temperature uniformity, copper plate bonded with heat conducting epoxy will be placed on the large side surfaces.

The diagram of the wedge in Figure 2-4 (of this report) shows six transducers mounted on a single wedge. In addition to the $0^{\circ}$ and $60^{\circ}$ transducers, there is a $0^{\circ}$ shear wave transducer and a pair of transducers at $42^{\circ}$. Why are these not included in the improved design shown in Figure 1? The shear wave transducer was used primarily to measure the speed of the shear wave in rexolite as a function of temperature and the voltage was not used in determining the density. In the code used at ORNL the data from the $42^{\circ}$ transducers were used to determine the sign of the reflection coefficient. The importance of the sign can be seen from the equation for the reflection coefficient at $0^{\circ}$, which is given by:

$$
\operatorname{RC}\left(0^{\circ}\right)=\left(Z_{\text {liq }}-Z_{\text {wedge }}\right) /\left(Z_{\text {liq }}+Z_{\text {widge }}\right)
$$


where $Z$, called the acoustic impedance, is defined as the product of the density and the speed of sound in that medium. If $Z_{\text {liq }}$ is less than $Z_{\text {wedge }}$, then the reflection coefficient will be negative. This means that upon reflection the wave will undergo a $180^{\circ}$ phase change. If $Z_{\text {liq }}$ is greater than $Z_{\text {wedge }}$, the reflection coefficient will be positive and the wave will not undergo a phase change. The voltage measurements will give the absolute magnitude of the reflection coefficient, but not its sign. This means that, if the liquid properties are unknown, then one cannot know if $Z_{\text {liq }}$ is larger or smaller than $\mathrm{Z}_{\text {wedge. }}$. In the code used at ORNL, the reflection coefficient at $42^{\circ}$ was used to distinguish between the two possible cases.

In the new design the sign of the reflection coefficient will be measured by noting a phase change between the signal reflected from the air pocket and that reflected from the slurry. When ultrasound reflects from the air pocket, the reflection coefficient for all angles is negative. Figure 3 shows the signal reflected from the air pocket and Figure 4 shows that reflected from the slurry. A cursor shows that, at a given time, the signal in Figure 4 is "flipped about the horizontal axis." Since the signal in Figure 3 has a negative reflection coefficient, that in Figure 4, must have a positive reflection coefficient.

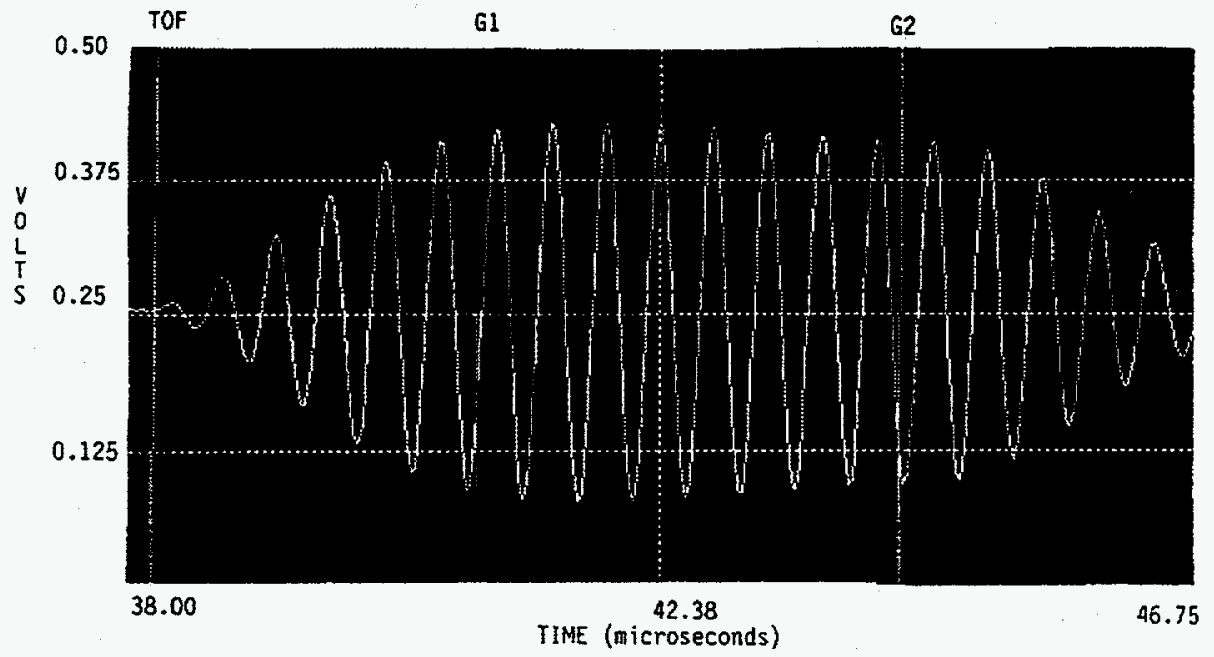

Figure 3. Signal on computer monitor when base of wedge in air.

A slight modification to the software would be needed for the phase determination. In fact, a version of that software already exists because it was used in the laboratory studies. But when automation of the data acquisition was necessary at ORNL, we decided to use the reflection coefficient at $42^{\circ}$ instead to determine the sign. In the revised version we have two signals at hand that we can compare to provide this data. 


\section{Operates with the Same Printed Circuitry}

It is important to note that the original printed circuit board contained four channels: two pulse-echo (F/F and $A / A)$ channels and two pitch-catch $(B / C$ and $D / E)$ channels. The same is required for the new design. So no changes are need to the printed circuit board.

The experimental setup and data acquisition software is obviously also set up for four channels. On-line calibration requires a new design for the wedge but no other substantial changes to the current system.

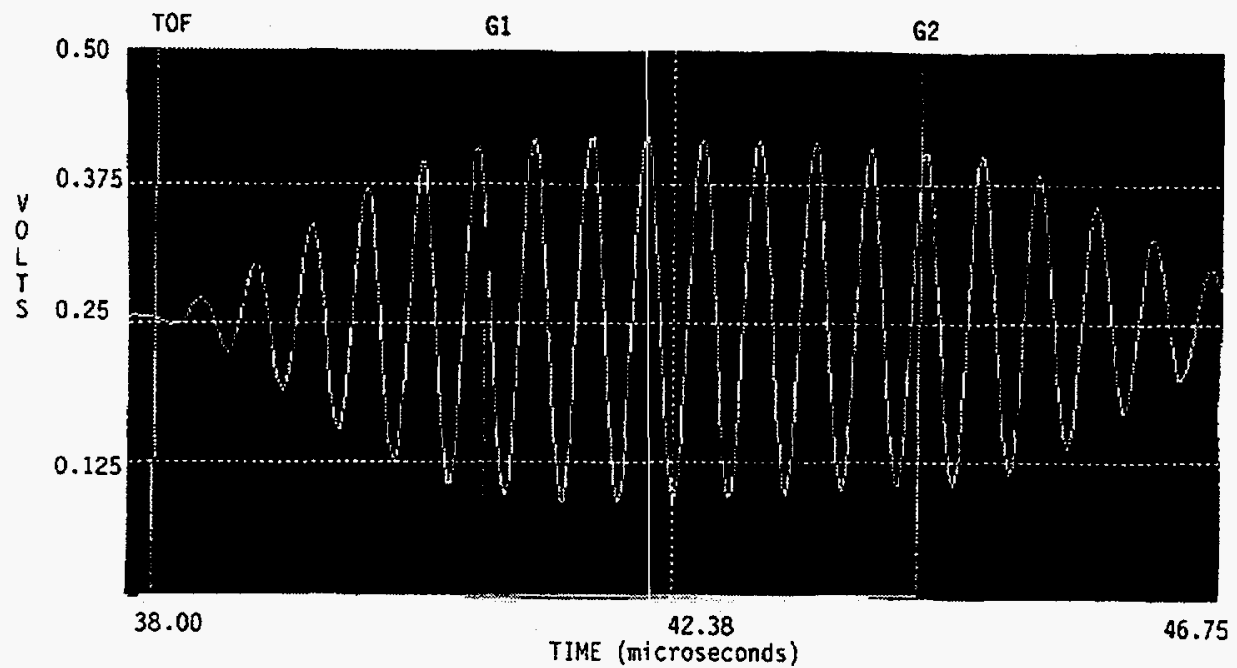

Figure 4. Signal on computer monitor when base of wedge is immersed in water.

Figures 3 and 4 show a signal appearing on the computer monitor. The cursors TOF (time-of-flight), G1, and G2 are set by the operator. The basic data are the maximum voltage of the signal between the clursors G1 and G2 and the time-of flight using the TOF gate. Even with changes in temperature, these three cursors positions are changed very little. In the tests at ORNL, the operator had to check the amplifier gain at the beginning of each run to ensure that peak signal was between 0.25 and 0.45 volts for the four channels. However, the setup just described can be carried out automatically using software. Since PNNL had two instruments participating in these tests, time constraints did not permit us implement this for the density sensor. However, a similar auto-setup was employed for the particle size sensor.

\section{Probe Repeatability and Accuracy}

In order for the sensor to give accurate values of the density, the voltage values must be repeatable. In order to test repeatability, data were obtained from October 6 through October 20, 1997 for water and air for the tank probe (because it was more 
convenient to use). The computer was turned off at night, turned on in the morning, and allowed to warm up for at least 2 hours. (The computer at ORNL was always turned on.) Data were obtained several times during the day. For transducer $\mathrm{F}$, in which ultrasound strikes the base perpendicularly, the results for 15 measurements for water at room temperature $(20.4 \pm 0.5 \mathrm{C})$ showed an average voltage of 0.357074 volts with a standard deviation of 0.002543 volts. These results shows that the reference voltages are repeatable within $0.7 \%$.

Table 1 shows data obtained in the laboratory at PNNL. Usually the water reference values were obtained first and substituted into the computer code and then the data for the liquid or slurry density were obtained. The error when compared to density obtained by weighing is very small (called measured density in Table 1). Table 1 represents the accuracy of the data that can be obtained with the new design because the voltage measurements for the slurry and reference will be obtained on-line.

Table 1. Density of liquids and slurries obtained from ultrasonic sensor compared with a direct measurement of the density. "SW" refers to sugar water solution. " $\mathrm{K}$ " refers to a slurry obtained by mixing kaolin (10 micron diameter) in a sugar water solution $50 \%$ by weight. "KS" refers to a slurry obtained by mixing kaolin and sand in a sugar water solution $50 \%$ by weight.

\begin{tabular}{||l|l|l|l||}
\hline \hline Liquid & Sensor Density & Measured Density & Percent Error \\
\hline & $\mathrm{g} / \mathrm{cm}^{3}$ & $\mathrm{~g} / \mathrm{cm}^{3}$ & \\
\hline SW1A & 1.010 & 1.016 & 0.6 \\
SW2A & 1.028 & 1.035 & 0.7 \\
SW3A & 1.045 & 1.052 & 0.7 \\
SW4A & 1.069 & 1.069 & 0.0 \\
SW5A & 1.095 & 1.099 & 0.4 \\
SW40 & 1.185 & 1.180 & 0.4 \\
SW50 & 1.222 & 1.220 & 0.2 \\
SW60 & 1.295 & 1.280 & 1.2 \\
K15 & 1.373 & 1.341 & 2.4 \\
K20 & 1.396 & 1.373 & 1.7 \\
KS10 & 1.345 & 1.335 & 0.7 \\
\hline
\end{tabular}

\section{Probe Attributes Not Evaluated During the Pipeline Tests}

Several attributes of the PNNL ultrasonic densitometer sensor were not directly evaluated during the pipeline tests. These attributes: operation over a greater density 
range to detect slurries and settled solids layers, a simple, compact design for deployment in short spool pieces and immersed in vessels or located in vessel walls; and the ability to operate in harsh, noise-filled environments are useful for successful deployment in radioactive environments during radioactive waste retrieval. Therefore, they are discussed further.

- The PNNL ultrasonic densitometer can interrogate extremely dense slurries and settled solids layers because the ultrasonic signal does not penetrate the slurry to evaluate the slurry density.

The sensor operates using signal reflection at the slurry probe interface instead of signal penetration. Therefore the sensor can evaluate the properties of slurries higher in concentration than those evaluated during the ORNL tests and can detect the presence of a settled solids layer. These are features not evaluated during the ORNL tests; however, the ability to detect in these ranges would enhance slurry characterization during radioactive waste transport and during tank mixing. Also the sensor can interrogate more dense slurries than ultrasonic probes that operate by sending a signal through the slurry to a receiver across the diameter of the pipe.

- The PNNL ultrasonic densitometer design is simple and compact and can be deployed to measure slurry density in vessels by insertion of a single sensor probe or by embedding the probe in the vessel wall.

The compact configuration means that the probe can be installed on pipelines in crowded locations where other instrumentation would not fit. The vessel probe design requires only one face to contact the slurry because the sensor operates using the signal reflected at the probe slurry interface instead of requiring a second sensor to receive the signal that penetrates through the slurry.

- The ultrasonic sensor is not affected by the electromagnetic noise that affected some sensors evaluated during the pipeline test.

The ability to function in areas of high noise allows the system to be co-located in pump pits or areas where other machinery operate in close proximity. This ability permits successful probe deployment in areas where other sensors could not be used reliably.

\section{References}

Greenwood, MS. 1998. Ultrasonic Fluid Densitometry and Densitometer, US Patent 5,708,191 issued January 13, 1998. 
Appendix E

RESPONSE FROM SANDIA NATIONAL LABORATORY: QUARTZ RESONATOR INSTRUMENT 


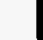




\title{
The Sandia National Laboratories Prototype Slurry Density-Viscosity Monitoring System
}

\author{
by \\ Richard W. Cernosek \\ Microsensor Research \& Development Department \\ Sandia National Laboratories, Albuquerque, NM
}

The Sandia prototype slurry density-viscosity monitoring system (shown photographically and schematically in Figures 1 and 2) delivered for evaluation at Oak Ridge National Laboratory is based on a mature quartz resonator technology. Significant laboratory development has occurred to mature this technology, and in recent years several field tests of other prototype systems have helped advance its use. This prototype system and the subsequent evaluation is unique in that (1) the exposure environment is much more severe than any others experienced and (2) the need to make absolute bulk viscosity measurements and the calibration of the instrument for that application. Following evaluation at the ORNL Comparative Testing of Slurry Monitors, we conclude that this technology, in its present state of development, has very limited use as a slurry absolute viscosity measurement instrument but is a unique tool for real-time, in situ monitoring of dynamic slurry viscous properties. The contents of this report detail the system and technology performance limitations and advantages based on the ORNL evaluations while offering comments in response to particular test occurrences.

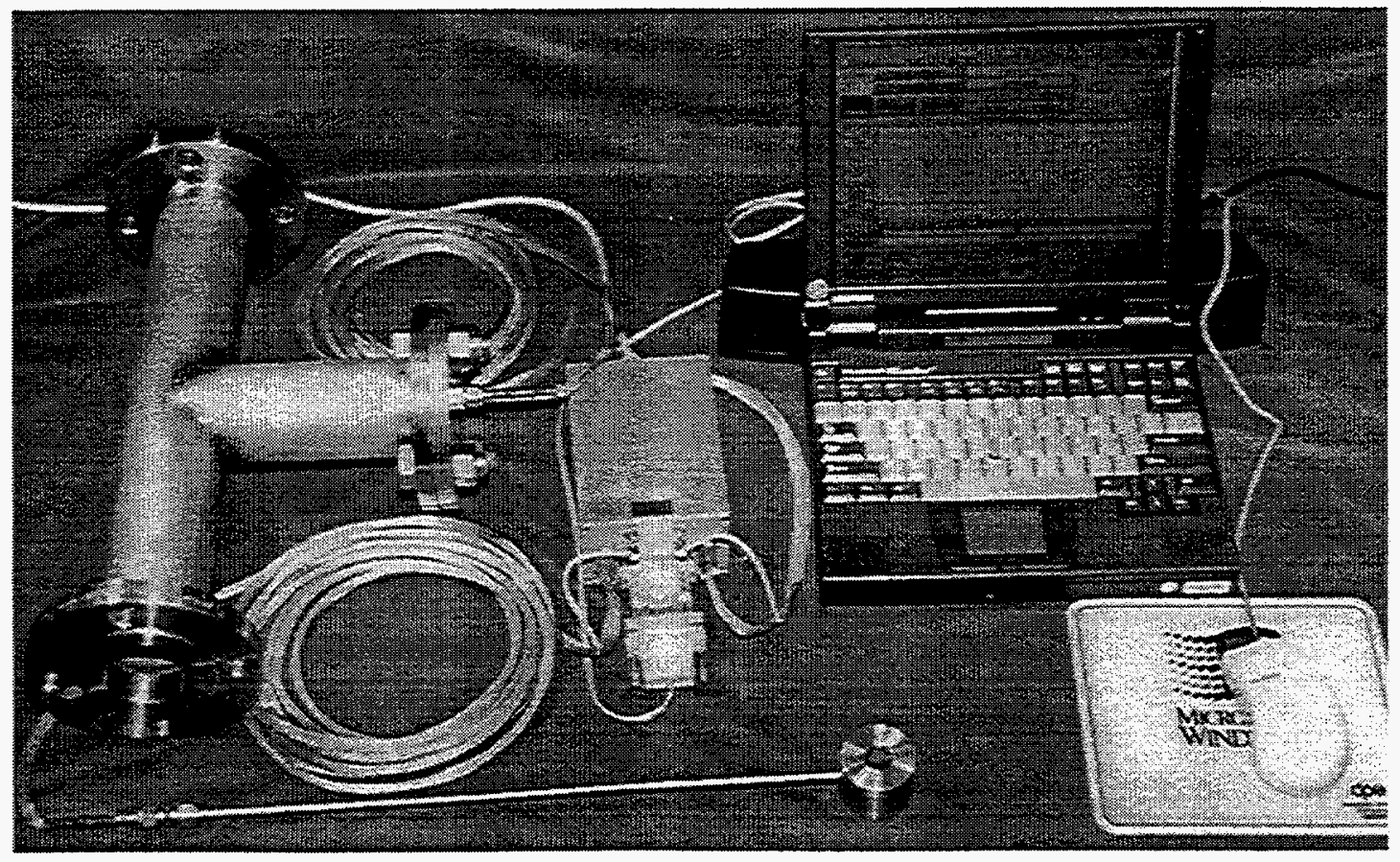

Figure 1. Photograph of the Sandia prototype slurry density-viscosity monitoring system. The system consists of two sensor probes, one for in situ monitoring in the slurry reservoir (bottom) and one for in-line monitoring in the flow loop (mounted in the spool piece at left); an interface electronic module (center); and a notebook computer (right). 


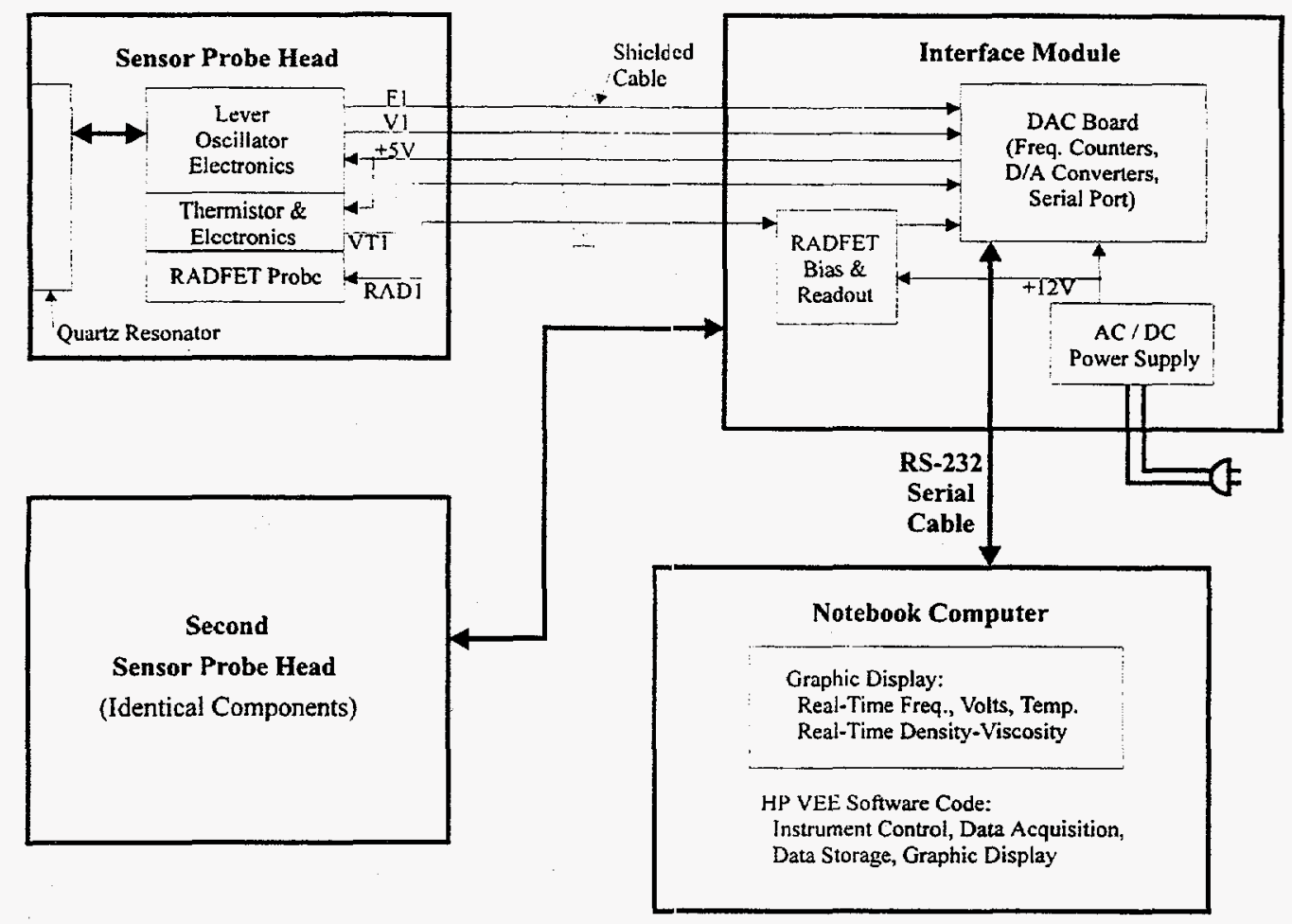

Figure 2. A block schematic showing the major components of the prototype slurry density-viscosity monitoring system. Both sensor probes functioned identically, though each was independently calibrated. The RADFET gamma detectors were operational but not needed since no radioactive slurries were tested.

\section{Performance Limitations}

Many of the limitations of the prototype density-viscosity monitoring system are due to the inherent properties of the quartz crystal resonator. Measuring viscosity requires moving a surface through a fluid and then determining the resistance to that movement. The quartz resonator accomplishes this task by placing the crystal into shear mechanical resonance and viscously-entraining the contacting fluid. Movement of the fluid is microscopic (crystal surface displacements on a nanometer scale) with shear wave decay length of a few micrometers. Effectively, a boundary layer measurement is made. Because of this shallow acoustic wave peretration, three limitations exist in slurry monitoring:

1. A bulk density-viscosity or viscosity measurement cannot be made. It is always assumed that a measurement of fluid properties made at the quartz crystal surface is representative of the bulk, i.e., the fluid is completely homogeneous.

2. Large suspended solid particles in the sluriy are only partially sheared by the moving surface and fluid. Particles with mean diameter much greater than the shear wave decay length are least "seen" by the resonator, and there is a tendency for the vibrating quartz surface to move the fluid around the particle and measure a lower viscosity associated only with the liquid. Thus, a diminished absolute response is often determined for slurries with solid particle sizes $>>10 \mu \mathrm{m}$ and for solid concentrations $>20 \%$.

3. Depositions and solid layers on the crystal surface skew the sensor response away 
from an absolute calibration. Any surface perturbation will illicit a response, and there are differences between viscous interactions due to liquids and synchronous movement due to solid deposits. In these slurry evaluations, often thick sludge layers built up on the sensor surface masking the ability to determine flowing slurry properties. Kaolin clay, as well as other fine solid particulates, has a high affinity for surface deposition.

All of these effects were observed during slurry testing at ORNL, and limited the instrument's ability to make a calibrated absolute density-viscosity measurement. Conversely, the resonator's ability to measure solid depositions allowed the instrument to monitor sucrose precipitation from high concentration solutions as the temperature dropped significantly between some test runs. These activities were of little interest to the ORNL test evaluators, but had tremendous impact on subsequent operation of the sensor system as the depositions rarely returned to solution.

Other limitations of this measurement system were also noted during the comparative testing of slurry monitors:

- The quartz resonators respond differently to non-Newtonian or shear-dependent fluids than to Newtonian fluids. A more complex system could be designed and calibrated to measure the non-Newtonian properties, but the development of such a system did not fit into the time schedule of this evaluation project. Many of the slurry simulants were non-Newtonian. The ORNL test team attempted to account for these effects by determining reference viscosity at specified shear rates, but that only partially addressed the concern.

- Part of the quartz resonator system calibration requires measurement of resonant parameters with the sensing surface unperturbed, i.e., operating in air. Once the sensor probes have been submersed in fluid, complete recalibration is not possible unless the probes are removed, cleaned, and dried. Only partial calibration can be accomplished in process, and then only if a known fluid is contacting the crystal surface.

- Abrasive slurries will eventually remove material from the resonator surface. Since the sensor response is directly mass dependent, any material removal is a bias on the system calibration. Fortunately, significant erosion was not a problem during these evaluations, and surface treatments are available to protect the crystals should future applications require them.

- Static pressures greater than $40 \mathrm{psi}$ shift the sensor response baseline of the quartz resonators. Since the crystals are piezoelectric, they have some inherent sensitivity to mechanical forces at the surface. Optimum implementations of the resonators for density-viscosity measurement calls for a configuration with air on the back surface of the thin crystal. Under fluid pressure, the crystal bends and eventually will fracture. The high pressure operation requirement for these evaluations was one we learned late in the system design process, so a quick-fix was implemented. A backing plate support allowed survivability of the crystal to $>160$ psi (verified in lab testing) but calibrated response was possible only to $\sim 40$ psi. Static pressures during the ORNL evaluations were stated as never exceeding 75 psi. However, significant pressure transients occurred at times during operations and were recorded qualitatively by the Sandia sensors (see transient plots later in this report). The crystal inside the in-line 
probe eventually fractured, and post-test inspection showed significant mechanical displacement of hardware in the spool piece. It was estimated that transient overpressures could have been as large as several hundred psi.

Most of the limitations listed in the above paragraphs can be overcome with additional development engineering. Sandia is alrealdy investigating new quartz resonator implementations for high pressure applications.

\section{Performance Advantages}

One of the big advantages of utilizing the Sandia quartz resonator technology for densityviscosity determination is the ability to implement in situ and in-line sensor probes for numerous tank or transport line applications. This puts the probe directly at the location for the desired measurement. Additionally, the sensor probes are small and inexpensive so that multiple sensors operated with a single system can be distributed for viscous property mapping.

Sensor response is fast and density-viscosity determination is rapid, leading to a system that provides real-time evaluation of slurry behavior. The prototype monitoring system recorded data during evaluation at intervals of 30 seconds or shorter. On most occasions, the Sandia system was allowed to run continuously. This enabled real-time information to be gathered not only during test runs but at critical times in between. It was during these periods of continuous operation that interesting real-time and transient results were observed. Some of these responses are shown in Figures 3 through 7 and are explained in detail below.

- Viscosity varies nonlinearly with temperature, so a measure of the slurry densityviscosity is a strong indicator of temperature-dependent effects. Figures 3 and 4 show the response of the Sandia sensor probe \#1 (the in situ tank or reservoir monitor) during two distinct recording intervals. Bcth plots show the gradual transition of test temperature from $\sim 25^{\circ} \mathrm{C}$ to $\sim 50{ }^{\circ} \mathrm{C}$. Both plots also show the degree of thermal control provided by the ORNL test systern; temperature fluctuations about $50^{\circ} \mathrm{C}$ is typically 2 to $3{ }^{\circ} \mathrm{C}$. Because the viscosity of the $60 \%$ by wt. sucrose solution is much greater than for the $50 \%$ solution, the change in sensor response during temperature excursions is much greater in Figure 4 compared to the shifts shown in Figure 3. These observations are enhanced by the built-in temperature sensors provided in the probe heads. Their primary function is for calibration corrections due to temperatureinduced effects in the quartz crystals, oscillator electronics, and contacting slurries.

- The density-viscosity sensors easily track the transient changes in sucrose solution concentrations. In Figure 5, the measured response from sensor \#1 changes as the sucrose concentration is adjusted from $50 \%$ by wt. in water to $60 \%$. Several sucrose additions were needed to accomplish the transition for test purposes, and the step-like response shifts indicate such. The slow decline in response following each sharp increase is due to the continuous increase in temperature and the dilution of the sucrose concentration as it is pumped through the test loop. The homogeneity of the sucrose/water solutions allows for very precise measurement of the transient viscous property changes. Slurries containing the kaolin clay and larger particulates were not as easily monitored. 


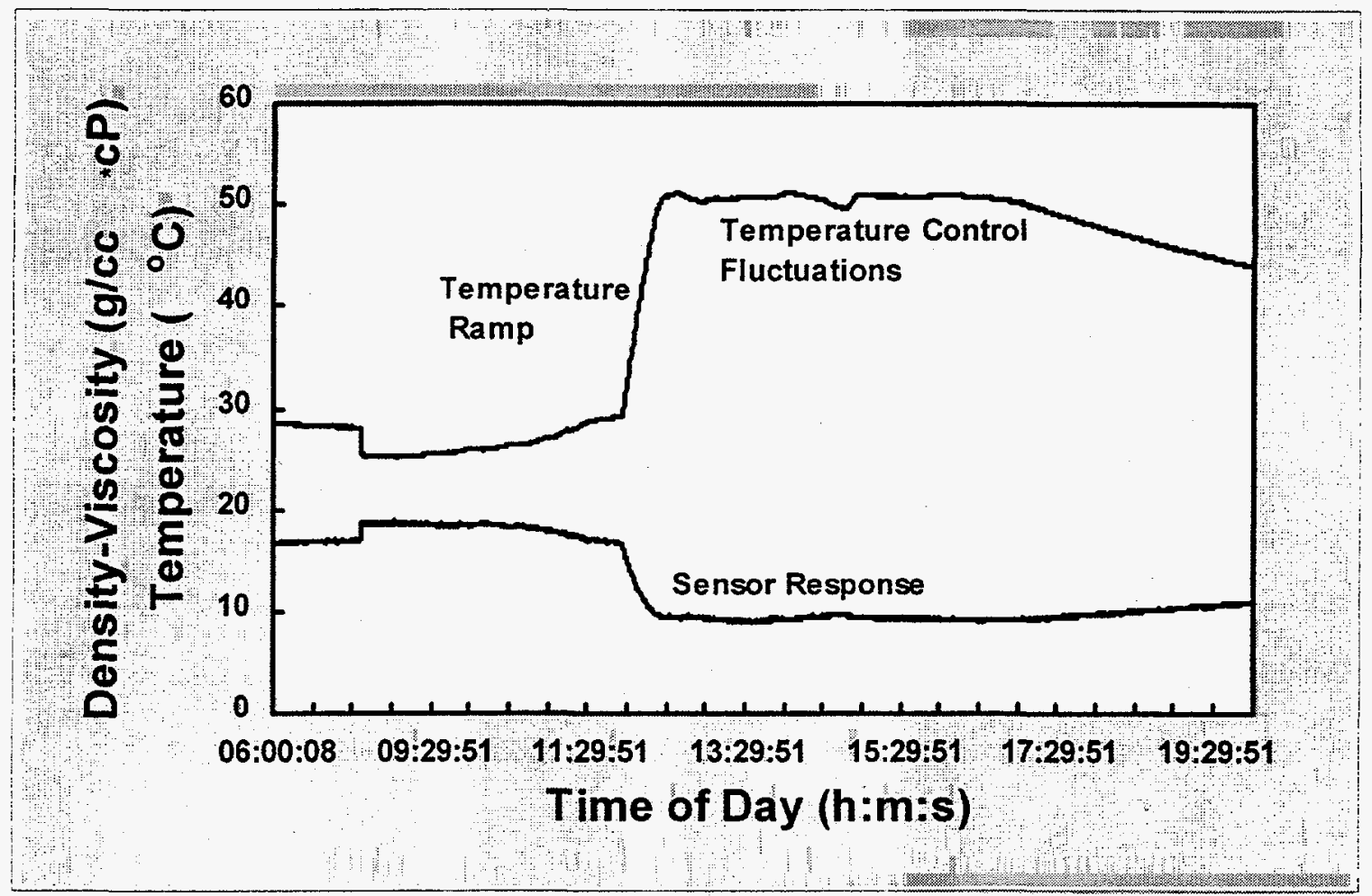

Figure 3. The measured real-time response of sensor \#1 (tank probe) and the corresponding temperature for a $13 \frac{1}{2}$-hour segment on June 25,1997 . The slurry used was $50 \%$ by weight sucrose in water. This segment shows the change in slurry viscous parameters during large temperature excursions.

- The transient effects due to pressure changes in the flow loop are illustrated by the measurements shown in Figure 6. In this plot, the two curves both represent the density-viscosity response measured for sensor \#2 (the in-line sensor probe), with the top curve extracted from the oscillator voltage shift and the lower curve extract from the frequency shift. The frequency-related measurement obviously is more sensitive to pressure deviations and flow effects, while the voltage-related measurement is less sensitive. This is expected since voltage shifts are direct indications of changes in fluid viscous properties. To first order, the quartz resonators are not affected by fluid flow. The deviations observed in Figure 6 are due to small pressure drops created by the moving fluid, velocity-dependent viscosity nonlinearities, and most-importantly the high static operating pressures of the pumped liquids. The large response spikes in the density-viscosity computed from the frequency shifts are created by pressure transients occurring between changes in flow rates. These transients are estimated to be as large as several hundred psi with some having durations of a minute or more.

- The quartz resonator sensors have the ability to distinguish the phase of contacting materials as each illicits a unique frequency and voltage response. Typically, phase transitions are easily detected by the resonators as response shifts are large and abrupt. In Figure 7 the response from sensor \#2 shows clearly the transient signals due to air injected into a slurry of kaolin/sucrose/water. As the entrained air bubbles stream past the sensor, they change both the fluid density and viscosity. The sensor capabilities are limited, however, as the two air injection rates used during the test 


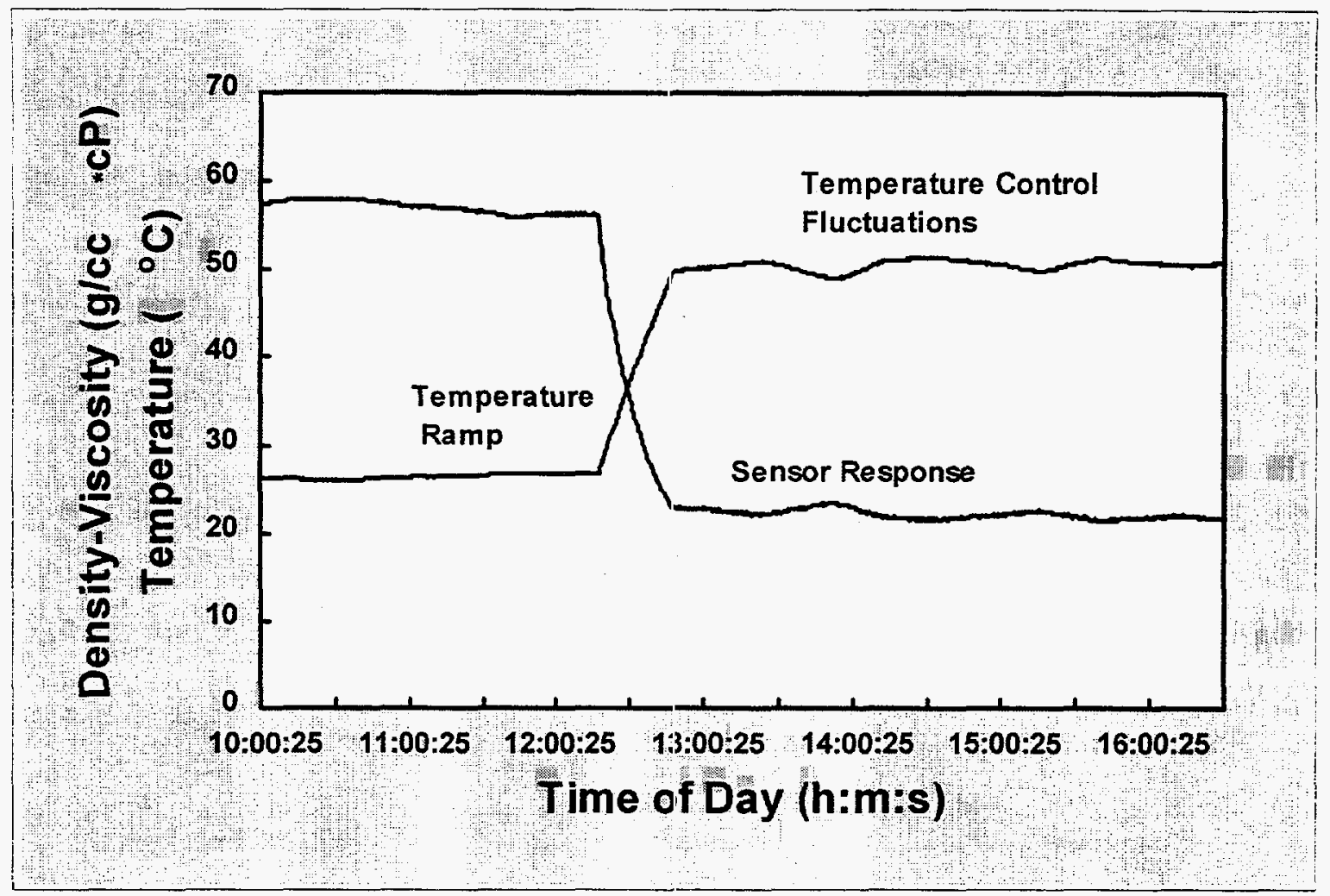

Figure 4. The measured real-time response of sensor \#1 (tank probe) and the corresponding temperature for a $6 \frac{1}{2}$-hour segment on June 27,1997 . The slurry used was $60 \%$ by weight sucrose in water. This segment illustrates how the sensor follows small slurry viscosity changes during temperature fluctuations about $50^{\circ} \mathrm{C}$ induced by the thermal control system.

run, $0.33 \mathrm{scfm}$ and $0.66 \mathrm{scfm}$, cannot be distinguished in the sensor response. At the time of this test, the thick slurry had forced the sensor operation into an anomalous (and uncalibrated) mode, such that the indicated absolute density-viscosity was quite high. This state of operation, however, did not prohibit the observation of transient effects induced by the aeration.

Significant development engineering went into the Sandia prototype system, which contributed to the robust configuration of the probes and interface electronics and the user-friendly operation of the total instrument. Aside from the few pressure problems associated with sensor \#2 in the flow line, no other significant operational glitches occurred. The system was designed to offer the test operators ease of installation, boot-up and continuous instrument diagnostics, and full, real-time numeric and graphic display of all sensor responses. This advanced level of instrument operation is a reflection of the mature state of the resonator technology and the associated engineering development.

\section{System Calibrations}

Extensive calibrations were performed on the Sandia prototype monitoring system prior to delivery for the comparative testing. In the laboratory, each sensor probe was exposed to a wide range of temperatures and fluid densities and viscosities so complete mathematical correction factors for responses could be generated. As indicated in previous discussions, several influencing factors can shift the operating baseline and skew 


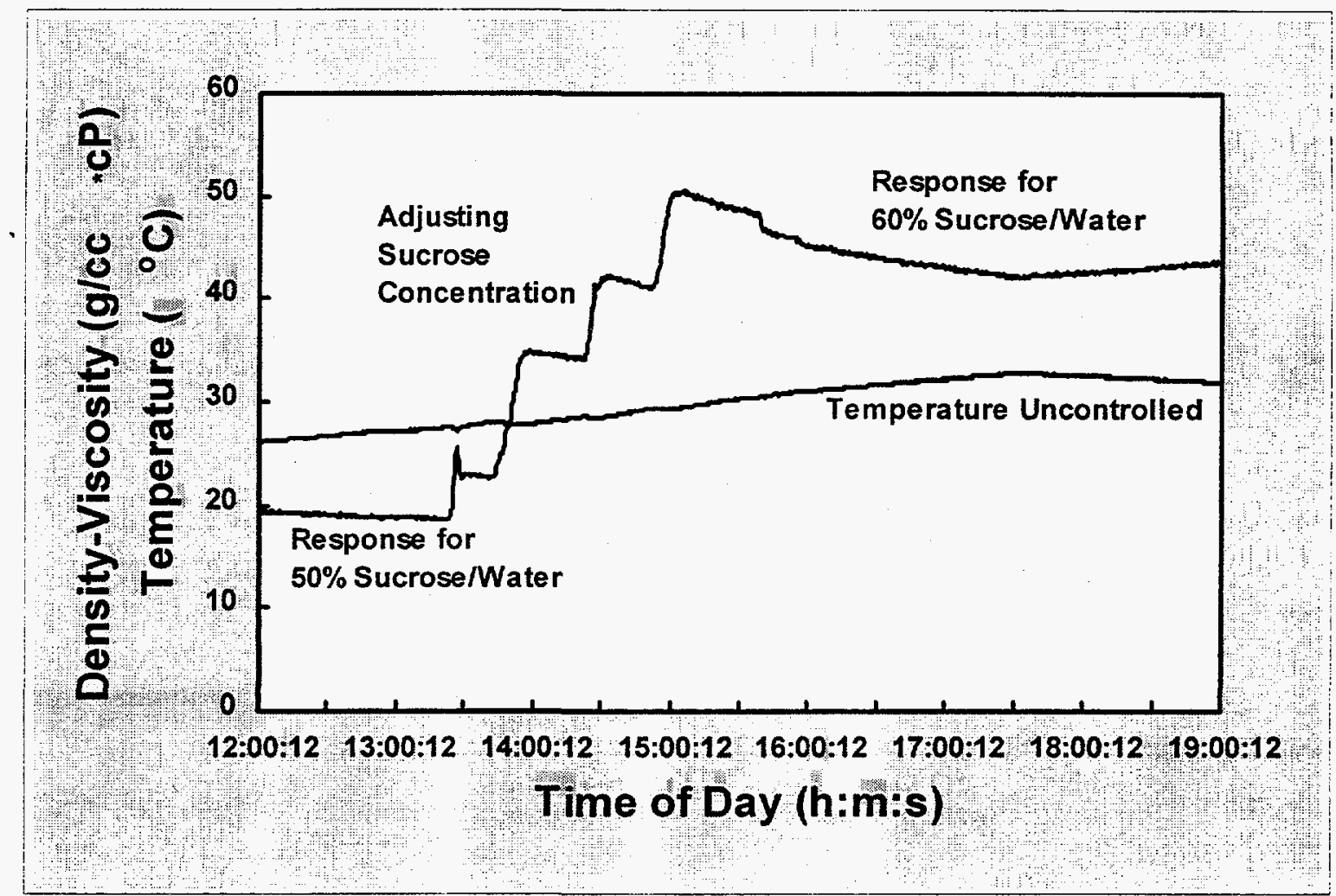

Figure 5. The measured real-time response of sensor \#1 (tank probe) and the corresponding temperature for a 7-hour segment on June 26, 1997. The slurry concentration was increased from $50 \%$ by weight sucrose in water to $60 \%$. The sensor response shows clearly the step changes as sucrose is added and the dilution that occurs as the slurry is pumped around the loop.

the calibration permanently. Still other factors can interfere with responses to mask proper operation and deviate measurements from the intended calibrated values. In a series of post-test analyses on sensor \#1, it was determined that throughout the slurry testing period at ORNL no permanent shifts in system calibration occurred, but the interference from several slurry effects prohibited adequate determination of absolute bulk density-viscosity. A similar analysis of sensor \#2 was not possible since the resonator crystal fractured near the end of slurry testing.

A summary of the calibration and operational analysis on sensor \#1 is presented in Table I. Detailed there are the instrument density-viscosity values, computed from both the frequency and voltage measurements, when the sensor probe was operated in air or submersed in water during different stages of the instrument evaluation. Initial checks in the laboratory at Sandia following instrument calibration indicated that proper values of density-viscosity were measured. [Accuracy for the instrument was stated as $\pm 10 \%$ for fluids with viscosities between $2 \mathrm{cP}$ and $140 \mathrm{cP}$ and measured at a temperature of $20^{\circ} \mathrm{C}$. For viscosities outside the stated range and for higher temperatures, the accuracy would not be quite as good; an estimate of the accuracy over the extended ranges $15^{\circ} \mathrm{C}<\mathrm{T}<60$ ${ }^{\circ} \mathrm{C}$ and $1 \mathrm{cP}<\eta<200 \mathrm{cP}$ was approximately $20 \%$.] Following delivery to the ORNL test site, the sensor was checked by Sandia personnel showing a proper air response but a frequency-related water response of $1.33 \mathrm{~g} / \mathrm{cc}^{*} \mathrm{cP}$. This value was high (outside of 


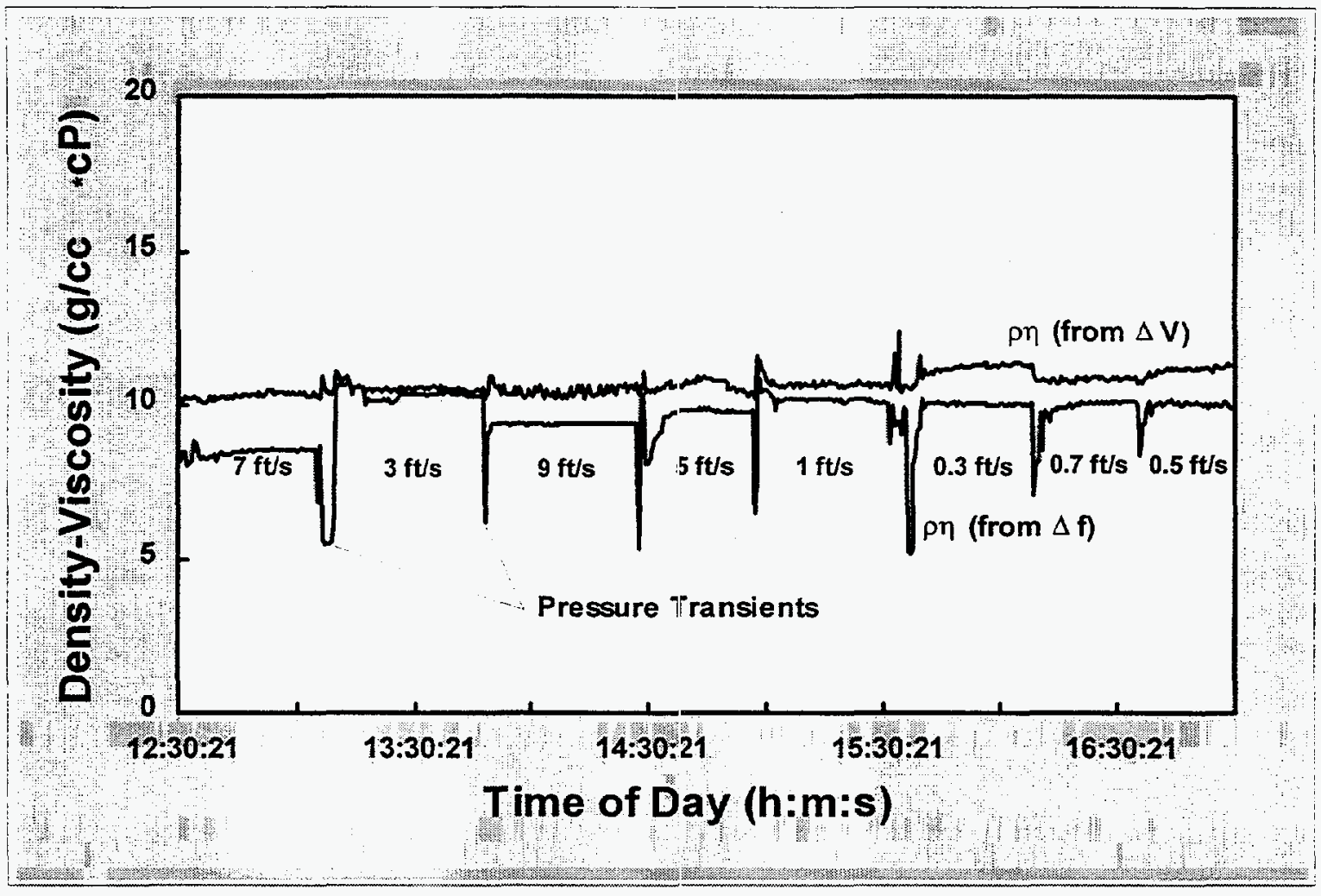

Figure 6. The measured real-time response of sensor $\$ 2$ (in-line probe) during a $4 \frac{1}{2}$-hour segment on June 25,1997 . The slurry used was $50 \%$ by weight sucrose in water, the temperature was $50^{\circ} \mathrm{C}$, and the slurry flow rate was varied as indicated. Both sensor responses (density-viscosity computed from the oscillator frequency and voltage shifts) are plotted; the pressure transients created during flow rate changes are obvious in the frequency response. The responses computed from voltage is relatively insensitive to flow rate.

calibration), but not alarming. However, during early test evaluation periods when only water was used in the ORNL tank and pipeline, the sensor gave density-viscosity readings of 1.57 to $9.2 \mathrm{~g} / \mathrm{cc}^{*} \mathrm{cP}$. Our interpretation of these responses was that a thin film of material (pump oil, or the like) had accumulated on the quartz resonator surface and was interfering with the measurement.

Post-test inspection of the sensor probe revealed some interesting results. These are given in Table I. Following the ORNL test period, the probe was removed from the tank and allowed to sit for several days without cleaning. Consequently, a hard layer of material accumulated against the resonator surface from the dried slurry mixture. When the sensor probe was interrogated, the measured values were as expected: no voltage-related density-viscosity signal (relative to the calibrated baseline) and a large frequency-related value. This response is indicative of a thick (rigid) mass layer. When the probe was submersed in a beaker of water, the layer softened, giving a resonator response for a viscoelastic film. Again, the response that was expected. Following a thorough cleaning of the crystal surface to remove all slurry residue, the probe response returned to its expected calibrated levels. When in water, the density- viscosity showed a value of 0.99 to $1.02 \mathrm{~g} / \mathrm{cc}^{*} \mathrm{cP}$; and when dry, the reading was $<0.01$. It was encouraging to observe 


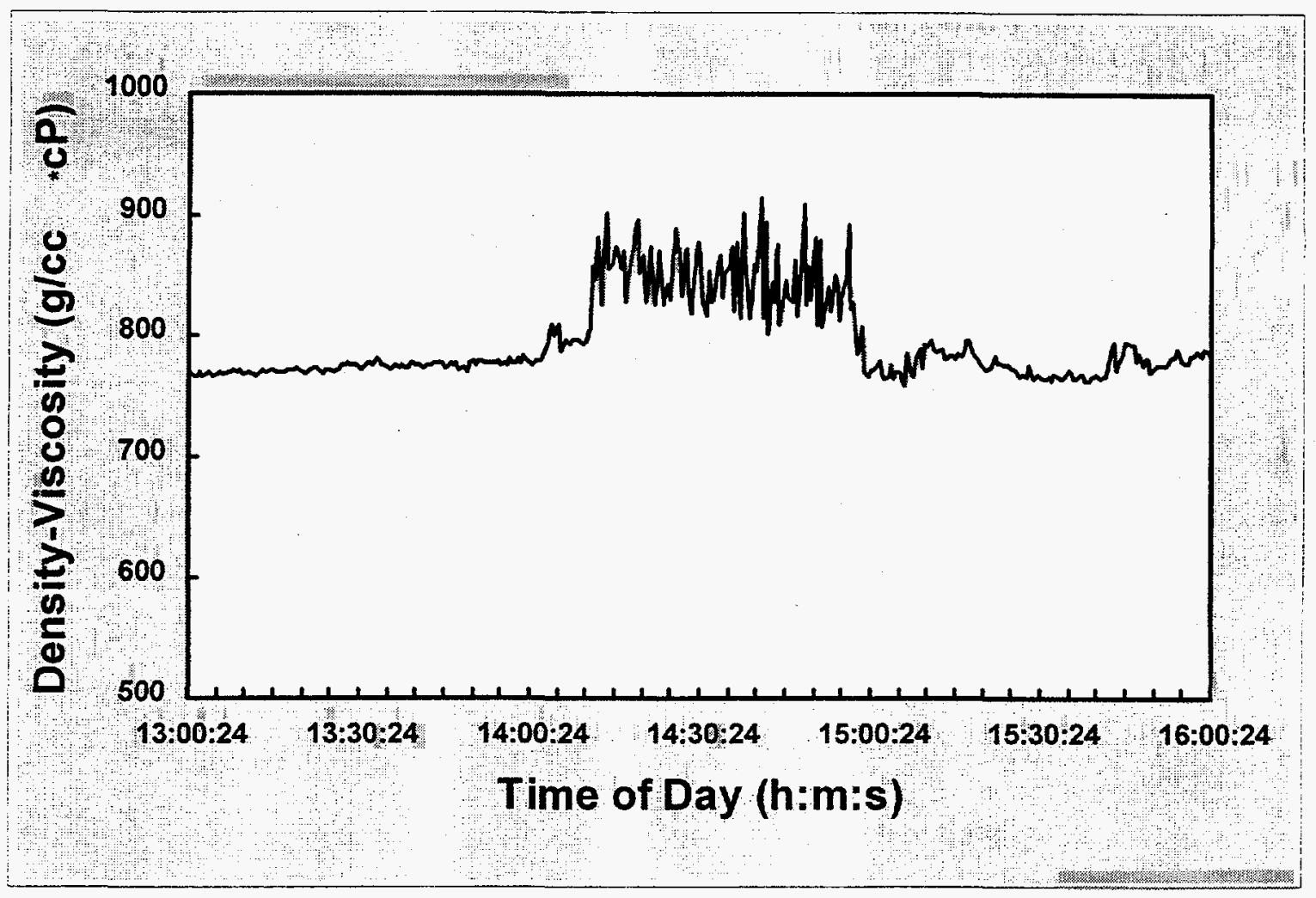

Figure 7. The measured real-time response of sensor $\# 2$ (in-line probe) during a 3-hour segment on August 6,1997 . The slurry used was $9 \%$ by wt. kaolin clay in a $50 \%$ by weight sucrose/water solution, and the temperature was $27^{\circ} \mathrm{C}$. The signal burst was created by induced air flow of $0.33 \mathrm{scfm}$ followed by 0.66 scfm (air flow rates cannot be distinguished). Even though the sensor was operating in an anomalous mode (indicated by the unusually large density-viscosity), the injected air flow could be detected.

that after several months of severe testing the sensor $\# 1$ calibration was still good, though the response during actual evaluation did not indicate the operation of a quality instrument.

\section{Final Observations and Conclusions}

The Sandia-developed density-viscosity monitoring system did not perform well as an absolute measurement instrument for slurry bulk density-viscosity. The poor rating determined during the evaluations is attributed to the limitations of the quartz resonator technology that provides the basis for the monitoring instrument. Too many factors associated with the test slurries, and subsequently those that would also be found in actual mixed-waste tank slurries, interfere with proper calibrated sensor operation.

As in any test sequence, however, the performance of the evaluated instruments is somewhat dependent on the test matrix and the interpretation knowledge of the test operators. As indicated in previous discussions and reiterated here, several factors about the test operations (especially some procedures that occurred between test runs when instruments were not monitored) were not conducive to proper Sandia instrument function, and some actually degraded the performance for subsequent testing. These statements are in no way intended to discredit the excellent job performed by the ORNL test team, as they devised a very equitable test matrix for instrument evaluation given the 
Table I. Response of sensor \#1 (tank probe) when operated in air and water at different points in the test sequence.

\begin{tabular}{|c|c|c|c|c|c|}
\hline Test Configuration & Fluid & $\rho \eta\left(g / c c^{*} c P\right)$ & $\Delta V$ or $\Delta f$ & Temp (C) & Comments \\
\hline \multirow{2}{*}{$\begin{array}{l}\text { In Lab at SNL after } \\
\text { full calibration }\end{array}$} & air & $<0.05$ & both & -23 & \multirow{2}{*}{$\begin{array}{l}\text { new, clean surface; } \\
\text { ideal conditions }\end{array}$} \\
\hline & water & $0.98-1.10$ & both & -23 & \\
\hline \multirow{2}{*}{$\begin{array}{l}\text { At ORNL prior to start } \\
\text { of slurry testing }\end{array}$} & air & $<0.05$ & both & 25.8 & \multirow[t]{2}{*}{ first checks at test site } \\
\hline & water & $\begin{array}{c}1.03-1.11 \\
1.33\end{array}$ & $\begin{array}{l}\Delta V \\
\Delta f\end{array}$ & 24.0 & \\
\hline $\begin{array}{l}\text { Early water-only tests } \\
\text { by ORNL }\end{array}$ & water & $\begin{array}{c}1.57-1.63 \\
9.2\end{array}$ & $\begin{array}{l}\Delta V \\
\Delta f\end{array}$ & 26.1 & $\begin{array}{l}\text { something depositing } \\
\text { on QCR surface? }\end{array}$ \\
\hline \multirow{2}{*}{$\begin{array}{l}\text { After all slurry tests } \\
\text { completed by ORNL; } \\
\text { sensor removed from tank }\end{array}$} & air & $\begin{array}{c}<0.01 \\
16.3 \\
\end{array}$ & $\begin{array}{l}\Delta V \\
\Delta f\end{array}$ & 23.0 & $\begin{array}{l}\text { rigid film dried on } \\
\text { QCR surface }\end{array}$ \\
\hline & water & $\begin{array}{c}3.7 \\
37.2\end{array}$ & $\begin{array}{l}\Delta V \\
\Delta f\end{array}$ & 22.7 & $\begin{array}{l}\text { viscoelastic film } \\
\text { formed on surface }\end{array}$ \\
\hline \multirow[t]{2}{*}{$\begin{array}{c}\text { At ORNL after cleaning } \\
\text { QCR surface }\end{array}$} & water & $\begin{array}{l}0.99-1.02 \\
0.82-0.84\end{array}$ & $\begin{array}{l}\Delta V \\
\Delta f\end{array}$ & 23.3 & clean, wet surface \\
\hline & air & $<0.01$ & both & 26.9 & clean \& dry \\
\hline
\end{tabular}

specifications and needs of the tank site users and then proceeded to admirably implement an aggressive test schedule. Though disappointed that Sandia's prototype slurry monitoring system did not perform better within the constraints of the comparative evaluation, we realize that simulations provided at ORNL still do not fully represent the severity of the actual tank environments.

The strength of the quartz resonator slurry density-viscosity monitoring system is its ability to function as a real-time, in situ or in-line measurement instrument for dynamic or transient slurry viscous properties. It has been shown to indicate density-viscosity shifts influenced by temperature changes, slurry component concentration, and injected aeration. Other indicators not shown graphically in this report are the ability to monitor precipitates and depositions and to indicate solid-liquid phase transitions. Process monitoring for various slurry operations might be the most useful application. 
Appendix F

RESPONSE FROM ENDRESS + HAUSER:

PROMASS CORIOLIS METER (DENSITY) 
Endress + Hauser Instruments • Greenwood, Indiana

February 25, 1998

T.D. Hylton

Oak Ridge National Laboratory

Chemical Technology Division

Post Office Box 2008

Oak Ridge, TN 37831-6330

Dear Mr. T.D. Hylton,

With pleasure, we took notice of the "Comparative Testing of Slurry Monitors" evaluation report. We would like to express our thanks to all the people involved in the evaluation for their excellent work.

We are especially pleased with your recommendation of the Endress + Hauser Promass 63M Coriolis meter (straight measuring tube), bascd on its performance to mcasure the density in Slurry applications.

The professional way of evaluating and reporting makes this report a very valuable document.

Yours Sincerely,

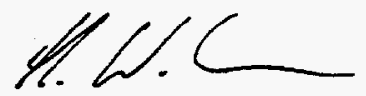

Marcel Woiton

Product Manager Mass Flow

Endress + Hauser

MW/vat 
Appendix G

RESPONSE FROM ZELLWEGER ANALYTICS:

BTG SMS-3000 SUSPENDED SOLIDS MONITOR 


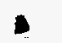

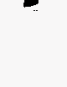

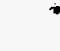


Zellweger Analytics, Ine. 100 Pork Avenue

Leogue Ciry, Texas 77573 USA

Tel: 2813322484

Fax: 2815546795

January 29, 1998

Mr. Tom Hyiton

Oak Ridge National Laboratory

Building 2528 MS-6330

P.O. Box 2008

Oak Ridge, TN 37831-6330

Re: Comparative Testing of Slurry Monitors

Dear Mr. Hylton:

Zellweger Analytics would like to thank the Oak Ridge National Laboratory for including our SMS-3000 in this evaluation.

Having reviewed the draft of the Comparative Testing of Slurry Monitors, we would like to provide the following comments regarding the test and findings.

1. Though the SMS-3000 Suspended Solids Transmitter and 4-Beam ${ }^{\text {TM }}$ sensors were originally developed for suspended solids measurement in municipal wastewater applications, it is certainly possible to apply the product in many other slurries with suspended solids.

Because the measurement principle is based on near-infrared light absorption and scattering, the measurement range will vary depending on the color and particle size of the media being measured. The range limit of $12-15 \%$ in a kaolin clay / water slurry is consistent with our results in similar media, such as lime slurries and, to some extent, talc.

2. The SMS-3000 has been replaced by the TXPro'M-S Transmitter. The TxPro-S is a singleinput design; the SMS-3000 is a four-input design. A new version of the TXPro, the TXPro-2, is due to be released in the first quarter of 1998 and will accept two sensor inputs.

3. Although the basic 4-Beam Alternating Light Principle of measurement has remained unchanged over the last several years, the materials of construction for the sensors has changed. The earlier epoxy molded sensors have since been replaced with sensors made from machined or molded plastic. Currently, the sensor head is constructed of CPVC and polypropylene with a polyurethane-jacketed cable. Since our experience using these materials in an ionizing radiation environment is limited, we cannot guarantee the life of the sensor. In addition, the sensor contains electronic components, which would likely have a limited life expectancy under these conditions. Our normal warranty period is one year for sensors. In typical municipal wastewater applications, the sensor will last for several years. However, it may well be that sensor life in an irradiated environment is reduced to months instead of years.

(2) estro 2 wo polymotron 2$]$ polymatron

A company of the Zellwoger huwo group 


\section{2 zellweger analytics}

Page 2

4. Although the 4-Beam measurement principle is capable of compensating for temperature changes, extreme temperature changes may have an influence. We normally expect less than $0.5 \%$ change in probe signal per $10^{\circ} \mathrm{C}$ risie.

The sensor has a "usable probe signal range". In clean water, the probe signal is typically around 1500 counts. As the solids concentration increases, so does the probe signal - up to around 10,000 counts. At this point, the signal to the detectors is approaching the noise level and the instrument will signal "depletion" or over-range. It is clear that a rise in temperature causes a reduction in light output from the LED's. Therefore, if the sensor is operating at a point that is near depletion, as would be the case in $10 \%$ kaolin, then a relatively small temperature increase would be enough to cause the reading to go to full scale. This would also explain why the instrument reading shows little or no change in the sugar-only slurry (Table 5-9) since the probe signal is at its minimum range.

5. Regarding the discrepancy of the instrument reading in kaolin / sugar, it is possible that a change in the refractive index of the media caused by the sugar would cause peculiarities in the results. However, we would need to condust further tests to gain a full understanding of why the instrument output appears to decrease at higher concentrations.

6. The 4-Beam TxPro-2 sensors will be of a digital, rather than analog, design. Additionally, we intend to directly compensate for temperature variations in the new sensor. This will provide better stability in unusual applications where temperature is changing rapidly.

Sincerely,

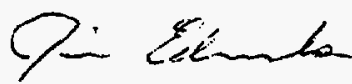

Jim Edwards

Technical Support Manager

Zellweger Analytics, Inc. 


\section{INTERNAL DISTRIBUTION}

$\begin{aligned} \text { 1. } & \text { C. K. Bayne } \\ \text { 2. } & \text { C. A. Bednarz } \\ \text { 3. } & \text { B. L. Burks } \\ \text { 4. } & \text { C. A. Chambers } \\ \text { 5. } & \text { J. A. Chapman } \\ \text { 6. } & \text { A. G. Croff } \\ \text { 7. } & \text { O. W. Hale } \\ 8 . & \text { M. T. Hurst } \\ \text { 9-13. } & \text { T. D. Hylton } \\ \text { 14. } & \text { L. L. Jacobs } \\ \text { 15. } & \text { M. A. Johnson } \\ \text { 16. } & \text { C. M. Kendrick } \\ \text { 17. } & \text { T. E. Kent } \\ \text { 18 } & \text { B. E. Lewis } \\ \text { 19. } & \text { J. M. Lynch }\end{aligned}$

1. C. K. Bayne

2. C. A. Bednarz

3. B. L. Burks

4. C. A. Chambers

5. J. A. Chapman

6. A. G. Croff

7. O.W. Hale

8. M. T. Hurst

14. L. L. Jacobs

15. M. A. Johnson

16. C. M. Kendrick

18 B. E. Lewis

19. J. M. Lynch

\section{0.}

21.

22.

23.

24.

25 .

26.

27.

28.

29.

30.

31.

32.

33-34.
A. P. Malinauskas
C. P. McGinnis
L. E. McNeese
S. M. Robinson
T. W. Schmidt
C. B. Scott
J. L. Stellern
M. G. Stewart
J. S. Taylor
S. D. Van Hoesen
L. D. Weems

ORNL Central Research Library

ORNL Laboratory Records-RC

ORNL Laboratory Records-OSTI

\section{EXTERNAL DISTRIBUTION}

35. Marvin S. Anderson, Ames Laboratory, 125 Spedding Hall, Ames, IA 50011-3020

36. Judith Bamberger, Pacific Northwest National Laboratory, P.O. Box 999, K7-15, Richland, WA 99352

37. Mark Boise, Endress + Hauser, Inc., 14 Diana Drive, Scottsville, NY 14546

38. Richard W. Cernosek, Sandia National Laboratories, P.O. Box 5800, M/S 1425, Albuquerque, NM 87185-1425

39. Hual-Te Chien, 9700 South Cass Ave., Argonne, IL 60439-4825

40. Eric Daymo, Pacific Northwest National Laboratory, Battelle Boulevard, MSIN: P7-43, Richland, WA 99352

41. Jim Edwards, Zellweger Analytics, Inc., 100 Park Avenue, League City, TX 77573

42. Daryl Green, U.S. Department of Energy, 55 Jefferson, EW92, Oak Ridge, TN 37830

43. Margaret Greenwood, Pacific Northwest National Laboratory, 2400 Stevens Drive, Richland, WA 99352

44. William J. Haas, Ames Laboratory, 128 Spedding Hall, Iowa State University, Ames, IA 50011-3020

45. Robert Hill, Instrumentation Specialists, Inc., 1359 Wenlock Road, Knoxville, TN 37922

46. Dave Hippensteel, U. S. Department of Energy, Nevada Field Office, 232 Energy Way, N. Las Vegas, NV 89030

47. Lynette Jagoda, Pacific Northwest National Laboratory, P.O. Box 999, MSIN: P7-43 Richland, WA 99352 
48. John B. Jones, U. S. Department of Energy, Nevada Operations Office, M/S 505-ETD, 232 Energy Way, N. Las Vegas, NV 89030

49. Doug Kuhns, Idaho National Engineering and Environmental Laboratory, P.O. Box 1625, MS 3920, Idaho Falls, ID 83415

50. Brenda Lewis, Westinghouse Savannah River Company, Bldg. 703 H, Rm. 99, Aiken, SC 29808

51. Thomas H. May, Numatec Hanford Company, MSIN: H5-61, P.O. Box 1300, Richland, WA 99352-1300

52. Larry. B. McDaniel, Numatec Hanford Corporation, MS H6-12, Location 2440 , STVCN/1207/RCHN, Richland, WA 99352

53. Cavanaugh Mims, U.S. Department of Energy, 55 Jefferson, EW92, Oak Ridge, TN 37830

54. Jacquie Noble-Dial, U.S. Department of Energy, 55 Jefferson, EW92, Oak Ridge, TN 37830

55. Terrance D. Phillips, Westinghouse Savannah River Company, Bldg. 703 H, Rm. 70, Aiken, SC 29808

56. Heather Sage, Fernald Environmental Management Project, P.O. Box 538704, MS-50 Cincinnati, OH 45253-8704

57. Shuh-Haw Sheen, Argonne National Laboratory, 9700 S. Cass Ave., Argonne, IL 60439

58. Dr. Eugene Standifer, Crystal Technology, Inc., 1040 East Meadow Circle, Palo Alto, CA 94303

59. Tom Thomas, Westinghouse Idaho Nuclear Co., Inc., P. O. Box 4000 , Idaho Falls, ID 83403-4000

60. Warren Thompson, Lockheed Martin Hanford Co., Inc., P.O. Box 1500, MSIN G3-21, Richland, WA 99352-1505

61. David Van Essen, 4000 Pleasant Ridge Road, Apartment M-47, Knoxville, TN 37912

62. Paul W. Wang, Concurrent Technologies Corporation, 320 William Pitt Way, Pittsburgh, PA 15238 